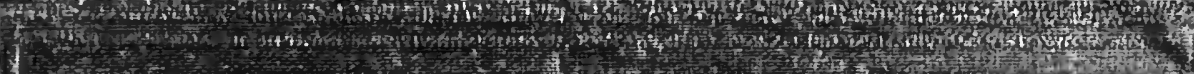

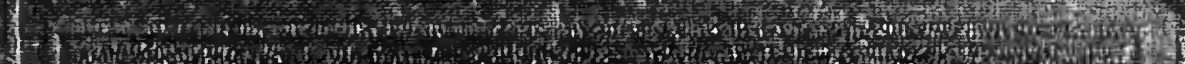

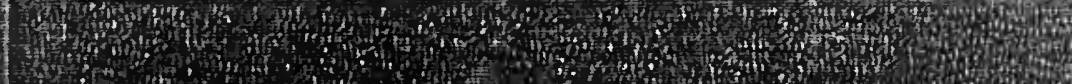
1.

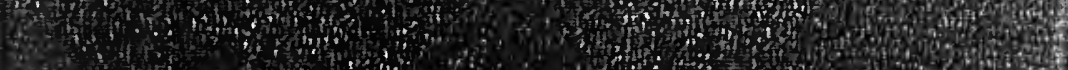
Q

6.7.

2.9.9.

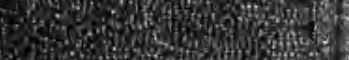

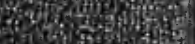
160. Q9.

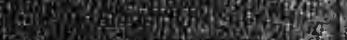
The

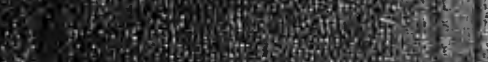
D. 30 .

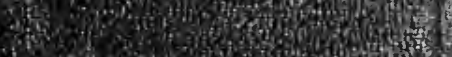
2u 20 -

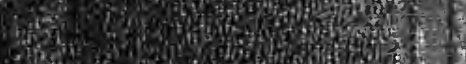

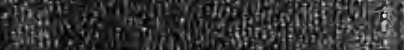
H.

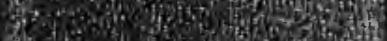

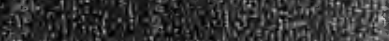

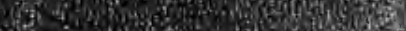

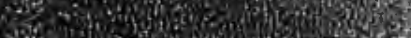

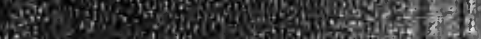
in 


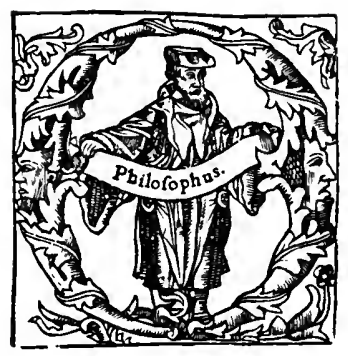

\section{WALSH \\ Philosophy \\ Collection}

PRESENTED to the

LIBRARIES of the

UNIVERSITY of TORONTO 


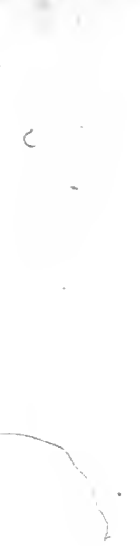




\section{Digitized by the Internet Archive in 2007 with funding from \\ - Microsoft Corporation}




\section{THE SUPERNATURAL.}





\title{
THE SUPERNATURAL
}

IN RELATION TO THE NATURAL.

BY THE REV.

\section{JAMES M`COSH, LL.D.}

AUTHOR OF "THE MIETHOD OF THE DIVTNE GOVERNMENT,"

"INTUITIONS OF THE MaND," ETC.

\author{
Cambridge \\ M A C M ILLA N A D C O. \\ AND 23 HENRIETTA STREET COVENT GARDEN \\ 迎ondon \\ II D C C C L X I I
}


BRLPAST : ALEX. MAYMB, PRINTER. 


\section{P R E F A E.}

THE author of this Treatise all along intended that his Work on "The Method of the Divine Government Physical and Moral" should be followed by another on "The Method of the Divine Government Supernatural and Spiritual." This Essay may be regarded as Part First of that contemplated work. Whether it will be succeeded by a Second Part, bearing more especially on the Spiritual Economy of God in our world, depends on so many circumstances at the disposal of a Higher Power, that he thinks it wiser to make no promise to the public on the subject. The questions agitated in our day have called on him, in the mean time, to give to the world the First or Apologetic Part of the intended publication. His deepest feeling, in now issuing it from the press, is a regret 
that it is not more worthy of the all-important theme discussed.

In this world of ours the work of destruction is easier than that of reconstruction. A few reckless men may, in a few hours, break or consume as much valuable property as would require many sober men, many years of toil, to repair or restore: When the authors of "Essays and Reviews" began to scatter inflammable materials, the first efforts of the defenders of the citadel attacked were naturally directed towards ascertaining the precise aims of the combatants, and staying the immediate effects on the minds of the nation. I suppose, however, that the public feel that we have had enough of disquisitions as to the position of the Essayists, and as to the tendency and probable effect of their writings. There is also a very general feeling that we must now have something beyond those excellent little articles and essays, which have been written with the view of counteracting the general influence of the doubts that have been insinuated in regard to 


\section{vii}

the Word of God, and the attacks that have been made on the fundamental principles of religion. The expectation now is, that there must be a laborious discussion of all and of each of the questions started, and this on their absolute merits, with a view it may be to existing controversies, but on grounds and by principles not peculiar to this or to any age.

It has often been remarked, that in a common-place subject it is easier to advance an acute objection than to offer a telling reply. A man may acquire a reputation for ingenuity more readily by proving that a stone is not a stone, than by a laboured demonstration that it is a stone. Nevertheless, the friends of religion, natural and revealed, must engage patiently in the work of defending what has been attacked. It may be all true that the objections have been offered before; it may also be true that they have been answered before; still, as long as the attacks continue, and there is a race of young men springing up who are exposed to them, those 


\section{viii}

set for the defence of the fortress must meet them, and this at the very points at which the assaults are made. This is what is expected, in the present day, of the defenders of religion. This is what they owe to truth; this is what they owe to the God of truth. It is thus that what seemed an evil may, by God's blessing, be turned to good.

We have seen a company of boys at the top of a steep hill setting a number of stones rolling, without seriously contemplating whither they might go, and what injury they might do among those sitting, or lounging, or working below. The writers of the "Essays and Reviews" have been acting very much like these youths. Seated on their academic heights, they did intend to let loose a set of active agencies which might move and startle the Church and the world; but I am convinced that some of them did not calmly weigh the destructive effects that might be produced on those beneath, as these rolling stones came rushing in among them. I believe that the issue, chronological and logical, of the 
views propounded, on those who fall thoroughly under their influence, must be a denial or at least a doubt, of any supernatural power having been in operation, at the creation of the world or since, either in the production of man or in order to his redemption. Whatever Mr. Temple or Mr. Jowett may have meant, we may see-unless it be counteracted-the proper result of the whole movement in once living faiths groaning, bleeding, and dying in that stony, arid, and horrid plain which Mr. Baden Powell has provided in his exclusive naturalism, in his mechanical law, and physical causation.

The profound Leibnitz, in writing to Arnauld, intimates his fear that the "last of heresies may be, I do not say Atheism, but Naturalism publicly professed." Had the fisherman, Peter, a prophetic glimpse opened to him of the same state of things when he speaks of scoffers who shall come in the last days, saying-" Since the fathers fell asleep all things continue as they were from the beginning of creation"? 
The questions started by the "Essays and Reviews" relate to the reality and possibility of supernatural operation; to the historical evidence substantiating Christianity ; to the inspiration of God's Word; and to the topics involved in these directly or collaterally. We must now have these subjects discussed, either in one great work issuing from the depths of a comprehensive mind, or, what may serve as good a purpose, in a number of treatises written by different men, each taking up the theme which he feels himself competent to treat. In this little work only one of the questions raised has been taken up. The special aim of the author is to disentangle the confusion which has crept into the discussion of one great problem, and to throw what light he can on the Natural and Supernatural, and the relation in which they stand one to the other, to man and to God. 


\title{
C 0 N T E N T S.
}

\author{
B $00 \mathrm{~K}$ FIRST.
}

THE NATURAL IN RELATION TO THE SUPERNATURAL.

CHAPTER I.

Man Discovering the Uniformity of Nature,

CHAPTER II.

In What the Natural System Consists,

CHAPTER III.

Mental Principles involved in our Conviction as to THE UNIFoRMity OF Nature, .. $\quad$..

CHAPTER IV.

How much is Contained in the Natural,

CHAPTER V.

The Natural a Manifestation of the Supernatdral, ..

BOOK SECOND.

THE SUPERNATURAL IN RELATION TO THE NATURAL.

CHAPTER I.

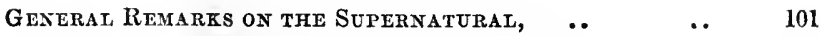

Sect. I. The Precise Nature of the Supernatural, .. 101

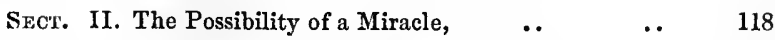

SECT. III. Purposes served by the Supernatural, $\quad$. $\quad 133$

SECT. IV. Relation of the Supernatural to the Natural, .. 150 


\section{xii}

\section{CHAPTER II.}

The System in the Supernatural.

SECT. I. There is System in the Supernatural, .. 166

SEct. II. The Typical System of Revelation, $\quad$.. $\quad 178$

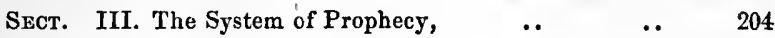

Sect. IV. The Plan of Christ's Life, $\quad$.. $\quad$.. $\quad 228$

SECT. V. The System of Miracles, $\quad$. $\quad \ldots \quad \ldots \quad 237$

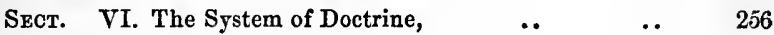

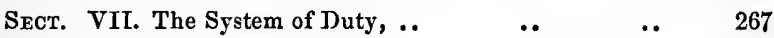

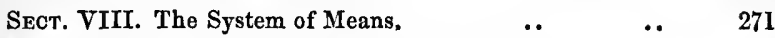

SECT. IX. The System in the Dispensation of Grace, .. 274

CHAPTER III.

The Evidences of Christianity.

SEct. I. A Study of the Christian Evidences. The Evidences a System, $\quad$.. $\quad$.. $\quad$.: 282

SECT. II. Connexion between the Miracle and the Doctrine, .. $\quad$.

.. $\quad$.

SEcr. III. Ends accomplished by the Systematic Character of Revelation, .. $\quad$.. $\quad$..

CHAPTER IV.

analogi between the Natural and Supernatural

SYSTEMS, •

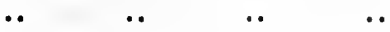

APPENDIX.

Anт. I. Oxford Philosophy,

353

ART. II. Bunsen and German Theology,

363 


\section{B $00 \mathrm{~K}$ FIRST.}

THE NATURAL IN RELATION TO THE SUPERNATURAL.

\section{CHAPTER I.}

MAN DISCOVERING THE UNIFORMITY OF NATURE.

IT is a most vivid and intensely interesting picture which is presented to us by Humboldt in the second volume of the Cosmos, where he unfolds the ideas which mankind have formed, in successive ages, of the magnitude of nature, and of the manner in which their views of earth, ocean, and sky, of plant, animal, and man, became enlarged, as voyagers and travellers explored new countries, and as science extended its observations and calculations, and combined them into general laws. It would be quite as interesting, and fully as instructive, to have a like panoramic view of the conceptions which men have been led to entertain, at various times and in various countries, of the nature and extent of uniformity and of law in creation, and of the enlargement of their 
apprehensions and beliefs, as observation and science pushed on their researches, and widened the sphere of their discoveries. In now endeavouring to furnish this, I am not to attempt such a glowing historical painting as Humboldt has set before us; I must content myself with a simple sketch in plain water-colours.

Let us try to put ourselves in the position of a shepherd, a hunter, or a tiller of the ground in the early ages of the world, or of an uneducated man in countries beyond or in states of society beneath the reach of civilization, as he looks out on the phenomena of nature. Two deep impressions, I think, would be left on the mind of such an one;-one, that there is uniformity, and the other, that there is irregularity in nature.

The uniformity presses itself everywhere on his notice. He sees it in day following night, and night succeeding day, in the sun pursuing his steady course in the heavens, and in the seasons appearing in due order; he discovers it in food nourishing and sleep refreshing him, in the growth of the grass and the trees, of his lambs and his cattle. But in the very midst of these regularities there are occurrences which come after a different fashion. The sun rises and sets with undeviating constancy, but the eclipse appears very inconstantly and the lightning flashes very unexpectedly. The seasons accomplish their 
beneficent rotation without a failure; but storms arise and rains descend (in most climates) in perplexing and puzzling uncertainty. His bodily frame performs its functions, and his grain and fruit-trees, his flocks and herds, spring up and grow according to a very obvious course, which he can, to a large extent, anticipate; but blight or disease may come upon them at most unexpected and troublesome times, to disappoint his plans and blast his prospects.

If our observer be a godly man, that is, with a heart inclined towards God, he will discover and acknowledge the presence of a Divine Being in each of these classes of objects. But, on the other hand, if he be disposed to live without God, and to keep Him at a distance, he may find a convenient means of accounting for both without calling in a living and acting being, employing physical agents to accomplish beneficent and moral ends. To explain what seems settled and constant he may give a power and a being to Nature, constituting it into a self-working machine, while he refers the irregularities and interferences to Chance, not that he ever thinks of defining Chance; but he means that the events come without any purpose of a designing mind.

But, meanwhile, man has deep religious tendencies and impulses, which will break out despite his unbelief and in the very midst of his 
ungodliness. Circumstances arise and feelings are awakened, which constrain him to look out for, or to believe he discovers, a Being above these mundane agents. But the whole history of man shows that while he has deep religious instincts, they do not usually work in a healthy manner. Too frequently they are in $a^{\prime}$ dormant state, and they are called forth only by what rouses the mind into excitement, into a state of hope or a state of fear. The consequence is that God comes to be seen in certain of His works, and not in others;-in those which move and alarm, not in those which come daily and steadily; in the drought or tempest which blights the crops, not in the heat and moisture which make them to spring up and grow and ripen; in the disease which wastes and ravages, not in the health which has sustained and gladdened the frame for years; in the lightning which smites, but not in the light which smiles; in the eclipse with its lurid darkness, but not in the pleasant sunshine daily playing on our earth; in the meteor which bursts out so ominously, but not in the stars which look down upon us so purely and benignly; in sudden and unexpected prosperity, but not in the common blessings which are showered upon us from day to day; in the storm which sinks the vessel, but not in the favourable breezes which have borne it along for such a length of time; in the 
preservation of the individual in a shipwreck, but not in that assiduous care which to so many has prevented shipwreck altogether. This is superstition, which, in its narrowness and partiality, discerns the God who is in all nature, only in certain portions of it. When unrestrained by foreign influences it soon issues in polytheism, or the belief in "gods many and lords many," each supposed to be engaged somehow or other in interfering with what has been settled, and in producing those irregularities which spring up in the midst of the uniformities, to control or to disturb them.

It is a perception of the uniformity of nature which forms the most effective natural means of making mankind keep hold of the unity of God. Those who have lost, or who have never reached, the idea that there is a connection between the various physical agencies in the world, are sure to look upon them as being directed or interfered with by a number of conspiring or conflicting supra-mundane beings, each with a purpose of his own; and I believe the great body of mankind can be kept from this error only by a direct revelation from heaven of the character of God. Even those who have a written word will ever be tempted, like the Jews in old times, to run after the worship of a multitude of gods, or like rude unlettered Christians in modern times, to 
make a subordinate class of preternatural beings, such as saints or witches, act an important part in those cross events for good or for evil, which interpose to help or to hinder the more direct and settled tendencies of nature.

But the same spirit of ungodliness which allures so many to an adulterous attachment to a multiplicity of gods, who suit their contracted views and corrupt taste, may take another form among those who have been kept from polytheism by a comprehensive conception of nature; or, by what is more common in the ages when persons begin to reflect and philosophize, by a vehement inclination towards abstract thinking, which, as in the case of the Eleatic school of early Greece, perceives, but exaggerates and misinterprets, the unity which exists amidst the variety of physical agents. The deep natural aversion to a pure and personal God, who sees the hearts and judges the deeds of man, tempts this latter class into pantheism, of a ruder or more refined character; and they look on nature personified as being God, and the sun, moon, and stars, or the animals in whom the principle of life is most active, or the more powerful physical agents, such as light and fire, as being themselves the acting deities. In many Eastern countries the two forms of error coalesce and exist side by side; the pantheism being the form adopted by the 
sages who mount up into high abstractions, and the polytheism furnishing the channels in which the religious feelings of the people expend themselves. These two, the nature pantheism and the nature polytheism, have a great many more points of affinity and bonds of communion than we might at first suppose. The philosophic parltheist is quite willing to allow the rabble to be polytheists, since they can rise no higher in their conceptions; he will let them freely indulge in the worship of the sun, and moon, and animals, and elements, and will himself fall in, without compunction, with their worship, looking upon the individual natural objects, or the symbols of them in the temples, merely as representatives of the Whole; and with this accommodation the polytheist is entirely satisfied, which he wonld certainly never be with the uncompromising position of stern distance held towards him by the pure theist. The two, indeed, often meet in the same individual; the pantheist, finding that his abstractions are cold and unattractive, has to lavish his pent-up feelings on beings who can hear and respond to the breathings or beatings of his heart; while the polytheist, in his times of deeper thought and sentiment, or of more terrible emergency, feeling as if all inferior and divided powers were failing him, casts himself on the One Supreme and Omnipotent God. 
Taking mankind as a whole, a far greater number fall into superstition than into pantheism. The victim of superstition, we have seen, feels his dependence on Grod only in regard to supposed interferences with the settled course of things. The Egyptians told Herodotus that, as their fields were regularly irrigated by the waters of the Nile, they were less dependent on God than the Greeks, whose lands were watered by rains, and who must perish if Jupiter did not send them showers.* Persons trained in these narrow views are apt to be very much offended when philosophers argue that all things are governed by laws, or when men of science shew them natural powers, where they believed there was only a Divine agent. They feel as if one part of God's works after another were being wrested from Him by presumptuous and impious men, who would, in the end, leave him no place at which he can interfere, or at which we may discern his agency. Hence the conflicts between science and religion, or rather between science and persons resolved to stand up for God, but who have adopted the doctrine that they must cease to recognise Divine action as soon as they find physical agency. As one field of nature after another is taken from Grod and given over to mundane operation, some grieve, others rejoice,

* Herodotus, II. 13. 
while a third class are exasperated into bitterness and fanaticism. Some feel their whole soul perplexed, and their heart failing them, as they find the gods driven from the woods and the streams, from the mountains and the stars, and allowed to interfere neither with health nor disease. Not a few, as they discover that the Divinity can no longer be found in what they have been taught to recognize as his place of abode and special sphere of action, are greatly tempted to abandon themselves to utter unbelief,-it is as if they had entered into the inner shrine of their temple, where they were told that God dwelt, and found it all emptiness-it is as if a Jew had been brought, by unexpected circumstances, or by a rash deed of profanity, into the holiest of all, and found there no ark of the covenant, no Divine presence. Others feel and express their joy, as they have been delivered from all fear of a God to judge and to punish; and they often break out into scoffing and profanity. As to the great mass of vulgar minds, they at once rush into an unwise and violent contest with the adrocates of natural agency; they denounce them as ungodly, and at times expose them to a virulent persecution. These throès are the Nemesis which ever pursues error (as well as crime), till thinking minds are led to undertake the task of readjusting the relations of physical and Divine agency. 
When nations are first brought into view by their historic records, we find them looking on certain objects and certain departments of nature as settled and fixed, while others are regarded as irregular, or at least disconnected the one with the other; the former being ascribed to the gods or to nature, the latter to the gods or fortuity, according as persons are piously or profanely disposed. It is in this state that we find Greece, when its earliest writings enable us to understand the views and thoughts of the people. The hills, the fields, the seasons, the ordinary life of the plant, of the animal, and of man, are objects about which little curiosity is excited, and little inquiry is made; they seem all ruled and determined, or they run their undeviating course without requiring any external aid to help them on. It is different with objects within the reach of man's view, but beyond his minute inspection, and with events which come with variations, or which appear at unforeseen times or with tremendous energy. As observation extended, and science co-ordinated the facts gathered, the portion of the universe seen to be regulated by law of some sort, became larger in itself, and in comparison with the seeming irregularities and anomalies. It was seen, from the time when observation began, that the sun has in himself some power of shining, and that his course is a regular one; 
but certain superstitions were interfered with when the Babylonian star-gazers could predict the exact time of the occurrence of the eclipses of the moon. Those who were taught to consider the heavenly bodies as divine, could not look with much favour on Anaximander of Miletus, when he instituted calculations as to the sizes and distances of some of the heavenly bodies; or upon another Ionian physiologist, Anaxagoras of Clazomenae, when he speculated as to the causes of the moon's light and the eclipses of the sun and moon, and maintained that the moon, like the earth, had plains, mountains, valleys, and dwellings, evidently for intelligent beings. A revolution was about to be effected in men's ideas of the world when Aristotle* elaborately demonstrated that the earth must be spherical.

Anaxagoras, it is well known, represented reason as the first or deepest principle in the system of the universe, and maintained that by it all things were caused and set in order. When some one read this to Socrates he was highly delighted, and thought he had now discovered a sufficient explanation of what came under his notice in the world. But having got the books of the Ionian physiologist, he was astonished to find that after making reason arrange all things, Anaxagoras makes no farther reference to it, but

* De Coelo, II. 14. 
calls in "air, ether, and water, and many other things equally out of place."* From the few isolated references to the doctrines of Anaxagoras handed down to us from ancient times, we cannot ascertain how he reconciled his two statements, of all things being caused and disposed by intelligence, and of the physical elements being the agents employed in the production of natural occurrences. But the criticism of Socrates, and we may add, the like criticism in the next age by Aristotle, $f$ shew that neither of these philosophers had attained clear ideas of the compatibility of all things being caused and arranged by Divine reason, and yet of the economy of the world being carried on under God by physical agents. Socrates may be taken as the type of the religious philosopher of ancient Greece or Rome, bent upon seeing God and the gods (for in his creed there is a somewhat incongruous mixture of pure theism and polytheism) in all nature and in a wellordered providence. Aristotle may be taken as the representative of the mere metaphysical and physical speculators of the same era, acknowledging a God or gods, and perceiving an order and a system, but not discovering or explaining how God is using all physical agencies for the accomplishment of his purposes. Neither of these profound thinkers seems to have risen to

* Phaedowf Plato, 105-108. † Metaph. I. iv. 4. 
the idea of a God acting everywhere in nature, by natural agency, according to natural law. Meanwhile, the great body of the people divided what we call nature into two parts, one of which they ascribed to the system of things, or to chance, and the other of which they ascribed to their gods, and they were jealous to an intense and vehement degree of all those philosophic speculators or physical inquirers, who maintained or who hinted that what they had reserved for these divinities could be accounted for by natural causes. I believe that the heart of many an earnest and thinking youth was wrung with agony, and could find no sympathizing one to whom to express it, as he struggled between the superstition in which he had been trained, and the natural discoveries which were being opened to him; as he strove to retain both, and found them to be incompatible; or as he abandoned the faith of his youth to give himself up to a cold and comfortless scepticism. It is painful and humbling to read the record of such conflicts, in which a steadily advancing science has ever been victorious, while its opponents have been obliged to give up one untenable defence after another. But it is not, after all, without its valuable lessons, for it shews that the defender of religion is betraying the cause committed to him, when he allows directly, or by implication, that God is not 
to be seen in what is brought about by those wise and beneficent laws which he himself hath instituted.

It can be proven that some of the ancients had grand glimpses of the unity of nature, evidently suggested by the correlations which were ever casting up among things, which at first sight seemed so unlike and disconnected. These were generalized far too hastily into doctrines not authorised by the facts, but some of them, notwithstanding, have turned out to be curious anticipations, and, as it were, presages of modern discoveries. The Pythagoreans traced regulated numbers aud forms through every object in the heavens and earth: it should be added, that they did so in a very mystical and unscientific manner. Plato delighted to recognize earthly things as being after the patterns of eternal wisdom; and as he often failed to discover the Divine model, he ascribed the failure to the incapacity of matter to receive the Divine idea. The views of these gifted men, though large and expanded, were shadowy and uncertain; they were the presentiments of genius looking to a few obvious facts, and not the results of a careful induction, and they were mixed up with innumerable errors. Of all the ancient sects, the Stoics, as we might expect from their methodical mode of procedure in everything, contrived to draw out the most com- 
plete plan of the system of the world. But their scheme was entirely theoretical, and was built on no induction of facts, and modern science has completely set it aside. By help of a passive principle which is matter, and an active principle which is God, and the four elements, fire, moisture, air, and earth, they constituted the world, in which the presiding principle is fire, identified by them with God; which world has undergone, and shall undergo, an infinite series of cycles, each closing as it had begun with a conflagration, in which all things are absorbed into the elemental, the intellectual, the Divine fire, out of which, as the heat subsides, there come, first the gods and the heavenly bodies, and then the earth with the objects on it, each new cycle exhibiting the same scenes as had gone before, so that in the next period (as in the present) there shall be a corresponding Socrates who shall marry a corresponding Xantippe, and be accused by a corresponding Anytos and Melitos.*

It is only in modern times that the doctrine of the unity and system of nature has been established on a basis of facts. It is interesting to observe the stages by which the human mind has proceeded in its progress. First, Copernicus promulgates the great revolutionary truth that

* Orig., Contra. Cels. IV. Seneca, Quaes. Natur. III. 29. M. Aur., Med. VII. 19. Plut. Contrad. Stoic, \&c. 
the sun, as the larger body, must be the centre of the system, and that our earth goes round him as a dependency - an idea which had been thrown out in a mystic way by certain Pythagoreans at a time when the world was not prepared to receive it, but is now taken by the modern world as a fertile seed into its bosom. A change from the earth to the sun as the centre of the system would not produce so great an effect on the physical world, as that produced in man's ideas when he felt that he had a new and larger centre, and was in close relationship with a wider universe. The mechanical discoveries of Galileo removed deeprooted prejudices, by shewing what was the law according to which bodies tend to the earth. But the greatest impulse was given to the popular feeling, when the recently invented magnifying glasses were directed by Galileo towards the sky, and shewed that the planet Jupiter has its satellites, even as the earth has its moon. The new world discovered by Columbus was, in a higher sense, a new world to man's intelligence, it added more to man's ideas than it added to his wealth or his possessions. The very common people could no longer look on the earth as a lump of stone and clay, with a flat but variegated surface, covered so far with water, when seamon returned to tell how they had actually circumnavigated our globe. Order was introduced into the wandering 
movements of the planets, when Kepler proved that Mars pursues an elliptic path, and thus gave us, by consequence, the very orbit in which our earth runs in space. When Newton demonstrated that the moon is held in her sphere by the same power as draws a stone to the ground, men now rose in their conceptions to a law which embraces and binds the whole material world. Henceforth, even in the common apprehension, those spots of light which dot the sky at night became enlarged into worlds, possibly the suns and centres of other worlds each as large as our earth. The researches which followed the discovery of Newton shewed that gravitation operates far as observation, aided by the telescope, can reach; and the calculations of the great continental mathematicians demonstrated that the variations in the movements of the bodies of the solar system are periodical, and that there is a self-regulating arrangement pervading the whole.

Another class of investigators have been strengthening and widening our conceptions by inquiries into the more latent forces which work on earth, and which seem also to be active all throughout the mundane sphere, such as light, and heat, and chemical action, and electricity, and galvanism, and magnetism. It cannot be said that as yet we know the essential nature of any of these forces, but we have discovered 
enough about them to be quite certain that they operate universally, and operate according to fixed laws. Those who looked on thunder as in a special sense the voice of God, and on the lightning as the minister of his vengeance, must have had their feelings somewhat shocked by the discovery of Franklin that thunder is the noise made by natural forces, quite of the same character as those which act everywhere in bodies on the earth's surface, and that the lightning is so far under the control of man that it can be drawn from the heavens by a kite. The doctrine of the correlation of the physical forces, more than even that of universal gravitation, connects every part of nature with every other, in a thorough unity of action. Sir Humphrey Davy correlated the chemical and electric forces. Oersted correlated magnetism and electricity. Faraday has magnetised a ray of light, and illuminated a stream of magnetism. Late discoveries correlate all the physical forces, including heat and light, and mechanical powers, and demonstrate that they are related even to the vital forces. By an appropriate arrangement, any one physical force can be got from any other; and the amount of any one which can be derived from a given amount of another is definite, and admits of definite expression. As light is one of these forces, and as it is by light that the stars are revealed to 
us, we are thus made to discover that there is a unity or connection of forces, running through the whole knowable creation, to the most distant star which the farthest seeing telescope has disclosed. Such discoveries are turnings at which we see new aspects of old and familiar objects; openings through which we get views of far distant scenes; elevations from which we descry the directions, the bearings, and the connections of tracts of the universe which were before regarded as divided, separated, and isolated.

Researches into the organic portions of nature have furnished equally beautiful illustrations of the order, and the unity of order, in creation. The observations of naturalists, the dissections of anatomists, the classifications of botanists and zoologists, shew that in every country, every plant and every animal, and every organ of every plant and every animal, is after a type or model, and that there is a mutual affinity. and a harmony among organized beings, from the lowest lichen up to the highest quadruped, and to man himself. It has been shewn that the whole skeleton of the vertebrate animal is made up of a series of seg. ments, which, with an infinite number of variations, are yet homotypal; that is, of the same general form. It has been shewn that all the parts of the flower of the plant, sepals, petals, stamens, and pistils are after the model of the leaf, and 
it can be shewn that there is a homotypal correspondence between the leaf with its veins or ribs, and the branch with its branchlets, and the whole tree with its ramifications. These discoveries make the animal and the plant a unity throughout.

Geology, the younger, does for time, what astronomy, the elder sister, had previously done for space; shewing that law reigns through all knowable ages, as the other had proven that it rules through all knowable places. It shews us the very same agencies working from the remotest ages; tracts of country widely separated from each other, raised or depressed by like causes; and corresponding or homoeophyte plants and animals appearing on regions or ages far remored from one another. There are disputes as to whether there have not been supernatural exercises of Divine power in the creation of new species or orders of plants and animals; and all believers in the Word of God, and most of those who have studied the psychological nature of the human soul, maintain that there must have been a special creative act when man appeared on the scene, but all acknowledge that physical causes operated on our earth, millions of ages ago, as they now do, and that on the plants or animals coming upon the stage, they are of the same fundamental types as those now on our globe, and 
that they lived, and propagated their kind, and died, as they do in our epoch.

These are the views entertained by all educated men in our day, and for the professed defender of religion to set himself in opposition to them, would only be to injure the cause which he is seeking to benefit. It is quite as possible for those who adopt and cherish these conceptions to be religious, as for those who have more contracted ideas and convictions as to natural law. It may be all true that they have difficulties and temptations to contend against; but these will be found to have their seat and their strength in the ungodliness of the heart, which is much the same in all ages; and though they may have taken a somewhat different form in this epoch of advanced physical knowledge, I doubt much whether they are greater and more formidable than those which have beset thinking minds in all times. It is surely possible for those who see natural law everywhere, to discover at the same time the present action of God. We should so train and discipline our minds, that we see God acting in all action, and living in all life. I believe we are now in more favourable circumstances than the heathen ever were, for seeing the Creator in all creation. In perfect conformity with all that science has discovered, we may look on the sun, moon, and 
stars as the symbols of his majesty; we may still hear his voice in the thunder and see his terrible power in the lightning. The gods have disappeared; but it is as ghosts flee before a brighter light, which discloses the one God in all his greatness, and higher beauties in him and in his works. God may still be regarded as compelling the clouds and hurling the thunderbolt, with this only difference, that we also look upon him as making the sun to shine, and spanning out the bow of heaven, and preserving us in health in the midst of a thousand dangers. We can dispense with Neptune ruling the waves and Aeolus the winds, when we have one great God taking care of all, and making them work in harmony. We no longer need Phoebus and his chariot and his coursers to convey the sun; we have a better provision for his fulfilling his course, in the laws and arrangements of the mundane system. It may have been a temporary disappointment to some, but should have been a permanent joy to all, when the Naiads were driven from the rivers, - on the banks of which we are encouraged to seek, and may actually find, communion with the one living and loving God. The Caffre, after becoming a Christian, may still see God as the rainsender, only he will now understand and believe that he does not send rain capriciously, but 
according to an ordained plan, and that the same God sends all other blessings as well, to call forth our gratitude in one full and swelling tide. The Hindoo may at first be pained when the microscope shews him that he is devouring living creatures in the food he eats and the water he drinks; but when he rises to more enlightened and expanded views, he will be glad and grateful to think that God has filled all nature, air and earth, woods and waters, with beings living and enjoying life, and as they do so, testifying of the goodness of Him who hath given them all their enjoyments : and in regard to his magnificent river, while no longer permitted to honour it as a god, or allowed to cast his aged mother into its waters, he will rejoice to look upon it as it flows along so majestically, and dispenses blessings on either bank, as a grand symbol of the power and the majesty of God. By the progress of science, the stars are driven into more distant regions of space, and creation into more remote ages of time; but then we look on the stars as worlds, and as centres of worlds, which can be numbered only by Him who made them, and, by moving back the beginning, we leave in front a larger space for the varied evolutions of Divine wisdom, with its infinite resources: Irregularities and anomalies decrease and at last disappear, but it is only that wonders 
may multiply and ever become more wondrous. Chaos is driven out of sight, and chance has no longer a place in which it can work; and all, that law may universally reign, with a living, an all-wise, and all-gracious God, as its giver and guardian. He who discovers God as acting in natural law may see God in the law as well as in the action, and may admire not only the power of the acts, but the wisdom of their mode of action.

After all, the views entertained by pious and reflecting minds in the simpler, and again in the more adranced ages or stages of the world, do not differ so widely as we might at first imagine. In primitive times, the observing man sees system, and he sees seeming irregularities; and the religious man ascribes both to God. In the scientific ages, the devout man observes the same two classes of phenomena;-he perceives mechanical law, and the regular successions and cycles of events; but he discovers also that there is an adaptation of one agent to another, and of one law to another, whereby God can secure the most minute providential occurrences, at times in unison with, at times in contradiction to, the more direct operation of the uniformities of nature. He discovers the difference of those two, as the early thinker did, with this difference, that he observes, what the uneducated man did not, 
that both are within the natural and ordained system of God; but with this far more important point of agreement, that he recognizes in both, as the primitive believer also did, the operation of God, fulfilling his purposes of unfathomable wisdom.

We must return to this subject. 


\section{CHAPTER II.}

IN WHAT THE NATURAL SYSTEM CONSISTS.

IT is clear that nature is a system, that is, a regulated structure. Let us endeavour to find out the elements of which it is composed. So far as man can rise to a reasonable opinion on so vast and complicated a subject, they seem to consist of a number of substances, with their powers or qualities, of a distribution of them in space, and with time for them to act in. These substances have a power of acting according to their properties; and being placed in a certain relation to each other, they begin to act; motions, changes, and new distributions follow. Thus, as things are so constituted that matter attracts matter, certain bodies are drawn towards each other, while others are driven farther away, by reason of the more powerful attraction of one or more of them towards a larger body. Again, certain substances combine chemically by their mutual affinity, while others are decomposed in consequence of the tendency of one of the elements to combine with an adjacent substance. This actual 
structure of the system is determined by the number of the substances, by the nature of their qualities, by the mutual relation of their rule of action, and by the arrangement and collocation of the objects. The present state of the universe is the issue of these agents, dispositions, and actions, all of which are ascribed by the pious man to God.

What the ordinary observer sees, what we all see prima facie in nature, is not the ultimate elements or original structure, but a derivative order, the result of arrangement and operation. The skeleton of the body is hid from our view by a filling up, a covering, and clothingfar more grateful to us in their rounded forms and surface colouring; and we can discover the bones and ribs, the moving and vital organs, only by an inspection below the surface, by a sharp and penetrating dissection. Thus, by a very simple observation, we can discern the alternation of day and night and the revolution of the seasons; but these flow from the motions and mutual adaptations of the earth and heavenly bodies, which were not found out till astronomy had made considerable progress through long ages of patient observation. It is easy to discover the general order according to which grain springs and animals grow, but to determine the precise mechanical, chemical, 
electric, and vital properties according to which the organism germinates and is matured, has been found by science to be a vastly more difficult undertaking. Science must ever commence with the observation of phenomena, that is, of individual facts as they appear, and it would rise to the laws of phenomena, which it does by generalizing the appearances that present themselves. It would thence strive after the discovery of the elementary objects in nature, and of their original forces or properties. It may be doubted whether even the most advanced science has succeeded in reaching this knowledge in any one department of nature. It cannot be proven that we have discovered the original constitution of any one body,-that even oxygen and hydrogen are certainly indecomposable elements. It is disputed whether the law of chemical equivalents is an original law of elective affinity, or results, as Dalton thought, from the size and form of the primary atoms. Some maintain that even gravitation is not an ultimate law of matter, and that it may possibly be generated by some other and wider and simpler force. The discovery of the primary nature, qualities, and constitution of substances may be, or quite as possibly may not be, within the grasp of human investigation. Still, it is the polestar which the scientific navigator never reaches, but which he sets before him, to 
guide him in the direction he would take among these moving elements which he would make to fulfil his purposes.

We are ever hearing, in these times, of the order of nature, and of the uniformities of nature, and of the laws of nature. The Rev. Baden Powell, in particular, is ever referring in all his works to the "principle of order," to the " grand principles of law," to "law pervading nature," to the "chain of universal causation," to the "invariable universal system of physical order and law." But no where has he entered upon a searching analysis, or given an exact statement of what is involved in these very wide, but not very definite expressions; and the consequence is, that he is ever making rash and unwarranted assertions as to the nature and extent of physical law. If we would understand precisely what the natural system is, we must look carefully into its structure. It will be found to comprehend the following parts:-

1. Every substance in nature is endowed with certain properties, original or derived. Thus, the soul is possessed of powers of consciousness, of sense-perception, and feeling. Bodies continue in the state in which they happen to be, whether this be motion or rest, unless they be influenced by powers $a b$ extra; all bodies attract each other inversely according to the square of the distance; 
the elements combine according to definite proportions; light is propagated by vibrations; action is equal and opposite to reaction; in polar forces, like repels like, and attracts unlike;these are samples of properties which may be simple or may be complex, but are, at all events, natural properties. These properties consist essentially in tendencies-not in acts, but tendencies to act, on the needful conditions being supplied. Thus, oxygen has the tendency to combine with hydrogen, and does combine with it, when the hydrogen is presented in the proper mode. Thus, it is the tendency of fire to burn when fuel is presented, arrd the tendency of a dead animal body to decay. It will be shewn, as we advance, that this tendency is never, properly speaking, interfered with in any of the miracles of Scripture. But our present aim is simply to bring out what is in the cosmical system.

2. The substances and their properties are correlated and distributed so as to produce a general and an obvious order. It will be shewn in a succeeding Chapter, that they are so adjusted as also to produce individual events, having an important bearing upon human character and human destiny. But our present concern is more especially with the order and uniformity of nature. These are effected by the arrangement of the substances with these properties, so as to 
produce here a contemporaneous order, and there a regular succession of phenomena which can be observed for scientific and for practical purposes. Of this description are the apparent motions of the sun, moon, and stars in the heavens, the seasons for sowing and planting, for reaping and gathering in fruit, the stages in the life of the plant, and a hundred other periodical laws which human beings can observe more or less easily, by science or without science, and to which they can accommodate themselves, and, as they do so, secure the blessings which nature has provided. All this order arises from arrangements among the substances with their powers. With other distributions and collocations of natural agents there might be no general laws, or the general laws would be different. The actually existing laws are admirably adapted to the constitution of man;-to his intellectual powers, which delight to discover class and cause, and the relations of means and end, and also to his practical convenience, as enabling him to anticipate the future from his experience of the past. It is very conceivable that these laws may be in themselves an end contemplated by God, and pleasing to him as he surveys them. It is certain that they are a means towards a farther end, a means of making creation intelligible to the intelligent creature, and capable of being used for practical purposes. 
Miracles, we shall see, are, in a sense, an interference with these laws. They fulfil their end, they draw the attention of spectators, they become "wonders" and " signs," and they attest a supernatural revelation, because they do not fall in with natural laws. But supernatural occurrences may (it will be shewn that in fact they do) take the form of order or system, and thus fall in thoroughly with an analogy which binds the natural and supernatural, as the two compartments of one great system, which God has constructed for the accomplishment of his ends of awful wisdom and bright beneficence.

3. There is a large yet limited body of objects and powers, constituting nature and performing its functions. I believe that the substances, with their properties, have all been created by God, and also that all their natural relations and dispositions have been instituted by him. No human power, no natural power, can add a new substance to nature, or destroy any existing substance,-we may burn the hay or stubble, but it is not thereby annihilated, one portion has gone up into the air as smoke, another has gone down to the earth as ashes. Not only so, it seems to be established by the latest science, that power cannot be created or lost, and that the sum of force in the world cannot be increased or diminished, by natural means. We may trans- 
form one natural force into another, or make one natural force produce another; but in all the mutual action of bodies, the sum of the potential and actual energies is never altered. Not only is it beyond created power to create or annihilate new bodies or substances, it is beyond all natural power to create or annihilate force. Nature is a self-comprised system, globe, or sphere; in se ipso totus, teres, atque rotundus.

In saying so, it is not meant to assert that this sphere has no points of contact or relationship with other compartments of creation, and still less, that it has no dependence on a higher and a supernatural power. All that we maintain is, that it has a number of agencies which, in their totality, combination, and action, constitute the system of nature. A miracle, we shall see, does imply the interposition of a power beyond this mundane sphere. It serves its end, because it is the effect of a supernatural cause.

But, meanwhile, let us understand precisely what is meant when it is said, that nature is a self-contained system. Let us not suppose that it has been proven that it needs nothing to support it, and that it will go on for ever if left to itself. 'The geologist, in his diggings, has gone a little beneath the surface, but has not reached the bottom in lis explorations; he has gone back many ages, but has not reached the beginning, 
which ever retreats before him. The astronomer has penetrated to great distances, but he has not reached the outside,- - he is just impressed the more with the vast circumambient region into which his telescope cannot penetrate. Science, in all its explorings, knows not when the beginning was, nor when the end shall be; knows not where the centre is, nor where the circumference is,-if indeed there be a circumference. This knowable world, however large and complete, is not, after all, the universe, but only a part of it; whether we follow it behind or before, above or beneath, on the right side or the left, it is seen to be broken off; beginning we know not when, ending we know not where, but certainly not when and where our vision fails; it looks hung from above, and resting below, on nothing discoverable by physical science. There is clear evidence that things have not always been as they now are: there was a time, for example, when man was not on the earth; an earlier time, when there were no animals on the globe. There is no evidence that there are physical agencies in the world which would keep it existing for ever. The continental mathematicians of last century thought they had gone a step beyond Sir Isaac Newton, and demonstrated that, according to laws now in existence, the machine would go on through all eternity, without requiring to be 
wound up, or receiving any aid from without. All that they proved was, that there is a beautiful self-adjusting or self-regulating arrangement in the solar system, which secures that the obvious variations of the motions of the planetary bodies are periodical. Later inquiry has shewn, that there are agencies now operating which must, in the end, dissipate the whole existing order of things; and the most advanced science has discovered no natural means of counteracting the destructive tendency. The following are the conclusions drawn by Professor W. Thomson :“ 1 . There is at present, in the material world, a universal tendency to the dissipation of mechanical energy. 2. Any restoration of mechanical energy, without more than equivalent dissipation, is impossible in inanimate material processes, and is probably never effected by means of organized matter, either endowed with vegetable life, or subjected to the will of an animated creature. 3. Within a finite period of time past, the earth must have been, and within a finite period of time to come, the earth must again be, unfit for the habitation of man as at present constituted, unless operations have been, or are to be, performed which are impossible under the laws to which the known operations going on at present in the material world are subject." *

* Transactions of the Royal Society of Edinburgh, 1852. 


\section{CHAPTER III.}

MENTAL PRINCIPLES INVOLVED IN OUR CONVICTION AS TO THE UNIFORMITY OF NATURE.

Oon belief in the uniformity of nature is, I am persuaded, the result of a large and long experience. It does not seem to be guaranteed by any native or necessary principle. There are, as I think, very clear tests by which supposed intuitive convictions of the mind may be tried. Intuitive or necessary truths are all self-evident; they are seen to be true on the bare inspection or contemplation of the objects. They are also necessary; that is, they carry with them an irresistible conviction that they are true and must be true. They are, farther, catholic or universal; that is, they are entertained by all men, on their minds being fairly directed to the objects. But our conviction as to the unity or uniformity of nature cannot stand these tests. It is not a self-evident truth ; men cannot, on the bare contemplation of the notions or terms, and apart from a course of experience and the gathering of facts, declare that law reigns over all objects in nature. It is 
not necessary, it is certainly not universal; for, in fact, the unscientific and the unlettered, who constitute the great bulk of mankind, are ignorant of it, and a vast number, were some one to propound the doctrine to them, would declare that it cannot be true, for that they see constant interpositions of supra-mundane agencies. The conviction is entertained steadily, and in regard to the whole of nature, by those only who have had the advantage of a scientific culture, by which, or by the literature in connection with it, they have been put in possession of the results of a very wide induction of facts.

Still I am inclined to think that there are native and original principles of the mind which incline us to look for, though they do not compel us, apart from experience, to believe in, law and uniformity in nature.*

1. There is an intuition which leads us to look on every object falling under our notice as having Being, something constituting it what it is, abiding in it, and going with it wherever it goes, so that we are sure that if we meet with that object again it will have this being or essential nature, which must ever con-

- I cannot, in this treatise, give a general exposition of the intuitive convictions which I here call in to explain our inclination to seek out for uniformity, and so I must refer to my work on the "Intuitions of the Mind." 
tinue with it, unless destroyed by something $a b$ extra. This intuition, commonly unobserved, enters into all our knowledge of objects, and makes us feel that we are surrounded, not with ideas, images, or spectres, but with solid and abiding realities. It is to be carefully noted, however, that this intuition does not vouch for the uniformity of nature. We have an intuition which says that every object must retain its being, unless changed by an external cause, but we have no intuitive means of knowing, as to any given object, whether it is the same as we met with before. We have to determine this by appearances, and by experiential rules of evidence. But, in forming our judgment, we may be mistaken, and, in fact, are often mistaken. The child frequently looks on a stranger, seen at some distance, as its father or mother; and all our lives we may be tempted to find identity where there is only similarity. The intuition of being, or identity, is, however, one means, not exactly of leading us to a conviction of the uniformity of nature, but of inducing us to look for the sameness of objects surrounding us.

2. There is an intuition as to substance and quality. This joins on to the one we have just been looking at, but goes beyond it. We regard every substance as exercising a quality, and every quality as implying a substance. We are thus 
led, when we perceive an object, to anticipate that it will have some kind of action, and we are thus carried up in our investigation from the properties exercised to the things that exercise them. All this does not prove that there is ever the same group of objects in nature, but it prompts us to observe the action of objects, and the uniformity of action of objects, falling under our notice, and to trace all action up to substances.

3. There is the intuition which leads us, when we discover an effect to look for a cause. This intuition connects itself with the other two; but it rises to farther truth. On seeing a change, we are sure that there has been an agent effecting it. This is the most active and potent of all mental principles in impelling us to the scrutiny of nature. We are not satisfied with the immediate present, we are sure that it has proceeded from the past; and we go back from the nearer to the more remote past, and we are not contented till we reach an all-sufficient cause which is not itself an effect. But this principle, while it ever prompts us to seek for the causes of the effects which come under our notice, and thus leads us to discover the causal connexions in nature, does not insist that all things proceed according to an eternal chain of physical or of mundane causation. The conviction does, indeed, demand a cause for every occurrence, but would be quite 
satisfied though some or all the causes were supernatural.

4. There is another native (not necessary) inclination of the intellect which has its influence in making us seek for, and in the end discover, the uniformity of nature,-it is the tendency to perceive resemblances. We love to detect likenesses of every kind, and by means of them to bring the multifarious objects around us into classes, into species, genera and orders, with due ordination and subordination. I do not look upon this intellectual impulse of the mind as being of the nature of a principle of reason, or an intuition guaranteeing necessary truth. It is merely a native talent, taste, and disposition, tending ever to act, and in doing so, to seek out its appropriate objects, that is, resemblances and affinities of every kind, and thus connect all nature by analogies, and bring all its objects into groups. All this does not prove that nature is uniform, it simply prompts us to seek out for the uniformities that exist. It is only on actually observing the analogies of nature, that we know them to exist; and the internal inclination does not guarantee their existence beyond the objects that have been actually examined. This same mental principle, on the discovery being made of supernatural operations, will delight to trace analogies between the 
natural and supernatural, and between one part of the supernatural and another,-and we shall discover that there is abundant field here thrown open for the exercise of the faculty.

These, or such as these-blended, in the quickness of mental action, as colours are on a rapidly circulating body-seem to me to be the mental principles which lead us to seek for a uniformity in nature. They constitute that instinct to which Thomas Reid, Dugald Stewart, and others of the Scottish metaphysicians so often refer, and which they seem to look upon as a simple principle, unresolvable into any other elements, whereas I regard it as the combination or issue of several mental intuitions, each inclining the mind in the same direction. It is to be specially noted, that no one of these mental principles of itself authorizes a conviction of the uniformity of nature, nor do they together sanction any such wide conclusion as that nature has nothing but physical or mundane law. Nor is any one of them, nor are the whole of them, inconsistent with a miracle. We may regard every object as having permanent being, without having any information or belief as to how many objects are operating around us, or as to whether they are within or beyond the domains of nature. We believe that substances will act, according to their properties, on the needful conditions being sup- 
plied; but this law of mind says nothing as to what substances are at work, or as to whether they are all within the circle of mundane agencies, or whether some of them may not be from a region beyond. Every effect has a cause; but for anything the intuition says to the contrary, the causes of the effects visible to us might be found quite as readily in Divine as in creative agencies. Our faculty of comparison prompts to the discovery of likenesses, but it is observation that finds out what are the actual analogies in the Cosmos. All that these intellectual propensities do is to instigate us to seek out for the permanence, the activity, the causal connexions, and the affinities that exist in the objects pressing themselves on our notice. As we follow them, and observe the phenomena, we arrive at the reasonable conviction that there is a universal system of natural law. But this is the product not of intuition but of a lengthened observation, to which, indeed, our intellectual promptings have incited us, while it is experience which furnishes the true ground on which the belief rests. The same experience which authorizes the conviction must determine the extent of it, and the limits to it. As it is by the evidence of facts that we reach the wide general maxim, that there is uniformity throughout nature, so we may also, by the same evidence of facts, reach the conviction that there is a super- 
natural power operating in the midst of the natural system. It will be found, indeed, that the very same intuitions which instigate us to notice the stability and the correlations of nature, also allure and prompt-indeed compel-us to go on to a belief in a supernatural power and activity. Our intuition as to being is not satisfied with dependent being; it feels that it has not got a deep enough foundation till it rests on independent being. Our intuition as to substance will go down till it reaches self-existing substance. Our intuition as to cause insists on going back to the Being to whom emphatically all power belongeth; and when an occurrence is discovered in this mundane sphere, beyond the capacity of natural agents, it demands a supernatural power. Our inclination towards analogies does instigate us to admire the wondrous affinities of nature; but it will be quite as interested in looking into the analogies between the natural and spiritual,-

\section{"And what if earth}

Be but the shadow of heaven, and things therein

Each to other like, more than on earth is thought?"

The above statement brings out, I believe, what our consciousness reveals of our actual mental operations; and it accounts, on the one hand, for that inductive propensity which ever incites minds of higher intellectual calibre to 
seek for the uniformities of nature, while it is quite consistent with the fact, that the great body of mankind have ever been prone to seek for supernatural interpositions amid natural occurrences; and it certainly shews that it is vain to appeal to any native principle of the mind as authorizing the rash assertion that a miracle is an impossibility.*

* Reid says, "God hath implanted in human minds an original principle, by which we believe and expect the continuance of the course of nature, and the continuance of those connections which we have observed in time past." And again, "Antecedently to all reasoning, we have, by our constitution, an anticipation that there is a fixed and steady course of nature."-Works (Ham. Ed.) pp. 198, 199. He allows that this expectation "leads us often into mistakes," p. 199. D. Stewart represents our "expectation of the continuance of the laws of nature" as " an original law of human belief," and seeks to explain by it "our conviction of the permanent and independent existence of matter."-Phil. Essays (Works, vol. v.) pp. 104-106. I greatly doubt whether the child or savage has any expectation or belief about a "steady course of nature" or "laws of nature." It has merely certain tendencies which make it look out for constancy and law, whether in nature or beyond it. 


\section{CHAPTER IV.}

HOW MUCH IS CONTAINED IN THE NATURAL.

Is the present day there is a constant reference to nature or natural law. But those who make the most frequent appeals to it generally take a very limited view after all, meaning by it merely mechanical, or, at the utmost, physical law,-thus contemplating only one of its many mansions. Let us comprehend and thoroughly realise the extent of the natural.

I. Let us observe the extent of the Physical.

1. The natural undoubtedly includes Order. It is the aspect of it most frequently dwelt upon in these times. In particular, it was the feature habitually and exclusively viewed by Mr. B. Powell, who seems, in the end, almost to have identified order with God; thus he speaks of the " great principle of physical order, and its consequences, as the indication of, or rather as synonymous with, reason and mind in the natural world." * By all means let us labour to discover the order in the physical world; and, as we do so,

* Order of Nature, p. 242. 
let us devoutly look upon it as the expression of intelligence. But the order of nature, least of all the "physical order," is not synonymous with "reason and mind," it is merely an indication of them; and the "reason" always resides in another sphere,-it resides in " mind,"- - that is, in the Divine Mind. Mr. Powell is ever representing order as the proof, and the sole proof in the world, of intelligence. But, amid all his dogmatical assertions, and wearisome repetition of assertion, we look in vain for the ground or principle on which he argues intelligence from physical order, and we are left in ignorance as to whether he proceeds upon intuition or experience, on a mental law or an external observational law, or on what else. I am inclined to look on order as the evidence of intelligence, because it is an evidence of design, and that it is an evidence of design, because the result of arrangement contemplating a wise and beneficent end. Certain it is that the order of nature is the issue of an assortment among very numerous and diversified materials and agencies. What a vast variety, within the Cosmos, of separate substances, animate and inanimate, material and mental, each with its distinct powers and rules of action. The order of nature is due to no one of these taken by itself. Take the forces which may seem the most strictly and numerically 
regulated-take the law of gravitation and the law of the chemical affinities of bodies-they are only single elements of the order which reigns in the compartments in which they are found. The law of gravitation might draw all bodies to one great centre, and bring all motion to a dead halt, were there not an adjustment of centrifugal and centripetal forces. Chemical attractions, among bodies incongruously huddled, might give play only to a war of jarring elements, or settle into lumpish compounds standing in our way. as an incumbrance. Order in the solar system, order in the earth, order in the structure of the inorganic materials in our world, order in the stems and flowers of plants, order in the organs and movements of animals, are all the result of arrangements made by a power without and above the material forces. Just as the figures in damask or in the carpet are made to come out from threads skilfully predisposed and then intertwined, so do the beautiful forms of plauts and animals - the elegant conical forms, for example, of pines and their fruit-the lovely shapes and colours of the corolla of flowers-the fine proportions and graceful movements of man and woman -all proceed from a skilful adjustment among rude materials. It is because order is the result of arrangement that $I$ am inclined to regard it as an evidence of intelligence. 
2. This order, as it results from means appointed by God, so it is also a Mean towards an End contemplated by God. In saying so, I do not mean to say that this order may not be in itself an end. It may be, that just because it is order it is grateful to the high wisdom of Him who delights in all his works. It may be, that it is also pleasing to the contemplative mind of angelic beings, as they look down upon its proportions and harmonies from their heights above us. But whatever else it may be, it is also a mean towards ends of very high importance. In saying so, I do not refer to relations which it may have to other and unseen worlds. It is clear that it is the order in our earth which constitutes it a compartment of the wide Cosmos known to us; and it may be, that it is the order in our Cosmos which makes it fit into a yet larger system of which ours is but a part. All this may or may not be,-we must so speak because the theme lies in a region beyond the clouds which ever bound our vision. But there is an end served by the order in our world of which we can speak with confidence; for it comes every where, and alluringly, and pressingly, under our view. The order has certainly and obviously a special respect to man. His intelligence is so constructed that he has pleasure in contemplating it, and is ever impelled to 
seek out for it, and he experiences a high delight in tracing the elements in the compounds, in grouping the individuals into classes, and in detecting the causal links by which the present hangs on the past, and has dependencies in the future. Not only so, it is because there are established order and law in the Cosmos, that man can accommodate himself practically to the position in which he is placed, take steps to draw in the good and avert the evil, and exercise an influence on coming events. It is because there are day and night in orderly succession that he knows how to plan his periods of rest and labour; it is because there is a regular succession of seasons that he knows when to sow his crops; it is because seed bears fruit after its kind that he knows what sort of crop to sow; it is because the laws of chemical composition and decomposition are invariable that he continues to partake of food in the confidence that it will nourish him; it is because there are laws of political economy that the statesman can add to a nation's wealth; it is because there are laws of mind and character that the wise and strong man can sway for good or evil the opinions and morals of the men of his own age, and transmit his influence to the generations that follow.

3. In nature there is Beauty as well as mechanical and physical law. I by no means maintain 
that the phrase beautiful, can be applied appropriately to every object in our world. A state of things in which everything was positively lovely, would, in the first instance, be too exciting, and, in the end, would pall upon the taste, by being too luscious and luxurious. I believe that every object in the Cosmos is useful, it is suited to its place, and it has a good end to serve; but it would be extravagance to affirm, that every surface of clay or cloud has aesthetic qualities. It is out of the midst of the more ordinary and commonplace scenes that certain objects riseas plants do from the soil of the earth; as damp vapours are lit up by the setting sun, as mountains lift up their heads from the plains-to melt and soften us by their loveliness of form or colour, to kindle our mind and our eye by their sharp and vivid outline, or to awe us by their huge bulk, or dizzying height, or irresistible power. Persons busied with the more sordid solicitudes of life have little time, except perhaps in a quiet evening after the toils of the day are over, to spend on the admiration of beauty; and, in fact, they have little relish for it except in its more obvious forms-as in the flowing stream, in the grassy slope, the fertile plain, the glowing evening sky, or the face and person of young man and maiden; but as mental cultivation advances, and accumulated wealth 
leaves leisure for quiet observation and reflection, the taste becomes more and more intense, and takes in a much greater sweep of things, and it is found that there are objects in nature to gratify it,-in sky and cloud, in mountain and valley, in tree and flower, in animal life lower and higher, in man and in woman; and that there are persons moved to produce objects of art for the farther gratification and elevation of it,-in music, in statues, in paintings, and, above all, in poems, which come nearest to the full symphonies of nature without us, and the capacity of the taste within. It would be for the benefit of the exclusive observers of mechanical law to contemplate this feature of the well-ordered Cosmos, were it only to raise them to something higher-as music and poetry are often made the stimulus wherewithal to raise men to noble thoughts and sentiments. They should observe that these very mechanical powers are often turned by God and man to the production of works of art, which lift us far above natural law into a region bordering on the moral and spiritual, to the existence of which they testify, and to which they are meant to be fit ministers.

4. There is in nature a Fitting of every one object and power to every other. I am convinced that there is a prior propriety in the very original constitution of the objects themselves, and of the 
powers or properties with which they are endowed. I argue this on two grounds. One is, that, so far as we are able to penetrate into the ultimate constitution of the powers of nature, we discover-as in gravitation and chemical affinities, and the dispositions of the organs of plants - numerical relations and proportions with a very profound meaning. The other is, that order is seen to be the result of their operation in actual nature, and it is not easy to see how such harmonies should result from the union of materials in themselves altogether discordant. But whether there be or be not method in the original structure of the substances in nature, whether the harmony has proceeded from concords or from discords, it is quite certain that it has proceeded from an arrangement of some kind -for even melodies, without assortment, will not produce harmonies by their conjunction; and so we are constrained to recognise superlative wisdom in the accommodation of every object to every other, of every group of objects to every other, of every system of groups to every other, and of the whole to every part, and of every part to the whole. The actual order of nature is the result, we have seen, of these conformities, and so must also be the beauty which consists in colour and form, in proportion and harmony. From these same arrangements pro- 
ceed other beneficent characteristics which we are now to consider.

5. In nature there is Final Cause, having respect to the comfort of the lower animals and of man. In the plant, the simple material elements-the oxygen, hydrogen, carbon and nitrogen-are made to correspond with one another; and the external stimuli of light and heat, moisture and food, so act on them as to produce that organic structure which is so pleasing to the eye of intelligence, and is made in its growth and fruit to furnish such nourishment to the animal creation. In the animal frame, bone so fits into bone, and bone is so adapted to attached muscle, and the vital organs are so suited to each other and to the nerves and brain, that the organism becomes a wondrous unity, in which every part has a function and subserves the good of the whole. This final cause, pervading, as it does, all nature, and especially every part of it bearing on animal comfort, is quite as obvious as the material or physical cause. Nor is it any valid objection that, as we know everything only partially and in progress, we cannot be prepared to pronounce upon the purposes of God. I give no credit for humility to those who tell us that it would be presumptuous in them to imagine that they can discover any of the designs of an infinite God. I am not disposed to 
lavish any sympathy on those who tell us, with a sigh, that they are so sorry that they cannot detect any special end in events which seem to move on like a stream in an unbroken flow. It is a great truth that we know but in part; but this implies that we do know, though only in part. He who denies this consequence is logically landing himself in a universal scepticism, which no man can consistently carry out. It is not required that we should profess to have "found out the work which God worketh from the beginning to the end," in order to entitle us consistently to affirm that we see so much of the work of God as to lead us to admire it and delight in it. It is not needful that we should be able to fathom all the mysteries of nature, in order to be quite sure that we know some of its laws, and somewhat of its method. Many a one who does not comprehend all that is in the Principia of Newton, does yet rejoice that he apprehends so much of the Newtonian discoveries, and can appreciate what he understands. We who are uninitiated should not attempt to guess at all that is transacted in our great mercantile houses, which trade with the ends of the earth, or find out the purpose aimed at by the general in all his military movements, or by the Ministerial Cabinet in all its counsels, though we may, without presumption, venture to say that we 
see some of the means employed, and some of the ends accomplished. I am using small matters to illustrate great ones. We should certainly never pretend to be able to find out all the purposes contemplated by God in any one of his acts and agencies, for I believe that, in the plenitude of his wisdom, he commonly accomplishes a great variety of ends by one and the same means. "Canst thou by searching find out God? Canst thou find out the Almighty unto perfection?" "Such knowledge is too wonderful for me; it is high, I cannot attain unto it." Still there is so much that we can know; it is meant that we know it; it is thrown open to us freely and ungrudgingly, as in a museum, or school, or garden, for this very purpose. "The secret things belong unto the Lord our God; but those things which are revealed belong unto us and to our children." God's works are throughout a manifestation of God, and are, so far, a revelation of his will. The scientific man is quite certain that he has discovered laws; they may or they may not be ultimate laws, but they are laws ruling in nature, and he can turn them to practical purposes. There are also in creation special ends which we can discover, and this without professing to know all the counsels of God. The fountain may be high up in mist or mountain beyond our reach, and the ocean into which the waters pour them- 
selves may be unexplorable in its vastness, still we know so much of the stream as it flows past us, or as we float on its bosom, to be quite sure that we see uses served by it, and know the direction in which it runs. I have really no moral tolerance for those who tell you that they are not sure whether the eye were made for seeing, or the ear for hearing, or the land for grasping, or the feet for walking, or the ball and socket joint at the shoulder to give a convenient and easy motion to the arm.

6. Nature throughout has a Respect to Man. All objects on the earth minister to his bodily wants, and are, so far, subordinated to him. Geology seems to shew that when man was about to come on the scene, there are plants, unknown before, which make their appearance to sustain his life, and contribute to his enjoyment-such as wheat, and barley, and oats, and rye, and Indian corn, and millet, and rice, and the plants which yield wine, and oil, and odours, as well as most of those, such as roses, which are covered with the flowers which yield him such delight. When he comes, he "has dominion over the fish of the sea, and over the fowl of the air, and over every living thing that moveth on the earth." As he uses his power, his intelligence is evoked and strengthened; for, if he would earn a sustenance, or enjoy the full blessings of life, he must 
cultivate the soil, and tend the plants, and care for the lower animals. The very order of nature, we have seen, is adapted to his contemplative intellect, which delights to resolve the complex structures of nature into their ingredients, to catch the classes according to which all the objects in nature are arranged, to trace the causes and combinations of causes from which all changes proceed, and to dwell on the proportioned forms and harmonious colours which everywhere draw our regards towards them. If we train ourselves to look on physical nature as a mean, having throughout a respect to man, to his happiness and elevation, I believe we will not be disiuclined to suppose that there may be other and supernatural means provided to further the same general ends of beneficence and morality.

And here it will be necessary to remove the impression, that because there are other purposes served by the agencies of heaven and earth, we are no longer entitled to look upon them as having the respect which our forefathers fondly imagined them to have towards the children of men. There was an excuse, they allow, for those who looked on the earth as the centre of the world, when they supposed that the heavenly bodies had a peculiar reference to man; but it is said to be absolutely ludicrous to entertain any such notion, now that we know 
that the earth is a comparatively small body dangling round a vastly larger one, and that the stars are themselves worlds or centres of worlds. But I maintain that all this is the conception, not of large, but of contracted minds, which look upon the great God as being like the great man, who must often neglect affairs of less importance in attending to matters of mighty moment. It would be a most unfortunate narrowing of a boy's idea of a father's love, were some one to persuade him, now that he sees that the father has wide cares as a merchant, or wider cares as a statesman, that one so burdened cannot possibly feel so deep an interest in his family as at one time he was supposed to take. On the same principle, it would truly be a lowering, instead of an enlargement, of our ideas of God's greatness, were we tempted to believe that, in fulfilling his purposes of wisdom towards these other worlds we have come in sight of, he is obliged to withdraw his special regards from his intelligent and responsible creatures on the earth. Those who would rise to a full comprehension of God's goodness, and of his greatness in his goodness, must learn to conceive of him, as not neglecting the part, because he has to take care of the mighty whole, and as making, in the riches of his resources and in the might of his love, as full a provision for our earth and 
for each creature on it, as if there were no other world or no other created being in the universe. It is all true that the man of devout spirit is inclined to say, "When I consider thy heavens the work of thy fingers, the moon and the stars which thou hast ordained; what is man that thou art mindful of him, and the son of man that thou visitest him." But while he is amazed at the Divine condescension, he does not doubt that condescension. He believes that the heavens are the work of God's finger, and that the stars are ordained by God; but he believes quite as firmly that God is mindful of the children of men, and graciously visits them. God's greatness is seen in his taking care of the little -as we reckon it in our littleness-equally with the great. The pansy, no doubt, is the product of wide physiological laws which have relations to many interests; but it can be shewn that, by the shape it has been made to take, and the harmonious colours of yellow and purple and white which come out on its corolla, it is exquisitely suited to the eye and to the tastes of men. The sun lightens other planets; but it lightens this one also as beneficently as if it had no other to shine on. These stars, no doubt, look far out with penetrating eye into space; but I am persuaded that every unclouded night they look down with benign regard upon our world. 
7. In nature there is a Special Providence. In all ages mankind have been inclined to believe not only in general law but in particular provisions which have a respect to the individual man and his special wants. The views entertained, both of one and other of these, by men of contracted vision and limited prospects, have been very narrow, and their opinions of the relation of the one to the other have commonly been very confused, and at times very erroneous. Still, mankind generally have risen to some idea of a settled system on the one hand, and of certain dispositions or interventions on the other; and they can be justified in believing in the existence of both. I maintain that advancing knowledge has not set aside either of these. I deny that in throwing open larger views of the general order it has made it necessary for us to overlook the special providence; for while God has so arranged his physical agents, that general laws, such as those of the seasons and of the stages in the life of animated beings, every where prevail, and prevail for the good of man, he has also so disposed them that by their combination or coincidence, crossing or collision, they produce individual incidents, which exercise a mighty influence on the world at large, or which meet the state and the wants of individual men at momentous or critical times in their history. 
The seasons revolve according to a regular system, but in the very midst of the heat of summer there may interpose,-and this by the prearrangements of nature,-a storm which wrecks the persons or fortunes of hundreds, or gives a new turn to the whole life and destiny of some individual. There is an average life for man upon the earth, but, by a natural disposition of natural agents, the child which has nestled itself in the warmest affections of a parent's love, may have its life nipped in the bud; or the youth, full of hope and activity, may have all his energies for ever arrested, and his fond plans finally frustrated by unexpected, but not unordained, disease or death; and one or other of these events may come home with very peculiar force to the heart of some interested individual, and have a greater influence on his or her future life in time or eternity, than has been exercised by all the more orderly events on which the scientific or philosophic mind is so apt to dwell. By all means let us observe the order in nature, for it is the work of God; but as we do so, let us not overlook the mutual fitting of objects and powers by which the order is produced; and let us also note how, by this same predisposition of laws and agents, there are brought about individual occurrences by which a mighty power is exerted on the destinies of the world at large, or of par- 
ticular persons; by which great men appear on the emergency to do their appropriate work, or by which great tides of popular feeling are raised up, evidently by a power from above drawing them, and to keep the sluggish waters of our earth from stagnating; by which the archtyrant is cut off when his schemes of wickedness were about to be consummated; by which the poor man has his wants supplied in the time of need; by which the guilty is detected, as by lightning flashing out and glaring upon him in the darkness as he did the deed; by which the falsely accused has his character fully vindicatèd and all suspicions dispelled; by which the man waiting for instruction is rebuked when he would become vain and proud, or cheered when he would lose his courage and sink; and by which the good man has his purposes of usefulness helped on to their completion-openings being disclosed to him on the right hand and on the leftmountains which seemed to shut him in, shewing an outlet for him as he advancesand the stream which bears him along having a channel provided for it, till it carries him to his destination.* We can surely believe that $\mathrm{He}$ who has so provided for the meanest of the earthly wants of his creatures,

* The author has explained this fully in the "Method of Divine Government, Physical and Moral."-Bk. II., chap. ii. 
will also provide for their deeper and spiritual wants.

II. In nature there are Souls with High Endowments.

It is an unfortunate incidental effect of the division of labour in science, and of the success which has attended the study of the physical sciences, and of the interest which has, in consequence, collected around them and the phenomena investigated by them, that the most wondrous object disclosed to us in our world has been overlooked by many who have a large knowledge of the heavens and earth, or a minute acquaintance with particular departments of them. Nature is a vastly richer field than some imagine; it has gems, which many never discern, as well as the stone and the clay which mankind are ever looking at. There is more in it than mechanical, and chemical, and electric force,more than the plant, with its vital power, more than the animal, with its sensations, its appetences, and its incipient reason. This earth has something nobler on its surface than the telescope has ever discovered in sun or star. This epoch of our world's history has in it a being vastly better, and, alas! vastly worse, than all the brutes which enjoyed life on its surface in the earlier geological ages. In the complex but compact structure of nature it is evident that some 
parts are higher than others;-some being, as it were, the moving powers, others the mere channels of transmission; some, as it were, the head and heart, and others the mere arms or limbs. In this economy the animate has a higher place than the inanimate. The plant, by its living power, draws rude matter into itself, 'and turns it to its own uses; while, again, the animal feeds upon the plant, and subordinates it to its own superior functions; and above them all is the soul of man, with its conscience and its free will, capable of controlling the animal instincts, and turning them to high moral ends. There is machinery in our world, we admit, but there are workmen with throbbing hearts moving and labouring in the midst of it, and these are also worthy of our attention and regards-the very machinery has throughout a respect to them. Verily, he must be guilty of a flagrant oversight who, in considering nature, overlooks human nature. It is as if one were to visit a great city, and admire its masonry and its architecture, and take no notice of the inhabitants, with their strivings and ambition, their sins and their sorrows; or travel through a rural district, and feel interested in the cottages and the culture of the fields, but neglect to make the acquaintance of the tillers of the ground, with their cares, their feuds, their industry and their vices; or as if one were to 
inspect a school, and note its order and its discipline, and not think of the motives throbbing in the hearts of the children; or it is as if one were to look down from a height on a battle-field, and follow the military movements, and never once be impressed with the passions quivering in the breasts of the combatants, or moved by the writhings of the wounded and dying.

1. Let us consider that the soul has high Intellectual Endowments. The mechanical inquirer is well employed when he is seeking to obtain the right expression of the laws of motion and force; the physiologist is fulfilling a very important function when he is trying to catch the more recondite laws of life; but let both acknowledge that in the mind of man there are still higher laws at work-if only the psychologist could seize them as they act, or rather that they exist and ever operate whether he does or does not succeed in apprehending or expressing them. And let not the psychologist, in his attention to the inferior parts of our mental nature, miss the higher and nobler. As he looks at the dependence of mind and body, let him not neglect its higher and more independent powers; as he analyses our sensations, and our instinctive feelings, and our remembrances, and our associations, let him not omit the higher attri- 
butes of mind. Whether metaphysicians have or have not succeeded in unfolding them, let us realise how much is implied in such an attribute as consciousness, the consciousness of self-the consciousness of ourselves as persons; how much is involved in our higher intelligence; in our being able to perceive truth, and necessary truth; in our being able to know things, and the relation of things; to know the necessity of mathematical and other relations, and the indelible distinction between right and wrong. These intelligent acts shew how closely we are allied to higher and supernatural intelligences.

2. Let us consider how much is involved in our having a Free Will, and in our being free agents. A fact is now before us of an altogether different kind from those which meet us in any of the lower departments of nature. In behalf of that fact we have the testimony of consciousness so clear, so decided, so assuring, that it needs no confirming evidence, and can be set aside by no seemingly conflicting proof. In order to gain all we need for our argument, we do not require to take a side with the Augustinian or the Pelagian, with the Calvinist or Arminian: we assume nothing beyond what Augustine and Calvin both acknowledge - that man has, in his essential nature, a power and freedom of choice, which makes him a free and responsible agent. Here, 
then; we have a being raised above all other sublunary agents, and closely allied to that free agent who is above nature, and from whose free exercise of power all nature has proceeded. At this point we have come in sight of that possibility of sinning which has issued in a fearful actuality; and this is the awful fact that seems to call for an interposition from a supernatural sphere.

3. The natural man has a Conscience, which discerns a moral good and a moral evil; which declares that there is a distinction between the two, indelible and immutable; which points up to a law altogether different in kind from mathematical or physical law ; a law with obligations requiring us to do this, and not to do that; a law above man, implying a lawgiver above nature-a lawgiver who must also be a judge, and call man into account for the "things done in his body, according to that he hath done, whether it be good or bad." Every one carries in his very nature feelings and principles which announce and guarantee all these truths; and whoever believes them, as the great body of mankind do believe them, in a less or more conscious manner, feels himself under a supernatural authority, responsible to a supernatural being, and about to exist in a supernatural state of things.

4. Man is, in his very nature, a Religious Being. 
This is attested at once by every man's internal feeling and by the records of history. Different accounts have been given of what it is in man's nature which makes him the subject of religious convictions, of religious fears, and religious hopes. Some have supposed it to spring from an immediate intuition or consciousness of God. I am more inclined to look upon it as the natural and intended result of several native intuitions called forth by, and proceeding upon, certain very obvious observed facts. The native principle of causation ever prompts man to seek for a cause of that order and beneficence which everywhere meet our eye in nature, and in the chase after subordinate causes he is never satisfied till he reaches a supernatural and Divine cause. Our moral faculty recognises, and looks up to, a law having authority, and this law is the expression of the holy nature of a lawgiver. Our conception and belief in regard to infinity can find nothing but an abstraction till they rest in an infinite God. According to the account now given, all the steps in this process are not immediately intuitive, nor is the whole apodictive or demonstrative like a mathematical proposition. There are observational or experiential elements entering into the argument; but these are facts which can be seen by all, and which press themselves on the attention of every one; and, with these 
facts before the mind, there are fundamental laws of thought and belief, which lead up to the conviction of a God to whom all power belongs, and who acts in all action, who is good and does good, who is entitled to our obedience, as he claims our obedience, and is greater than we can conceive-so great, indeed, that he cannot be greater. The conviction thus wrought in us is one which may be very much crushed by intellectual degradation, and become confused, or all but overcome, through sophistry; still it is there in the breast, very much undeveloped it may be, but ready to be developed-like the plant in the dark cellar, as it were, longing for the light and creeping towards it; ready to come forth under influences in any measure favourable; often bursting out in very adverse circumstances; making unsophisticated man everywhere, from love or from fear, from selfishness or from duty, a worshipper of the God or gods recognized by him, and rendering those who have been misled by infidel sophistry unsatisfied and restless, and ever doubtful of their own doubts.

5. The soul of man is Immortal. Our conviction of this truth, like that in regard to the existence of God, seems to be the issue of a number of mental principles looking to external facts, and all concurring towards one conclusion. The sense and consciousness of self as a separate 
person, the absence of any evidence that this self dies, the shrinking from the very thought of annihilation, the impression that the soul may live when the body dies, all conspire to produce a deep conviction, which can scarcely be eradicated, and which no good man would eradicate. Our sense of moral obligation, and of responsibility, exerts a yet greater power over us-we feel that. we must appear before God in judgment. These, and it may be other feelings, have raised, or, aided by tradition so far preserved through these feelings, have kept alive, a deep persuasion among all nations that the soul at death has to appear at a judgment seat, to be there consigned to a place of happiness or of woe.

III. Nature has within it abounding Sin.

It requires some skill to place this truth in its proper light (or darkness) as a truth of natural religion. For there can be no doubt that we owe, to some extent, the knowledge and the sense of $\sin$ to the revelation that God has been pleased to make of his will. Still there is a sense of sin, developed or undeveloped, in all men. Every one is obliged to acknowledge the justice of the charge when he is dealing honestly with himself, though he may deny it with great vehemence when others attack him, or when he is determined to defend himself from the reproaches of conscience. Again, the extensive prevalence of vice 
in the world is recorded by every faithful chronicler, is mourned over by every moralist and philanthropist. The extent and depth of the evil are apparent from the very efforts made to stem it, and which may have helped to turn it away from particular channels, but have not succeeded in drying up its bitter waters. The Word of God presupposes the fact of the existence of sin, even as it supposes the fact of the existence of God; and it charges man, in the name of God, with being ungodly, and expects to meet with a response in the heart and conscience, and is, in fact, answered by an echo, often very weak, and at times interfered with in the noises of the day, and not heard when disturbed by the tumults of life, but audible ever in the quieter hours of reflection and self-examination - as we have heard an echo in the quiet of evening, which would not sound in the bustle of the day and when the winds were raging. It is in very proportion as persons realise this great fact that they are prepared to listen to the revelation which God has been pleased to make in the Gospel. Those who speculatively deny the natural truth will be tempted to doubt of, or deny, the supernatural one. Those who feel the deep natural wants, and who see very clearly that nature cannot remedy them, will not be indisposed to welcome the supernatural remedy, 
provided it comes with the proper evidential support.

For mark what it is we meet with everywhere in the world around us, and deep down there in that dark nature which we carry with us. The facts are as patent as any that physical science looks at, and they have a prior and a deeper claim upon our immediate attention, for they have a closer connexion with our essential being and our destiny. We have a conscience within. us which announces, on the one hand, that there is a moral law above. us and binding on us, and, on the other hand, that we have not kept that law. We find proof, on all hands, that God hates sin, and yet we see sin abounding all around us in the world which God has made, and over which he rules. Everywhere in heaven and earth do we see order, and yet everywhere, in the midst of that order on earth, do we see sin, which is manifestly disorder. Physical law is viewed in the highest light when regarded as a mean to moral good as an end, and yet how frequently do the means fail to secure the end,-and that pure sun lights men, as they go to perform deeds of darkness, and the riches of the earth incite lusts and pamper. luxury. We are sure that God must punish sin, and we see him often punish it in this world; and yet quite as often do we see wickedness. 
triumphing. How often is the judgment delayed, very possibly that it may only be the more terrible at last-as we have seen the cloud gather and thicken, that in the end it may burst with more fury. Or rather may not the punishment be delayed in order that the offender may repent and be forgiven? yes, forgiven-we look for it, we cry for it, we hope for it. In our world the shadow pursues the light, but the light also pursues the shadow-which is from a light shining above us, though obstructed by the vapours arising from the damps of the earth. Clouds there are, threatening destruction, yet there is a bow upon them-from a still shining sun-encouraging us as by a smile. Yet, while we hope, we cannot point to a ground of hope; the conscience is there, ever ready to raise its voice as an accuser, but where is the voice to declare the pardon? He who ponders these facts, in their relation one to another, as intently as the physicist does the unexplained phenomena of the universe, will find himself in terrible perplexity. $\mathrm{He}$ hears the earth, in its travailing, uttering a cry, but, as he listens, he can hear no answer from the earth, and he looks up and almost expects to hear it. from heaven. He admires nature-he cannot but admire it, and he approves himself as he admires it, and yet he is confident that there is something wanting, and he argues that, under the 
government of a good God, there must be something to join on to what he sees broken off so abruptly. He argues that, outside the natural, there must be a supernatural part-the two constituting the perfect whole; and he infers this almost as confidently as Columbus, and others before him, argued that there was a new world lying West of the old, long before it was actually discovered-almost as surely as mathematicians concluded that there must be a new planet outside the old ones and part of the system, when yet the telescope had not lighted upon it. In consequence of the scientific expectations, many an eye looked from Teneriffe far into the West, in order to see the new land, and not a few thought they saw it when it was only a cloud that appeared; and many a glass was directed to the heavens to find the wanting planet-some thinking they had found it when it was only an old star that came into view; and, in like manner, multitudes have looked prematurely for the supernatural revelation, and been disappointed or deceived; yet these very anxious looks, and the repeated belief in spite of failure, prove the depth and reasonableness of the expectation, which, again, is a sort of prognostic or guarantee that it will, somehow or other, at one time or other, be gratified.

IV. In nature there is a Moral Government. 
This government is very complex. It is so because of the variety of ends which it has to serve, in a state of things in which man is free and man has sinned, in which God condemns sin and favours the sinner.

1. God encourages the morally good. This is evident, first of all, in the agreeable feelings which all benevolent affections raise, and in the echoing pleasure which the reflective conscience feels in the contemplation of all good actions. These are the immediate rewards which virtue reaps. They are quite as clearly rewards as those given in the family by the father to his obedient children, or those bestowed in the school by the master to his diligent pupils. There are other and more indirect encouragements;-in industry commonly securing a competent portion of this world's goods; in excellence of character gaining trust and esteem, and opportunities of rising in this world; in the benevolent being helped on in their schemes of usefulness, and in love kindling love in return.

2. Sin is so far discountenanced and punished. There are the direct consequences in the painful sensations which accompany all the malign affections; in the weariness and ennui that come after sinful indulgences, as vultures do on the back of the carnage; and, above all, in the 
accusing conscience which gives its warning-at least after the first transgression in a particular line, and raises up fears to haunt the guilty wherever they go. The judicial condemnations, the impositions of fines, the confinements and the executions, are not more certainly penalties in the government of nations, than these inward reproaches are punishments in the kingdom of God. There are other appointments which have also a penal character. Thus we see idleness and vicious indulgences landing the possessor in poverty; and the drunkard and licentious, as it were, sold into slavery to pay the expense of their lusts; and the deceitful caught in the net he has laid for others. At times, too, we see the bold transgressor, who has lifted his head as a headland facing the sky, struck visibly as by lightning from heaven, or wicked men who have combined to raise an impious tower of defiance scattered by a confusion among the builders. The connexion between the moon's motions and the tides of the ocean, is not more certain than that between sin and suffering;-the dependence in both these cases may seem somewhat complex, and to have exceptions-which, however, are only seeming; but in both it can be firmly established,-it being vastly more important, however, that we observe it in the latter case than in the former, and also certain 
that mankind generally have been constrained by their apprehensions to attend with far greater eagerness to the moral than even to the physical connection.

3. God is delaying the punishment of transgressors, thus giving to all a period of probation. $\mathrm{He}$ is good and kind, and often continues long to be so, to those who have broken and are still breaking his law. "He maketh his sun to rise on the evil and on the good, and sendeth rain on the just and the unjust." The governor is evidently also the father of those he is called to condemn, and we see that he is loth to condemn and slow to strike, and all that he may give space and opportunity for repentance.

4. God will in the end punish offenders. We argue this very immediately from the imperative character of the law, which cannot let go its requirements and must exact its penalty, and from the immutable character of God the governor, who upholds that law as his own law prescribed as the rule of the universe. It is clear that the eye of our ruler is ever upon us, and when his uplifted arm is staid for a time, it is only that it may come down with more terrible power in the end-as the avalanche collects for years, and then, as it is loosened by a heavenly beam, descends on the instant. Often may we track Divine justice pursuing its victim through a long 
series' of years, and a complicated course of things, and at last springing upon it at the opportune moment when escape is hopeless. The explosion which rouses the whole community is from the simple application of a spark to a train, which had long been laid. All this prepares us to believe that God will by no means spare the guilty, and that, "though hand join in hand, the wicked shall not be unpunished."

5. Now, it is because the government of God has all these ends to accomplish, and has to deal with such a multitude and diversity of human beings, so mixed up one with another in the various relations of life, in its family ties, its friendships, its connexions of business, of neighbourhood, and of country, that it is so complicated and so difficult of interpretation. God must encourage the good, and yet not so encourage them as to pamper their self-righteousness and make them feel that they have no sin. He has to shew his disapproval of the sin, and yet he would spare the sinner and allure him to repentance. $\mathrm{He}$ spares the sinner, and yet he must not countenance him in his sin. By one and the same event, one man has his wickedness exposed, and another his innocence cleared; one is cheered and quickened, another is rebuked and arrested. Every member of the household is in a different mental or moral or spiritual state, and needs a 
different lesson; and the family occurrence has a lesson to each, to father and mother, to sister and brother-possibly far-reaching consequences to that little infant. The great public event which is a judgment upon the community, is a blessing to certain individuals; or while it is an appropriate trial to certain persons, it is a benefit to the nation. Often does the warning seem to come after the judgment, as the report comes after the shot has done its work-as the roar of the thunder is heard after the lightning has smitten its victim; but the audible signals may be a warning to others, and the judgment has at last descended on those who got admonition upon admonition without attending, and who have now to be cut off without farther notice. When the instruments of God's government have such diverse ends to effect, no one should pretend to be able to find out all the purposes of God in any one occurrence; it will generally be enough that he discovers the lesson which it reads to himself as an individual. Our Lord severely rebukes those who looked upon calamities as judgments proving guilt on the part of those on whom they fell, and tells us expressly that those who had been slain while offering sacrifices at the altar, and those on whom the tower of Siloam had fallen, were not to be reckoned as sinners above others 
(Luke xiii. 1-4). But while we must be on our guard against rash judgments in individual cases, every one is expected to discover certain great moral laws, such as the law of reward, the law of penalty, the law of forbearance, and the law of final retribution. Unsophisticated men have ever, in fact, held more or less firmly by these general beliefs, and though they have often felt the dispensations of providence to be dark and mysterious, and experienced an extreme difficulty in determining in any given case which of these purposes, or how many of them, are intended to be served, or, indeed, what purpose has been accomplished, and have often pronounced rash and uncharitable judgments on others, yet they have always, and in spite of appearances, held that the judge of all the earth must ever do right, and have believed and been sure that a just end has been served, even when they have failed to discover it. Admirable as is the machinery employed in the evolution of the bodies of the solar system, and admirable as are the arrangements for enabling organisms to fulfil their functions, I am convinced that the adjustment of means and end in God's government will be seen to be vastly more wondrous and wise when the whole wheels and their fittings and products are fully disclosed to the saints in the world to come, and the meaning of every dispensation clearly explained. 
But while we have so much certainty on these topics, we find the certainty only landing us in deeper uncertainty. We are sure that God hates, and that he will punish sin, and we hope that he is ready to forgive it; but we have no means of bringing together and reconciling these different convictions. We here fall in with an awful chasm; we believe that in a world, under a good God, there must be some bridge to span it, and yet as we grope in the darkness we cannot find it. $\mathrm{He}$ who has realized all this certainty and uncertainty will not turn away with levity or contempt from what seems a supernatural method of reconcilement, and of turning the uncertainty into certainty. 


\section{CHAPTER V.}

THE NATURAL A MANIFESTATION OF THE SUPERNATURAL.

BEFORE mounting into the higher and more recondite region of the Supernatural, we may gather into a few groups some of the truths picked up by us in the lower fields of the Natural.

\section{$\S 1$.}

Religion should never be regarded as an isolated act or exercise. Godliness should run through the whole man, his whole temper, beliefs, and acts, and should guide him in the view he takes of all the objects coming under his notice. In particular, it should lead us to look on nature as a whole, and on every part of it as a manifestation of God.

The natural implies the supernatural. The fitting of every one object to every other, and the order of nature as the result, presuppose a disposer of the several agents. The combination of means towards a beneficent end shows design 
contemplated by a designer. In particular, the soul of man, with its free will, its intelligence, and its reason speculative and moral, claims for its author a living Being possessed of these qualities in an infinite degree. The intuitive convictions of the mind, looking to obvious facts, insist on all this; insist that the world, as an effect, implies a being above it as a cause, indeed, are not satisfied till we rise beyond the chain of causation to the uncaused, beyond the dependent to the independent. We cannot understand the physical, unless we bring in the hyperphysical. In contemplating the finite we are necessitated to believe that there is an infinite. The sense of moral obligation proceeds on the existence of a moral law, which implies a lawgiver, who is the judge of his intelligent creatures, and of all their actions, and who must, therefore, institute a searching judgment day, and distribute impartial retributions in a supernatural state of existence.

\section{$\S 2$.}

The religious spirit recognizes God in all nature; it sees him as upholding all substance; as the porver in all force; the actor in all action; the mover in all motion; living in all life; shaping in all forms; organizing in all systems; himself the light and the fountain from which all other lights are fed; knowing in all knowledge; 
himself lovely, and the author of the loveliness in every kind of beauty; himself good and in every good deed; compassionating wherever there is sorrow; helping in all timely succour; the judge when justice is dispensed; the avenger when wrong is remedied; cherishing affection to all his creatures; and loving in all their holy love.

$$
\S 3 .
$$

But man in his ungodliness has failed to see God as he should have done. This ungodly spirit has taken various forms. Atheism sees God in nothing,-fails to see his wisdom in the order of nature, and his providence in the gifts bestowed on his creatures; and it is atheism, whether with the ancient sceptic it does not, or with the modern sceptic it does, discover order and method in the universe. Pantheism consists in failing to distinguish God from his works, and this, whether it looks upon the works as being God, or on God as existing only in his works. Superstition sees God in certain of his works, but not in others; in those only which excite, and move, and startle, not in those which are more regular, and constant, and familiar. True piety sees God in every agent, and would gather from every occurrence the lessons which it is fitted to read; and it is true piety, whether it does or does not discover the second or instru- 
mental cause,-the difference between the piety of the unscientific and the scientific man lying only in this, that the former may discover God, and God only, as the actor, whereas the other sees, besides, somewhat of the system on which God proceeds, and the physical agents employed by him. As against the atheist, who believes only in fate, or who looks on all things as produced by mechanical causation, or as brought about by chance, piety ascribes every object, and traces every event, to God; it will not hand over the beneficent order of the seasons to blind law, nor abandon the extraordinary coincidences of Providence to accident; it cannot allow the course of things to take the credit of these bright stars and beauteous flowers; and when health is restored, after a period of sickness, it gives the glory and the thanks to Him who has arranged the means and been operating in them. It rejoices, with the pantheist, to see God in all his works; but it will not allow that God is exhausted by his works; it believes that God was before his works, is above his works, and is independent of them. As against the superstitious man, it claims for God the symmetry and the harmony of nature, as well as those occurrences which may seem to come as anomalies or interferences; it discovers him in the storm, but it also feels him in the calm; it sees him in the 
disease which prostrates our energies and makes us realize our helplessness, but it also constrains us to recognize him in the health which has buoyed us up for years.

$$
\S 4 .
$$

The ungodly spirit may coexist with all degrees of ignorance or of knowledge as to the system of nature. It may exist in the most ignorant peasant, or in the most degraded savage, who discerns in the earth only the clay and the clod; who can appreciate the tree as bearing fruit or yielding shelter, but discovers nothing else in it; who appreciates his sheep and his cattle, only as beasts to yield him sustenance and clothing; and who esteems the sun merely as a beneficent light for the day, and the moon and stars as useful lamps hung out in the darkness of night. It may dwell in the breasts of the half-educated or semi-civilized, who see natural law, and natural law only, in the more regular occurrences, -in the revolving stars and revolving seasons, in the springing of the grass and grain, and in the growth and sustenance of his own frame,-and who divide other and more irregular occurrences between chance and the God or gods momentarily loved or feared for the gifts sent or the judgments which may seem impending. It may lodge, in intensest keenness, 
ready, when provoked, to break into terrible bitterness, in the deepest heart of our men of science, who, in studying and admiring mechanical power, and chemical and electrical forces, and vital energy, and in viewing the adaptation of every one part to every other merely as the condition of existence, resist and resent the presence of a living and spiritual God acting in all these agencies, and employing them for the accomplishment of his moral ends.

$$
\S 5 .
$$

The religious spirit is equally compatible with all degrees of ignorance in respect of the order of nature. The rudest barbarian, the uneducated labourer in our civilized countries, the child just beginning to use its senses intelligently, may be taught to contemplate every object in earth or sky, may be taught to regard star and flower, tree and mountain, shower and sunshine, prosperity and adversity, life and death, as the operation of God's hand,-the physical cause being all the while concealed or unknown. The man more intellectually advanced may discover order and law in certain courses of things which look constant and settled, as in the motions of the heavenly bodies, and the ordinances of the seasons which supply him with food; while in other occurrences, as in his preservation from 
eminent danger, and the opportunities of receiving special privileges, he may discover interferences, or rather dispositions, to accomplish a special end; but he delights to acknowledge God and his wisdom and goodness both in the regular positions and the irregular interpositions of things. Finally, he who has fallen in most thoroughly with the spirit and the method of induction, and who believes in universal law reigning in all ages past and present, even in stars visible only by the telescope, and in molecules invisible by the microscope, in every change of our ever changing bodily state, and in every impulse of our ever active minds, may have a faith as strong as that of the child or peasant, while it is more enlightened and expanded. The only difference between these cases is, that, in the first, the man of faith sees God and God only in his work; that, in the second, he observes a general plan in some of God's works, and a special end in others, and the presence of God in both; while, in the third, he beholds a general plan in all, but a plan arranged for the very purpose of accomplishing all and each of the purposes of God, general and special. In the first, the intellect could take in no more, but the faith was as extensive as the intelligence, so that, wherever a work was discerned, there, also, the worker was acknowledged. In the second case, 
the man's intellectual vision was enlarged and his faith widened with it; he got glimpses of an order, which he contemplated as a Divine plan, and also of particular purposes secured. In the third, science has carried him to a height whence he observes that the design is so universal as to require no interferences, that in the plan itself are such adaptations, such windings round the object meant to be preserved, and turnings where an obstacle presents itself, that the most minute purposes of God are fully executed. He knows that the lily grows by natural law, but he believes also that it grows by the arrangement and the very power of God, and that God clothes it with beauty. He knows that the sparrow lives and dies according to physiological laws, but he knows also that a sparrow cannot fall to the ground without God.

$$
\S 6 .
$$

Let not the scientific or half scientific man smile at the piety of his child, or ridicule thedevoutness of his servant, who discerns the great acting power, but may have missed the secondary instrument; who knows that God makes his sun to shine, though he is not aware that his beams come in vibrations; who believes that God sends the rain, though he has no idea that electricity has to do with it. Nor 
let the ignorant man, in his ignorance, charge the philosopher with atheism when he delights to detect not only the Divine presence and power, but the Divine plan, and to look into the internal mechanism which makes the hands to move over the face of the great timepiece standing before him in nature. But we behove to rebuke the peasant and the very savage, when he can inhale the breeze of heaven and eat the corn of earth, without giving God thanks. And we are entitled to reprove the philosopher, and this in the very measure of his pretensions to a higher light, when he discovers order, but fails to notice design; when he examines the structure of the machine, but overlooks the name of the Maker inscribed on it; as he incessantly watches the apparatus, but avoids taking any notice of the great moral and spiritual ends promoted by it.

\section{$\S 7$.}

We cannot with any propriety say that mankind, in these latter days, are brought into closer contact with the natural; for in early times most persons had to earn their sustenance by hunting wild beasts, or tending their herds, or tilling the ground; and in "this age of great cities" multitudes are very much removed from close intercourse with green fields and trees, 
with fowls and cattle. But to counterbalance this, the educated are now trained to look more intently on the scientific structure of nature; and the dwellers in the villas that girdle our great cities, and the summer saunterers by the sea shore, and the autumnal ramblers over our mountains, bring themselves to appreciate every varied aspect of sea and sky, of rock and mountain, and they talk of nature with a rapture which would have appeared affectation to our forefathers. This state of things has its temptations. That which was meant to be a veil to keep us from being blinded by the effulgence of the light -while it let the glory of God shine throughwe have made a screen to conceal him, and we have gazed at the screen, and the figures upon it, and we have stayed there without looking on the living face beyond. The more vulgar minds stop short, and satisfy themselves with the comforts, the wealth, the glitter of this world, cherishing meanwhile no love to the giver, and feeling in no way their need of God himself, as better than all his gifts. Minds of a higher but not a holier spirit content themselves with inspecting the machinery; like children, they gaze at the chariot, its wheels, and its motions, but without looking above it to Him who rides on it so majestically to scatter blessings and administer justice. Others, more refined, are exposed to a 
different class of temptations; they are seduced by their highly cultivated tastes into the worship of foam-born beauty.

\section{$\S 8$.}

But that high-born soul of ours can never be satisfied with the mere mechanism of nature. The railway steam-engine is an imposing object, as it moves on towards us so determinedly, as it sweeps by us with so fixed a purpose on the way which has been prepared for it towards its station, which must be duly reached at the appointed minute. But, as we look at it, we love to think that human intelligence has planned it; we are relieved when we are able to believe that a conscientious skill is guiding it; we love to see it bearing human beings along with it on errands of business or of pleasure; and we would not choose that there should be nothing in our world but iron-bound roads and unrelenting machinery; nay, we long at times to get away from it, to be out of the reach of its smoke and the sound of its clanking wheels and rails, and we steal away through some green loaning scarcely knowing, and not wishing to know, whither we are being carried; or we march up into the clear mountain, where, as we breathe the bracing breeze of heaven, we forget that there is mechanism, or remember it only to 
rejoice that we are above it. In like manner, while we should ever acknowledge that it is a good thing that there is mechanical power in our world, and that it moves in such fixed grooves, and according to such measured stages, and while we take advantage of all this for the purposes of profit and gratification, and after wandering away from it into more inviting regions, we are glad to come back to it, to help us on our earthly way;-yet there is something within us which will not allow us to rest in these mechanical movements of nature; something which constrains us to look on physical force as the manifestation of the Divine power, and is relieved when it can look on the arrangements according to which it acts as made by the Divine skill; and which ever allures us to rise into a more elevated and a purer region, whence we may look down on all this, and trace its studiously reticulated plan, or lose sight of all this as we gaze into the heavens, and behold there still more glorious objects looking down upon us so purely and benignantly from their lofty spheres, where, no doubt, they are not lawless, but where their law is justice and their operation is love.

$$
\S 9 .
$$

The man of aesthetic taste tells us how much pleasure he enjoys in communion with nature. 
And it is a good thing for us to be able to enter, as it were, into the feeling of God's works, to allow our soul to take, as the sea does when placid, the colour of the sky above it,-to reflect, as the lake does, the trees and hills on its banks :to be refreshed, for example, with the freshness of the air of heaven, or to be enlivened by the purling of the stream, or to enter fully into the gloom of the deep woods; to catch thoroughly the revival of the morning, to brace ourselves up to the activity of the day, to reflect from our spirits, like burnished windows, the glow of sunset, and to sink into quiescence, like the twilight which succeeds, ere night comes like death to close the scene; or to feel our souls bursting with life like the buds in spring, and melted and softened by the heat and beauty of summer, and striving after an exuberant fruitfulness like that of the fields in autumn, and taking the pensive hues of the leaves in the declining year, and coming under the melancholy of the falling leaf, and realizing the need of shelter as we look out on the ravings of the storm in winter. But all this does not rise to true fellowship, and we shall, in the end, be miserably disappointed if we look upon it as such ; the soul will ever be driven back upon itself in utter loneliness if it does not find a living agent in the midst of the scenes. That is the noblest beauty, which is associated with 
life,- that is the highest sublimity, which is associated with power; dissever the two, as we do when we cut off God's works from God, and nature will appear as a branch cut off from the tree-we feel that we would soon have to cast it away, or as a stream cut off from its fountainwe feel that its moving power is gone. Though we may admire fine statues, we would not choose to be shut up in a hall of marble figures; we would weary even of a picture gallery, with all its symbolic influence and its rich suggestions, if we had to dwell in it for ever; and, on a like principle, we would become tired of the very grandeur of our world, if the images of life and love were finally discovered to be without a reality. Have not all of us felt nature to be awfully cold and distant, as we looked upon its never-moving mountains, or into these depths of stars so pure but so little interested in us ?-we have felt how unbearably lonely it would be to dwell in a world in which there was nothing but these. The soul is not satisfied even with the multitude of men and women on the earth's surface,-most of us must have felt at times terribly solitary in a great city. We long for communion, but it must be a reciprocal communion, and our fellowship with nature is gone when we look upon all as dead. Those of us who see nothing in an idol but a dead image, can never bring our- 
selves to worship it, however beautifully it may be carved. We would feel our prayers coming back upon us with a chilling influence, like breath going up in warm moisture, and coming back in rain or snow, were we required to put up our petitions to the cold mountains, or the frosty stars; for we know full well that they do not hear us, that they do not reciprocate our feelings, that they cannot help us. The soul does crave for fellowship, but it must be with a living being who knows what we feel, and returns the feeling; and nature can help us in all this, only as its forms and aspects are viewed as the symbols of Divine life and Divine love.

\section{$\S 10$.}

Our internal position and our inward feelings both impress us with the idea that the natural is encompassed all round by the supernatural, as the world is by the "welkin." After all, our Cosmos is not the $\pi \delta \pi \tilde{\alpha}$, though there are some who so represent it; it is only to the whole what the earth is to the Cosmos; like the earth, it is a globe, and it is in a sense independent, but in a higher sense, it, and man who dwells on it, hang, or are made to stand, through a binding power like the gravitation which binds our system into one ; and influences are shed upon them from a higher sphere, bene- 
ficent as the light of sun and of stars. The beauty in our visible Cosmos is merely like the sheen of stars in the waters of our earth, the reflection of the glory of a supra-mundane region. Pursue any one line, starting from the earth, or the present, or self as a centre, and it it runs out,- - with space-into the infinite,-which is supernatural. Follow the links of causation upwards, and the mind insists that the chain must hang on the uncaused,-which is supernatural. As we go down from one dependency of being to another, the reason comes to independent substance,-which is supernatural. As we go back into the past, the stream, as we mount it, leads us to a fountain which is its own original,-and the unoriginated is the supernatural. If we go out into the future, with the soul as it leaves the body, we are in the unending world to come,which is supernatural.'

In all his deeper moods, man is made to feel his dependence upon, his nearness to, the supernatural. The hope of it cheers him in his temporal difficulties; and he feels he can ever appeal to it, as a just tribunal, from present disorder and injustice. The darkness of night shews us objects which are concealed in the light of day - for it is when the glare of sunlight has died out that we see those stars and constel. lations in the height of heaven; and, in like 
manner, there are high heavenly lights discerned by the spirit of man in the darkness of adversity, which may not be perceived in the sunshine of prosperity. I believe that the fear of a supernatural power haunts man-as his sins do-more or less consciously, all the time he is on earth; and a judgment seat, from which he cannot escape, is ever seen by him standing at the close of life. In particular, every human being is made to feel himself very near the supernatural as he contemplates death-the death of a fellowman or his own death;-he feels that something is about to depart, or has departed, into the supernatural. Surely he who believes that something thus goes out from our world into another, will not be inclined dogmatically to affirm that there may not also come something from that other world into this, were it only to train the young immortal in its mortal sphere, for its immortality in the sphere beyond.

\section{$\S 11$.}

This thought, like every other profound thought, brings us to the profoundest thought in the universe-to the sin which opens like a fathomless gulf below, facing the brightness of the Divine holiness which shines from above, but cannot dispel the gloom beneath. He who does not see this is overlooking the most mys- 
terious fact in our world, the deepest fact in our nature; it is as if a man were to visit one of our great cities and look only at its palaces and its temples, and go nowhere else than to its festivals and its banquets-never entering those lanes where poverty would hide itself, or taking any notice of those haunts where sinful pleasure revels, or of those sinks behind them, into which iniquity at last pours itself. Surely he who looks into this fearful abyss, and feels that he is being driven into its awful depths, may well be glad and grateful when told that God has interposed his arm to save us.

\section{$\S 12$.}

It is in very proportion as mankind see God in the natural, that they are disposed to look for a supernatural manifestation. He who does not see God in his works in the world, will in no way be inclined to look for higher operations. $\mathrm{He}$ who contemplates exclusively the mechanical or instrumental portions of the universe will discover nothing to lead him to look for the interposition of a spiritual remedy to meet a spiritual evil. He is prepared to believe in a supernatural appearance who thoroughly discerns God in the natural, and he is best prepared who looks up to the highest glories, and looks down into the deepest mysteries of the universe. He who looks 
on all these objects in earth and sky as the works of God, will easily believe that he may have other works. He who looks on these powers of nature as agents of God, will at once acknowledge that he may turn them to whatever uses he pleases. He who discovers God making provision for the most minute temporal wants of his creatures, will not be inclined to scoff at an arrangement which, be it mundane or supra-mundane, makes provision for the relief of man's spiritual wants. He who looks on nature as an apparatus of means to support moral ends, will not be indisposed, as these bulk largely before his view, to believe that God will employ every means, be it natural or be it supernatural, to promote these ends. He who looks on God as the author of all excellence, and as delighting above all things in moral good, and hating sin supremely, and who discerns sin raging as a fire in the fairest portions of our world, and who has, after looking above him, and around him, and within him, come to the conviction that, if left to itself, the fire must go on devouring and consuming for ever, on the materials supplied by the corrupt human heart, will surely rejoice to learn that God has interposed to extinguish the flames.

We are not yet in the region of the superwatural, but we feel that we are on the very verge of it, and that it may soon appear. 


\section{BOOK SECOND.}

THE SUPERNATURAL IN RELATION TO THE
NATURAL.

\section{CHAPTER I.}

GENERAL REMARKS ON THE SUPERNATURAL.

SECT. I.-THE PRECISE NATURE OF THE SUPERNATURAL.

WE have seen that in this world there is a set of objects and agencies which constitute a system or Cosmos, which may have relations to regions beyond, but is, all the while, a self-contained sphere with a space around it-an island separated so far from other lands. This system we call "Nature," and the events produced by the agencies we call "Natural." The beings above this sphere, and the agents beyond it, though it may be acting on it, we call "Supernatural." God, who created the cosmical agencies and set them in operation, is himself supernatural. When a supernatural being or power 
operates in nature, we call the work supernatural. The effect is among cosmical objects, it is wrought in men's minds or bodies, or in physical nature around them. It is thus only that it can fall under our experience, internal or external, under our consciousness or under our senses. But the power to produce that effect, and the agent in whom that power resides, do not lie within mundane potencies, but in a region above and beyond. The work of creation is supernatural, it is a work in nature proceeding from a power above nature. The raising of the dead would be supernatural, for there is no plyysical or physiological law capable of producing such a result.

By this representation we are saved from certain mistaken views as to both the natural and the supernatural.

We see that in representing an event as natural we are not placing it out of the dominion of God-for we put the whole of nature under its Maker. A natural event is produced by natural causes, but these causes have been instituted by God. I believe that Deity is working in them, as he is certainly working by them. We see, farther, that a new, a wonderful, a startling, an anomalous event is not, therefore, supernatural. The sun setting in the tropics about six o'clock, is not supernatural; nor is it a 
miracle when, in the arctic regions, his light lingers on the earth for months without a night. Just as the sun, in his daily rising and setting, is not preternatural, so neither is the moon in her more irregular course, nor are the planets in all their wanderings, nor the comets in their widest eccentricities. The meteor flashing across the sky is the work of God, but it is not a supernatural work, nor is the awful thunder, nor the swift lightning, nor the pestilence as it flieth in darkness and visits a city to decimate its inhabitants. It is not a miracle when a tower stands, nor is it a miracle when it falls and kills "thirteen" persons, while others may escape. It is not supernatural, but natural, when the ship sails along buoyantly in the favourable breeze; and it is not supernatural, but natural, when it is wrecked by a storm which arose, as it passed a rugged coast, and drove it upon the rocks. It was certainly by the appointment of God, but it was quite by natural agency, that ninety-nine persons in the ship perished, while one was saved; it behoves that one to bless the Lord for his wonderful escape, and his gratitude should not be lessened when he discovers that God has accomplished it by a particular whirl of wind, raising a fortunate wave which brought a fragment of floating wreck to him, and drove it on to the shore as he clung to it in despairing agonies. 
We have seen (Bk. I. chap. ii.) that in nature every substance is endowed with certain properties, which act on the needful conditions being supplied; that the objects are so disposed as to result in general laws; and that there is a large but limited body of these substances with their powers in nature. Let us inquire how a supernatural or miraculous event stands in regard to each of these peculiarities of the natural.

I. In regard to the natural endowments or tendencies of natural objects, they are in no way destroyed by the supernatural action.. No one reckons the nature or the action of a natural substance as annihilated when it is restrained or directed by other natural agents. It is the tendency of the earth's gravity to draw all bodies to its surface; but this quality is not extinguished, it is merely counteracted in the circumstances, when we hold a stone in our hand and keep it from falling. A blow is directed against us, which would fell us to the ground, a bystander interposes his staff, and we escape, and in the whole we have only each agent acting according to its nature. It is the same when a supernatural power interposes. It is the tendency of fire to burn, and this tendency it must ever retain, as long as the substances acting in the fire keep their endowments; but this tendency may be counteracted by other agents, either 
natural or supernatural; it may be counteracted by natural agents, as by water thrown upon it, or it may be counteracted by the immediate power of God, as when it was not allowed to consume the three children of Israel who were thrown into the fiery furnace in Babylon,-but the fire all the while retained its power, as was shewn by its consuming those who threw them in, and it was restrained by the power of God only, as it might have been curbed by cosmical powers.

II. In regard to the general laws or obvious uniformities of nature, it should be allowed that miracles do not fall out in accordance with them. These general laws serve most bountiful purposes. It is because of their prevalence that man can so far anticipate the future, and draw towards him the good and ward off the evil. A system of things in which miracles were ever interfering with the established order or course of things, - so that no one could commence a course of action with any assurance that it would not be disturbed by some interposition from without, - would certainly not be suited to man, with his present nature and constitution. But it is to be observed, that even in the natural system there is such a disposition of agents that unexpected events are ever occurring, fitted to impress him with his dependence on a higher power and 
wisdom than his own. He who sows in spring will usually reap in autumn, and he who follows industry will commonly secure a worldly competence; yet the best laid plans of man will, at times, be so frustrated that he has little or no crop, and he who has been diligent in his calling, may, after all, be left in poverty. Often when our confidence was the greatest, are we made to say-"I returned and saw under the sun, that the race is not to the swift, nor the battle to the strong, neither yet bread to the wise, nor yet riches to men of understanding, nor yet favour to men of skill, but time and chance happeneth to them all." While a constant and capricious miraculous interference with the plan of nature might disturb all the principles of probability on which men usually act,-all such, for instance, as those on which insurance offices proceed,-no such prejudicial effects could follow from an occasional miracle which would lessen human foresight and limit human sagacity only to a small and unappreciable extent, beyond the restraints already laid on them by the cross events of providence. And it may be observed, of the miraculous interferences of God brought before us in Scripture, that they are only occasional. In all the dispensations of God, general laws have been the rule, and miracles the rare exceptions-so rare as not to interfere with the anticipations of 
human wisdom. Twice only did our Lord, when on earth, distribute food in a miraculous way, and when the people began to trust in this mode of procedure, he ceased to make any such provision for them; and his other miracles-such as the healing of the sick (as Dr. Chalmers has remarked), had no tendency to induce imprudent expectations, as no one would be likely to bring on bodily disease in the hope of having it cured by the power of Jesus. The miraculous interpositions of God have never tended, in any way, to lessen men's motives to industry and activity. They have ever been so introduced into the natural, as to honour the natural,-I mean the sinless natural,-and allow it to fulfil its full intention. Not only so, I hope to be able to shew that they have been wrought upon a plan or system, analogous in many respects to the system of nature, and that in the supernatural, as in the natural, there are order and law, which enlarge our wisdom by shewing us new and more spiritual relations of things, which quicken our energies by the liberal blessings that may be obtained in the use of appointed means, and extend our foresight, by the telescopic views opened, of far distant scenes in the earth of the future, and in the kingdom of heaven.

III. In regard to the circle of agents acting 
in nature, a supernatural event is caused by an agent from a region beyond them. It serves its end because it is so.* But then it is the effect of a power, of the existence of which we have evidence in the action of nature-a power which is, in fact, ever operating in nature, though after a somewhat different mode.

The account now given implies, that in the discovery of the supernatural, there is a process of inference in which we rise from the effect to the cause. An objection, founded on this circumstance, has been started, to the possibility of proving a miracle. We can never, it has

* The pantheistic Spinoza defines miracle-" Opus cujus causam naturalem exemplo alterius rei solitae explicare non possumus, vel saltem ipse non potest, qui miraculum scribit aut narrat."-(Tract. Theol.-Pol.: vi. 13.) According to this view, a miracle is something which we cannot, or which those who narrate it cannot explain by natural law, but which has always a natural cause. It could easily be shewn that this defective view influenced the speculations of the German rationalists of the end of last century and beginning of this, when they (g.e. Paulus) set themselves with such preposterous ingenuity to discover a natural explanation of the miracles of Scripture. It might also be shewn that this swayed Schleiermacher (who had such an admiration of Spinoza) when he represents miracles as being such merely relativelythat is, for those for whom they were at first done, and springing from Christ's deeper knowledge of the natural and connexion with it (Christl. Glaube). From these German sources, similar defective riews have come into our own country. Some, with the view of recommending miracles to the exclusive believers in nature, have taken great pains to shew that they proceed from higher natural law; while others, or the same, represent the higher sentiments of gifted men as inspired. We shall see infra that this is to strip miracles of their peculiarities, and to make them incapable of fulfilling the end designed by them. 
been said, see a miracle, we can merely see an event which we argue to be miraculous, and the argument must carry us into very recondite considerations, which metaphysicians only can unravel, or perplex as they would unravel. This objection can seem plausible only to those who have contracted a senseless prejudice against metaphysics, and are utterly ignorant of their nature and their office. For every one who has studied the operations of the human mind knows, that in the case of all our convictions, except those which are intuitive, there is reasoning, and commonly reasoning from effect to cause. The metaphysician has proven that we do not see distance-that we do not know intuitively the distance of the house or hill-we infer it from what we see. We do not see the love or the anger that burns in the bosom of a fellowman, we conclude it from the expression of his countenance, from his manuer, or his words. A body is seen lacerated on the ground,-this is all we perceive,-and when we declare that a man has been murdered, and go on to seek out the guilty party, we are arguing, and arguing from effect to cause. Such inferences, indeed, are involved in the convictions which we form and act upon in all the ordinary affairs of life, and he who would refuse to accept them must needs go out of the world. In all such 
cases the process is a simple one, (indeed it is only the metaphysician who knows that there is ratiocination); but the inference is equally easy, when, from the fact given, that a man has risen from the grave, we conclude that a supernatural power has been exercised.

It should be allowed that we are not entitled to look on an occurrence as supernatural unless we are satisfied, not only that it cannot be explained by known law, but that it is beyond the power of natural agencies. We do not reckon the disease which has blighted the potato plant for so many years as miraculous, nor do we reckon the cholera as supernatural in its mysterious visits, because science has not been able to detect the producing causes; for we are confident, on the ground of induction, that the cause does lie among natural agencies, discoverable or undiscoverable. We do not allow that the phenomena of mesmerism are miraculous, be. cause we are not able at the present stage of physiological and psychological science to explain them thoroughly; we have an idea that part of the appearances may be ascribed to the pretension or deceit of the operators, and we are sure that the explanation of what is real is to be found in the mysterious agencies which work in the border territory between mind and body. The defender of miracles must be prepared to 
accept the responsibility of shewing, not only that the occurrences are inexplicable, but that they are beyond the capacity of natural agency.

The principle now announced enables us to draw sharply the distinction between the higher moods of the natural man and the inspiration of God. Every one, I should hope, has felt himself carried at times into a high mental region, where he has breathed a purer, or at least a more stimulating atmosphere, and got glimpses of far distances. These are precious moments in the midst of the worldliness by which we are held down to the damp surface and the clay of our earth. There are men who have been privileged to rise more frequently, and to dwell more habitually in these higher regions. How expanded the view which opened to Plato, as he speculated on the relation of God, of the soul, and of the world! How pure and spiritual the air in which the bard of Paradise Lost and Paradise Regained habitually breathes! At such times-alas, how rare!-but at such moments-alas, they are but moments!-we feel as if we were inspived by a higher life; and not unfrequently have persons under the influence of these high impulses been said to be inspired. The language is not inap. propriate; it contains a great truth. These occasional uprisings of the water shew how high the elevation from which man has descended, and to 
what a height he may yet be raised. They are the lingering light of a sun which has set, but which once shone upon our earth; they are the dawn of a light which may yet appear. But, after all, these moods are in the region of the natural, and not of the supernatural. As we look up to these heights, and as we ascend them, we may be tempted to think that we are mounting into the sky, but we are, ever and anon, made to feel that we are only on one of the mountains of the earth. We would detain these moods-as we have often wished to detain the long and pleasant light of summer-as we have often wished to prolong the glow of the evening sky-but it is all in vain, the light departs in spite of all our efforts to keep it-it fades into darkness as we gaze upon it. As we linger on these heights we are wrapt in mist and cloud before we are aware, and had better descend quickly to a lower and a safer level. If, through pride and presumption, we seek to loose ourselves altogether from terrestrial influences, we shall find, as we would mount on the wings we have formed, that the wax melts, and our flight ends in a fall-a fall into vain fancies and deceptions. How often have those who have thus tempted the Lord their God, by striving to reach a dizzy point, and by casting themselves down thence without any promise of help to stay them, only fallen ignominiously 
amid the scoffs and jeers of men. The weakness by which even the best of such have been beset, and the mistakes into which they have fallen, shew that they have never been under the inspiration of a Divine and unerring wisdom. Still these convulsions shew what man is capable of ; the remains of man's strength, they are evidences of what he could do if complete health were restored. They are not inspirations, except in a metaphorical sense, but they show the possibility and desirableness of such an inspiration, should God in his grace be pleased to grant it.

But it has been urged, that upon the condition now laid down we can never prove a miracle, as it is beyond the capacity of man to tell what powers are in nature. You may shew us, it is said, a phenomenon inexplicable in our present state of knowledge, but this does not prove it to be beyond agencies of nature as yet undiscovered by man. We do not know, it is said, the nature of the sun's atmosphere, nor of the composition of the comets, nor of the forces which operate in the production of the crystalline structure of minerals, nor of the ether which seems to vibrate through all nature; but no one supposes any one of these to be produced by angelic or satanic influence, or by the Divine power acting apart from a physical cause. The progress of science, it is urged, is ever disclosing new powers in 
nature, of which those who lived in former times had no idea, or of which they caught merely imperfect glimpses. It is only in modern times that we have any adequate conceptions of the mighty influence exercised by electricity and by magnetism; only of late years that we have had any notion of there being such varied powers in the sunbeam. Who can say, in these circumstances, that there may not, among the yet undiscovered powers of nature, be agents capable of explaining all these occurrences which we represent as miraculous? "What is alleged is a case of the supernatural, but no testimony can reach to the supernatural; testimony can apply only to apparent sensible facts; testimony can only prove an extraordinary, and, perhaps, inexplicable occurrence or phenomenon; that it is due to supernatural causes is entirely dependent on the previous belief and assumptions of the parties."

The answer to all this is so very easy and obvious, that I give little credit for candour to those who have not seen it. It is all true that we do not know the extent of the powers of nature, but, then, there are some things of which we are quite certain that they are not within the range of natural agency. We certainly do not know anything like all the powers, psychological

* Baden Powell, in "Essays and Reviews," p. 107. 
or physiological, which operate in man's mind or bodily organization, but there are some exertions of which we are quite sure that they are beyond human strength. We give full credit to the recorded instances of the great sagacity of Newton, when lie guessed at scientific truths which have been established only by much later investigation, but every one sees at once (what Newton took such delight in expounding) that the greatest human shrewdness-that the shrewdness of Newton himself-could not foresee what the Hebrew prophets foretold hundreds or thousands of years beforehand,-a long series of events, with minute incidents, brought about by a varied and unconscious instrumentality. We have no doubt of the accuracy of the accounts given of the wonderful capacity for acquiring a variety of languages possessed by certain individuals; but we know full well that uneducated fishermen and mechanics could not at once, and without being taught, have addressed a multitude of persons gathered from a variety of countries, each in his own language. We certainly have very little acquaintance with the forces which operate in the brain and nervous systems of the lower animals, or with the instincts which guide them; but we know enough to convince us that the ass could not speak, except by a supernatural agency working in it. It might be difficult for the most 
skilful physician to say as to certain maladies, whether they are or are not likely to be cured by human art, but he could have no hesitation in declaring as to certain organic diseases, that they cannot be healed on the instant, or at all, by natural means. There is much about the human body and soul which must for ever remain concealed from us in this world; but we know for certain that there is no power in any man to raise himself or his neighbour from the dead.

In order to settle such questions, it is not needful that we should have explored all nature, or that we should have drawn out a list of her forces, and be able to specify their mode of operation. The most cursory observation of the man of ordinary sense leads him at once to the sound conclusion. Science, as it advances, confirms the decision. Induction, as it widens, shews the extent of the dominion of natural agencies, but it shews, at the same time, that they all run in appointed channels, and in no others; that they have all their fixed amount of force, and nothing more; and the very progress of science, in explaining so much, enables us, on firmer grounds, to declare as to certain occurrences, that they are altogether and certainly beyond natural power. Nor does this conviction depend, as Mr. Powell would insinuate, on the 
acquired sympathies, the inexplicable beliefs, and unreasonable assumptions of the parties, but on general principles, discovered by good sense and common observation, and sanctioned by the most advanced inductive logic.

While it should be admitted that, so far as the establishment of the first miracle is concerned, the burden of proving that there is a power beyond nature lies on the defender of the supernatural, it does not therefore follow, that the same stringent condition can be exacted in regard to alleged miraculous occurrences, which are part of a supernatural system, or which come in under cover of other supernatural events, shewn to be so by the most rigid rules of evidence. The most confident believers in natural law should be prepared to allow this. There are mysterious occurrences in nature, which we should not be entitled to declare to be the result of pure cosmical agency, were it not settled by a wide induction, that general law has such prevalence. The established uniformity thus carries over to natural law many individual phenomena, of which we might not be able to say, if we looked at them apart, whether they are or are not the product of mundane agencies. Surely those who claim all this, as I think they are entitled, on the one side, should be prepared to allow, on the other, that 
if once it be established on strict principles of evidence, that one grand miracle has taken place, - say the resurrection of Jesus from the dead,-it might bring in other miracles connected with it on easier terms. It will be shewn, as we advance, that the revelation which God has been pleased to make of himself, in the Old and New Testament, is a system with a compact structure and organization, and connected means and end. When it is shewn that, as a whole, it is supernatural, it should be conceded that portions which might not, - of themselves, admit of being shewn to be miraculous by stern rules of evidence, may be logically regarded as being so, as carrying with them the sanction of the whole of which they are parts.

SECT. II.-THE POSSIBILITY OF A MIRACLE.

Spinoza, the father of modern pantheism, was the first, so far as I know, who denied the possibility of a miracle.* He did so, on the ground

* Natura itaque leges et regulas, quae aeternam necessitatem et veritatem involvunt, quamvis omnes nobis notae non sint, semper tamen observat, adeoque etiam fixum atque immutabilem ordinem; nec ulla sana ratio suadet, naturae limitatam potentiam et virtutem tribuere, ejusque leges ad certa tantum et non ad omnia aptas, statuere. Nam quum virtus et potentia naturae sit ipsa Dei virtus et potentia, leges autem et regulae naturae ipsa Dei decreta, omnino credendum est, potentiam naturae infinitam esse ejusque leges adeo latas, ut ad 
that God and nature are one, that the potency and virtue of nature are the very Divine potency and virtue. This doctrine he sought to establish by a formidable array of abstractions which he never compares with realities, and by deductions from principles which are not self-evident, which are not sanctioned by reason, and some of which are obviously false. In the great metaphysical ferment which was stirred up in Germany, the last quarter of last century and the first quarter of this, a large body of the speculators were seized with a most extravagant admiration of the "thought bewildered" spectacle-grinder of Holland, and a number of them arrived at much the same view as he did in regard to miracles. In particular, J. G. Fichte, who made the whole external world the projection of a universal Ego (who can understand this?) proceeding according to the self-evolving laws of the universal mind, comes to the conclusion that, though God could or should perform a miracle, it would be impossible for man to come to the knowledge of it, so shut up is he in the forms of his own mind.* Ever

omnia, quae et ab ipso divino intellectu concipiuntur, se extendant.Spinoza, Tract. Theol.-Pol.: vi. 11.

* Es kaun also die Frage gar nicht davon seyn, wie Gott eine übernatürliche Wirkung in der Sinnenwelt sich also möglich denken, und wie er sie wirklich machen köune; soudern wie wir uns eine Erscheinung als durch eine ibernaturliche Causalität Gottes gewirkt denken können? \&c.-Fichte, Versuch Einer Kritik aller Offenbarung, \$ 9. 
since the days of Fichte, there have been persons maintaining that a miracle, or the power on the part of man to discover a miracle, is an impossibility. Those holding the doctrine in this country, have seldom announced with clearness the grounds on which they proceed, and we commonly find them flitting from one defence to another, as may suit their purpose. So far as their arguments proceed, like those of Spinoza and Fichte, on pantheistic principles, they are to be met by those facts which undermine pantheism, that is-by standing up for the trustworthiness and veracity of intuitive convictions, which Kant, and the schools which ramified from him, have entirely overlooked, particularly the intuition of self-consciousness-the consciousness of self as a person. Only admit this intuition, which has, to say the least of it, as deep a place in our constitution as space and time, or any other of those forms or categories of which the disciples of Kant make so much, and it at once saves us from a waste of energy in fighting with the spectres which the transcendental metaphysicians have raised up, and with which speculative youths still amuse themselves, though I rather think that no one now believes in them. Take this deep conviction with us, and it at once shews us that "all" is not "one," since we, ourselves, are persons, distinct from God on the one hand, 
and the world on the other, and enables us, with the aid of very obvious observation, to reach a personal God above nature, who, indeed, works in nature, but who also works independent of it.

In our own country, David Hume, the sceptic, started every sort of objection to the evidence adduced on behalf of miracles; but he nowhere denies the possibility of a miraculous occurrence. Mr. B. Powell everywhere charges alleged miracles with being contrary to reason, inconceivable by reason, and set aside by the inductive philosophy; but he never attempts to shew how all this must be so, or that it is so, and instead of proof, he gives us reiteration after reiteration in very much the same phrases, which are nowhere explained; and he does all this with a haughtiness of manner, and a dogmatism of tone, which may impose upon weaker minds which would save thought by leaning upon others, but which rather stirs into an attitude of opposition those who would part with any other attribute rather than their independence of thinking and judging. We are entitled to insist, that those who reject miracles specify the precise grounds on which they do so.

The impossibility of a miracle can be maintained, so far as I see, on two, and only two grounds, worthy of being looked at; one is the ground of intuition or intuitive reason, and the 
other the ground of an enlarged experience gathered to a point by induction. Let us examine each of these separately:

1. It is conceivable that a miracle may be contrary to intuitive reason. I freely admit that there are truths which the mind sees at once, and by intuition. If a miracle were contrary to this immediate vision of the soul, or the principle on which it proceeds, it would certainly be impossible to establish it to our minds; for the proof, however strong, could not have greater force than the original principle which it would set aside. But there is no intuitive perception, no fundamental law, no constitutional principle of the mind contradicted by a miracle.

I believe that there is a principle in our mind which leads us, on discovering an effect, to look for a cause. If a miracle were contrary to this law, it would be impossible to establish it. But it has been shewn, again and again, that a supernatural occurrence is not inconsistent with the mental law of causation.* Our intuitive conviction does not require us to seek for a material or mental cause to every effect, it is equally satisfied when it meets with an adequate mental

* As by Thomas Brown-("On Cause and Effect"-Note E.)-A miracle is " an effect that indicates a Power of a higher order than the powers which we are accustomed directly to trace in phenomena more familiar to us, but a Power whose continued and ever present existence it is atheism only that denies." 
cause. I seek for a cause of the movement of my arm, which a moment ago was still, but is now lifted up, and I am contented when I can refer it to my volition that the arm should be moved. I see traces of design in the construction of that house or temple, and I must seek for a cause, but the mind feels that it has enough when it can ascribe it to the intelligence and taste of an architect. Nor does the principle of causation insist that every effect in nature must have a cause in nature; it is quite satisfied, when it cannot find a cause in nature, to discover it in an agent beyond nature. Thus it is that, not finding in nature a cause of the design in nature, we refer it to a supernatural intelligence. A supernatural event is not an effect without a cause, it is merely an effect without a cause in the agencies working in that system which we call nature. The intuitive principle has an important part to act in the process of reaching the supernatural power in the miracle-a part very much the same as that which it has to perform in rising from nature to God, as the author of nature. Not being able to discover a cause among natural agencies, the mental principle insists on a supernatural cause, and rejoices to recognize it in Him to whom all inquiry into causes ever conducts us, and in whom all power resides. 
But here it will be necessary to distinguish between two things which have often been confounded:-between the principle of cause and effect, and the principle of the uniformity of nature. The principle of causation insists, that every effect has a cause. I look upon this as an intuitive principle. It can stand the tests of intuition. It is self-evident; the mind, on the bare contemplation of an effect, discovers that it implies a cause. It is necessary; no man can be made to believe otherwise. It is catholic or universal; every one on discovering an effect looks for a cause. It is an internal principle, looking to and guaranteeing a corresponding external reality. To this law there are no exceptions; to this law, I believe, there can be no exceptions. It holds good in nature; it holds good beyond nature. Every thing that begins to be, must have a power producing it. It is thus we argue, that the world, as a structure produced and arranged, must have had a producing and arranging cause.

Of quite a different character is the principle which leads us to believe in the uniformity of nature.* We have seen (Bk. I., chap. iii.) that

* It is one of the gravest defects of a work of great excellence, but of very grave defects-I mean the "Logic" of Mr. J. S. Mill-that the author confounds, all throughout his Chapter on Induction, our belief in Causation, with our belief in the Uniformity of Nature. I have commented on that confusion elsewhere.-Intuitions of the Mind, pp. $275-278$. 
it caunot stand the tests of intuition :-it is not self-evident; it is not necessary ; it is not universal. It is discovered, not by an immediate perception of the mind, but by a large and a long experience; the experience of ourselves and others over an extensive range of facts. It declares, not that every effect has a cause, but that the common mundane occurrences have a cause in the agents at work in the mundane system. It declares that fire left to itself will burn, but it does not say that fire may not be counteracted by a higher and a Divine agency. It says that, consigned to the processes in nature, man's body will die, but it is not entitled to affirm that man may not be brought to life again by supernatural potency. For scientific purposes, and in the way of widening our idea of the order of the universe, it is a most influential law. But to this law, it is quite conceivable, there may be exceptions,-to this law I believe there are exceptions. It is by observation and induction that we have discovered the law; it is by them, and by them exclusively, that we discover the extent and the limits of the law. This brings us to consider the other ground on which a miracle may be rejected.

2. It is conceivable that a miracle may be contrary to experience. The first objection is commonly urged by metaphysicians, most commonly by those who have been caught in the 
toils of pantheism. This second is more likely to be advanced by physicists, who have fixed their attention so exclusively on the system of natural causes-mechanical, chemical, and vital-that they can see nothing else.

What is it that the inductive philosophy has actually established? It has shewn that there is a set of agencies working in nature, and that there is uniformity in their operations. All this has been discovered by a very wide induc. tion, wider than we have in favour of any individual law in any one department of science; and I rejoice to go as far in this direction as the most advanced inductive philosophers possibly can. But when, not content with affirming, they make strong denials, I draw back, and I put myself on the defensive. I agree with them, without reserve, when they say that there are agencies working in a system; I dispute with them when they declare that there can be nothing else, and I press them for their proof. If they appeal to reason or intuition, I meet them in the way $I$ have done, and shew that, while every occurrence has a cause, this does not require that it must have a physical or mundane cause. If they appeal to experience, then on the field of experience I meet them.

And I tell them, at the outset, that it is not possible, in the nature of things, that they should 
be able to establish the doctrine of the uniformity of nature as a law which can admit of no exceptions. No general maxim can be shewn to be necessary by experience - by experience which must necessarily be limited. In ten thousand million of occurrences on earth we have found nothing but natural agencies;-this will never entitle us, by any logical rule, to declare, dogmatically, that in no other occurrence can there be supernatural agency. In a court of law, the testimony of a thousand witnesses, that they did not see a particular individual commit a murder, cannot set aside the testimony of two credible witnesses, that they saw the deed done. On a like principle, the fact, that in common terrestrial affairs there is only natural agency, can never authorize us to set aside at once, and without examination, every case of alleged supernatural interference. Our appeal being to experience, we must be prepared to abide by the result of experience. If there be a prima facie case of supernatural action, it is, at least, worthy of our examination, and if it relates to some important matter in which God our Maker seems to be making intimation of his will, it demands our careful and candid attention. If the evidence advanced in its behalf be good, standing the usual tests of testimony and historical evidence, we ought to yield our assent, which we are in no 
way entitled to withhold on the ground of some general principle of the uniformity of nature,a principle derived solely from experience, and which we must submit to be limited by experience.

And here it will be needful to refer to the wretched sophism which has been advanced, about its being unreasonable or impossible to suppose that God should work miracles, as this would be inconsistent with his unchanging purposes. His will, they say, is expressed in his works, and any action of a different kind would shew that God is changeable, and that his works in nature are not perfect, and not worthy of him. It requires very little penetration to discover the quiet assumptions on which this reasoning is founded. It assumes, that because nature is an expression of God's will, there can be no other expression. It assumes, that because God acts after a particular mode, no doubt for wise reasons in the circumstances, he can never have reasons for acting after a different manner in other circumstances. It assumes that an addition is an inconsistency; that to superinduce anything farther upon something previously existing is to declare that which thus existed to have been wrong or bad. It argues no inconsistency in the Divine plans, that there was first a long period in which there 
were only plants and the lower animals on the earth's surface, and that afterwards God placed man on our globe; on the contrary, distinguished naturalists have argued, from the very animal forms which appeared in the early ages, that it must have been the purpose of God the Creator from the beginning, to introduce upon the scene a being bringing out more fully the capacities of the type. It has been shewn, in last Book, that the natural seems to look for the supernatural. It will be shewn, in what is to follow in this Book, that the supernatural fits in most admirably into the natural system, and that the two form the joined and adjusted compartments of one grand temple, designed from all eternity in the counsels of God, and now being reared in time,-the one being as it were the outer, and the other the inner apartment. "For there is a tabernacle made; the first, wherein" are natural gifts "the candlestick, the table, and the shewbread, which is called the sanctuary; and after the second vail, the tabernacle, which is called the holiest of all," wherein are yet higher gifts, and an immediate revelation from God, "which had the golden censer, and the ark of the covenant overlaid round about with gold, wherein was the golden pot that had manna, and Aaron's rod that budded, and the tables of the covenant, and 
over it the cherubims of glory shadowing the mercy-seat."

We are now in circumstances to examine the statements of Mr. Powell, in the "Essays and Reviews." $\mathrm{He}$ is everywhere referring to the "fixed laws of belief, and our convictions of established order and analogy" (p. 106); but he gives no explanation as to what he precisely means. The following is the most specific language which we can find in his writings, and it is sufficiently vague:- "The entire range of the inductive philosophy is at once based upon, and in every instance tends to confirm, by an immense accumulation of evidence, the grand truth of the universal order and constancy of natural laws, as a primary law of belief so strongly entertained and fixed in the mind of every truly inductive inquirer that he cannot even conceive the possibility of its failure" (pp. 108, 109). Again, "the enlarged critical and inductive study of the natural world cannot but tend powerfully to evince the inconceivableness of imagined interruptions of natural order or supposed suspensions of the laws of nature" (p. 110). He adds, miracles are "seen to be inconceivable to reason" (p. 126).* I have searched through all his voluminous discussions as to the order of nature, without finding any-

* I quote from the Fifth Edition of "Essays and Reriews." 
thing more definite than the above. But, from such language, we cannot find on what grounds he would have us reject miracles thus summarily, and without inquiry into the evidence by which they are supported. Some of his expressions seem to mean that he would dismiss them at once, on the ground of some internal principle called "reason," or a "primary law of belief." Other expressions would rather imply, that he would have us set them aside on the ground of some law reached by observation and induction-"by an enlarged critical and inductive study of the natural world." The impression left is, that we are justified in discarding the supernatural on both grounds; the inductive philosophy is represented as "based upon" a primary law of belief, and it "confirms it." But we cannot submit to be deceived by such a thaumatrope fallacy, in which the author appeals to fact when driven from reason, and goes back to intuition, or reason, when it is shewn that experience cannot cover his position. Nor can we allow him to take advantage, as he seems inclined, of both collectively, till he has explained and vindicated each separately. If his appeal be to reason - meaning intuitive reason, or fundamental laws of belief - then I meet his dogmatic assertion by a dogmatic denial. There is no primary law of the human mind which au- 
thorises us to reject a miracle without looking at its evidence. He tells us that miracles are "seen to be inconceivable by reason." If he means that we cannot have an idea of a miracle, that we cannot conceive it, in the sense of picturing or representing it to the mind, the statement is simply false, for we can easily form the idea or notion of an event in nature-say a person rising from the dead-with a cause beyond nature. If he means, by a miracle being inconceivable by the reason, that we cannot judge it or believe it to be true, I maintain, in opposition, that there is no intuitive law of belief which is inconsistent with a miracle; and reason commands us, in matters of experience, to be guided by observational evidence, and not by a priori principles. If, on the other hand, the principle to which he appeals is supposed to be the result of experience, then I maintain that experience can sanction no such wide negative law, and that the evidence of experience is in favour of the occurrence of certain miraculous events bearing testimony to a most momentous revelation from heaven. 
SECT. III.-PURPOSES SERVED BY THE SUPERNATURAL.

We advance a step farther in our discussions in this section, but it is only a single step. We are to inquire what purposes may be conceivably served by the supernatural; but we are not, at this place, to endeavour to prove systematically that these ends are actually accomplished. This may be done more effectively, after we have looked in a more particular manner at the character of the supernatural revelation. But, first, it will be proper to shew that there are certain ends which do not require supernatural agency to produce them, inasmuch as they may be secured by the natural.

1. It is not needful that a miracle be wrought - say that one should rise from the dead-to convince us that there is a God. For all this is very evident from the frame of the world, and is pressed upon us by deep internal convictions. Some have maintained that the existence of God might be proven by the miracles recorded in the Scriptures. These, it is said, have come down to us as well-attested facts, which, in their character and mode of operation, argue a power above the mechanism of nature. I am not inclined to go so far as to affirm that there is no force whatever in this line of argument. I believe that the truths 
revealed in Scripture are so self-evidencing, and that the great facts of the New Testament are so well attested, that they are fitted to impress us with the conviction that there is a living power above the dead universe. It is a matter of fact, that it is mainly by means of the Bible and its supernatural truths, that the idea of God is first suggested to those who have been brought up in a Christian land. I am also fully persuaded that to most minds the revelation of God in his Word is a means of strengthening and rendering more real the conviction which may be gathered from his works. Still, it is ever to be resolutely maintained, that " the invisible things of God, from the creation of the world, are clearly seen, being understood from the things that are made-even his eternal power and Godhead." The Bible everywhere assumes that there is a God; it presupposes that men believe in God, and it comes as the Word of that God. The Christian apologist who acts wisely should proceed on a previous demonstration of the Divine existence, or rather upon man's conviction that there is a supernatural Being, and bring in that Being as the cause of the miracles which are recorded in the volume of inspiration.

2. We do not require miraculous operations to bring about the ordinary events of God's pro- 
vidence; to procure a supply to our bodily wants; to secure us from danger, when God so means it; to visit us with affliction, when the Divine faithfulness knows that we require it; and to help on individuals and the race in the onward march of intelligence and civilization. A provision has been made for all these in the plan of nature, in which God has general laws, to which mankind can accommodate themselves, and fittings of one agent and law to another, whereby he accomplishes each of his special ends. In this economy, everything has been arranged from the beginning, with such wisdom and foresight, that it does not need to be amended. God gives no encouragement, either in his Word or in his Works, to those who expect him to work miracles to save them from the consequences of their own folly, or to help a cause which may be carried by human zeal and energy, aided by such predispositions as God may have made in his natural providence.

But when all this is allowed, it does not go to prove that the supernatural is unnecessary. Man, indeed, must ever be careful not to go beyond his proper province, in making affirmations regarding what God may do or must do. Some defenders of Christianity speak of the "necessity" of a Divine Revelation. The language is strong, as coming from a creature like man, 
whose capacities are so restricted and opportunities of knowing the possible ways of God are so confined. But while it should ever be far from us to dictate to Deity, we may carefully look at the state of things in which we find ourselves placed, and at the relation in which we stand towards God, and reverently observe how certain great purposes worthy of God, suited to our world, and bearing upon the crying wants of man, might be served by a supernatural action or revelation, should God be pleased to grant it. Enough, at least, may be discovered to obviate those objections which proceed on the allegation that the added supernatural must be incongruous with the previous natural, and be a reflection on the consistency of God. It will appear that the supernatural fits into the natural, and carries out fully the Divine purpose, as manifested in the world.

I. The principal ground on which we anticipate a supernatural interposition of God is, undoubtedly, the existence and universality of $\sin$. We have here a fact in nature to proceed upon, and we feel constrained to trace its relation to God and to his character, as revealed by nature without and nature within us. It is quite certain, on the one hand, that sin exists; equally certain, on the other hand, that it is a violation of the law of God, and offensive to Him who hath 
instituted it. We are sure that God condemns sin, and yet we have strong hopes that, somehow or other, he may provide forgiveness for the guilty. Nature shews that God is good, but fails to point out a way by which the sinner may be reconciled to that good God. It is at this point that the revealed fact of the Word comes in to meet the mysterious fact of nature. The incarnation of the Eternal Word, followed by the setting of a perfect example, by the working of a perfect righteousness, and by piacular suffering and death, is the great supernatural event, carry. ing all the others along with it, as the streams which feed it, or the rivers which flow from it; as its antecedents, or its consequents; as means towards it, or issues from it. Admit this grand occurrence, and we feel that we may admit a thousand more, provided they stand in a relation to it. We have now a new and a grander central sun than that of our natural mundane system, and we have no difficulty in conceiving that there may be many bodies rolling round it, as secondaries or dependencies.

II. Another ground on which we may be led to anticipate the Divine interposition is to be found in man's distance from God, and ignorance of him, coupled always with the desirableness of knowing God, and his willingness to be known. The circumstance now referred to pro- 
ceeds from the other, but it comes to us with a peculiar aspect. We discover two classes of facts in nature, which seem to imply a third class above nature, in order to reconcile them. These natural facts meet us, whether we look to the world at large or to our own individual religious experience.

Looking to mankind at large, we find, on the one hand, as Paul told the men at Lystra, that God "has not left himself without a witness in that he did good, and gave us rain from heaven and fruitful seasons, filling our hearts with food and gladness" (Acts xiv. 17), and on the other hand, that men have not attended to that witness, or have not understood it aright. The heavens declare the glory of God; but how few of those who have dwelt or do dwell on the earth have looked up to the heavens, and risen thereby to clear apprehensions of his nature and perfections. God does reveal himself in these his works, and yet does it not look as if he were concealing himself behind them? How few of his intelligent creatures have recognized him, or have worshipped him, except in the most horrid and tortured shapes, which are a caricature of his excellencies and a mockery of his greatness, in which his purity is omitted, and his goodness turned into favoritism and caprice, and his spiritual nature reduced to sensuous forms! It 
has again and again been shewn, till it has become commonplace-and men who hate commonplace turn from it-but it is an established truth which no one can deny, and the importance of which cannot be over-estimated, that no nation of itself has (and very few individuals have) risen to the knowledge of one God apart from a written revelation. This induction is as wide as any in physical science, embracing not only ancient but modern times, not only barbarous and degraded countries, but semi-civilized countries of vast magnitude, such as India and China, and highly civilized countries, such as ancientGreece, and countries capable of the highest political organization, such as ancient Rome. All history, too, testifies, from Greece downwards to modern Japan, that the picture drawn in the close of the first chapter of the Epistle to the Romans is a true one; that when men "knew not God, and glorified him not as God, neither were thankful," they have everywhere been given up to uncleanness and other sins, such as murder, deceit, malignity, practised without public reprobation, or an effort being made to stay the evilinasmuch as men not only "do the same, but have pleasure in them that do them." On the other hand, it is clear that God wishes that he should be known; and, as Paul taught the Athenians, that men "should seek the Lord, if 
haply they might feel after him, and find him, though he be not far from every one of us" (Acts xvii. 27): and it is certain that the knowledge of God is a higher knowledge in itself than the knowledge of his works, or than any other knowledge can be ; and that it has an elevating tendency upon the thoughts, and a purifying influence upon the morals of a people; while it brings to all, but especially those in affliction, a thousand comfortable assurances. Is any man justified in dogmatically affirming that this God never has made, and that he never can make, a fuller and a comforting revelation of himself to his intelligent and anxious creatures everywhere seeking him-as they shew by their very errors, and yet ever feeling that they have not found himas they shew by their dissatisfaction and restlessness? The human spirit seems to anticipate that, though God has "winked" at "this time of ignorance," yet he will, at the set time, break the silence, and "command all men everywhere to repent" (Acts xvii. 27, 30) in order to a restoration to himself. I believe that he who has reflected deeply upon nature and all its mysteries, and upon the actual state of mankind and their relation to God, will be the most disposed to consider and to weigh the facts and arguments which might be advanced to shew that God has been pleased to make known a 
way of access to him. He who perceives that it has been by the Bible that Grod's unity and his higher perfections have in fact been made known to that portion of the human family which know and recognise these truths, will surely not be disposed a priori and peremptorily to decide that the book cannot possibly have come from God. Nor let any one urge that the light at present diffused over the professedly Christian world would remain on our earth even though the Bible were withdrawn as a heavenly luminary. From all that history teaches regarding mankind we may be sure that in such a case the light at present diffused, like the sun's beams through our atmosphere, so that many fail to recognise the luminous centre from which it proceeds, would soon lessen, and would finally disappear, among the great body of the people, were the Bible, as the source, withdrawn,-just as the day, after a brief splendour, sinks into twilight and darkness when the sun ceases to shine. Yes; let us realize -it may be profitable for us-the position of our world were the Bible found by German critics or Oxford essayists to be so full of errors that no one could discover from it what was truth and what was error. What would the great body of the people in these lands now have to fall hack upon? What would we now have to carry with us when we addressed the heathen or the 
outcast? Would not the great mass of mankind feel licensed to abandon themselves to shameless ungodliness and sensuality, from which they would be roused only, by occasional religious awakenings, to feel that they were groping in darkness, in which they would find gods or demons, suited to their tastes or created by their fears, among imperfectly discerned natural objects? I believe that the very educated, when the darkness had settled down, . would feel God disappearing more and more from the view, and becoming, in fact, an unknown God-at best a mere point of light"a postulate of reason," as some one admits him - seen in the incalculable distance, not as a sum shining all around, but as a star exercising no appreciable influence on our earth.

The very same impression is left when, instead of looking at the world without, we listen to the breathings of our own spirits. In our deeper moods we feel as if these souls of ours had some affinity with God, and yet it is in our moments of deepest thought and emotion that we are made to feel most impressively that he is at an infinite distance from us. Many a profound thinker has felt, as Heraclitus of Ephesus did, when he describes the name of Zeus as "the one object of wisdom," which "wills not and yet

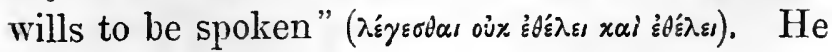


seems as if $\mathrm{He}$ were offering us communion with himself, and yet we are ever baffled and beat back in our efforts to enjoy the privilege. We are ever induced to mount, but as we do so by natural means, we find that, after all, there is no atmosphere to float us beyond a very short height, and that we never get beyond the gravity of earth, which, in the end, draws us back to its hard and cold surface. There are times when our spirits, as if at the invitation of God, would boldly go up to heaven's gates only to find them shut and silent, and we come back sulky and disappointed. How often have we felt our prayers ascending as vapours, drawn up by a genial heat as we think in the heavens, only to return as snow to damp and cool, or as hail to smite us. All these natural facts and intimations combined seem to shew that God is displeased with us, while yet he loves us; not countenancing us in our sins, and yet sparing us in the midst of them; shewing his disapproval of our conduct, but yet waiting to be gracious and showering favours upon us in order to melt us into gratitude. Could any man, living in a heathen land, be giving offence to that God, were he to pray that $\mathrm{He}$ would reveal Himself more fully, and shew the way by which the sinner may approach him?

But if God is to provide a reconcilement of 
these chasms, that reconcilement must be preternatural, and if he is to reveal this method of reconciliation, it must be in a supernatural way,-the revelation itself is supernatural, it is a voice out of and beyond the natural sphere. To preclude God from supernatural action, is to shut him out from providing a remedy for the evils which sin has entailed. To make it impossible to prove the supernatural, is to shut out man from ever knowing that there is forgiveness and peace. But if God is to reveal his will it must be in a way intelligible to man, and the intelligent nature of man requires that there be evidence that it is God that speaks.

III. God may prove to us a supernatural revelation by miracles of evidence wrought on natural agents, but by an action beyond the sphere of nature. For if God is to reveal the supernatural to us, say that his Eternal Son became flesh and made reconciliation, it must be through the natural. In saying so, I do not speak of any absolute necessity in the nature of things, but of a necessity arising from the nature of man, and of the mundane system in which he is placed. A revelation to man is a revelation to a being within the sphere of nature. Not only so, but that revelation must be made by means which can reach him. It must be made immediately to his soul by intimations to it, or 
it must be made externally through his bodily senses. I suppose that to the inspired prophets the revelation was made by a mental representation, accompanied by a conviction very analogous to the intuitive conviction which makes us trust our senses or our memory, that is, a conviction carrying in itself its own evidence and validity. Such a persuasion must come to every individual expected to be swayed by it. It is quite conceivable that God might thus supernaturally work a conviction in the breast of every man. He has, I believe, imprinted certain natural beliefs on the souls of all men, such as that every change implies a cause, and that sin deserves punishment. It is quite conceivable that God might add to these native ones another, whereby we should be led to believe at once in the doctrine of the Trinity. Such a conviction would, in its very nature, be necessary and irresistible, it would leave no room for free will either in a good or bad exercise, no room either for choice or rejection. But it is not thus that God reveals to us the great practical doctrines and duties of religion and morality. Instead of driving us irresistibly by instinct, he leads us by mediate evidence, which we are expected to receive, but which we may also reject. But it is no evidence to me of Jesus being a Divine teacher, that he was so 
esteemed by a person named Paul or John, who lived eighteen centuries ago. If evidence is to be furnished to mankind generally, it may be best addressed to the senses. And how can man be so effectually convinced that God is acting or that God is speaking, as by witnessing acts wrought in nature above all natural power, wrought by the Being who at first produced nature, and who can change it as it pleases him. The miracles of Scripture are all wrought in nature,- the effects are in natural agents, and become thus cognizable by man; but the cause must be in a power beyond any natural cause.

This is the proper place for a statement as to the phrases employed in such discussions. As a matter of propriety and convenience, we may speak of whaterer is supposed to be beyond the natural, as "preternatural." The phrase will apply not only to the Divine action, but to the agency of such beings as ghosts and demons,to all such operations as witchcraft and necromancy. We may reserve the phrase "supernatural" to the Supreme Being, and to the works performed by him, and to the objects created by him beyond the natural sphere, such as angels and the world to come. We would confine the word "miracle" to those events which were wrought in our world as a sign or proof of God 
making a supernatural interposition or a revelation to man. We must ever view creation as supernatural, but we do not speak of it as miraculous. We look upon the incarnation of the Son of God as supernatural, we do not employ it as a sign or wonder for evidence. We believe the conversion of the sinner to transcend all the natural efforts of the corrupt heart of man, but we do not advance it as a miracle for proof, though it may carry strong conviction to the man himself, and produce an impression and a prepossession on those who were cognizant of the former man, and now mark the change wrought upon him. We would confine the phrase miraculous to those signs, wonders, and miracles which were wrought by Moses and the prophets, by Jesus and the Apostles, to summon the attention of spectators, and to gain their reasonable conviction as to the Divine origin of the message proclaimed, and the system of religious doctrine set forth.

IV. It is conceivable that the supernatural in our world may be the means of bringing it into harmonious connexion with other portions of the universe. Though no wise man will ever attempt a scientific demonstration of it by the light of nature, yet the deepest thinkers, looking to the infinitude of space and the greatness of God, have been prone to believe that God has 
other systems beyond ours, created in the fulness of his wisdom and his love. We can never, indeed, know anything positive of these other worlds; they lie in the dim and distant horizon of our vision, and we cannot say whether it is floating vapour or solid land that we see. When we are in this state of perplexity the Scriptures of the Old and New Testament come to us as the Word of God, and proclaim that beyond the region visible by man, there are "thrones, and dominions, and principalities, and powers." They also inform us that beings in these other worlds take an interest in the supernatural events which have been transacted on our earth,"which things the angels desire to look into" (1 Pet. i. 12); and that the work of the Mediator, in bringing God and man into reconcilement, also brings our world, and the sinful inhabitants of it, into unison with other worlds and the beings who people them: "For it pleased the Father that in him should all fulness dwell, and having made peace by the blood of his cross, by him to reconcile all things unto himself; by him, I say, whether they be things in earth or things in heaven" (Col. i. 19, 20). These are pleasant glimpses, opened to us through the loopholes of our present place of confinement, of scenes in which we may expatiate when the earthly house of our tabernacle is dissolved. 
V. Altogether, the supernatural may be considered as the complement of the natural, or the carrying out to its proper conclusion of what is involved in the present system of things. It is certain that the natural system is the effect of a prior supernatural action; and it seems to point on to some supernatural consummation. I suppose we could not appropriately represent the existence of the soul in the world to come as natural; but the everlasting life is implied in the temporal life, as the flower is in the bud. It would be an inaccurate use of language to speak of the resurrection of the body as natural, but the resurrection is certainly quite in consonance with the high natural endowments of man. That reproaches of conscience should pursue the commission of $\sin$ on earth, is an arrangement of God's natural providence which points to a more fearful retribution in a future life. It is the same with most of the supernatural manifestations of God brought under our view in the Word; they are the realization of what is implied in the system of nature, being the fulfilment of a plan, or the supply for an obvious want, or the completion of what had been commenced.*

* This may be the proper place for referring to the discussions which have taken plaee, as to whether miraeles are against nature, or violations of the laws of nature, and as to whether they may not be 
SECT. IV.-RELATION OF THE SUPERNATURAL TO THE NATURAL.

\section{In the Scriptures the distinction between} the natural and supernatural is implied and proceeded on, but is not drawn abstractly or theoretically. The precise scientific difference between the two cannot be discerned till research

conformed to a higher nature. The controversies on these topics have generally been distinguished by much confusion. A -miracle may be said to be against or not against nature, according as we understand "against." They are against nature as they counteract natural action, - just as one natural agent may be against another-as water may counteract fire; but they are not against nature in the sense of being in opposition to the design of nature as a work of God. They are violations of the laws of nature, inasmuch as they arrest what would take place according to natural agencies ; but, after all, they only enable nature, as a work of God, to carry out its full design. "The miracle is not unnatural," says Dr. Trench, "nor can it be ; since the unnatural, the contrary to order, is of itself the ungodly, and can in no way, therefore, be affirmed of a Divine work."-(Notes on the Miracles of our Lord, chap. ii.) The statement is prettily worded, and has a truth in it. But it contains an amphiboly in regard to the meaning of the word "natural." By nature, in the proper use of the term, we mean the system of things in the Cosmos; and certainly a miracle is non-natural, that is, not from the natural, though it is not therefore " unholy," as it proceeds from a holy sphere bejond. The unnatural is "unholy" in a different sense, as meaning something inconsistent with the plan of God in nature. The truth of the statement lies in this, that miracles are in complete harmony with the design of God in the works of creation. But a statement to the effect that they are natural would be altogether wrong; as the "natural" properly means that which is produced by cosmical agencies; and such language is apt to leave the impression that miracles might be explained by some higher material or mental causes. 
has made such progress as to convince men that nature is a self-contained system. If the inspired writers had been taught constantly to keep up the line of demarcation, their statements would have been unintelligible to the great body of their readers in that age, and in every age, including even the present,-quite as much so as if they had represented night and day as being produced by the earth spinning on its axis, instead of speaking of the sun rising and setting. In the Word of God, both the natural and supernatural are referred to as the operation of God, as the manifestation of his glory, and the expression of his will. Still, the distinction is kept in view, and is expressly appealed to. No speculative or abstruse principle is announced, but the inspired writers point to an occurrence as in its very nature beyond human or mundane agency, and so as evidential of an interposition from heaven, or sanctioning a revealed doctrine. "We know that thou art a teacher come from God: for no man can do these miracles that thou doest, except God be with him" (John iii. 2). "Since the world began was it not heard that any man opened the eyes of one that was born blind" (John ix. 32). Here there are no philosophical inquiries as to what the powers of nature can do and what they cannot, but certain works are appealed to, as being beyond all human potency. 
The supernatural, though different from the natural, is not to be regarded as altogether disconnected from it, or as standing in no relation to it. The supernatural, in coming into the lower sphere, acts in unison with the agencies already there. This is only what we might expect, as both are the operations of God and parts of one comprehensive plan. A careful inquiry will shew us that the supernatural is superinduced upon the natural, and acts upon the natural, subordinating the natural to it, without destroying it, but, on the contrary, raising and exalting it, all in very much the same way as the higher natural acts towards the lower natural.

For there is a higher natural and a lower natural. Whether we look to the inspired record in Genesis or the disclosures of geology, we are taught that the work of creation was a progressive one. First, there may have been a time when the earth was simply mineral; then it appears clothed with plants; animals in due time come forth to browse upon them; and, as the completion, man stands up to gaze with intelligent eye upon the whole. There is a unity of plan running along all this series. The plant, when it comes, is higher than the mineral,-a new power, the vital, has been superinduced; but still the organic is dependent 
for nourishment on the inorganic, and all the forces which operate in the mineral are active in the plant. Look at the more complicated crystals,-look at the frostworks on our flagstones and windows, so like the tree in their ramifications, - and you at once see that powers are operating there which are to appear in a more advanced form in the plant. When the animal appears, it has something not in the plant,-in particular, it has a power of sensation and voluntary motion; but still it retains all the power that is in the mineral, and is dependent for food on the vegetable; and so closely are the plant and the brute allied, that it is difficult to draw a line which will decidedly separate the higher forms of the one from the lower forms of the other. And when man walks forth to contemplate all these objects, it is evident that there is a higher principle in him, which is not in the mineral, nor in the plant, nor in the brute; but it is just as clear, that he has affinities with the lower creation, arising from the lower creation tending upwards toward him. Made of the dust of the ground, his bodily frame is subject to all the inorganic laws of the world, and at last returns to the dust, out of which it was formed. As an organism, he is subject to all organic laws; he needs breath and food from without, and has an allotted period of existence. 
As an animal, his bones and his muscles, his very nerves and brain, are after the same model as those of the brutes; like them, he needs organized matter whereon to feed; and like them, he is susceptible of pleasure and pain. It may be maintained that the lower animals are, in a sense, anticipations of humanity, and have appetites, instincts, attachments, -as for offspring and home,-perceptions, and a sort of intelligence, which, though not identical with, are homologous to, certain of the lower endowments of man.

All this does not prove, as some would argue, that man is merely an upper brute,-possibly sprung from the monkey, or removed from it only as one species is from another. In his bodily frame he may be simply a new species, the highest of animated organisms, - with the fore limbs turned into hands, and his frame raised into an upright attitude,-and even in this, so far anticipated by the ape. But in his soul, endowed with the power of discovering necessary and immutable truth, and of discerning the difference between good and evil; capable of cherishing voluntary affections - which alone (and not mere instinctive attachments) are deserving of the name of love,-and of rising to the knowledge of God, and of communion with Him ; by reason of this soul-responsible and immortal 
-he belongs not merely to a new species or genus of nature, but to a new order in creation. In respect of this, his nobler part, he is made not after the likeness of the brute, but after the image of God. He stands on this earth, but with upright face he looks upward to heaven.

Still, man is not an anomaly nor an exception in the scene in which he is placed. That scene has long been in preparation for him, and when he arrives, he is to be the head and the crown. Superior to all creation, he is yet allied to all creation. Above the earth, he is yet drawn to it by an attraction which binds him and it together. In his body connected with the lower creation, in his spirit connected with the Creator, he is or ought to be a bond connecting God more intimately with his works. But, alas! man is not what he was meant to be. We cannot look on man in his present state as the consummation of creation. As the plant points upward to the animal, and the animal upwards to man, so does man, in his present condition of groaning and travailing, anticipate a redeemed, a regenerated, and a glorified humanity.

There is no incongruity in fact or in appearance between the higher natural and the lower natural;-between chemical action and mechanical power-which is controlled by the affinities of bodies; between the vital and the chemical- 
whose attractions must give way before the power of life; or between the mental and the vitalwhich can be so swayed and directed by the ideas, purposes, and determinations of the mind. Each of the new powers is something superinduced upon the old. I have sometimes thought that the very rise in the natural, from the lower to the higher-so constant, so regular, so systematic, so evidently ordained-may point to, and almost guarantee, a rise from the natural to the supernatural. As the inanimate has rișen to the animate, as the animal has risen to man, so do we hope that the animal man may rise to the spiritual man. "Howbeit that was not first which is spiritual, but that which is natural; and afterward that which is spiritual" ( 1 Cor. $\mathrm{xv}$.46). I suppose that a being of high intelligence, looking at the ape on the pre-adamite earth, might have guessed that a creature with higher endowments would soon appear to carry out more fully the capacity of the type; and, looking at man as he is, at his wondrous gifts and equally wondrous defects, I cherish the hope that he is but the rude anticipation of what he is to become. Howbeit, when that state of things comes, the whole natural shall be raised up to the supernatural, and the supernatural shall be natural, as being visibly embraced within the system, and these oc- 
casional interpositions in our era shall be looked back upon as the prognostics of the grander epoch which has succeeded. But, instead of keeping up in these airy regions of speculation, we have firmer ground to stand on as we come down to remark that; as the lower nature is subjected to higher nature, so is natural action subordinated to the supernatural agency.

Not even at the present advanced stage of knowledge are we able to say how the higher natural stands toward the lower natural, how, for example, the chemical works upon the mechanical, or the vital on the electric, or the mental upon the animal functions. If we do not know the modus of the action of one kind of natural force upon another, even after all the experiments of modern science, how can we expect to know the mode of the operation of the supernatural upon the natural, in which one of the active powers is from a region on which we cannot experiment, and operates according to laws which we have no adequate means of discovering by generalization. When such questions are started, our wisest course is to say, with the parents of the blind man when they were interrogated as to their son, "By what means he now seeth we know not." But it is plainly within our reach to note, that there is an 
analogy between the action of the higher agents of nature on the lower and the action of the supernatural upon the natural. When the vital power-whatever it be-works among the mechanical and chemical forces, it does not annihilate them, it simply subjects them to its sway. We often see all the three combine in one result, and even when the lower is restrained by the higher it has still the tendency to work, and will work as soon as the restraint is removed. Again, when, by an act of my will, I move my.arm, the mental does not supersede the physiological, it rather summons it into action. So when the supernatural descends among natural forces, physical or mental, it may not be to abolish them, or nullify them, or even supersede them. Even when they are counteracted, we may see their tendency breaking out at the points at which the supernatural is not acting; and, in many cases, we may trace, in the effect, their joint operation, in which there is no dishonour put upon the supernatural in its association with the natural, as long as natural agents are agents of God, which they always are, excepting in so far as they may be contaminated by the sin of man.

The natural does appear operating and cooperating with the supernatural in not a few of the dispensations of God. Every one observes, 
in the pages of the inspired volume, the native talents, tastes, and temperaments of the writer. In the Pentateuch we have a narrative usually clear and bracing as our atmosphere, but, when the subject requires, darkened with awful clouds or shooting forth swift lightnings. In the Book of Job, we look, as by a window, into the hearts of primitive thinkers as they pondered the mysteries of God's government, as they wandered in the darkness, as they erred in their self-con. fidence, and were rebuked by the light. The fire of David, as it rages in its fierceness or melts in its tenderness, breaks out in every one of his Psalms. The wisdom of wisdom is graven -as lines are on the brow-of every one of the sayings of Solomon. The word seraphic, so often applied, is vividly descriptive of the flights of Isaiah as he soars upward into his native sphere above, with unwearied wing, glistening in the beams of heaven. We see that Jeremiah has been made to eat a roll full of mourning, lamentation, and woe, which, however, in the rumination of it-like pensive melancholy-is not without its profit and even its sweetness. The soul of each of the four Evangelists takes in so much of the spirit of Jesus; thus Matthew accepts one part, and John drinks in another portion; and each gives out what he has been able to receive of the fulness. The underlying 
doctrine is the same in the Epistles of Paul, of James, of Peter, and John; but each brings out in his own way the truth which approves itself most entirely to him. The rapid ratiocination of Paul has made him relished by the western intellect, while his eagerness of spirit and fervour of feeling have carried forward many who would have experienced a difficulty in following his quick transitions of thought. James has ever recommended himself, both by his style and sentiment, to those who delight in calmness, prudence, and practical wisdom. Certain German theologians are fond of magnifying the Pauline and Petrine differences; to me it seems very clear, that the doctrine of both is obviously the same, and that even the manner of the two does not differ so widely, though I think we do not discover so vigorous a logical step in Peter, while at times there would burst out a greater impetus, were it not that his spirit has been subdued by frequent falls, followed by searching corrections. With those who love intuitive contemplation, and who are averse to all discursive or concatenated thought, in which there is more than a single step between the premiss and conclusion-more than the going back from a fact to a principle-John has been an especial favourite, as he looks himself, and makes us look, directly on the object, aiding us at times 
only by a symbol,- - and there are seasons, I think, in the lives of all of us when we feel that it is thus-even by him who himself leaned upon Jesus' bosom-that we are brought nearest to God and to heaven. It is a most happy thing for us that the pure light of heaven is thus bent and made to shew various colours as it reaches our mundane sphere, being reflected from, and refracted by, the hearts of holy men of God, who "spake as they were moved by the Holy Ghost," but who, at the same time, spake in human tongues to human beings.

We see, too, that as the spiritual comes in among the natural in the human heart, it does not destroy human individuality and nationality, though it sanctifies and elevates both. The man of high intellect is still a man of high intellect, while the man of weak understanding must remain a man of weak understanding; the man of resolute will is still characterized by strong determination; the man of warm feeling is now, as before, easily moved and melted; and the man of eccentricity may continue to do singular actions, - the whole of the natural endowments being, all the while, kept under strict moral restraints, attracted by more powerful magnetic motives, and directed to higher ends up in the heavens. We have to add, that the lower propensities peculiar to the individual - the lust, the vanity, the pride, 
the self-esteem-will be apt, also, to stay deep down in the heart, to burst out at times in terrible volcanoes, and pour their lava on all around, till such time as their source is dried up by the power of the "spirit which lusteth against the flesh," and shall finally subdue it.

The peculiarities of his training, of his race, and his country, appear in the Christian, and in his very Christianity. The religion of the poor is of a somewhat different type from the religion of the respectable and comfortable middle class, and the religion of both is not the same as that of the refined and aristocratic classes. The Christianity of the rude and ignorant differs from that of the highly civilized and the learned. The Christian student of Oxford differs from the Christian student of the Dissenting Academy, and of the American Colleges, while all three differ from the Christian student of Edinburgh, who, again, feels that he is not the same as the Christian student of Berlin or Geneva. The Christian man of the type of the covenant, burning earnestly to make his nation and his church what they ought to be, differs from the Christian of the puritan phase, asserting individual liberty, and seeking to elevate the world by means of individual spiritual men leavening the mass around them; and both differ from the Christian who sings Wesley's hymns, and gets his feelings warmed at the class 
meeting, and pays and prays for the conversion of sinners; and scarcely one of these understands, as certainly none of them is understood by, the Christian of the Anglican establishment, who would, by all means, have religion respected and respectable, lifting its head calmly but boldly in the high places of the land, while he would have the gospel preached to the poor, without money and without price. The character of the man, of his early history, and of his temperament, is apt to come out in the struggles made by the soul, when the spiritual power is bringing it under its sway. This appears, particularly, in our seasons of revival. The breath of the returning spring may be felt by all the plants of the earth, by the strong oak which stands out in the breeze and in the sunshine, by the lily down in the waters, and the fern in the dark glens or caves; but each feels it after its own fashion, and has its own hindrances to contend against as it would burst into life, and is liable to its own elemental attacks and internal maladies; and so it is with the spiritual life in the soul. He who has been wisely and carefully trained, both in religious knowledge and self government, may be affected as deeply when he feels himself under the firm hand of a Divine power arresting him, as is the man who has received no training, or a bad training, and has just heard the Gospel for 
the first time : but the struggle in the case of the latter, as never having been taught to restrain his impulses, will probably be vastly more violent, and be accompanied by a greater number of those pathological affections which are produced by high feeling. Our very national peculiarities come out in our Christianity. In the early Church, the Christian Jew was still a seeker after supernatural signs, and the Christian Greek a a seeker after a subtle and dialectic wisdom, and the Christian Galatian an impulsive Celt, and the Christian Roman an organizer of men. In these times, the German Christian is still a German, and the French believer is still a Frenchman, and the English and the Scotch shew their national characteristics in their religion. In our narrowness, we Britons look on the German Christian as somewhat too dreamy and passive, and the Frenchman too quick and sentimental, but we should remember that they shew the same peculiarities in their worldly pursuits. The Englishman thinks the Irish minister too oratorical when he preaches, and the Scotchman too argumentative, while the Irishman and Scotchman complain of the quietness of the English preacher. All these are apt, when they view one another at a distance, to doubt of each other's Christianity, but as they come nearer, and hold a closer communion, they find that with minor 


$$
\text { ON THE SUPERNATURAL. }
$$

differences they have far more important points of resemblance,-having all of them a family likeness, as being begotten of God, and growing into a likeness to their elder brother. 


\section{CHAPTER II.}

THE SYSTEM IN THE SUPERNATURAL.

SECT. I.-THERE IS SYSTEM IN THE SUPERNATURAL.

BY system we are to understand things arranged, objects or truths set in order. There are such systems in nature. The sun and the bodies rolling round him constitute such a system. There are evidently systems in the starry heavens. The atmosphere, with its rarefactions and condensations, with its calms and its storms, is a system; as is also the ocean, with its evaporations, and the counterbalancing flow into it of waters from the land. Every organism, vegetable and animal, is such a system,--all the means are ends, and all the ends means. And as there are systems in nature, so nature as a whole is a system. The phenomena are all correlated, as causes and effects, or by mutual resemblances and affinities. Persons are accustomed to express this, by saying that all things are governed by law. But there has been an immense amount of confusion, and not a little error, in the views 
entertained by many as to the nature of physical law, and the relation of law to God. 'The language often employed implies that there is a necessity laid on God to proceed by natural law. And it should at once be admitted, that every act of God is, and must be, conformed to his own moral law, that is, moral nature. But it has been shewn again and again that law in morals and law in the occurrence of physical phenomena are not the same things. It should be allowed, too, that law, in the sense of system or co-ordination, rules everywhere in nature. But it is rash in the extreme to affirm that God should, or that he must, act in this way and in no other. The order of nature has all the appearance of an arrangement or device for the accomplishment of wise and beneficent ends. It is a fact that it is made to supply the wants of God's creatures, and to render nature intelligible by the intelligent creature. Whatever else natural law may be, it is certainly an expression of the Divine wisdom, as a wise means of accomplishing a good purpose.

I am to shew, in these Sections, that in the supernatural dispensations of God there is a grand system, with subordinate systems,-a sun with planets, and planets with satellites,-an organism made up of living organisms. But let us understand precisely how much, and how 
little, is meant and implied in this language. It is not to be interpreted as involving that God behoves to proceed by natural law, we being judges; or that from the necessity of his nature, or of things, he can proceed no otherwise. No doubt, all that God does must fall out according to a purpose in the Divine mind; but the individual occurrences may, or they may not, be dependent on created agencies. It should not be allowed, for one moment, that we are not at liberty to look upon an event as springing from the supernatural power of God, unless it can be shewn to be a link in a concatenated combination. There is a loose and empty style of speaking in our day, about miracles being, after all, referable to a higher law, which either has no definite meaning, or may be understood in a misleading sense, and, at the best, is in no way fitted to gain the opponents of supernaturalism, who, by law, always mean one consistent thing, and that is, natural law. If it is meant that miracles can all be referred to some higher natural law, discoverable or undiscoverable, the impression may be left, that they are like meteors or like mesmerism, simply mysteries which may yet come within natural explanation, and which cannot, therefore, be evidential of supernatural action. If it is meant that they can all be referred to some supernatural law, 
known or unknown, the assertion is made without a warrant from reason or from revelation. It would be most presumptuous in us to affirm that we can, in every case, discover the law to which the supernatural operations belong, or so much as be sure that there is a law. It is quite conceivable, indeed, that there may be some such law beyond our ken, but of what use can it be to appeal to a law unknown and unknowable. It is quite as conceivable, that God may have wrought in our world an isolated occurrence, having no connexion, physical, causal, or dependent, with any other mundane occurrence, except the profound relations which all things have one to another in the Divine mind.

But keeping these explanations steadily in view, we may reverently inquire whether there is not system in the supernatural revelations and dispensations of God; and as we do so, we shall find not a few traces of connexion and plan. I speak of traces, for in many cases we have nothing more than prints, - such as we have seen in the snow, giving evidence of a living creature having mored in a particular direction, but scarcely indicating what the animal was. Seldom can we rise to so full an apprehension of the supernatural system as we have attained in these last days of the natural. A number of reasons can 
be given for this. An obvious one is, that we have scarcely so large a body of clear facts out of which to rise to the knowledge of the law by generalization. Another certainly is, that we seldom see the clear and undisturbed operation of the supernatural and spiritual law-in most cases we obtain only interrupted glimpses. How difficult did astronomers find it for long ages to determine the precise path followed by the planets, not because the planetary motions are irregular, but solely because no one ever saw them performing a full revolution; all that could be seen was, that they were in one position at one time, and in a different position at a different time, and it was out of the individual observations that they had to gather the law by computation. We are in much the same position when we would settle the law of supernatural occurrences. We see that there is a course pursued; we may even anticipate it to some extent,-as in ancient times they could predict the time of the rising of a planet, when as yet they were ignorant of the precise law of the planetary movements; but we may commit great blunders if we dogmatically affirm that we know its precise orbit as it moves through space and time,-quite as great as the ancients fell into when they settled prematurely the planetary paths into cycles and epicycles. A third reason may very possibly be, 
that the laws of the supernatural may, in their very nature, be beyond human comprehension; their cycles may be more sweeping than those of the farthest travelling comets, or the largest starry constellations; they may run from eternity to eternity, or come out from eternity into time, or their rule may lie altogether in the Divine intelligence and will, and not be disclosed to us by a positive statement, or by an observable series of connected occurrences.

Making these abatements, we may yet maintain that we discover clear indications of ordination and subordination in the supernatural dispensations of God, analogous to, though by no means identical with, those of the kingdom of nature. There are everywhere relations, evidently heavendesigned, of one thing to another. There are parts related to parts, and all constituting a connected whole. There is an apparatus instituted to produce a grard result, and, everywhere in the process, means producing ends, and ends which are means to higher ends. There are series flowing on like rivers in their appointed channel, and bearing their waters, and much wealth that floats on them, to their appointed destination. There are times and seasons-like the days and years and geological epochs of the natural world - which begin at a point and reach a consummation. There are correspondences among cha- 
racters and ordinances not unlike those beautiful homotypal, homologous, and analogous correspondences which later science has been discovering everywhere in the vegetable and animal kingdoms. There is a gradual advance in light and knowledge, and a development like that of the plant-till seed is brought forth; like that of the geological ages-till the earlier types are all fully unfolded and embodied in an archetype. There is more than a conglomerate of systems, there is a group, there is a system, of systems. Whatever other centres the inferior systems may have, they all form part of one grand system, circling round an attracting body, which keeps them in their places, and illuminates them as they rotate around it. Need I say that this object is Jesus Christ, in his incarnation, his life, his death, and ascension.

The supernatural dispensation has respect throughout to God, to his law, and his glory, on the one hand; and to man, to his sins, and his restoration to peace and holiness and communion with God through a mediator, on the other. It is said to originate in the Divine love, to be the product of the Divine wisdom and power, and to manifest the Divine righteousness and faithfulness. It brings peace to man, plants him on the elevation from which he had fallen, and sends him forth on a career of evangelical 
obedience. It is not needful to quote isolated passages to prove this, - it is written on the very face of the Word of God, it is woven into the very texture of the supernatural system. It is briefly expressed in the song of the multitude of the heavenly host, "Glory to God in the highest, and on earth peace, good will toward men."

There are intimations not obscure in Scripture of particular economies holding a relation to the great one devised in the counsels of a past eternity, which is being executed progressively in time, and is reaching forward to the coming eternity. It is very often described as a covenant. David speaks of it as " an everlasting covenant, ordered in all things and sure" (2 Sam. xxiii. 5). Of that covenant Jesus is the mediator (Heb. xiii. 6). That covenant takes special forms in different circumstances and in successive ages. It is, for example, a covenant with Noah, with promises given to him and his posterity, and obligations laid on them (Gen. vi. 12). It is a covenant with Abraham, concentrating titles and privileges in him and in his seed (xxii. 17, 18). It is a cove. nant with the children of Israel at Sinai, in which a most instructive but somewhat burdensome ritual is enjoined, while large assurances are held out to them (Deut. iv. 13, \&c.). It is entered into specially with King David as the father of a seed (Ps. lxxxix. 3). The later prophets speak 
of the covenant in its older form giving way in favour of a new covenant. "Behold the days come, saith the Lord, that I will make a new covenant with the house of Israel and with the house of Judah." "After those days, saith the Lord, I will put my law in their inward parts, and write it in their hearts, and will be their God, and they shall be my people (Jer. xxxi. $31,33)$. In interpreting such passages, the word covenant has often been stretched far too rigidly; to bring heavenly things down to the level of human transactions. Still, the language points to a counsel of vast depth which we cannot fully fathom, and to an arrangement with obligations and sanctions entered into with men, in all cases through a sacrifice-the typical sacrifices in the older dispensation, and the real sacrifice in the New Testament.

The word ordinance is applied by the inspired writers to the arrangements which God has made in nature. "Thou hast established the earth, and it abideth; they continue this day according to thine ordinances, for all are thy servants" (Ps. cxix. 90, 91) : compare Job xxxviii. 33 ; Jer. xxxi. 35 ; xxxiii. 25). It is the word applied in Scripture to those orderly injunctions which God laid down to the Church as to the services required of His people. The covenants of God had all ordinances of Divine service (Heb. ix. 11). 
In the Old Testament Church there was in the priesthood an order of Melchizedek (Heb. v. 6, 7), and an order of Aaron (Heb. vii. 11). The sanctuary and its furniture were all made after a pattern shewn by God to Moses on Mount Sinai (Heb. viii. 5).

There are also traces of a plan in the New Testament. It is a kingdom, a kingdom set up on the earth, not a kingdom of this world, but the kingdom of heaven upon earth, with a living king, but to be established and defended not with carnal but spiritual weapons (John xviii. 36 ; 2 Cor. x. 4). It is a house, a building in which Christ rejected is the corner-stone, and built upon him are, first Apostles, and then all his followers, each in his own place, as living stones. The company of the faithful is at first a very small one, meeting in an upper room at Jerusalem; but, in consequence of a predetermined and prayed for outpouring of the Spirit-the reward and the first-fruits of Christ's work-the number is largely and rapidly increased; and in an age or two the Gospel is preached for a witness in all the provinces of the Roman empire. But in the midst of these triumphs there are intimations that antichrist is already working, that there will be a long falling away, and that the Church will have much to suffer (2 Thess. iii. 31-2; 1 Tim. iv. 1-8). The inspired 
volume closes with a prophecy of things that " must be hereafter" (Rev. iv. 1), in which there is a book of Providence with seven seals opened, and seven angels sounding trumpets, and seven vials poured forth, all shewing that there is a pre-ordained system in the evolutions, and battles, and final triumphs of the Church. The history of that Church is symbolized in the life of its earthly head. Descending from heaven, its earthly birth is in the stable at Bethlehem; it goes on doing good, and spreading a hallowed influence around it, in lowliness and comparative obscurity; and in the conflict in which it seems defeated it gains its greatest triumphs, and when it seems buried out of sight it rises and reigns for ever.

In the Sections which follow, I am about to shew that Revelation is systematic throughout. After this has been done, the reader will be in a better position to appreciate the advantages arising from this mode of procedure. At this place it will be enough to indicate them in rude outline. The systematic character of the alleged revelation, its close connexions, and its varied relations to God and to man, enable us to establish with more ease and certainty, that it is a real revelation of God. The general supernatural character of the revelation also takes out of the region of the natural a number of 
events which we could not certainly pronounce to be miraculous, unless from their connexion with the system. The whole becomes more comprehensible by the mind of man, which seeks after the correlations of things, when we see somewhat of the plan of the procedure and the ends contemplated. Nor is it a small advantage of the orderly character of the revelation of God, that when we apprehend it, we are able at once to set aside certain pretensions to supernatural action-just as the naturalist, from his acquaintance with the homologies of nature, at once turns away from the stories about the unicorn and the sea serpent. Nor is it to be omitted, that as the knowledge of natural laws gives us prescience, and enables us so far to anticipate the future, so the systems of types, of prophecy and doctrine, and the general laws of the spiritual economy, open far ranging views of the coming destiny of our world, and give us glimpses through the rolling mists of the world to come. 
SECT. II.-THE TYPICAL SYSTEM OF REVELATION.

Every man of science knows that there is a system of types in nature. Tracing it from the geological ages down to the present time, we find it characterized by several marked features.

First, there is a set of agencies in nature producing orderly results. We see this even in inanimate creation, in the spheroidal shapes of the planets, in the elliptic movements of the bodies moving round the sun, and in the motions of the stars through space. We may perceive it on the earth, in the regular crystalline forms which minerals assume, and which bring them under rigid mathematical laws. Every one may observe it in the forms of plants and animals, and in the cycles which they run as they advance from their germ through settled stages to their maturity, and then die and disappear. The cell out of which the whole structure is formed has its regular shape and constitution. Every member has its model form; the stem in the plant, the bone in the animal, being typically a column enlarged at each end. Every organ of the plant, be it leaf, or branchlet, or root, is made to take its own form, and there is a typical shape for each of these in every species of plant. There is, likewise, a model for erery vertebra in the 
backbone, and for every limb of the animal. By the combination of the several typical parts, the whole plant and animal is also made to take a general typical form, which allies it with the members of the organic kingdoms, and a special typical form, which distinguishes it from all others.

Secondly, the agencies at work produce a series of orderly results in succession, each growing out of others antecedent. It is thus that we have the "herb yielding seed, and the fruit tree yielding fruit after his kind, whose seed is in itself after his kind," and the animal begetting an offspring after its own likeness. It is thus that in the geological ages we have every epoch arising out of the preceding one, by causes natural or supernatural. Some have supposed that the whole can be accounted for by natural causes still operating, and have certainly explained much in this way, though they have hitherto failed to give any account of the introduction of the first organism, or of successive orders of plants and animals. Others have been more inclined to think that the production of new species of animated beings has proceeded from natural causes undiscovered, perhaps undiscoverable by man, and certainly not acting in the present state of things. Others at once call in a supernatural power to account for the pro- 
duction of every new species of living being. It is not needful for our present purpose to take any side in this controversy, except to declare that natural causes certainly seem utterly incapable of producing such a being as man, and that the statement of Scripture that man was created by a special act is in full accordance with the facts of science. It is certain on all the theories that, by an agency of God, natural or supernatural, one state of things has arisen out of another; part of the causes, those bearing on the inanimate portion of the earth, being allowed on all hands to be natural, and the whole being resolved, on every hypothesis, by the religious man, into the counsel of God. Coming down to the human and historical period, we find the present state of things to be the issue of all that has gone before. Thus the civilization of these times is the product of a long series of causes, among which we must place the learning and refinement of Greece and Rome, which again were influenced by still older and eastern states of society. We get only glimpses of the order of the geological epochs, and of the very complex march of historical events, and there is quite as much need of restraint as of encouragement being bestowed on the rash theories which are being promulgated to account for the whole process. But we see enough to convince us that 
there is a pre-ordained geological, and, we may add, social plan, in which the present has a relation to the past, and proceeds out of it according to the arrangements of an all-wise counsel.

Thirdly, natural agencies produce a succession of results in which there is progress. For there is certainly a law of progression, and of development too, in the mundane system. Speculators, indeed, have often misinterpreted and perverted it, some setting aside all Divine agency in favour of mere physical causation, and others admitting God only pantheistically, as acting in nature but not above it. Still there has been, and there evidently still is, an advancement from the lower to the higher, and the springing of a farther stage from a simpler state of things. Geology shews an advance, from seaweeds up to the plants yielding the richest fruits and to the trees of the forest, and from zoophytes up to quadrupeds and to man. In our own epoch the discoveries of science and the inventions of art are new powers added to help on the advancement of the race; and they make the ground yield a larger produce; and they give to human beings a greater power over the elements; and they increase the number of rational creatures in proportion to the irrational; and they provide a better sustenance for man's wants; and they 
lessen disease and prolong life; and they help on our advancement in knowledge and refinement. All this is evidently predetermined by God, for it is palpably the result of agencies which he has instituted.

Fourthly, there is a still more peculiar element in the typical system of nature-the earlier is a sort of prefiguration of the later. The seed contains what is to become the full-grown plant. The embryo has already what is to expand into the full-grown animal. The earlier geological ages shew rude types, with capacities which become developed only in the more finished forms of later vegetable and animal life.

The language of our two greatest living naturalists cannot be too frequently quoted as to the prophetic plan of nature. "It is evident," says Agassiz," "that there is a manifest progress in the succession of beings on the surface of the earth. This progress consists in an increasing similarity to the living fauna, and among the vertebrata especially in their increasing resemblance to man. But this connexion is not the consequence of a direct lineage between the faunas of different ages. There is nothing like parental descent connecting them. The fishes of the Palæozoic age are in no respect the ancestors of the reptiles of the secondary age, nor does

* Agassiz and Gould's Comparative Physiology, p. 147. 
Man descend from the mammals which preceded him in the tertiary age. The link by which they are connected is of a higher and immaterial nature; and their connexion is to be sought in the view of the Creator Himself, whose aim in forming the earth, in allowing it to undergo the successive changes which geology has pointed out, and in creating successively all the different types of animals which have passed away, was to introduce man upon its surface. Man is the end towards which all the animal creation has tended from the first appearance of the first Palæozoic fishes." The language of Owen is equally explicit*:- "The recognition of an ideal exemplar in the vertebrated animals proves that the knowledge of such a being as man must have existed before man appeared; for the Divine Mind which planned the archetype also foreknew all its modifications. The archetype idea was manifested in the flesh long prior to the existence of those animal species that actually exemplify it. To what natural laws or secondary causes the orderly succession and progression of such organic phenomena may have been committed, we are as yet ignorant. But if, without derogation of the Divine power, we may conceive of the existence of such ministers, and personify them by the term 'Nature,' we learn - On Limbs, p. 86. 
from the past history of our globe that she has advanced with slow and stately steps, guided by the archetypal light amidst the wreck of worlds, from the first embodiment of the vertebrate idea under its old ichthyic vestment, until it became arrayed in the glorious garb of the human form."

Let us inquire whether there may not be something analogous to all this in the dispensations of grace.

I. There is an order and a method in the supernatural dispensations of God. - In nature there is a uniformity of composition and structure, and a unity of aspect, which enable the experienced eye to distinguish at once between the works of God and the works of man, between the actual phenomena of the world and the creations of human phantasy. There is a like unity in the revelations of God. From the beginning, they appear as an announced provision for saving a people from the effects of the fall, through a Deliverer sent from heaven, but tabernacling on the earth. This idea, without being fully unfolded, runs through all the dispensations of the Old Testament, is embodied fully in the work and death of Jesus, and is declared categorically by the apostles in their epistles. This gives a unity to the doctrine-it all hangs on the circumstance that God has provided a ransom for sinful man; a unity to the events of prori- 
dence-to the deliverances, for example, wrought for God's people in successive ages; a unity to the ordinances and worship,-they invite us as sinners to approach God, propitiated by an atonement; a unity to the very characters set before us for contemplation,-they are all justified by free grace, and they walk by faith, and are seeking to become holy.

II. One dispensation rises out of another. In geology there are mineral, but more especially fossil characteristics, which enable us to group the strata into systems. If we compare the older with the later, we find them differing very widely from each other-thus we seek in vain below the Tertiary Formation for any species of animal now living. But on the other hand, we discover a unity of type running through the whole series, and if we compare the immediately successive formations, the differences do not appear so great, and farther research is tending to fill up the breaks. There are, in like manner, systems or economies in the supernatural dispensations, as revealed in the Word, such as the antediluvian, the patriarchal, the Mosaic, the prophetical, consummating in the Christian. There is, no doubt, a vast difference between the light enjoyed by us in Christian times, and that vouchsafed to the patriarchs, indeed, to any who lived before Christ-" he that is least in the kingdom of 
heaven" is greater than the most privileged of those who lived in these early times. In the palæozoic times, if we may so call them, patriarch and prophet have an antique aspect, and a stiff and rigid shape, compared with the more flexible forms of life in Christian times; but there runs a unity of type through the whole doctrine and all the characters, and the one system ever. slides into the other. We can see that the Christian dispensation, though an advance, grew out of the Jewish, and how the Jewish sprang from an older economy.

III. There has been progress in the religious systems. In geology there have been fanciful, and falsc, and atheistic theories of development; but there is, after all, a true doctrine, and this whether men have or have not been able to seize it. With not a few partial breaks and anomalies, there has been an advance from the lower vegetable and animal to the higher; and also an advance from the more general and rude to the more specific and adapted; from a loose life spread over the organism to a more localized and intense life; from organs suited imperfectly to many purposes, to organs fitted admirably for more special ends; from rude instruments of defence and attack, to a more refined apparatus for preservation; from vague to more peculiar instincts; from instincts which go on blindly to 
a purpose, to instincts which ean vary the action to suit the circumstances, and on to rudimentary reason. There is a parallel advance in religious knowledge and spirituality in the reign of God, as a system introduced into our world. It is the same God that is revealed in the Book of Genesis, in the Book of Isaiah, and in the Epistles; but surely he is more fully disclosed in the last of these than in the two previous, and in the second than in the first. It is the same method of reconciliation made known to fallen man in the sacrifices of Abel, of Noah, of Abraham, and of the Levitical institutions; and again in the life and death of Christ, and the commentary on the whole, which we have in the Epistle to the Hebrews; but in the former the figure is veiled, and we see only the general form, whereas in the latter it is fully unfolded to our view; in the former it is seen in the dawn ere the sun rises, in the latter under the light of day. The morals of the Old Testament and the New are fundamentally the same; but in the former they take a more prohibitory and minutely technical shape than they do in the Sermon on the Mount, where our attention is called not so much to the form as to the spirit which animates it. There was an advance in the knowledge. of the disciples, from the time of their early pupilship, when they shewed such 
ignorance, and fell into such blunders, down to the time when they were guided unto all truth by the Spirit. It may even be admitted, under certain restrictions, that there is development in the Christian Church. There is, indeed, no addition to the truth revealed, no change in the rule of faith and morals. But surely we who dwell in these later times, with all the lights kindled by those who have gone before, and specially with the beacon lights kindled on the rocks on which many have been shipwrecked, are in better circumstances to appreciate the full spirit of the Word; and it is certain that the knowledge of Divine truth is every year covering a larger portion of the earth's surface.

IV. There are prefigurations in the supernatural dispensations. In particular, there are events, institutions, and persons that look forward to Christ and to Christ's day. These constitute what is usually called Scripture types by theologians. But the typical system of the Word of God is of a vastly more comprehensive character than divines have conceived it to be. In order to determine its precise nature, and to illustrate the whole subject, it will be needful to inquire somewhat minutely into the meaning of the phrases by which this peculiarity of the Divine dispensations is set forth by the writers of the New Testament. 
In the Word of God the phrase "type" and

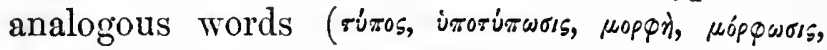

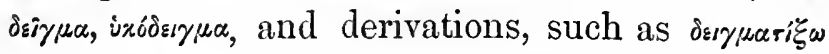

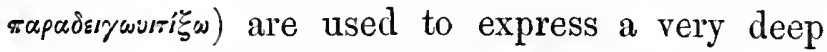
idea running through the whole Divine economy resembling the "idea" (ios a and $\varepsilon^{z} / 0$ s) and the

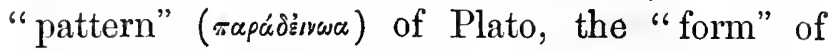
Aristotle ( $\varepsilon^{\prime}(0)$ s), borrowed from him by the schoolmen, by Bacon, by Kant, and logicians generally, the "law" of modern physical science, and the "type" of natural history. This meaning has been very much lost sight of by divines, in consequence of their constructing a system of theological (so they avow) instead of a system of Scriptural types. The words I refer to signify literally a form, likeness, specimen, or image. They are employed in Scripture to set forth a great truth, which has seldom been seized in all its width or in all its particularity. They denote that, in the spiritual economy of God, things are fashioned after a pattern, just as the natural sciences have shewn that there are types or model forms all throughout the works of God.

Taking the word type (rurros) and its compounds, we find it used in its literal sense, as when the Apostle Thomas declares, "unless I shall see in his hands the type of the nails, and thrust my hand into his side, I will not believe" (John xx. 25). The children of Israel are repre- 
sented as taking up in the wilderness " types or images of Moloch and Remphan, gods whom they worshipped" (Acts vii. 43). Becoming somewhat more metaphorical, Claudius Lysias is spoken of as writing a letter after the "type" or manner that follows (Acts xxiii. 25). Moses is commanded to make the tabernacle of witness " according to the type that he had seen" (Acts vii. 44). Paul tells us that Moses, when he was about to make the tabernacle, was commanded to make "all things according to the type shewed" him in the mount. (Heb. viii. 5.) Turning to the passage in Exodus, we find that the word used is "tebegit," meaning form or exemplar, and it is translated

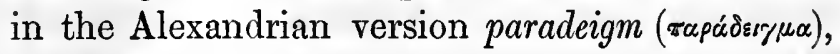
the very word so often employed by Plato. Paul represents the first man as a "type of him that was to come" (Rom. v. 14). The same Apostle speaks of believers everywhere, as being examples or types to others. Thus the Thessalonians are described as "types to all that believe in Macedonia and Achaia" (1 Thess. i. 7). He exhorts the Philippians, "be followers together of me, and mark them which walk so as ye have us for a type" (Phil. iii. 17). He speaks of himself as working with labour and travail night and day, that he might not be chargeable to any, in order to "make ourselves a type to you to copy" (2 Thess. iii. $\delta$ ). Jesus Christ is represented 
as shewing forth in Paul, "all long-suffering for an under-type (irrorixwors) to them which should hereafter believe on Him to life everlasting" (1 Tim. i. 16). Peter exhorts elders to be "types to the flock," and points to the chief Shepherd as about to give the reward when he comes (1 Pet. v. 9). There are said to be types not only of persons and of character, but of doctrine. The Roman believers are spoken of as "having obeyed from the heart that type of doctrine which was delivered" them (Rom. vi. 17), and Timothy is exhorted to " hold fast the undertype (ivóruxwors) of sound words which he had heard of Paul (1 Tim. i. 13). There are said, too, to be types in the administration of God in punishing the wicked, as when he overwhelmed those that sinned in the wilderness. "These things were our types, that we should not lust after evil things as they also lusted," and the Apostle adds: "All these things happened unto them for types, and they are written for our admonition, upon whom the ends of the ages are come" (1 Cor. x. 6, 11).

Other phrases are employed to present the same general truths. Thus Sodom and Gomorrha, and the cities about them, are "set forth as a sample ( $\delta \varepsilon \bar{\gamma} \mu \alpha)$, suffering the vengeance of eterual fire" (Jude, verse 7). It is said of Christ that having by his cross "spoiled principalities 
and powers he made a sample of them ( $\delta \delta \varepsilon \gamma \gamma \mu \alpha \dot{r} ı \sigma v)$, openly triumphing over them in it" (Col. ii. 15). Paul says of the priests that offer gifts according to the law that they serve "unto the exemplar

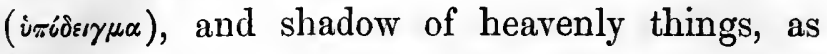
Moses was admonished of God when he was about to make the tabernacle, for see, saith he, that thou make all things according to the type shewed thee in the mount" (Heb. viii. 5). The same apostle, speaking of those who rebelled in the wilderness, exhorts us to labour to enter unto rest, "lest any man fall after the same example ( $\dot{\pi} \pi \delta \delta \varepsilon \gamma \mu \alpha)$ of unbelief" (iii. 11). Using the same word, Peter speaks of the overthrow of Sodom and Gomorrha as " an ensample unto those that after should live ungodly" (2 Pet. ii. 6). James employs the same phrase when he exhorts us to take "the prophets who have spoken in the name of the Lord for an example of suffering affliction, and of patience" (v. 10); and our Lord says, "I have given you as an example that ye should do as I have done to you" (John xvii. 15).

Man is everywhere represented as made after

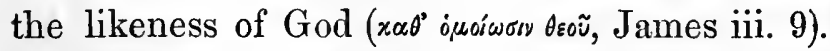
Jesus Christ is represented as being made in the

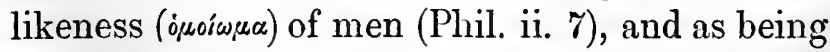
sent in the likeness of sinful flesh (Rom. viii. 3). The Apostle Paul often brings out the analogy between Christ's crucifixion and death and his 
people being crucified and dying unto sin, and between his resurrection and continued life and their conversion and spiritual life. In particular, "If we have been planted together in the likeness (ijuoiwua) of his death, we shall be also in the likeness of his resurrection" (Rom. vi. 5).

Christ Jesus is represented as being "in the

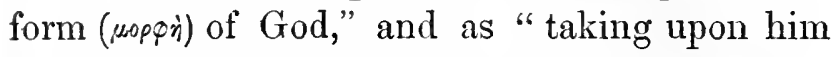
the form of a servant," and "made in the likeness of man," and "being found in fashion (бxinuarı) as a man" (Phil. ii. 5). Paul addresses the Galatians as his little children, of whom he travails in birth again, " until Christ be formed or figured" $(\mu \circ \rho \varnothing \omega \theta \tilde{n})$ in them (Gal. iv. 19).

Jesus is said to be "the image (six $\left.\dot{\omega}^{2}\right)$ of the invisible God" (Col. i. 15), and to be the "brightness of his glory, and the very figure ( $\chi$ apaxrìp) of his person" (Heb. i. 3). Those whom God foreknew " he predestinated to be conformed to the image (eir.ury) of his son, that he might be the first-born among many brethren" (Rom. viii. 29). Paul, speaking of believers, says, "we all with open face beholding, as in a glass, the glory of the Lord, are transformed into the same image

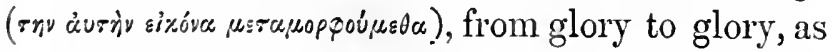
by the Lord the Spirit" (2 Cor. iii. 18). Again, "As we have borne the image of the earthy, we shall also bear the image of the heavenly" ( 1 Cor. xv. 49). 
The New Testament represents the prefigurative system of the Old Testament as the shadow (oxsa) of a coming substance. Paul speaks of the Old Testament ordinances as a "shadow of good things to come, but the body is of Christ" (Col. ii. 17). The priests under the law are described as serving "unto the example and shadow of heavenly things," that is, of Gospel things (Heb. viii. 5). There is a distinction drawn between the shadow and the image (six the "shadow," and not the "very image" of the things (Heb. x. 1).

I have placed these passages together, that we may have before us at once a full view of the typical doctrine of the word of God, of which Divines, from neglecting to look at the meaning of the words, have formed very imperfect notions. There is more here than the prefigurations of which so much is made by theologians, who, in overlooking the fundamental truths, have missed the ground on which the real prefigurative system of the Word of God proceeds. According to the Scripture account there are, first, model or pattern forms, which are always to be traced up in the last resort to God himself, to perfections of his, or devices of his wisdom. We have such in man as he came forth in the image of God; we have such in the laws of his retributive justice in punishing the wicked; we have 
such in the great deliverances wrought for the Church; and we have them, above all, in Jesus Christ, in his person, and in his work. Secondly, there are objects or events constructed after these patterns, by a set of agencies natural or supernatural, and they run on in a series ever repeated, like a family likeness going down from one generation to another. From these two circumstances there springs a third-that there are, what I would call not types generally, but what I would call prefigurations or prefigurative types, that is, events and institutions pointing forward to others to come, in the case of the prefigurations of Christ to a great Archetype (not antitype*) in whom all the features of the model meet. We may always discover some one, and, at times, all of these in the types of Scripture.

1. There are in the revealed dispensations of God typical events, that is, events after a common and pre-ordained type. These relate generally to evil incurred, to a deliverer raised up, and a deliverance effected. There is a flood from which some are saved, by an ark built by one instructed for this purpose. There is a national bondage from which the people are rescued by a leader chosen and trained, and are at last conducted into

* Great confusion has been introduced into the whole subject of typology, by its being supposed necessary to discover an antitype opposed to every type. 
a rest prepared. There is a long series of conquests by, and subjections to, neighbouring tribes, and then liberty achieved by a person stirred up to drive back the invaders. There is a captivity, and at a predicted time a rescue and a return. All these great providential events had lessons for the times in which they occurred, and they have lessons for all times. They left deep impressions on the minds of the whole Hebrew nation, and they have created and fostered a set of far-ranging ideas, which have been handed down from generation to generation, by the record of the events. They still supply images, far more vivid and far more powerful than words, by which to think of great spiritual truths. We think of sin as a subjection, a slavery, a captivity, and of Christ as a deliverer, and his work as a deliverance.

2. There are typical ordinances, that is, ordinances after a pattern, and pointing as signs to spiritual truths. There were, from the very introduction of sin, appointed offerings which were presented, no doubt, partly as thanksgivings for mercies and acknowledgments of dependence, but were specially sacrifices of animals in which sin was confessed, and suffering acknowledged to he deserved, and faith expressed in a substitute. The worshipper never drew near to God, except through a mediating priest, and had to profess 
unworthiness whenever he came to ask blessings. In the Levitical institutions there were neverceasing ablutions, pointing to defilement contracted, and to the need of washing, and almost all things were purged by blood, shewing that it was by suffering and death that acceptance was to be secured, and sanctification effected. To let him know how it was that his prayers were to be accepted, the worshipper was to pray with his face towards the tabernacle or temple, and at the hour, morning and evening, when the lamb was being offered in sacrifice. When the people prayed without, the priest presented incense within the sanctuary, kindled by fire from off the altar on which the animal had been offered, to shew that there was need of a work to be transacted with God, proceeding on the sacrifice which had been offered. The grossly carnal, no doubt, did not discern the meaning of all this, and rested in the form without feeling the breathing spirit, and many, even of the spiritually-minded worshippers, may not have been able to expound the truth theoretically or doctrinally as we can do. But the ordinances left their impressions on the minds of the devout, and these the very impressions produced by the expository statements of the New Testament. The rationale of the instruction was not explained at these times, when the church was under tutors 
and governors, but the training did not the less bear its fruits. These were the objective means, -and I believe we can conceive of no better,by which a series of subjective ideas, having a deep place in our deepest nature, were evoked into consciousness, and developed into proper form, and propagated from soul to soul, and handed down in ever increasing precision from one age to another. He who would take away these truths from the Old Testament, would be tearing out the very vital organs which make the body to live, and breathe, and move.

3. There are typical men, that is, persons moulded on a pattern, and pointing to a chief pattern. This is a doctrine which may be so stated by friends or foes, as to make it look ludicrous. Yet it is not so unreasonable when it is properly apprehended. Natural causes operated, always under a providential arrangement, and along with spiritual and divine influences, to produce the mode of action and style of character which were thus representative. The events ordained by God, and among which his people lived, the manner in which they were taught by the ordinances to view and to worship God, and the whole experience through which they passed, must, of themselves, have fashioned a type of manner and spirit and conduct, quite as naturally as physical causes, and social and moral 
influences, fashioned the Jewish make and features. By agencies natural and supernatural there were moulded a series of men such as Noah, and Abraham, and Moses, and Daniel, after the model set before them, and bearing the image of the Coming One, to whom they looked, -it should be added, always in an imperfect, and often in a mutilated manner.

Thus understood, there is really nothing unreasonable in the idea of their being typical men, formed after the pattern copied by them, and so far exhibiting that pattern. No doubt it is a doctrine which may be made ridiculous, when fancy is allowed to run riot unrestrained by judgment, and resemblances are dwelt on which are mere coincidences, or which are created by the eye that is looking for them. It is wisest, and in every way best, in tracing the analogy between type and archetype, to keep to the general features which strike all, and strike at once, instead of going down into numerous and petty details. And in looking to the types we must never admire nor imitate the picture, excepting in so far as it has been faithful to the Great Original, on whom, and not on the mere copies, our eyes should mainly rest. If only we are guided by a constant respect for the Divine Word, and guarded by ordinary sense, it will be interesting, and may be profit- 
able, to contemplate certain of the excellencies of Jesus reflected from those who looked forward to him and to his day.

The type often runs on from the Old Testament into the New, and from the church on earth into the church in heaven. There was the rest of the Sabbath in Eden; there was the rest in Canaan after the wanderings of the wilderness ; and the Psalmist points on to a rest not yet realized (Ps. xcv. 11); from which the Apostle argues, as Jesus, i.e., Joshua, had not given. rest, that "there remaineth a rest to the people of God" (Heb. iv. 9); which rest is, first, peace of conscience in the peace-speaking blood of Jesus, then peace of heart in the pacifying power of the Spirit of Jesus, and the whole a foretaste and an earnest of the unending rest of heaven. In this sense there are types in the New Testament as well as in the Old, Jesus Christ being the archetype in both-with this only difference, that whereas in the latter the figures look forward to Him, in the former they look back to Him, as the grand central figure evidently the head and chief, and the source of influence and of interest. In particular, there is a correspondence or a parallelism between the life of Christ and the life of his people. They are associated with him in his very death,- they deserve death, and he dies for them, and they die in him; by 
his death they are delivered from the death which is the wages of sin, they are crucified with him, he dies for sin and they die to sin. There is a still closer connexion between the life that is in him and the life that is in them; the Spirit which raised Jesus from the dead quickens them; his resurrection is an earnest of their resurrection; the life that is in him flows into them; and because he lives they shall live also,having spiritual life in them as an assurance that they shall enjoy life with him for evermore. Eminent believers, who have drunk deeply of his Spirit, come thus to be types of him; they have his life in them; and they copy his example, and are being fashioned after his pattern, and are made ready to join his society in the mansions of his father's house in heaven.

It is the typical system of nature which, always with the sky above, is the main means of giving a unity to nature in our apprehensions. Wherever man goes on the earth's surface he finds, in the midst of an infinite variety, a sameness in the forms of plant and animal, of man and woman, which makes him feel that he is not in another world-that the New World is only the other half of the Old. In like manner, it is by the typical forms of the Word of God, always in connexion with the Archetype,-more than even by the consistency of doctrine,- that 
there is imparted a unity and a harmony to our religion in the ideas we entertain of it. Just as wherever we travel we discover that all mankind are of "one blood," with common laws of intelligence and common appetencies and sympathies, so we are made to feel that, with not a few individual and national differences, the Church is one in all ages and countries; that the New Testament is only the Old Testament in a more advanced form, and that its living members are all citizens of the same commonwealth and speak the same tongue. Separated as we are from them by long ages, we can enter into the experience of Abel as he offered his "excellent sacrifice;" of Abraham, as he walked by faith and as a pilgrim; of Moses, as he endured as seeing him who is invisible; of Paul, as he ever met with the "law in his members warring against the law of his mind ;" and divided as we are from them by wide oceans, we draw to our hearts, as brothers, the Christian of America, the Christian of India, the Christian of the South Seas, and the Christian of Africa. All these join us in singing the Psalms of David, and the spiritual songs of a host of writers for the last three thousand years, and, in doing so, they and we feel that we have the same trials and the same conflicts, the same encouragements and the same supports. The song of Moses is 
the same with the song of the Lamb, and those who have learned to sing it on earth will sing it in heaven.

Nor is it to be omitted, that these types give a vividness-like reality-to the Divine record; we feel as if we had seen the persons and mingled in the scenes and taken part in the transactions-not of late indeed, but at some far past time in our history; and as if in them we had laid up in our memory a set of photographs, which we can carry with us wherever we go, of persons and of objects which have interested us supremely. Not only so, the types supply us with a series of symbols, which, better than any words or phrases, enable us to think of great spiritual verities, - they are better images than the Romish Church supplies to its devotees, and not liable to the same objections-they are the cherubic figures of the New Testament representing redemption and the redeemed; and we still and habitually contemplate Christ's piacular work under the image of a lamb offered in sacrifice, and of his saving power under the image of the serpent raised for the healing of the wounded. 
SECT. III.-THE SYSTEM OF PROPHECY.

A prophet, in the language of Scripture, is one who speaks to us in the name of God. "The word of the Lord" comes to him, and he is authorized to announce, "Thus saith the Lord." $\mathrm{He}$ may have to compile an authentic record of facts in which the interests of the Church are involved, or to reveal a new and hitherto unknown truth, or to put forth an exhortation, or utter a warning, or predict an occurrence in the distance.

There was doubtless a providence in the raising up of prophets in the Old Testament Church. They do not appear at every time, they come in at the appropriate season to discharge their burden. They are often very visibly fitted, by their natural gifts, for the special task they have to accomplish. It is so with Moses, both as an actor and as an author; the training through which he passed has given him large experience of mankind, and, along with spiritual influence from above, has subdued the natural keenness of his temper, and prepared him for bringing that vast multitude out of captivity, and for legislating in their behalf and bearing with their provocations; while his style is suited at once for narrative and for the highest poetry, being usually simple 
and pure, but fitted to rise and swell with the grandeur of the theme. Does God wish to secure favour for his people at the courts of princes, he raises up such men as Joseph, and Daniel, and Nehemiah, in whom the loftiest wisdom was softened by gentleness and courteousness of manners. Does he purpose to scourge wicked kings and a degraded people, he summons to the work an Elijah, whose emblem was the fire which he so frequently wielded. Is it his counsel to rouse a self-righteous people from slumbers which are like unto death, he raises up the Baptist as "the voice of one crying in the wilderness." As with their natural gifts and character, so also with the predilections of their age and country, they are sanctified and not destroyed. There is, indeed, a higher and supernatural power of inspiration working in them, revealing to them what they could not otherwise have known, imparting to them a power beyond their natural endowments, and protecting them from error into which they -might have fallen. Still, the higher and the supernatural does not destroy the lower and the natural-which supplies the wires along which the heavenly power moves. The prophet is, after all, a man of his own time, speaking to the men of his age in the spirit and in the language of his country. What he delivers is indeed from 
God,- - che claims our attention to it on this ground, and our Lord so speaks of it,-but it is also from himself, it comes out from his own mind and breast. The prophet can say, "The hand of the Lord was upon me," "I was in the Spirit and heard," "The Spirit of the Lord came upon me;" but it can be said quite as truly, "as is written in the book of Esaias the prophet," "Then was fulfilled that was spoken by Jeremiah," as " speaketh our beloved brother Paul in all his Epistles." It is the shepherd boy, now a king, who speaks with such spirit in the Psalms; it is the gatherer of sycamore fruit who unrolls his burden in Amos; it is the Jew, brought up at the feet of Gamaliel, but with a dialectic skill called forth in Tarsus, a city of no mean reputation for philosophy, who writes to the cities which had been stimulated by Greek culture; while it is the Apostle that had leant on Jesus' bosom, who closes the Canon by alluring us to dwell at once on the object whom he loved and whom he would have us to love, and by opening to us, through vision and symbol, glimpses of the future. The breath of heaven plays down upon an instrument fashioned on the earth. How the two were conjoined, the natural with the supernatural, I believe the prophets themselves were not able to declare,-any more than we are able to tell how our souls are super- 
induced upon our bodies, or how our vital ener. gies work with the mechanism of our frames.

We cannot rise to an intelligent comprehen. sion of the Scriptures of the Old and New Testaments unless we look at both these aspects. If we do not acknowledge the Spirit of Inspiration throughout, we cannot know what is truth and what is error, we have no standard and no ultimate test. If the reader's own spirit is made the test, and constituted a "verifying" faculty, this leaves him to take what pleases and to reject what displeases,-to take the doctrine and reject the morality, or to accept the morality and omit the high truths on which it is founded; or to grasp at one doctrine and leave out the others - say to take the unity but repel the trinity of God; or to prize one set of preceptssay all that relate to outward morality, and dispense with those which enjoin humility, repentance, and purity of heart. But while we discern everywhere the Spirit of the Lord, we must be wilfully shutting our eyes if we do not also observe the spirit of the prophet, nay, the spirit of his country, the spirit of his age, possibly the spirit of his profession, and the spirit of his time of life. Every one discovers the difference between the mode of writing in the Psalms and in the Proverbs, in the prophecies of Isaiah and of Jeremiah, in the Epistles of Paul and of John. 
We see that it is a warrior who writes in many of the Psalms ; a man of rank, wearied with the world, of its show and its pleasures, who utters his experience in the Book of Ecclesiastes; a patriot, overwhelmed by his country's desolation, who pours forth his sorrows in the Lamentations; and an active worker and an active thinker, full of a great cause and engaged in a hard struggle, whose mind is labouring in the Epistles to the Geutiles. There is evidence in every page of the New Testament, that it is the Jew that writes and not a Greek or a Roman. The prophet is throughout a man of his age and his country; and in respect of astronomy, and chemistry, and geology, and political economy, and psychology, no way beyond his time,-except that he is kept from positive error in his utterances. Verily, all thinking men would be made infidels, were they compelled to believe, in spite of what they see so obviously, that God speaks in the Word independent of the natural agent.

It was by thus employing human beings as his messengers, that God secured that the prophets spake to the men of their generation and their nation. They found valuable records of what God had done for his people, or they got declarations from trustworthy witnesses of memorable events, and they proceed to draw them out in 
order, in their own style, and to suit the men of their age, being always guided in their selection of facts, and saved from errors on the right side and left, and quickened throughout by a higher spirit. Or they felt keenly the evils prevailing in the Church around them, their righteous souls were vexed from day to day by the unlawful deeds that were committed, and they sighed and cried for the abominations which were done in the midst of them, and out of the abundance of the heart the mouth spake, and they unrolled their complaint as a burden that weighed terribly on their souls. Or they saw that their erring and smitten countrymen needed encouragement in their disasters, in their slavery, or in their banishment, and they rejoiced to place before them the new hope which God condescended to raise up as a light in the darkness. It is most interesting to us to observe the human working with the Divine; the human, as the lower, being always subordinated to the Divine, as the higher and the authoritative. It is quickening to us to feel, that when God speaks, as he every where does in his Word, it is through a human and not an angelic messenger, and that it is in human speech, coming through the operation of a human understanding, and from off a human heart, and is thus received by our ear, by our understanding, and our heart. It is in- 
structive, withal, to have the truth presented in such different lights, and under such varied aspects, as it is reflected from the men and their times and their country; and as we examine it, to discover the higher and ever higher place allotted to the moral and spiritual, compared with the sensible, the symbolic, and ceremonial, till we reach the brightest and purest revelation in the person of Christ, and in the doctrines of his apostles.

Sometimes the instruction was uttered orally, and it spread from one man to another,-as intelligence travels, often with amazing celerity, in countries in which written or printed communications are unknown; and it was handed down as a precious legacy from one generation to the succeeding. From the very institution of the Hebrew commonwealth at Sinai there was a body of Levitical scribes, whose office it was to give instruction to the people, old and young; and from the time of Samuel, there was a special "School of the Prophets," who proclaimed the will of God in a more public manner. But every one knows how truth becomes corrupted as it passes thus traditionally to distant regions and distant ages; and so we have from an early date, from the time of Moses, the lively oracles of God committed to writing; and the volume, at first small but with most 
precious contents, gets additions at irregular intervals, till now we have a book as large as the common man can well master, and with a body of truths quite sufficient to exercise the deepest thoughts of the deepest thinkers. This teaching, like everything else in the natural and spiritual providence of God, is progressive, it is a seed springing, expanding, and ripening. The teaching of the early times is for the benefit of later ages. The pupils of one age become the teachers of the next, and add their own acquisitions to the stock of knowledge which had been received by them, and the whole goes down the stream of time as a gathered and accumulated freight. Ideas are kindled by symbols, and great providential events, and deeds of faith and selfsacrifice, and are passed like torches from hand to hand. By the "gifts and sacrifices" under the law, the ideas of gratitude and devotedness to God, the ideas of $\sin$ and atonement were stirred up and kept alive. By great historical occurrences - such as the deliverance from Egypt and the restoration from the captivity of Babylon, the idea of a salvation from the condemnation and slavery of sin was raised up and made to float through ages, till it was fully realized in the life and character and work of Jesus. All this revelation, from its commencement in Genesis to its close in Revelation, has been preserved to 
us as the wisdom of divers ages and men and nations, as well as the wisdom of God, for "holy men spake, being borne or carried ( $\left.\phi \varepsilon \rho^{\prime} / \mu \varepsilon v 0 r\right)$ of the Holy Ghost" (2 Pet. i. 21).

Such language implies that the Scriptures are, throughout, the work and the Word of God. It is God who speaks by his prophet, "Well spake the Holy Ghost by Esaias the prophet" (Acts xxviii. 25). Paul, writing to a minister who was to expound it, says expressly, "All Scripture is given by inspiration of God" (2 Tim. iii. 16). This language is not to be so stretched as to imply that the writing of the Scriptures was supernatural throughout, for in that very Word the natural, so far as it is not sinful, is described as the operation of God, as Elihu says, "There is a spirit in man, and the inspiration of the Almighty giveth him understanding" (Job xxxvii. 8). But the statement assuredly carries with it that the Bible is free from error; for error never can be the work of God, or come from the inspiration of the Almighty.

Coming now to that branch of prophecy which is predictive, we find that it, too, is of the nature of a system. It appears, like every living thing on the earth, at first as a seed or germ, which is evidently to grow into a living organism; but the wisest man cannot very well tell what is to be the special form taken by it. All that we 
can gather from the first prediction is, that One sprung from the human race is to appear and to remedy the effects of the fall, and crush the very head of the Arch Enemy, while he himself is to suffer in the contest; and that there is to be an enmity throughout the world's history between two manner of people, the seed of the woman and the seed of the serpent (Gen. iii. 15). It is not to be supposed that we have transmitted to us every revelation which God was pleased to make to the early Church; what is handed down may be taken as specimens of the remainder. The predictions were like the heads of families in these times, who were the progenitors of a numerous seed, to whom they left their name, their privileges, and their wide possessions. A new germinating promise or prediction-like a new species of plant or animalis deposited at every great crisis of the Church, when a new formation (to use a geological phrase) is being introduced, or when hope might be extinguished by threatening evils. It is when the traces of the flood are yet upon the earth, and the fear of the recurrence of a similar catastrophe is oppressing the mind, that the assurance is given that waters shall never again sweep away the inhabitants of the world (Gen. ix. 11). It is when the visible Church is being narrowed into the one family of Abraham, that 
in the very foundation of the structure then reared there is deposited the truth that his seed was to be a blessing to all the nations of the earth, who are therefore once more to be embraced within the commonwealth (Gen. xxii. 18). When Jacob is dying in a strange land in which terrible oppressions are about to come on his descendants, this hope is kept up by his assuring them of a Shiloh who was to gather the people to himself (xlix. 10). When the children of Israel are constituted into a commonwealth, and are about to be settled in the land allotted to them, a new series of budding promises, with far-ranging warnings of judgment, are announced to them, with the special assurance of a prophet after the type of Moses, who shall exercise authority and command attention (Deut. xviii. 15, 18). In the comparatively settled state of things which succeeded, it does not appear that the harp of prophecy uttered any new prediction. But from the time when the state has reached its highest worldly prosperity under David, down through its declensions, divisions, and scatterings, till the people once more have a settlement in their land, there is a series of predictions at once comprehensive and minute. In the time of their great warrior king they relate specially to a kingdom to be established in the family of David, but of a far higher character than any 
temporal sovereignty, there being at the same time intimations not a few, that the throne is to be reached through suffering and blood. From the time of Hosea and Amos in Israel, and of Joel and Isaiah in Judah, there are distinct announcements of the dissolution of the existing kingdoms as a punishment of their wickedness, but only that the prophets may exhibit in a brighter light the unending reign of peace that - was to follow. When the Jews were led into captivity, they carried their predictions with them, and these formed a bond of national union and a ground of hope, and allured a body of people to return to their land in very discouraging circumstances; and to them, as they rebuilt their temple and reared the walls of their commonwealth, encouragements were held out by Haggai, Zechariah, and Malachi, sufficient to keep the nation in a state of waiting and expectation. Again, there is a period of four centuries in which there is no new supernatural element introduced; but as things take their natural course, a soil is formed out of which the Messiah comes, as "a root out of a dry ground." The long-expected One rises at the appointed time, like the sun upon the earth, but evidently not from the earth. The predictive portion of prophecy thus forms a system, rising like a river from a fountain, and augmented at irregular dis- 
tances by stream after stream as it moves on,and we may add, going out (as we shall see forthwith) as gradually by many mouths. We cannot understand prophecy at all, unless we view it in this its complex structure and varied adaptations, unless we bear in mind in particular, that the doctrinal, the preceptive, the promissory, and denunciative parts are indissolubly interwoven with the predictive parts, unless we observe that the utterances are brought out or occasioned by contemporaneous natural occurrences, and that they had a meaning and a lesson to the generation of men to whom they were first delivered, and that the prediction was a gradual rolling on of threads of anticipation,even as the fulfilment (as we shall see immediately) is a gradual rolling off from age to age of a web of accomplishments.

The prophet is a man of his time, and is consequently the better able to speak to the men of his time. It is Jacob speaking to his children, as he dies in a strange land; or Moses, ere he leaves the people whom he had so long guided, giving his last warning and blessing; or it is David raised from following the ewes to a kingdom, and seeing a far more glorious kingdom in the future. In the ages when the commonwealth has culminated and is visibly declining towards a troubled evening, there is a wild and a plaintive tone 
mingling with the more cheerful notes in the song which the prophets sing. They have a woe to unburden; they have a judgment to denounce upon Israel or upon Judah, as it becomes bold in its idolatry and its rebellion; or it is the burden of Nineveh, or the burden of Egypt, or the burden of Babylon, or the burden of Tyre, or the burden of Edom, as each of these in its turn oppresses the children of Israel, or threatens to crush and extinguish that church which is the hope of the world. The spirit of the prophet is deeply moved as he sees his countrymen forsaking the true God for the worship of idols, and leaning upon other arms than the power of God, and he pours forth his denunciations with an earnestness which obviously comes from his deepest heart, but, at the same time, with minuteness of detail and incident, which, when we compare it with the fulfilment in after ages, shews clearly that his eyes had been supernaturally opened to look into the far distant future (Deut. xxviii.; Jer. xv. 4, xlvi. 13, 26 ; Ezek. v. 15). It is when Nineveh is threatening the liberties, and the very existence of God's people that Nahum utters his denunciation-"What do ye imagine against the Lord? he will make an utter end; affliction shall not rise up the second time. For while they be folden together as thorns, and while they are drunken as drunkards, they shall be devoured as 
stubble fully dry;" and again, "the gates of the rivers shall be opencd, and the palace shall be dissolved;" "the gate of thy land shall be set wide open unto thine enemies; the fire shall devour thy bars" (Nah. i. 10, ii. 6, iii. 13). It is when the children of Israel are going down to Egypt for help, that Ezekiel proclaimed, "And the pride of her power shall come down," "and her cities shall be in the midst of the cities that are wasted" (Ezek. xxx. 6, 7). It is when Babylon is rising into power, or when her power is at its height, and Judah is completely at her mercy, that one prophet after another pronounces her doom (Isa. xiii.; Jer. l., li., \&c.). It is when Tyre is at the summit of its commercial greatness and wealth, and alluring the children of Israel to idolatry, that Ezekiel declares "For thus saith the Lord God, when I shall make thee a desolate city, like the cities that are not inhabited, when I shall bring up the deep upon thee, and great waters shall cover thee" (Ezek. $\mathrm{xxv}, \mathrm{xxvi}$ ). At the very time when Petra seemed to be an impregnable stronghold, and was an emporium of commerce, its desolation was foreseen by more than one prophet (Jer.x. lix.; Ezek. xxxv., \&c.). The prophecy flows ever out from the bursting or bruised heart of the prophetas incense does from the crushed plant, or blood from the wounded body; and it had a 
lesson of warning or of encouragement to the men of the prophets' times, as the fulfilment of it has a similar lesson to us and the men of all times."

All this does not prove, or tend to prove, that the predictions are merely the natural utterances of the roused spirit of the prophet; it simply shews, that God had prepared by natural means the instrument into which he was to breathe, and from which he was to bring forth such strains of exultation or of plaintiveness. In using thinking and feeling men as his agents, God does not destroy their intelligence and moral feelings, or extinguish their deep aspirations, but rather allows to all of them active exercise and play, with a full outflow and outburst. In speaking by his servants the prophets, he speaks not only by their mouths, but by their hearts, burning with indignation against sin, and with zeal for the Lord God of Hosts. When the kings went down to Elisha to consult him, he said, "Bring me a minstrel, and it came to pass when the minstrel played, that the hand of the Lord God came upon him." It is upon the spirit of his servants, roused by a hatred of sin and a love of God more than ever they were by

* It is scarcely necessary to mention that the congruity between the prediction and the time at which it was uttered, is beautifully brought out in "Davison's Discourses on Prophecy." 
the strains of the minstrel, that the Spirit of God comes and they prophesy. But it is the Spirit of God that speaks through them after all, as is proven by the nature of their utterances, so full of God, so characterized by high moral aims, and by the fulfilment of their predictions, corresponding in all cases to the general tenor, and coming down in innumerable cases to the very letter, of the prediction.

But, in order to understand the accomplishment, we must keep in view that there is also a systematic development and an adaptation in the time and manner in which the events are evolved. The predictions are never of such a character that they might enable any individual, or combination of individuals, either designedly to fulfil them, or successfully to thwart them. The accomplishment has almost always been brought about by pure natural agents, or by persons unconscious that they were serving any such purpose; in many cases, by partics seeking rather to stay or frustrate them, as when the Jews fulfilled the predictions concerning Jesus in putting him to death (Acts xiii. 27). The prophecies, as for example, those regarding the final spread of the Gospel, are never so constructed as to encourage those who read them, so to see the future that they may give up action, and idly wait for what they know must come 
with or without their exertion. The event, when it occurs, is brought about by the usual course of things, but arrives in so incidental a manner as to shew that no human sagacity could have foreseen it; and with such an accordance between the words of prediction and the occurrence as to prove that the prophet had got a glimpse of it down to its very details, by light from heaven streaming through the clouds of our earth and illuminating it, till it caught his eye even at the great distance at which it was from him. The system of prophecy is thus a vehicle, a vessel moving through time at a somewhat slow but precisely regulated pace, taking up the rich freight it carries at the appropriate times, and giving it out at the appointed places, ever gathering and ever giving out. We see things only in progress, but already there is enough accomplished to convince us that the rest will be fulfilled in its season, and that in the end not one jot or tittle of the utterances of the prophets shall remain unfulfilled.

The doctrine of a double sense in prophecy has been so perverted, that calm and sober men are apt to be prejudiced against it. Its advocates have discovered so many fanciful meanings in Scripture, that shrewd and suspicious minds have been led to doubt whether it has a meaning at all, and been sceptical of the first meaning 
when they detected such far-fetched attempts to discover a second. The friends of the Bible must ever beware of playing into the hands of the infidel by making the oracles of God bear any resemblance to those which issued from heathen groves and temples, in language which had studiously more than one meaning, in order that persons might fix on the one coming closest to the event when it actually fell out. But, while we guard against this excess, we must be careful not to strip the prophecies of any of their fulness of meaning - of which the defenders of a double sense had a glimpse, but which they utterly failed to interpret accurately. The prophecy is always one and the interpretation is one; but it may refer not merely to one isolated event, but to a series of occurrences, all of much the same general character, and developed the one from the other; it may refer to a body with a head and many members. "The seven good kine are seven years, and the seven good ears are seven years, the dream is one. And the seven thin and ill-favoured kine that came up after them are seven years, and the seven empty ears blasted with the east wind shall be seven years of famine." The prophetical system here connects itself with the typical, that is, with the uniform mode of the Divine procedure, whereby events are developed one out of another, after a 
pattern, or are thrown out of a common mould.* It is as if a naturalist were to tell us that the paIm or the antelope is of such a form and aspect; his description would not have a double or ambiguous sense, but it would apply to a whole group of plants or animals, some of which however might more fully realize the picture than others. What the prophet sees in vision is not so much a single mountain, as a chain of mountains of the same formation, and all of the same general contour; it being possible, all the while, that some one, the largest and the most marked, may be taken as a type of all the others, and embody every feature of the prophet's vision. Prophecy is thus the prescience of a providence unfolding a Divine plan. The great English philosopher who taught men how to interpret nature, has also taught us how to interpret prophecy, "Divine prophecies," says Bacon, "being of the nature of their Author, with whom a thousand years are but as one day, are not therefore fulfilled punctually at once, but have springing and germinant accomplishment, though the height and fulness of them may refer to some one age."

* There are remarks with a profound meaning in the Chapter on "Prophetical Types, or the Combination of Type with Prophecy," in Fairbairn's Typology of Scripture. I have always thought, that this able work is injured by the author not taking the word type throughout in the Scriptural instead of the theological sense. 
When the patriarchs uttered the striking predictions regarding their descendants, which are recorded in the early Scriptures, their language had no double or uncertain meaning; it had its fulfilment, however, not in a single person, but in the family or the tribe. The prophet seizes, as it were, on the family likeness, and sketches it on his canvas, and the features are found to come out in the race-possibly with greatest prominence in some great personage in whom the prophecy culminates. It is thus we are to interpret the developing utterances of judgments to descend on the enemies of the Church, as on Egypt, and on Nineveh, and on Babylon, and on Edom, and on Tyre; they are executed in a succession of events till Egypt becomes "the basest of kingdoms" (Ezek. xxix. 15); till it is seen how the Lord has "cast abominable filth" upon $\mathrm{Ni}$ neveh, and "made it vile, and set it as a gazing stock" (Nah. iii. 6); till Babylon has "become heaps," "without an inhabitant" (Jer. li. 37); till all the cities of Edom have become "perpetual wastes" (Jer. xlix. 13); and Tyre "a place for the spreading of nets in the midst of the sea" (Ezek. xxvi. 5). It is thus we are to understand the threatenings against the Jews; they are accomplished from age to age, but are realized with a special emphasis in the destruction of Jerusalem, first by Nebuchadnezzar, and then by Titus, in 
which the most minute features of the prophetic picture come out, down to the mother eating her own child, "for want of all things secretly in the siege and straitness, wherewith thine enemy shall distress thee in thy gates" (Deut. xxviii. 57). The repeated predictions about the Jews being "scattered among all people from the one end of the earth even unto the other" (Deut. xxviii. 64), were accomplished by a series of events in God's ordinary providence, as by their being carried away captive by the Chaldees, and again scattered by the Romans; and it is also, I suppose, by natural agency -in part by the pride and obstinacy of the Jews-that they are not to be lost while thus scattered, "saving that I will not utterly destroy the house of Judah, saith the Lord, for lo, I will command, and will sift the house of Israel among all nations like as corn is sifted in a sieve, yet shall not the least grain fall upon the earth" (Amos ix. 8, 9). It is thus, too, that we have the fulfilment of the general sketches of the great antichristian corruption; the lineaments come out in the course of ages down to such particulars as "forbidding to marry," and "commanding to abstain from meats" (2 Thess. ii. 3-12; 1 Tim. iv. $1-5$ ). In all these cases the occurrences being according to a type or law, make it quite possible that the prophecy, without having a double meaning, 
may extend over a whole course or series of objects or events.

According to the view now given, a typical event being one of a series, may, as coming early in the series, be a precursor and a sort of prediction of others to follow. The deliverance from Egypt being after the type of the deliverance from sin, the former is a prefiguration of the latter, and the analogy holds good down to Jesus' coming out of Egypt; and hence the saying of Hosea (xi. 1), "when Israel was a child then I loved. him, and called my son out of Egypt," applies to Jesus (Matt. ii. 15). The paschal lamb being typical, the resemblance reaches to the circumstance that as a bone of the paschal lamb was not to be broken, so neither was a bone of Christ broken as he hung on the cross (Ex. xii. 46; John xix. 36). Elijah and John the Baptist being of the same type, the latter is predicted under the name of the former (Mal. iv. 5; Mat. xi. 14). The catastrophe which broke up the Jewish commonwealth in the time of Titus being of the same general character as that which is to break up the present dispensation of our world, the prophetic description of the one merges quite appropriately into that of the other, as Jesus answers the questions of the disciples about the destruction of Jerusalem, and the "end of the 
world" (Mat. xxiv). As Christ and his people are one, there are statements which apply both to him and to them, to him as their surety and head, and to them in him. The passages in the Psalms and the Prophets about kings of the earth setting themselves, and the rulers taking counsel together against the Lord and his anointed (Ps. ii. 2); about his being compassed about with enemies and forsaken of the Father (xxii.); about a familiar friend lifting up his heel against one who trusted him (xli. 9); about being despised, rejected, wounded, bruised, and suffering travail of soul (Is. liii.), have their full meaning in him, but may also refer to all who suffer in him and for his sake. The passages which imply sin, such as " $O$ God, thou knowest my foolishness, and my sins are not hid from thee" (Ps. lxix. 5), must apply primarily to sinners, but secondarily to him on whom was laid "the iniquity of us all," and "who his own self bare our sins on his own body on the tree." The interpretation in both these cases is not two but one, because of the unity or identity of the subject. On the same principle the glowing and exulting passages at the close of Isaiah, and elsewhere in the prophetic writings, as to the glories of the coming kingdom, refer, no doubt, to Christ's victory over sin and death, but may be quite legitimately applied to those who are 
kings under him, as they conquer their spiritual foes, while it will receive its full accomplishment in what remains yet to be disclosed of the splendors of Christ's kingdom.

SECT. IV.-THE PLAN OF CHRIST'S LIFE.

The title assumed in this Section may seem a bold, almost a presumptuous one. But there is evidently a unity in the constitution of Christ's person, in his character, his life, his work, and the end for which he lives, which we may reverently inquire into.

Here, as in regard to every other object falling under our notice, we find that we cannot go back to the absolute beginning: the fountain is among heights beyond our reach. But far as our eyes can penetrate we see that there is a Divine Counsel and a Divine Plan; and it is ordained that the Logos which was " in the beginning," which " was with God," and "was God," is, in the fulness of time, to associate himself with humanity, and to appear on our earth, there to engage in a work with far-reaching consequences, and to submit to awful suffering and a mysterious death; out of which mighty good is to accrue to our world, as grain springs from the corn of wheat which is buried in the earth and 
dies there (John xii. 24). What a depth of meaning in the expression the "Lamb slain from the foundation of the world!" (Rev. xiii. 8). A vast apparatus of means is set agoing in order to his coming; before him is a glorious streaking, rising into a glow, in the sky ere he rises. From the long procession that goes before of stars to light the Old Testament Church, we have some idea of what the greater Light is to be. At the set time he appears on our earth; a body having been prepared for him, that he might be bone of our bone and flesh of our flesh, only without any of the hereditary $\sin$ that cleaves to us. Descending from a supramundane sphere, he enters completely within our terrene sphere, and accommodates himself to all its laws. He takes upon him, not the nature of angels, but is the seed of the woman, and the seed of Abraham; he is born of a woman; is in weak and helpless infancy, grows in wisdom and in stature, is subject to Joseph and Mary; he eats, drinks, and sleeps; he walks on the earth's surface, bound to it and its ordinances, and subjected to its privations as any other weary man is,-only as we look, as we cannot but look, at his person, we see the glory shining through the veil of flesh; and while we feel that he is man, emphatically man, the model man, the Son of Man, we are ever made to 
acknowledge and to realize that he is clothed with Divine perfections, that he is also, and at the same time, the Son of God,-the twofold nature being all the while combined in a simple unity, the parts of which cannot be separated nor decomposed.

As we meet with him and hold intercourse with him (as he allows us to do), we are sure that we have fallen in with a being who is not, who cannot be of this earth. Lowly he no doubt is, but the lowlier he is in guise, we are the more certain that we have fallen in with one who has alighted from a higher and purer region, and bears with him the air of his lofty rank. It is clear that he has not come to our earth for the purposes of display. Ever hiding himself from the view, it turns out that he cannot be hid; growing up "like a tender plant," our attention is called to him by the fragrance which breathes from him. Our eyes are fixed on him as he passes by, and we discern his beauty; but as we feel it we experience a diffi-. culty in saying wherein it consists, just as we cannot tell wherein lies the loveliness of light, we can only point to it as we would to a star, and say, behold and see its beauty for yourselves. It is now believed that the light and heat of the sun do not come natively from himself, but are the result of an action from without; but the 
light and heat, the light of purity and the warmth of love, that radiate from Jesus, come from his very nature and his inner heart, and they flow out spontaneously on all around. It is the very light of God, but shining through a veil of humanity, and so seen by us under a milder lustre, which indeed allures but does not blind us. We are encouraged to draw nigh to him; we feel "drawn with the cords of a man, with bands of love ;" in coming to him we feel that it is man coming to man; that he is the very type of man, the man of men, with the nature, with the heart of a brother; and we go into his presence and his company, and he talks with us by the way, and is known by us in the breaking of bread,- - the conviction being ever pressed upon us that there is more than man here-that there is one with a Divine power and drawing us with a Divine love. High, no doubt, he is, so high that we cannot attain to his elevation; but we see that as he stands on his height, he is holding out a hand to help us to rise to him. Bright, no doubt, is his example, so bright that we discover we can never come up to it; and yet we feel that we are purified in looking at it by faith, and sanctified in the attempt to copy it.

As he emerges into view from the designed obscurity of his childhood, we see that he has 
a work to do. Ere that work is fully entered on he looks forward to it, and at the age of twelve he intimates that he "must be about his father's business." As he commences his public ministry, he announces "that he must fulfil all righteousness." It is clear that he is under some covenant to do this and avoid that. Thus, he cannot command stones to be made bread, to appease prolonged hunger undergone in obedience to the Father's will, and, as we know, to make atonement for man's sins of appetite. He has an allotted time to do the work. "I must work the works of him that sent me, while it is day : the night cometh, when no man can work" (John ix. 4). When his hour is not yet come he will not be hastened (John ii. 4; vii. 6); and his enemies are powerless in their attempts to seize him (John vii. 30 ; viii. 30). When his time is come, he is delivered into the hands of men who thwart their own purposes, and unconsciously accomplish the counsels of heaven in crucifying him (Matt. xxvi. 18, 45; Luke xxii. 14 ; John xii. 23 ; xiii. 1 ; xviii. 1). There is evident relief and satisfaction when, in reference to the arduous work given him to do, he is able to say, "It is finished" (John xvii. 4; xix. 30).

He has not only a work to do, he has a suffering to submit to. He is tempted in all respects 
like as we are; he has to earn his sustenance by the sweat of his face, or have it supplied to him in his wanderings by the charity of those who are smitten with love to him; he is without house, or home, or where to lay his head; he is exposed to hunger and thirst, to pain of body and sorrow of mind; we read of his "strong crying and tears " and it is appointed unto him, as unto all men, once to die. He walks our earth, and does his work, and submits to these privations, being all the while under a mysterious load such as no other human being had ever to submit to,-being such, indeed, that we cannot fully fathom the cloud, though we get some idea of its vastness and its blackness, as certain expressions break from him: "I have a baptism to be baptized with; and how am I straitened till it be accomplished" (Luke xii. 50). He cannot express it to men, but pours it out to his heavenly father. "How is my soul troubled; and what shall I say, father, save me from this hour ; but for this cause came I unto this hour" (John xii. 27). We comprehend much, but cannot fathom all the depth that is in such expressions as these, "Being in an agony," "My soul is exceeding sorrowful, even unto death." We see that it is an agony exceeding that which has been laid on ordinary martyrs, who have often triumphed in the prospect of their death; a sorrow exceed- 
ing the deepest gloom that has ever gathered around an ordinary human spirit, as it took the darkest view of itself and of the world, of sin and of God. All this has been appointed beforehand, in an everlasting counsel to which he had been a consenting party, and he submits to it in accomplishment of what had been undertaken by him. He shewed his disciples how he "must go unto Jerusalem, and suffer many things of the elders and chief priests and scribes, and be killed and be raised again the third day" (Matt. xvi. 4). He told them after his resurrection, "Thus it is written, and thus it behoved Christ to suffer and to rise from the dead on the third day" (Luke xxiv. 46).

This work and these sorrows had evidently very profound purposes to fulfil. We should never pretend to be able to compass all the ends served by them, as they look towards God and his glory, towards other worlds, towards all the things that were created by him, "that are in heaven and that are on earth, visible and invisible, whether they be thrones or dominions, or principalities or powers" (Col. i. 16). But we can discover and apprehend some of the grand designs accomplished, for they are revealed in the Word, they have a reference to us, and we hear a voice responding in our hosoms. The moral monitor within tells us, that we ought to work 
out a righteousness upon the earth, and that we have not done so; and here Christ is represented as providing it for us, that we may receive it by faith (Rom. iii. 22). We have it clearly announced, that by these sufferings Jesus pays a penalty and secures a redemption- "For Christ also once suffered for sins, the just for the unjust, that he might bring us to God" (1 Pet. iii. 18). In all this, glory is given to God. "Father, glorify thy name. Then came there a voice from heaven, saying, I have both glorified it, and will glorify it again" (John xii. 28). We can so far understand, because we can appreciate this, this obedience rendered in default of ours, these sufferings endured in our room and stead. The structure thus raised over a grave, and cemented by blood, may have relations indiscernible by us; it goes down to depths which are beneath, and it goes up to heights which are above our view; still it stands there as a bridge with deep foundations and strong ramparts, with a way opened by which we may pass from a state of condemnation to a state of justification, from a state of alienation to a state of fellowship. "My God, my God, why hast thou forsaken me?" was the question put in earnest tones by the sufferer upon the cross, and no answer was given, for he who put it was, at the time, under the hidings of the father's face. Let us come to the foot of 
the cross and answer it: "He was wounded for our transgressions, he was bruised for our iniquities, the chastisement of our peace was upon him, and with his stripes we are healed."

As he descended at first from a higher sphere, so we feel all along that he cannot remain for ever on our sin-tainted earth, and we expect him to mount into the pure region whence he came. When he ascends into heaven, it is "he that came down from heaven, even the son of man which is in hearen." TVe go out with him as far as Bethany. In accommodation, as it were, to the natural, he goes up in order to his ascension, to the Mount of Olives; but it is by a supernatural power that he thence ascends into heaven. A cloud wraps him from our view. We are sure that he who has toiled and suffered and died for the children of men, will not forget them in his new sphere, but will bear them upon his heart. We rejoice when we learn that he ever liveth to make intercession for us, that he has gone to prepare a place for us, that he sends his Spirit to prepare us for that place, that he will come again and take us to himself; and we feel that it must be the highest blessedness to dwell in his presence, to drink of his wisdom, and share in his joys.

This is the portrait presented to us, set in a very simple framework evidently constructed by 
men of no artistic skill. Can it have been drawn from imagination by fishermen and mechanics from Galilee? As this question is put to us we answer unhesitatingly, that it must have been taken from a living original.

SECT. V.-THE SYSTEM OF MIRACLES.

There is evidently a rule in the Divine Mind according to which miraculous interferences take place, and this whether man is or is not able to ascertain its exact nature. Miracles have not been wrought in all ages; they seem to be confined to selected seasons, when there were to be developments of that plan of redemption which had been devised before the creation of the world. Even in the ages in which they occur they are not performed everywhere and on every occasion. The working of God in our world is, in all ages and courtries, as the usual rule, not after the supernatural, but the natural mode, which is always to be understood, however, as embracing a pre-ordained providence, bending down with adaptive flexibility to the case of the most minute objects. God would have all men, always and everywhere, to look for the ordinary supply of their wants to that cosmical administration which he planned from 
the beginning in infinite wisdom, which his intelligent creatures may practically understand, and to which they find it good to conform; and he never leads them to entertain the hope that be is bound to interfere, or is likely to interpose, to save them from the consequences of their own folly, or to ward off affliction which may be predestinated for their good.

Our Lord let the Jews know very decidedly, that miracles were not to be performed on the demand of every applicant craving for wonders, or anxious to be freed from attending to the means which Providence has sanctioned for. securing the ordinary blessings of life. When he saw that the multitudes were beginning to follow him because of the loaves and fishes which he had multiplied, he wrought no more wonders of that description. $\mathrm{He}$ rebukes the Jews because they were ever demanding signs from heaven, and he told the people of the city in which he had been brought up, "I tell you of a truth, many widows were in Israel in the days of Elias, when the heaven was shut up three years and six months, when great famine was throughout all the land; but unto none of them was Elias sent, save unto Sarepta, a city of Sidon, unto a woman that was a widow. And many lepers were in Israel in the time of Eliseus the prophet; and none of them was cleansed, 
save Naaman the Syrian" (Luke iv. 25-2\%). Those human agents, who were empowered by God to work miracles, could perform them not at their own pleasure, but only as a higher wisdom saw fit to allow them. Our Lord refuses to turn stones into bread, in order to relieve the cravings of hunger within him, and announces clearly that man must submit to the natural ordinances of God; he declines also to cast himself down from the pinnacle of the temple, and to make an empty show by saving himself from the natural consequences; and he declares that, to act otherwise, would be a tempting of God. We can see a reason, I think, why he should not have come down from the cross when his persecutors demanded it; for, had he come down, man must have sunk into the depths of perdition. But, no doubt, he had equally profound and cogent reasons, in other cases, for refusing to interfere with those normal arrangements of things which the Godhead, and he in the Godhead, had made in the depths of eternity. There were evidently rules laid down by him in infinite wisdom as to the dispensation of miraculous powers. The disciples ask him why they were defeated in their attempts to dispossess a person labouring under demoniacal influence, and he tells them it was because of their unbelief, and adds, " howbeit this kind goeth not out 
but by prayer and fasting" (Matt. xvii. 21). It is said of him, that when he went into his own country, "he could not do many mighty works there because of their unbelief." Not, surely, that it was physically impossible for him to do so, but because there were rules of wisdom according to which he dispensed, or allowed to be dispensed, his supernatural gifts; and it was one rule, that there must be faith on the part of the worker, if need be, to the extent of engaging in special fasting and prayer, and faith, too, on the part of the recipient, faith proceeding on what Jesus had already done as the ground of new favours.

It is clear, from his whole manner of acting, that to Jesus the natural and the supernatural are alike possible and alike easy-alike natural if we may so speak. Yet he is ever restraining himself in the outgoings of his miraculous energy. $\mathrm{He}$ is like the man of large wealth and large benevolence, who could always give charity, but does not always do so; giving so often as to shew that he is always disposed to give, and withholding only when he has good reasons,-very commonly in the circumstances or character of the applicant, and because mischief would follow. So it is with Jesus; we see that there is all power in him, but that he is ever keeping back the supernatural exercise out of respect to the 
natural, which is his own ordinance; and out of respect to mankind, who understand the natural, and must gather their ordinary instruction and blessings through it; and out of respect to his own disciples, who must not be allowed to expect that the supernatural will take the place of the natural in the common affairs of life; and because he ever expected faith,-as the benevolent man expects gratitude in the measure of the favours bestowed.

It would be a great mistake to suppose that the miracles, wrought by Moses and the prophets in the Old Testament times, or by Christ and his Apostles in New Testament times, were meant merely to show the Divine power, or to act as evidences of the truth of religion. He who takes this narrow and exclusive view, will find himself in hopeless difficulties when he would understand the miracles; for he would see on the one hand, that all the supernatural acts performed were not specially evidences of the truth of revelation, and on the other hand, that our Lord often refused to perform miraculous acts which would have been proof of his Divine power.

The extravagant statements in regard to miracles, by certain defenders of Christianity, in the two or three last ages, have led some in our day to depreciate them altogether as evidences. This I reckon a very unjustifiable reaction, which has 
led the parties into a very unwise and unsafe position. For in the Word of God miracles are appealed to in proof of the supernatural power of Jesus, and of the truth of the doctrines which he taught. Nicodemus comes to Jesus as a teacher sent from God, on the avowed ground that no man could do the miracles which Jesus did except God were with him. When the Baptist sent two of his disciples to ask of Jesus if he were the Messiah, "Jesus answered and said unto them, Go and shew John again those things which ye do hear and see; the blind receive their sight and the lame walk, the lepers are cleansed and the deaf hear, the dead are raised up and the poor have the Gospel preached to them" (Matt. xi. 4, 5). "The works which the Father hath given me to finish, the same works that I do, bear witness of me that the Father hath sent me" (John v. 36). "The works that I do in my Father's name, they bear witness of me" (John x. 25). "Believe the works, that ye may know and believe that the Father is in me, and I in him" (x. 38). He requires us to believe him "for the very works' sake" (John xiv. 11). "And many other signs truly did Jesus in the presence of his disciples, which are not written in this book; but these are written that ye may believe that Jesus is the Christ, the Son of God; and that believing 
ye may have life through his name" (John xx. 30,31 . It has been said, that the apostles appealed to miracles only before rude and unlettered people; but in speaking to the men of Athens of the resurrection of the dead and of the judgment day, Paul declares, "whereof he hath given assurance unto all men, in that he hath raised him from the dead" (Acts xvii. 31). In order to have the circle of witnesses complete when Judas fell, it was ordered, that of those men which had companied with the other disciples, "all the time Jesus went out and in among us, beginning from the baptism of John until that same day he was taken up from us, must one be ordained to be a witness with us of the resurrection" (Acts i. 21, 22).

He who leaves the supernatural element out of Christ's life is abandoning his cause, and if he be a professed defender of Christianity, he is betraying it. If the writers of the Gospel history be true men, as they certainly seem, Jesus must have performed actions far beyond the power of nature-for example, if there be any truth in their statements, he must have risen from the grave. If they be not true men, but mere inditers of myths, our faith in Jesus as a reality is gone. Men of common sense, in every walk of life, see this at once; nor will it be possible for those who have set them sliding on the 
downward scale, to stop them in their descent. Nor would the supposed miracles be any proof of the Divine Mission of Jesus, were they merely portents-that is, curious natural phenomena, seized by knowing men to favour their own ends. Once look upon them as in any sense ingenious deceptions-such as that which Columbus played upon ignorant men when he predicted an eclipse -and our faith in revelation is shaken to its foundation, with nothing left on which to rebuild it. Once admit that there is studious concealment or trickery of any kind, and every honest feeling within us insists, that those who employed this cannot have had the authority of the God of truth.

But while the works performed by Jesus are certainly evidences of the Divinity of his mission, we must also regard them in other lights and as serving other ends. The supernatural events of the New 'Testament go by three different names, each of which represents them under a different aspect. Peter represented Jesus as "a man approved of God among you

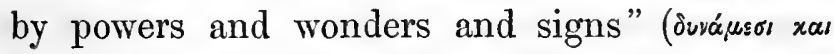
"śpaбı xai onusiors, Acts ii. 22). They are called "powers," as expressive of the mighty power at work. They are called "wonders," because they summoned and legitimately commanded attention. They are also called "signs," as 
significant of something beyond themselves, as manifestations of a Divine operation and as evidence that God is giving his sanction. The "powers, wonders, and signs" wrought by Jesus Christ were like his discourses, the expression of his full character, of his power no doubt, but also of his wisdom and his love. I believe they were a "type" or " sign" of his special mission.

It is a circumstance worthy of being noted and pondered, that by far the greater number of the miracles performed by Jesus Christ when he was on earth consisted in the healing of diseases. Not that they were exclusively of this description. They ranged over a large portion of the wide domains of nature. His birth was announced by an angel; when he was born a company of the heavenly host appeared to shepherds on the plains of Bethlehem; at his baptism the heavens were opened; at his command winds and waves were hushed, a fig tree withered away, a herd of swine ran headlong into the sea, and fishes filled the nets of the Apostles; Moses and Elias conversed with him on the mount of transfiguration; an angel was seen strengthening him in the garden of Gethsemane; he expired amid convulsions of nature; an earthquake threw open the sepulchre on the morning of the resurrection; and at last the heavens received him as he ascended into glory. Still, by far the greater 
number of his signs and wonders were "powers" of healing, and to them he referred when the disciples of the Baptist were sent to inquire if he were the Messiah (Mat. xi. 5). The question arises, why were his miracles usually of this character?

1. In this way our Lord shewed-his benevolence as well as his power. His "powers" were not displayed in such acts as in making rivers run back to their sources; or in causing the heavenly bodies to wander from their spheres, or in spreading wasting and destruction. How different in their whole spirit and character are the miracles of Jesus, from those attributed to Simon Magus, who was reported to have shewn walking statues, to have made dogs of brass and stone to bark, and mountains to leap, while he himself flew through the air. Our Lord came not to destroy men's lives, but to save; and his "powers" consisted mainly, in remedying the evils existing on our earth, specially in healing those who were afflicted with bodily maladies. He thus accomplished, as God commonly does in his providence, two ends by one and the same means:- he showed that he came to this earth gifted with Divine power; but he shewed too, that he came filled with Divine Love.

2. Our Lord's miracles were typical. He came to restore order where disorder had prevailed; 
and it was most significant that his chief works should have consisted in remedying evils, specially in giving health to the diseased. His miracles were thus expressions of his wisdom and prescience, as well as of his love and power. They were after the model or form of his general office and mission; they were ensamples of the power which he has exercised in all ages, and which he is exercising in this, in delivering the souls of men from the dominion of sin- "Who forgiveth all thine iniquities, who healeth all thy diseases."

The diseases. which Christ cured may be regarded as typical of the spiritual maladies healed by him. Sin is to the soul what disease is to the body. Disease is to man the fruit of sin-of which every one must have felt it to be an expressive outward image. Disease springs from a derangement of the organs-it hinders the proper exercise of the functions; disease is death begun, death is disease finished. So sin is a disease in the soul ; "when lust hath conceived it bringeth forth sin, and $\sin$, when it is finished, bringeth forth death." All men are under sin, just as all men are liable to disease. But in what a variety of ways may the disease which wastes and finally destroys the body attack us ; it may come in the loss of some of the bodily senses, in the quenching of the eye, or the stop- 
ping of the ear; it may come in the lameness of an arm or limb; in the paralysis which deprives an essential member at once of all power of action; it may come as fever, drinking up the strength by its heat, or as brain malady, which makes the very intellect to reel and stagger. The sin which assails all, may come in a like diversity of forms. Let no one congratulate himself in the idea that he is not a sinner, because he has not fallen into every possible sin. The self righteous man boasts that he is not immoral, and the drunkard that he is not dishonest. It is as if a man were to boast that he is in health because his limbs are whole, when consumption may have begun its wasting process in a vital organ. As all men are under spiritual disease, so all men need a soul physician, and such we have in Him who, when on earth, "healed all manner of sickness, and all manner of disease among the people."

We may regard the varied modes in which persons seeking a cure came to Jesus when on earth, as typical of the ways in which the sinner should draw nigh to the Saviour. There were commonly means of some kind employed, by those who had their infirmities healed by Jesus. They had heard somehow or other. of him and his miraculous power, they were impressed with their need of some one to deliver them from 
their maladies, and they were led to believe that Jesus could do this. So far all were alike. In other respects they differed,-very much I suppose according to the natural character and temperament of the individual, and the circumstances in which he was placed. Some, when they heard he was approaching, laid their case before him as he passed. Others sought him out when he was yet at a distance. Some were not able to come to him themselves because of their lameness, or sickness, or palsy, but they secured friends who carried them to him on couches. Some cried to him with loud importunity, as feeling the urgency of their case. Thus the two blind men begging by the way side, when they heard that Jesus passed by, cried out, and when the multitude rebuked them they would not hold their peace, but "cried out the more, saying, Have mercy on us, O Lord, thou Son of David" (Matt. xx. 31). Others, it may be, not less anxious and confiding, were more bashful and retiring. The centurion, whose servant was sick, believing strongly in the power of Jesus, and deeply impressed with his own unworthiness to receive Jesus under his roof, beseeched him to go no farther, but only to speak the word, when his servant would be healed. The woman who had been labouring under an issue of blood so many years, durst not venture to address him, 
but concluded, that if she had but faith to touch the hem of his garment she might be instantly restored. Some, as they pleaded, dwelt upon the dreadful nature of their complaint, and their cry was for mercy; others gave a fuller expression to their faith and confidence. "If thou wilt, thou canst make me clean." "Speak the word only, and my servant shall be healed."

Such cases recorded for our benefit are deeply instructive, both in their sameness and in their differences. It is in much the same way that sinners still draw nigh to Jesus. They have heard of him with the hearing of the ear, and they have felt, to a greater or less extent, their need of him; some having had a deep sense of the evil of sin generally; others having felt acutely the evil involved in some particular sin; while a third class, perhaps, have been more alarmed for the dreadful consequences which may follow, in this world or the world to come. They have all been led, too, to believe in Christ's power to save, and his willingness to save. So far all are alike. But there may be differences in the way in which different persons approach him. Some wait for him very diligently in the use of means; not that they trust in the means, but they look for him as they use the means, and are found standing at the posts of his gates, and in the paths which he is wont 
to frequent. Others are almost impatient of means; not that they despise means, but they rise instantly above them, to Him who alone can remove their maladies. Some, afraid of giving offence, stand afar off and beat upon their breast, saying- "God be merciful to me a sinner." Some under a deep sense of sin, and an awful fear of the wrath of God, cry out in terrible earnestness for mercy; others enter at once into the enjoyment of peace. Some give a fuller expression to their sense of $\sin$, and their fear of hell; others, all along, give a higher place to the outpourings of confidence and love. But whatever be the lesser differences, they all come to Him, of whom they are sure that he can and will heal their maladies.

The manner in which Jesus healed diseases is typical of the way in which he saves and sanctifies. In the case of all the cure was effected by the power of Jesus; but there was a diversity in the manner of his action. Sometimes he answered the cry of distress at once-" I will be thou clean," and immediately the disease was removed. At other times there was delay before the prayer was granted: thus the woman of Canaan had to submit to repeated refusals, and had to put up repeated requests, ere the gracious words were addressed to her-"Be it unto thee even as thou wilt" (Mat. xv, 21-28). 
In some cases he granted the request without requiring the person to undertake any work, or undergo any process; he speaks the word and the cure is effected. In other cases a step has to be taken, a means used, an operation performed. Thus he said to the ten lepers, Go shew yourselves unto the priests, and it was " as they went they were cleansed" (Luke xvii. 14). When they brought to him the man with an impediment in his speech, " he took him aside from the multitude, and put his fingers into his ears, and he spit, and touched his tongue; and looking up to heaven, he sighed, and saith unto him, Ephphatha, that is, be opened, and straightway his ears were opened, and the string of his tongue was loosed, and he spake plain" (Mark vii. 32-35). It was thus, too, that he acted towards the blind man of Bethsaida. "He took the blind man by the hand, and led him out of the town; and when he had spit on his eyes, and put his hands on him, he asked him if he saw ought? And he looked up, and said, 'I see men as trees walking.' After that he put his hands again upon his eyes, and made him look up; and he was restored, and saw every man clearly" (Mark viii. 22-25). On another occasion he used a more elaborate means, but still not a process of itself fitted to effect the end. In curing a blind man "he spat on the ground, and made clay of the spittle, and 
he anointed the eyes of the blind man with the clay, and said unto him, Go, wash in the pool of Siloam (which is, by interpretation, Sent); he went his way, therefore, and washed, and came seeing" (John ix. 6, 7). I believe that there is a like sameness, and a like diversity in the manner in which God converts the sinner. Sometimes he does the work at once, in the fulness of his grace. In other cases he delays granting the prayer of the anxious inquirer; not that he would make him cease from prayer, but he would thereby make him plead more earnestly. Sometimes he seems to require nothing to be done; on other occasions he bids him go and do this and do that, and as he does it the cure is performed. "There are diversities of gifts, but the same spirit; and there are differences of administration, but the same Lord; and there are diversities of operations, but it is the same God which worketh all in all."

The effect produced is always health and activity. When Jesus put forth his power, the eye which had been blind saw; the ear which had been deaf heard; he who had been sick arose; he who had been leprous had his flesh made fresh and whole; he who had been torm with demons, sat at the feet of his deliverer clothed and in his right mind. It is the same when the soul is converted and sanctified. The organs which 
had been distempered are made whole; the functions that had been disturbed act aright; and with the life there will be activity-activity in the service of God, activity in doing good, activity in relieving distress, in lessening prevailing sins, and in promoting the extension of the Redeemer's kingdom: When the fever of Peter's wife's mother was subdued, she " arose and ministered" to Jesus. Those that were brought to Christ on couches, he sent away bearing their couches by means of the strength imparted to them. Those who are brought to Christ lame, he sends away leaping, and exercising and invigorating the powers they have received in running in the ways of his commandments. Those who come to Christ blind, he sends away beholding and admiring the glory of his person and his works. Those who come to Christ dumb, he sends away with their tongues loosed, and exercising their newly acquired gifts in singing his praises.

If we had been privileged to accompany Jesus in some of his earthly journeys, what a glorious sight would we have seen,--not, indeed, such as this world wonders at and admires, when it applauds the warrior cutting down and destroying the strong and healthy men before him,-we would have witnessed a very different, but a far grander scene. We should have seen before him, 
as he was about to pass, the road covered with couches, with the sick laid out upon them; and the dumb, when they could not speak, striving to give expression to their woes by their earnest struggles; and the blind, when they could not see, crying to be taken to him. This was the scene before him; and behind him, after he had passed, were the sick bearing away their couches, and the lame leaping like the harts, and the dumb singing his praises, and the blind looking after him with joyful eyes, and the lunatic in their right minds, and those lately dead in the embraces of their friends. These were the effects which followed Christ's visits wherever he went. And he is Jesus Christ, the same yesterday, to-day, and forever. His office is still to seek and to save that which was lost. He is in this world now by his Spirit, as he once was by his bodily presence. True, he is not to be discerned by any pomp or external splendour ; " the kingdom of God cometh not with observation." But, by the eye of faith, we may discern him still going about in our world, and continually doing good. Before him are persons inflicted with all manner of spiritual maladies :- some under the power of wild passion, by which they are led captive at pleasure; some covered all over with the leprosy of vice; all of them blind to the perception of spiritual beauty, and deaf to the voice 
of God addressed to them. Wherever Christ goes the way is strewn with such; and wherever he goes he leaves behind him the traces of his presence. Before him, as he marches through our world, are the blind, the deaf, the dying, and the dead ; and behind him are the seeing, the hearing, the living, the lively, and the loving. "The Spirit of the Lord God is upon me; because the Lord hath anointed me to preach good tidings unto the meek: he hath sent me to bind up the broken-hearted, to proclaim liberty to the captive, and the opening of the prison to them that are bound; to proclaim the acceptable year of the Lord."

SECT. VI.-THE SYSTEM OF DOCTRINE.

The mind of man begins its intelligent acts, not with the general and the abstract, but with the singular and the concrete; not with principles and with qualities, but with individual objects as they present themselves, and in the exercise of their properties. The boy does not set out in his mental activities with speculating like a logician about man and his rationality and responsibility; but he forms a familiar acquaintance with his nurse, and his mother, and his father, and he feels the force of a command as 
uttered by them, and his first reasoning may be to the effect, that if he would obtain a gift from them, he should make known his wants by some audible symbol. When this same boy begins to exercise his faculties about religion, which he may be led to do in very early life, he does not set out with abstract doctrines about Grod and his attributes; but, if he is blessed with Christian parents, he commences with an apprehension of God as living and loving and acting, and of Jesus Christ as suffering and dying on earth, and now up in the heavens ready to do good to him and to all. It is as persons advance in life and in intelligence, that they learn to comprehend and admire the separate qualities that meet in the individual person, and the general rule which brings the miscellaneous objects into a unity of view and conception. The abstract principle, and the general rule, when they are apprehended, keep the intellect steady, and they guard it from much seductive error, into which those fall who mistake the accidental for the universal. It should be added, that this good is gained only when the abstractions and generalizations have been properly made; for we may be landed in confusion and in very fatal errors if the facts have been mutilated in the logical process, or the law be any thing more than a generalization of the individual cases. 
The great body of mankind do not much relish highly generalized laws or abstract dogmas; they understand the principle best when it comes to them as an exemplification-they prefer the living being to the bony skeleton. This is the case with the young; with not only children, but young men and maidens who compose so large a portion of every community; with the uncivilized who, even at this day, constitute by far the greater number of the inhabitants of the earth; with, I believe, even the majority of the cultivated and refined, who turn with more eagerness to the tale in our libraries than to the scientific or philosophic treatise. In conformity with all this, we find doctrinal propositions and refined distinctions constituting a comparatively small part of Scripture, which instructs us more frequently by narratives, poems, precepts, prophecies, symbols, threatenings, judgments, promises, parables, and examples. But all who can understand it are the better of having the rule as well as the illustration; and there are thinking minds in all ages and states of society, and grades of life, which can apprehend general truths and profit by them, and the number of persons craving for such instruction increases rapidly as education advances; and so we have doctrinal statements here and there in all the Scriptures, but more especially in the Epistles of Paul, 
written when revealed truth was addressed to those whose minds had been cultivated by Greek literature and philosophy.

There is, undoubtedly, a system of doctrine underlying all the scattered, and the at times apparently isolated, revelations of the will of God; underlying the whole ordinances and dispensations of Scripture, the very history and poetry, the expostulation and exhortation. Paul speaks of the Romans as obeying the type of doctrine which was delivered unto them (Rom. vi. 7), and exhorts Timothy to hold fast the under-type of sound words which he had heard (2 Tim. i. 13). It is not needful that every private Christian should have a full comprehension of this system, or be able to expound it in categorical propositions. Many have caught its spirit, and been able practically to conform to it, without knowing it speculatively; just as the great mass of mankind can so far accommodate themselves to natural law without knowing it scientifically - are quite aware, for example, that a stone will fall to the ground, though they are entirely ignorant of Newton's law of universal gravitation. But there is a set of connected principles binding the whole series of supernatural dispensations and the scattered declarations of the Word, just as there is a Divine idea or plan running through the whole 
mundane system, through all its stellar movements and organic forms. By a careful and. cautious inquisition of nature we can make it reveal some of its secret machinery; and we are quite sure that we have discovered not a few of the laws of the world, though we should never pretend that we have found out all its laws or its ultimate laws. By a like reverent study of the revelations of God we may rise to very enlarged conceptions of the plan of redemption; and we may be quite sure that these are substantially correct; though we should ever beware of stating or averring that we have embraced the whole truth in our systems. We are greatly aided in this by those generalized statements, combining a vast number of other and more particular statements into one, which are presented every where in the Word, but become more numerous in the later Scriptures.

The improper and excessive application of the forms of human logic (and this often a very doubtful and technical logic) to the expression of Divine truth, has tempted many in our day to turn away with strong distaste from all systematic or dogmatic theology. This I regard as a most unwarranted reaction, from the excessive refinements and minute distinctions of the scholastic and of certain portions of the puritan theology. I admit, at once, that the human 
mind cannot systematize all spiritual truth, just as it cannot arrange all natural truth. Those divines shew their ignorance and presumption, and not their knowledge or wisdom, who profess to give us the whole system or body of divinity. It hath not entered into the mind of man to conceive the body of divine truth in its rast dimensions; and certainly no one should attempt to give a full portraiture, so as to delineate all its significant features, and the iridescent play of feeling on them, and its agile but complex movements. I doubt much whether we have attained a full comprehension of any one truth of revelation or of nature; and preposterous it is, in the extreme, for any one to affirm that he had mastered all truth. An inspired apostle acknowledges, "We know in part, and we prophesy in part." But while we know only in part we do know in part, and prophets have prophesied in part. By the ordinary exercise of our observational and reflecting faculties, we can discover analogies, affinities, and connexions, and we can generalize what we notice, and express the laws which we reach; but all the while we should not dogmatically affirm that we have risen to the ultimate or the absolute trutl. Everywhere have we exemplifications so clear and simple, that they enable us at once to catch the rule or principle, which again entitles 
us to make important practical applications: Here and there do we see regular arcs of revolving wheels, from which we may calculate the whole circle. Any one may discern the general type of doctrine, at first with a very dim outline, but coming out more and more distinctly in the clearer light. Above all, we have in the Word of God itself, and especially in the writings of Paul and John, doctrinal statements in the form of epitomes, or compendious declarations of vast sweep and comprehensiveness.

I admit that these abstracts (like the abstracts of science) are felt to be exceedingly bare and uninteresting when they are presented to a mind ignorant of the individual and the concreteindeed they are scarcely comprehensible by one who has not, in his previous training, had the means of imaging them and thinking of them by incident or by symbol. They are rarely presented to us in the early and preparatory revelations, which give us instead the example, the figure, the parable, the analogy. They have a value when they follow up a course of instruction conducted by deeds and symbols, and gather into a head, and express in a general law, the results of the whole preceding process of training, observation, and thought. Thus employed, they serve a purpose, and a high purpose, to the church and individuals. Those abstracts of cardinal 
truths which are embodied in our creeds and confessions, are standards of weight and measure, by which to detect unsound doctrine, and keep it from passing current in the visible churches. The simple and clear enunciations presented in our catechisms assist the young to rise to a clear notion of what they are expected to believe; and may serve, in all their future lives, to give a connexion to the individual truths offered to them. The grand general views presented in sermons and religious treatises, more especially when couched in language borrowed from Scripture or conceived in its spirit, may furnish an elevated theme of religious meditation; may save us from theoretical errors and practical mistakes; and unconsciously render our piety more enlightened in its spirit and more consistent in its action.

It must needs be one of the labours of the theologians of our day, to disentangle our systematic divinity from all metaphysical subtleties, from all antiquated jurisprudence, and from all logical distinctions, other than the most obvious and natural. This is a task which I would not commit to every one. There is a risk, that those who set about it most eagerly, in gathering up the tares root up also the wheat with them. Still it is a work in which those who are competent must engage; for it is certain that "every plant which our heavenly Father hath not 
planted shall be rooted up" (Mat. xv. 13); and it is surely better that the encumbrances should be taken out of the way by the friends than by the foes of religion. What could look more thoroughly established than the cosmogony which divines, till within the last age or two, were in the habit of drawing from the earlier chapters of Genesis? Yet we have been obliged to review it; and we now discover how many inferences of our own were superadded to the simple statements of the Word. Physical science has thus given a reproof and a lesson to systematic theology, which it should seek to profit by, in the way of making it more humble and less constructive in its dogmas. I suspect that higher intelligences may discover quite as many flaws in our logical or inferential systems of doctrine, as there were in the old theological geology. But just because theology must take down some of its additions which were supposed to be buttresses, while they were really obstructions, it is the more needful to watch, lest, in the work of upturning, it undermine any part of the heavenly temple. Care also must be taken, that in removing the old impediments we do not allow any new logic or philosophy,-be it the more imposing theories of Schleiermacher or Coleridge, or the more rigid but negative systems of Kant or Hamilton,- to take their place, and thus accu- 
mulate a Herculean task of cleansing for the generation that is to come after. And while we exclude all inventions of man from theology proper, as supposed to have the sanction of inspiration, it would be infatuation to refuse to employ, as an outward defence, any of those well-founded distinctions and apt phrases which theologians have called in to shew how Divine truth is consistent with itself, and to answer plausible objections. Nor is there any reason why a philosophy should not seek to sanctify itself by an alliance with religion; provided always that it does not attempt, like the great German systems of Schelling and Hegel, to overpower the simple truths of the Word; and provided, farther, it does not so identify itself with religion, that when the philosophy is seen to be a failure, Christianity may be supposed to fall along with it.

But, without leaning upon any philosophy except the philosophy of good sense, or any logic except the logic which all men employ in every mental exercise, or any jurisprudence except that of the spontaneous conscience, it is possible to trace a connexion among many of the truths of the Word, and to give them a suitable expression. We see in Revelation, first of all, an eternal counsel contemplating a manifestation of the Divine glory - that is, of the Divine perfections- 
in providing a Saviour for man fallen into sin and degradation. From the very entrance of transgression into our world there are notices of him; and there are intimations that he is to descend from human nature, while yet he is related to the Divine nature, which is essentially one and yet plural. Various anticipations of him appear; a symbolic mode of worship is instituted; profound ideas and convictions are excited and deepened; a special family is chosen to preserve and transmit the knowledge and conceptions; and along with these a pure morality in a somewhat rigid and ceremonial form. As ages advance, the spirit shines more and more clearly through the body in which it dwells. In the fulness of time the long-predicted and anticipated One appears, very God and very $\mathrm{N}$ an ; the Revealer of the will of God and the teacher of mankind; the Redeemer who makes atonement and who conquers by suffering; the King, who rides lowly into our world, and who is at last to conquer it all in the name of "truth, and meekness, and righteousness." We see that he is calling a people, who are all being sanctified by him, and are thus prepared for an inheritance in which the holy shall be forever separated from the unholy. Ever spreading wider and wider the boundaries of his spiritual kingdom on earth, and reducing the rebellious elements into order, his 
reign shall at last extend over the whole earth, apparently for a long succession of ages. A plan like this evidently underlies the whole supernatural dispensations; and it has within it a set of agencies which, though unseen because of their depth by superficial men, have yet, in fact, formed the elevations and depressions, and by consequence the whole shape, and contour, and aspect of our world's history.

\section{SECT. VII.-THE SYSTEM OF DUTY.}

There is evidently a type of duty running through the whole revelation of God, and underlying all its particular precepts. It is, to a considerable extent, coincident with a prior and a natural law, imbedded in the very constitution of man. Not that we are to look on the law written on the heart of man as rendering the law written in the Word unnecessary. For, first the law of conscience is felt by the great body of mankind to be very vague in its instructions. The inscription may at first have been sharp and clear, as it must certainly have been deep, to outstand all that man has passed through, as the soul has been swept over by sin as by a flood. In fact, the moral power in man exists very much in the form of a capacity and a 
tendency rather than an energy, and it needs a favourable training to bring it into healthy exercise; it needs a revealed law applied to it to make the invisible writing legible. The advanced conscience of these times is, no doubt, the outgrowth of native principle, otherwise circumstances could not call it out; still it is also a growth produced by external stimuli, and chiefly by the light which has been diffused every where throughout our atmosphere by a heavenly luminary-many in our cloudy world never perceiving the source from which it comes.

Much of what is revealed, it may be admitted, is a republication of the law of nature-it being understood, however, that what is now published clearly had been published only obscurely before. We have such a law in the Old Testament, where, however, it appears in a somewhat rigid form and with a considerably stern look, and without those more loving features which attract us in the New Testament; we hear it spoken in the midst of flames, we see it written on stone, and all its commandments are prohibitive. It is in the New Testament,-more especially in the Sermon on the Mount, and other discourses of our Lord, and in portions of the Epistles, - that we see what is the spirit of the Law, and what the principle which underlies it. "Thou slialt love the Lord thy God with all thy heart, and 
with all thy soul, and with all thy mind. This is the first and great commandment. And the second is like unto it, thou shalt love thy neighbour as thyself. On these two commandments hang all the law and the prophets" (Matt. xxii. $37-40)$. In favour of this law the natural conscience gives its testimony; it is the fully written and preserved copy, which enables us to read the dimmed and defaced one, which, however, suffices to shew that the revealed law corresponds to the natural and original one.

But in this law revealed in the Bible there is something beyond what is in the natural law of conscience, that which is superinduced being all the while in thorough harmony with what is written on our nature. There is, for example, a gracious law of the Sabbath, providing periodical rest for a body which has to toil, and also securing, as still more important, indeed essential to the sustaining of religion in a land, a season for the acquisition of religious knowledge, and for religious education and training generally among young and old, and a time of blessed quiet in which the soul may hold undistracted communion with God. But the specialty of the code of duty revealed in the Bible lies in its clearly announcing what we ought to do, as sinners turning from sin, and returning to God. Even at this point, the revealed law has something to appeal to in 
the natural conscience, which is prepared to admit that man has sinned, and that he ought to repent and amend. But then the conscience has no special information nor instruction, no assurance or promise for the returning sirmer, and the reason is, that it knows of no method of reconcilement with God. It is upon the mediatorial work made known by the supernatural revelation, that all the evangelical duties proceed, and these duties are all graces-such as faith, and repentance, and meekness, and patience, and the love of a reconciled heart. As to repentance, the natural conscience gives only impulses, compunctions, fears, which indeed would stir up action, but it utters no certain sound as to what should be the course of conduct pursued; and the confused convictions are apt to flow out in"self-imposed mortifications and penances, which are felt, after they have been gone through, to be no atonement for the transgression, and so bring no peace, but rather restlessness, to the roused spirit. As to faith, the natural conscience has no object to reveal except God the governor and judge, no being standing in such a relation towards us, as to draw forth and gain and fix our confidence. Instead of gentleness, forbearancc, patience, the natural feelings raised by the accusings of the moral avenger, are anxiety, doubt, fretfulness, and resentment. No 
doubt, the ethical prompter within announces that we ought to love, but scarcely holds ont any incitements to draw our hearts towards a God who hates sin, but of whom we know not how he forgives $\sin$, or whether he forgives it. It is certain that there is no room, no motive, in natural religion for what is called evangelical love-the love which cleaves to God as a reconciled God in Christ; the love which makes the Christian feel that, as having received mercy himself, he should be merciful to others; that, as having heard the joyful sound himself, he should hasten to have it rung in the hearing of all others, and particularly of the poor, the ignorant, and the outcast. There is here spread out to our view a code of duties, or rather a group of graces, altogether peculiar to revealed religion, as founded and proceeding upon the revelation of a Divine Messenger who comes with overtures of peace to sinners.

SECT. VIII.-THE SYSTEM OF MEANS.

When man would secure any natural blessing, he uses means. If he would reap, he must sowthat is, he must scatter in order to gather. When he would obtain a competent share of the blessings of this world, he is diligent in his call- 
ing. When he would reach a higher knowledge, he hegins by mastering the elements. If he would get love, he must begin by giving love. There are, in like manner, means of obtaining blessings in the kingdom of grace; here, too, he who would reap must sow-he who would rise to sight must begin by exercising faith. The means by which we obtain the common blessings are, in both kingdoms, very simple and very obvious; the most careless may discover them, a child may understand them. In the spiritual kingdom, he who would obtain the blessings must ask them from Him who dispenses them. $\mathrm{He}$ who would acquire Divine knowledge must read the lesson book which the great Prophet of the Church has written, and hear those who have been appointed to expound it. There are symbols of entrance into communion with Christ, and symbols of growth in the Divine life, which all will be disposed practically to value who aspire after admission into the kingdom or advancement in it. Those who would obtain the spiritual grace will cherish trust and love towards Him who is the fountain of grace.

\section{"If a flower}

Were thrown you ont of heaven at intervals, You'd soon attain to a trick of looking up."

But there are better gifts thrown out from heaven 
than flowers; and those who wish and wait for them acquire an upward, a heavenward look.

In both, the means are usually crowned with success. He who continues in the use of them, sooner or later secures the blessing. But in neither are they certainly successful. He who has sown may not reap on the first harvest, nor is he sure of reaping every harvest. The diligent man may be disappointed in some of the plans which he has devised with greatest wisdom, and pursued with greatest energy. In like manner, he who reads and prays may not get the spiritual blessing the moment he asks, nor always when he asks. In both kingdoms, God has given sufficient inducement to the use of means; but in both he has kept the issue in his own hands, that all men, and all Christians in particular, may feel their dependence on him.

But, with the general correspondence there is a curious point of difference, which illustrates very strikingly God's method of accomplishing the same end by a difference of means. In both he has secured diligence; in both he has shewn that we are, after all, dependent on him. But, while these purposes are secured in both cases, there is this difference, that, in the kingdom of nature, the means accomplish their end by their own natural power, and fail only by cross arrangements of Providence which thwart their action and disappoint 
their issue; while, in the kingdom of grace, the means cannot accomplish the result, except by the immediate indwelling and operation of the Spirit of God. In the secular affairs of life, it is of all things essential that men use the means, in order that the economy of this world may move on, and that human activity may supply what mankind need; and all this must be done, whether men sinfully trust in the means, or are made to see that they need the blessing of heaven upon them. But, in the kingdom of grace the end throughout is a spiritual one, and men must not be allowed to trust in the mere ceremonial, in the opus operatum; the Christian must be taught throughout that the whole work is of God, and that trust in him is an end, as well as a means, in the spiritual economy.

SECT. IX.-THE SYSTEM OF THE DISPENSATION OF GRACE.

Not only is there system in the objective truths and ordinances of God, there is method in the manner in which the grace of the Spirit is dispensed.

There is plan in the manner in which it is imparted to every individual believer. It is an active element, introduced among old and opposing elements also active. It is likened to leaven 
deposited in the mass and fermenting it. It is ordinarily obtained in the use of means, thus rendering those who would secure it watchful and vigilant. From the very first, it meets with obstacles from the corrupt ingredients among which it is introduced. Commonly there is a great chafing of spirit as convictions lash the soul-like as winds do the ocean. Often is there a violent struggle in the throes of the new birth, as pride, and self-righteousness, and cherished lusts, oppose the entrance of faith, and self-denial, and love-and are defeated. The ocean, even when the waves are high, never seems to rage in all its fury except at the shore where it is opposed by barriers. The deepest stream will flow along softly, and almost imperceptibly, as long as it runs in a smoothly-worn channel; but let there be opposing rocks or cliffs, which dash it from one to another, and it is forthwith lashed into foam. It is from a like cause that Satan and our evil propensities never rage so furiously as when the grace of God, like a strong and immovable rock, opposes itself to the proud waves of the passions. There is more or less of a struggle during the whole life of the Christian. Hence, the spiritual life in the soul of man has ever been felt to be a work, in which toil has to be undergone in digging and building, and a warfare, in which 
there are many foes to contend against. "The flesh lusteth against the spirit, and the spirit against the flesh, and these are contrary the one to the other." This is a universal description of the believer's experience. The feelings of the writers of the Psalms are the same as those of the apostles; there is the same wrestling between two opposite principles, the same fears and hopes, the same anxieties and encouragements, the same defeats and conquests. Read the Confessions of Augustine, the lives or letters of the Reformers, and the diaries of later Christians, and there is the same sorrowing over a remainder of sin, with which there is a contest kept up, and which they hope in the end to conquer. It is very interesting, and instructive withal, to observe this uniformity of Christian experience; to observe believers separated from each other by so many ages, and living in such different states of socicty, so much the same in their feelings and in their character. We perceive that religion is alike in all ages,-the same grace of God acting on the same perverse nature.

But in this warfare, however doubtful the contest may seem at times to be, the spiritual power is all along the stronger, and will at last be seen to be so, as it gives peace of conscience and peace of heart, as it diffuses inward satisfac- 
tion, as it puts down heart corruption, as it elevates the whole motives of life and ends of being, as it expands and warms the heart by a self-forgetting love. It is now seen clearly by the Christian that what is thus planted within him is not a passing impulse, a floating fancy, a notion springing spontaneously, which may disappear as speedily, but is a system; he calls it a principle, a life-it is a seed becoming a plant, a birth maturing into a full grown being. There is evidently: a rationale in it throughout, though the man may not be able to discover all its laws and its reasons; and he piously ascribes the whole to the sovereignty of God, by which he does not mean the arbitrariness of God, or the capriciousness of God, but the inscrutable wisdom of God, and the goodness of God, who does all things wisely and well, but without condescending to submit his reasons to us. It is part of this wise system, that the work of grace is a progressive one. Not that the believer is every instant advancing in the Divine life. Alas, there are times when he feels as if all spiritual life within were withering and dying. But even then he is like the plant in winter, with some life and substance, ready for the first genial approach of spring, as "a teil plant and as an oak, whose substance is in them when they cast their leaves, so the holy seed shall be the substance thereof," 
and the believer on the whole is making progress, just as the healthy and vigorous tree does, from year to year. His course is like that of a stream, it may at times be a crooked and perplexed one, at times it may seem a backward one; but it is all the while pursuing its way, gathering contributions in its very turnings and windings, and widening and deepening as it moves on. The Christian has often been compared to a traveller. The traveller, on his way to the summit of a mountian, may meet with deep valleys, down which he has to descend, in order to his farther ascent, but on the whole he is rising higher. So it is with the believer; he may meet on his journey with valleys deep and dark as those of Baca, but on the whole he is rising nearer and nearer to perfection, and as he mounts, he breathes a purer and more ethereal atmosphere, and gains a wider and a nobler prospect.

Comparative anatomists have traced a curious general correspondence between the growth of the animal in the womb, and the advance of animated beings in the geological ages,-there being a progression in both cases from the lower to the higher, from the more simple and general to the more complex and special. I suppose that this correspondence arises from there being, in both cases, a like living agency acting in like circumstances. However this may be, it is cer- 
tain that there is an analogy between the system of grace in the heart of the individual, and the system of grace in the world. This correspondence arises from the life in the church being, like the life in the heart, a spiritual power in the midst of carnal materials. The one, like the other, is commonly conveyed by means, the instruments in the case of the church being commonly men and women, whose hearts have been kindled by it into a flame, and who now propagate the fire. In both, the spiritual power is a leaven pervading the circumambient mass - a plant meeting obstacles, and overcoming them, and ever, in the most unfavourable circumstances, seeking and growing towards the light. What a ferment in the first instance, when the gospel gets an entrance into a land; its disciples are everywhere maligned, are often shut up in prison, or consigned to the flames. All along, the church while in the world is a different body from the world, which is ever seeking by threats or seductions to drive or draw it from its allegiance to Christ. In these circumstances the church is often exposed to severe suffering, which is allowed to come upon it in the way of a chastening-which it deserves, which it needs. For how apt is that church to fall asleep when it should be active; or to trust in forms and ecclesiastical arrangements when it should be 
breathing the living spirit; or to drop some of the great truths which have been committed to its care; or to neglect certain great duties devolving on it_as for ages it neglected missionary effort; or to waste its energies in fruitless efforts -as in mediæval times in architecture and in ritual-or as in these times in the wars of contending sects. From all these and other causes, the church at large needs afflictions, as the private Christian does ; and to keep it from settling upon its lees it is emptied from vessel to vessel; and offences come to make it feel where its strength lies; and heresies spring up to compel it to fall back more implicitly and unreservedly upon the revealed truth of God; and lest it should waste its energy in an internal strife, it is made to see a powerful enemy in front. But in spite of all these persecutions, at times in consequence of them, it is making progress. Not that it is ever progressing, or progressing always at the same rate. Its movement is like that of the ocean by tides and waves, like that of light by vibrations. "We see not yet all things put under him," but we see a living power at work which shall at last bring all things into subjection. In reference to his own personal work on earth, Jesus could say ere he expired-" It is finished." He can say the same in regard to the work which he carries on in the breasts of 
his people, till all sin is conquered-" It is finished." He will at last be able to use the same language in regard to the work which he is conducting on earth, till the knowledge of the Lord covers the earth-" It is finished." 
CHAPTER III.

THE EVIDENCES OF CHRISTIANITY.

SECT. I. A STUDY OF THE CHRISTIAN EVIDENCES. THE EVIDENCES A SYSTEM.

IT was never intended in this Treatise to furnish an exposition of the Evidences of Christianity; this has been provided so frequently and so satisfactorily in other works that I feel I have nothing new to offer. My aim has been simply to clear the ground of incumbrances and obstructions, so as to allow us to attend to the instruction: "Walk about Zion, and go round about her; tell the towers thereof. Mark ye well her bulwarks, consider her palaces ; that ye may tell it to the generation following." It has become necessary in these days to keep inquiring minds from starting, after the manner of the German Strauss and the British Baden Powell, with the principle that everything that professes to be supernatural is to be regarded as opposed to reason and the inductive philosophy. I have gained the end I had in view-so far as apolo- 
getics are concerned-if I set out intelligent young men upon the study of the Christian Evidences, prepared to consider the proof advanced as if it were in favour of a natural, and not a supernatural system.

The way in which we who live in these times and countries arrive at a reasonable belief in the Divine origin of Christianity, does not differ essentially from the manner in which we reach an independent conviction of the existence of God. In both we may start with certain ideas, and it may be prepossessions and educational faiths; but we could easily lay these aside-and in these enlightened times would certainly lay them asidewere it not that they are authorised, sanctioned, and confirmed by what is ever pressing itself upon our notice:-in the one case, that of our belief in God, by internal principles, founding on the obvious traces of order and adaptation in the universe; and, in the other, that of our belief in Christ, by the truths of the Word, and the external evidence in its favour, as these recommend themselves to our moral nature, to our felt wants, and to our intelligence.

Let us exactly estimate the position in which a thinking youth finds himself in our land, in these times, when he would examine the Christian religion and its evidences. He has been taught that this religion, professed by his parents 
and generally by his countrymen, rich and poor, learned and unlearned, has come from God. He has an acquaintance, more or less particular, with the tenets set forth in the Scriptures; and he sees the influence which they exercise on society at large, or on individuals. $\mathrm{He}$ has enough to prevent him from summarily rejecting Christianity, and to make him feel it to be his duty to make farther inquiry into the religion and its credentials. If he has ever thought on the subject of evidence, he will see that, in all practical matters, the proof which convinces comes from a variety of quarters, and that assent is gained by the concurrence of independent facts. First, we may suppose he considers candidly the doctrines set forth in the written record, and he is constrained to acknowledge as to many of them, that they are worthy of God, as he is made known by inward conscience and outward providence, and that they are suited to man, to his moral nature, his deeper wants, and his position as a being who has to appear at a judgment seat. $\mathrm{He}$ finds it stated, that the Founder of the religion wrought miracles of power and mercy, and that he rose from the dead; he does not propose to settle theoretically what nature cannot do, and what it can do, but he is sure, that if one raised others from the dead, or rose himself, the operation is beyond 
all natural agency. He reads the testimony of the witnesses, and sees it to be characterized by open and transparent guilelessness, and he feels that he should trust it as he does the narratives of Herodotus, or Xenophon, or Julius Cæsar, as to ancient history; or of Bruce, of Park, or of Livingstone, as to distant countries. He finds, too, a series of predictions of a very old date, and he compares them with events certainly of a later date, and detailed by independent annalists and travellers, and he is constrained to discern a correspondence far beyond what human sagacity could have foreseen. The evidence which is thus so accessible to him, he finds to be a system, every part of which supports the other, and all tend to one conclusion. He has already good prima facie proof in favour of Christianity, quite as much so as in behalf of the ordinary truths of science, or the common events of history, or the occurrences of his time and neighbourhood. What I insist on is, that as he yields his assent to the natural truths, and acts upon his conviction, so he should also give a willing assent to the supernatural acts; and, as this is pre-eminently a practical matter, he should add the consent of the will to the assent of the understanding, and enter by faith into possession of the blessings secured.

As he does so he will find that new evidence 
pours in upon him. His eye having been singly bent upon discovering the light of truth, he is rewarded first by discovering light, and then, in that light he finds his way to more light. When the boy believes the Copernican and Newtonian theories of the heavens on the fair evidence presented to him, he finds in all his after life experimental confirmation of the doctrines. The young anatomist who rejects the theory that the backbone is made up of vertebræ will find himself involved in ever-increasing difficulties, as he would reach a consistent view of the skeleton; but, let him admit the hypothesis, and he has corroborations in every bone of the frame. In like manner, he who rejects Christianity shall find that he has turned his back upon the light, and that he is walking into deeper darkness; while he who is led to embrace it, by its primary proof, will find that he has his face to the light, that the shadow is behind him, and that more light shines upon him as he advances. He will see every day, more and more clearly, that the gift of God's Son harmonizes all things in this world; and, as he exercises faith on the Saviour, he has within himself the most convincing of all proof, because an experimental proof.

But neither is this evidence independent of the other proofs, and we run the risk of extinguishing it, or rather of hindering it from 
being kindled, if we do not allow them to feed it. For the question arises, how are those who have not this inward witness to obtain it? If the answer be, by confiding in the religion proffered us, this only raises the question, on what ground is this demanded? If the reply be, "only believe," I ask, believe in what? and if the demand be to believe in the religion of our fathers or of our country, then I shew that this would justify the Arab in believing in the Koran. The human intellect is so constituted that in order to conviction there must be fair evidence supplied, and when this is not presented, minds of the higher sort will be apt to resist and resent the attempts made to coerce them, or to gain them on the ground of mere hereditary opinion. There is an utter ignorance of human nature shewn by those who tell the anxious inquirer that he needs no other witness than the experimental one, for the person feels -painfully feels it may be-that as yet he has not that heart testimony, and may probably turn upon you, and tell you with great bitterness, that he is without it, and ask what you can do for him in his present state. As I understand the plan of salvation, there must be some faith before any man can have the inward light. It is to faith, as receiving it, that the grace is imparted which becomes the witness. The evi- 
dence which gains the assent may not embrace all that is expounded in books of apologetics; it may not be systematized or expressed by him who is swayed by it; it may be of the simplest possible character, derived from the reading of the Word, and a recognition of the truths there revealed as suited to our nature, and evidently provided by the good God who made us, and the holy God who rules the world; still it is evidence good in itself, and when it gains the will and has power in the heart the man has now more satisfactory proof, than ever he had before, in this light within,- which has depended on the preliminary faith and evidence, only as the burning lamp has upon the taper which kindled it. It is upon this internal experience that the believer ever falls back, when at any time he is harassed by doubts or oppressed by fears. $\mathrm{He}$ may not be able to answer all the objections urged against religion. He may not be able to shew wherein lies the fallacy of Hume's objections to miracles-any more than he can solve all the dfficulties which the same ingenious sceptic has started about the existence of matter. He cannot, it may be, shew the very reconciliation of the progression in the opening chapter of Genesis, with the progression of palæontology, (though he sees a general correspondence,) nor rebut every scoffing assertion, put by the Rev. 
Rowland Williams into the mouth of Bunsen (who never scoffed, and was so devout and loving, despite the emptiness and inconsistencies of his creed), nor clear up every doubt uttered with so wild a cry by the Rev. Benjamin Jowett, who looks so sorry because he has lost his early faith, and yet cannot repent of his having parted with it. Still, he has attained a most reasonable conviction, and he stands-and he feels he can stand firmly-upon the overwhelming evidence which he has in the felt power of religion. So far as he has time to enter into the controversy, he is convinced that the argument is all on the side of the defenders of Christianity: But his defence, when every other fails him, will be- "I am not able to demonstrate it, or confute all your objections; but I feel it, I know it to be true." The meaning of all this is, that he, a simple, perhaps an unlettered, or a practically busy Christian has not been trained and is not accustomed, to give his reasons for his conviction. But he is not, therefore, without his reasons. It is an argument valid in every way; it is an argument with the premises and the conclusion both within his own experience. It is an argument from effect to cause; he argues that the religion must be Divine which has had, which has, such a beneficent influence in giving peace and in gaining victories over the evil inclinations of the heart. 
According to this representation, there is an important end served by works on the Christian Evidences. I am aware that some excellent Christians speak disparagingly of all books on apologetic theology, and of addresses on religious subjects to what they call the logical understanding. And $\mathrm{I}$ allow at once that the understanding cannot do everything, that it cannot fulfil the highest offices in religion; I admit it as a fact of our mental nature, that no logical act of the mind does of itself call forth feeling. No abstract notion, no general notion, no proposition as a proposition, no linked ratiocination, is fitted to excite love or emotion of any kind. Feeling is evoked by the perceived presence, or by the mental apprehension and image of a person, or of an individual object of some description. But still, the discursive processes of the mind, as part of the constitution given us by God, have important purposes to serve. The abstract or general notion logically formed clears our apprehensions, and may allow the affection to flow forth towards its proper object. A false proposition assented to, and a perverted train of reasoning, may turn aside the whole current of the sentiments, when they were ready to flow in the right channel. Conrince the son that his father has committed a dishonest or dishonourable action, and his feeling of esteem 
instantly suffers a fearful revulsion. Reason us into the opinion that Jesus Christ is not what he professed, or that he did a dishonourable action, and our reverence for him is sadly interfered with. When the understanding is not gained, the pictures of the fancy pass away like the incidents of the drama or the novel, which no doubt leave their impression for good or for evil, but do not engage any abiding affection towards the character's, or issue in any course of practical conduct directed towards them. It was never meant that our varied mental powers should be separated in the convictions we cherish towards God and the homage we pay him,just as it was never intended that we should mu. tilate or divide the members of our frame in our corporeal exercises. Every one knows that the utter neglect or even the undue use of any of our bodily organs disfigures the general form; and a like prejudicial influence is exercised upon the soul when, in our pious acts and services, we disunite those faculties which ought all to be consecrated to God, and dedicated to his service, and which ever operate best when they cooperate,-when, for example, we give.such a dominating authority to the understanding as to become rationalists, or so indulge the feelings as to become sentimentalists, or allot to outward symbolism such a position in our worship as to 
make it take the place of God. We do claim for the understanding an important place in religion, as being in a sense the very bones of the body, and yet we would have no one to stop and rest satisfied with a mere head conviction. There is never true faith till the will, the choice, the consent of the mind be gained-that is, till we, as it were, concur in what we discover to be true. And with this, and following upon it, there will be affection,-affection warm and living, rising beyond all discursive acts, embracing the object and clinging to it with a grasp which can never be loosened.*

It was a most perilous course which was followed in Oxford an age ago, when men of erudition and friendly to religion laboured to shew that the Evidences of Religion, Natural and Revealed, could not stand the tests of logical evidence. Two very opposite and yet not inconsistent results followed. Those who had deep natural faith, feeling that they must have something to lean on, were induced to leap into the arms of a pretended infallible church, rather than be left in the dreary desert of unbelief, or be driven out into the awful gulf of atheism. As falling among other materials,

* The above is the way in which I would settle the questions discussed by Dr. Dorner in his Letter to the British Churches, by the Bishop of Cork in his Letter to me, and again by Dorner in the Tahrbücher für Deutsche Theologie. 
the sparks kindled a very different conflagration. Not a few, unable to accept the inconsistencies and follies of the Romish Church, were left out on the wide waste to which they had been conducted by those who should have led them in a far different route, and have ever since been restless-and conceited withal; looking wise above others, as they let you know that they see the errors of the vulgar creed, but ever constrained to look out on the dark waters before them, and unable to settle on any fixed conviction, or accept any solid doctrine; and in this painful position some of them pour out their soul in a plaintive tone, as those who have lost something in which they trusted, but in which they trust no longer; while others find a sort of relief in scoffing and reviling.

Nor is this state of things much if at all improved, when some of those who go to the negative side, after they have shewn or rather asserted that the ordinary arguments in behalf of Christianity are inconclusive, hand us over to an inexplicable, an unreasoning, and unreasonable faith, which says nothing in behalf of Christianity more than it does in favour of Buddhism. 'This was the very method of David Hume as he mocked at Christianity,- - he was not meaning to treat religion with disrespect when he shewed that it could not stand a sifting inspection by 
the reason, he was rather honouring it when lie consigned it to the region of faith !! It is a curious circumstance, that some unwise friends of Christianity at the time were deceived by this style of speaking, and actually maintained that the great sceptic was benefiting religion, and placing it upon a surer basis than those who defended it by argument. This is the method which has been followed in our day by Mr. B. Powell, who proceeds systematically to undermine our belief in the supernatural, as a reasonable conviction which can stand the tests of modern induction, and then commits us to some sort of faith or moral vision, of whose nature he gives no account, and whose claims upon our attention he is at no pains to vindicate. It is a circumstance to be regretted that this is the method practically followed by some in our time, who would shrink with horror from the blank scepticism of Hume, and are entirely opposed to the cold naturalism of Mr. Powell. Those to whom I now refer, after cutting off all the common arguments in behalf of the Divine existence and of Christianity, still insist that mankind should believe. But it has turned out, as any man of ordinary sagacity might have foreseen, that those who have followed them in their speculative scepticism refuse to be led by them-indeed feel that they cannot obey them-when bidden 
to believe. These doubts and sceptical principles may exercise no influence for evil on those middle-aged men who have reached a settled conviction, and who can stand secure, though the ladder by which they mounted be taken down, as they will certainly be felt to be harmless by those who have the light of the Spirit to keep them from wandering; but I fear, that unless counteracted, they may leave their impression on those young men who have attained to no decided belief, and who feel that they have no means left them of reaching the heights which they see far above them. The natural effect on their minds will be, that they decline accepting a religion which is supposed to be incapable of defence; and it is vain for good men to exhort them to seek the light, after they have taken such pains to shew that there is no evidence that light is to be found.

In opposition to all this prevailing style of thought and sentiment, of doubt, insinuation, inuendo, and complaint, it should be openly declared and resolutely maintained that the Divine origin of Christianity can be defended to the satisfaction of the human understanding. The Rev. Mark Pattison would leave the impression on our minds, that the Defences of Religion by writers in England, from the Revolution Settlement to the Middle of Last Century, were 
an entire failure. But among his learned literary sketches, and his petty carpings, we look in vain for any clear and broad statement of the grounds on which he reckons the arguments as inconclusive. Some dozen writers of considerable ability had made an attack on Christianity, and they were answered by many scores of authors, who wrote hundreds of works of all sizes, from the ephemeral pamphlet up to the octavo or folio of several volumes, and poured them forth every year, at times every few months, for two or three ages. The works of some of the deistical writers had a considerable salelarger than even the "Essays and Reviews" have had-and the authors and their supporters spoke with high confidence, and boasted that as Christianity had already been abandoned by free and independent thinkers, it would be cast off by all before the end of the century. The names of some of the English deists are still occasionally referred to, but their works are placed upon the inaccessible shelves of our great libraries, and are seldom taken down except by literary antiquarians and theological controversialists. The same fate has befallen the greater part of the replies to them, many of which were distinguished by ability quite equal to that of their opponents. In opposition to the ipse dixit of Mr. Pattison, I give it as my decided convic- 
tion, the result of a considerable acquaintance with both sides of the controversy, that the objections of the deistical writers were fully and fairly met by the defenders of the faith, as they were certainly believed to be so by the country at large, which, long before the time when Christianity was expected to fall, had ceased to read the attacks on it, and therefore ceased to read the mass of the replies to them. And there were defences produced at that time, such as those of Clarke, of Butler, and of Lardner, which are not superseded, which have never been systematically answered, and which are not to be overthrown by a small criticism, or the detection of some non-essential oversight or inaccuracy. It is all true that the defences were not always nor usually such as would be advanced in our day, but then, neither were the assaults. Those who stood up for Christianity, caught the spirit of their times; they had to proceed on the principles given or granted to them, and to make their arguments face the weapons of the opponents. In modern warfare we do not use shields as the ancients did, nor do we erect the same sort of fortresses as our fathers did in feudal times. When the philosophy of Locke was reigning in last century, the assailants of Christianity proceeded upon its mixed sensationalism; utilitarianism, and rationalism, and the defenders 
of Christianity did the same, and foiled their opponents with their own weapons. Now that the reaction against Locke has been very strong among a certain class of thinkers, it would not be wise to reproduce the old defences in precisely the same form,-just as no one would now erect the old baronial tower to resist the modern gunnery and grape shot. But the Christianity which survived the autumnal decay and the winter cold of last century will not only stand, but will shoot vigorously upward, in the spring revival with which it is now visited, and will be found-like the plant-to have defences ready to meet the attacks made on it.

The infidel writers of our day have not more ability than those of the first half of last century, and they certainly have not nearly the same amount of originality and independence. Their weapons are avowedly borrowed from Germany, and the objections advanced, whether philosophical, critical, or historical, have, I believe, been answered in the land of their birth. In that country the great theologians of the age now passing away, and of the present age, have wrestled with the infidelity of the past age or two, and have overcome it. It is scarcely honest in men who are scholars, to propagate the objections, the cavils, and the doubts of the rationalist or infidel writers of Germany, without 
letting us know that the leading living divines of Germany think they have answered them, and are generally allowed to have done so by those who study these subjects in that country; and that the young life of Germany is so convinced of this, that the students of the Universities with eager looks throng (as I can testify from personal visits) the class rooms of the defenders of the old and orthodox theology, while the rationalists are lecturing to nearly empty benches, the few occupants of which shew plainly, by their whole manner, that they have no faith in their preceptors. It was not right in Mr. $R$. Williams to use the name of Bunsen, without apprizing us that that distinguished man has not had, for the last ten years, the least influence in Germany as a thinker or a divine,-however much he has been revered and beloved for his genius, his literary ability, his attachment to religious liberty, and his noble personal character as a man and a Christian. In a treatise devoted to a special topic, we cannot give the defences that have appeared in Germany of the Word of God and its leading doctrines; but they will now be produced in abundance in this country, either in translations, or, better still, transmitted through the minds of Englishmen, who, while they freely use the materials prepared for them, at the same time give them a 
form and a direction suited to the tastes and wants of our age and nation.

The Christian apologist should ever bear in mind as for himself, and he should always let it appear in his writings, that he does not stand on any one of the proofs, since he has so many. Every one of the parts, indeed, has some force, but their strength lies in their combination. He who would force an entrance is not to be allowed to break the links one by one, - but must face the whole complex chain-work. It is easy to insinuate doubt and start difficulties, - there are some whose intellectual temper leads them to do so in regard to every topic; and in every profound subject perplexities can be found by those who are bent on discovering them. It should be allowed in regard to revealed truth, that it is not difficult to fall in with real difficulties :originating in the brevity of the narratives transmitted to us ; in our consequent ignorance of the whole facts; in the apparent discrepancies thus produced as we want the reconciling fact; in the incidents having occurred in remote ages and times, when the manners, and feelings, and modes of speaking and address, were so different from what they now are; in natural feelings being allowed their play in the inspired writings; in the occasional corruptions which have crept into manuscript texts of the Scripture; in 
the high and mysterious character of many of the doctrines taught; and in the limited capacities of man; or it may be in many other circumstances. By fixing the attention on one or two of these difficulties, and by gazing on them till they have become enlarged and assumed a formidable shape in the twilight, we may create a plausible objection,- - just as we have found in our own personal history, that the most innocent incidents have been made to take a sinister and suspicious appearance, by being separated from the circumstances and the connexions. It is the policy of the infidel, to draw off the attention from the grand body of evidence to the minute perplexities and apparent discrepancies, and this often by hint and inuendo, rather than direct assertion. Christian apologists, each in his own department, must consider these difficulties; but they should never allow their whole forces to be drawn down into a disadvantageous hollow, where the fight becomes a squabble, in which a very weak but impudent enemy may seem to be gaining the victory. In going down to meet the adversary in detail, they should feel for themselves, and make it appear to all onlookers, that their strength lies in their grand general proof; and as they do so they may, without damaging their cause, allow that there are difficulties which they cannot entirely 
meet, and mysteries which they cannot fully clear up.

Were it within our special subject, it might be shewn by a historico-critical dissertation that, in every age of the Church of God, sufficient evidence has been furnished to the candid mind of the operation of a supernatural power. It should be added, that in no age has proof of such a character been furnished as to preclude the possibility of doubt. I believe that the very existence of God is not a truth of so intuitive or demonstrative a character, as to make it impossible for the fool to say in his heart that there is no God. In regard to the Bible revelation, God has given sufficient proof to convince every truth-seeking mind, but not enough to prevent cavilling. There is thus a sort of moral probation in the way in which the evidence is presented.

In some respects it is more difficult for those educated up to the advanced science of our age to believe in a supernatural operation, than for those who lived in earlier times, when the distinction between the Divine and the mundane had not been clearly drawn. And, again, since the days of Niebuhr, historical criticism has been altogether setting aside a thousand legends, in which our forefathers supposed there might be some discoverable truth. But then, to coun- 
terbalance all this, we have now reached a firm settlement and a clear expression of many scientific and critical principles, which were before undefined and disputed. In primitive ages and rude states of society, it has not been determined how much or how little nature can do, and so persons ascribe to the supernatural what is purely natural; but they may also refer to nature what is miraculous. In such stages of society, adults are in the position in which children still are, who would not be astonished though you were to tell them that a dog had spoken, or that a cat could fly, or that the moon might be brought down and exposed for inspection on the table. The savage could easily be persuaded that balloons are heavenly visitants, and that steamships are moving gods. In such a state of things, much might be ascribed to the unknown powers of the world, which really came from the special operation of God. But in these ages and countries, while we are still far enough from knowing all that nature can do, we know that it has certain impassable limits imposed upon it; we know that no human skill can cure organic diseases, that no human power can raise the dead. Historical criticism has certainly set aside many narratives which were fondly credited in former days; but then, it has laid down rules which decide that certain other narratives are 
not to be denied. It has made us doubt of the legends of early Greece and Rome, because we have, in fact, no original witnesses in their favour; but it has made it impossible for us to doubt of the poisoning of Socrates, of the conquests of Alexander, of the battle of Pharsalia, of the assassination of Julius Cresar; and none of these events is supported by better evidence than the crucifixion of Jesus and his resurrection from the dead.

If it be true that in these times we have a more expanded view of the system of nature, it is also true, that from the height we have reached, we have a better comprehension of Christianity, of its varied evidences, and of the influence which it exercises for good on nations and on individuals. If the telescope has disclosed to us new worlds under natural law, the revelation of God has shewn us spiritual lights, which we now clearly discover to be under yet higher law. If geology has carried us far beyond human and historical ages, and has shewn the same causes operating in them all and down to this present time, the Word of God brings before us a counsel and a plan, beginning before creation, and kept in view in all creation, and being executed in time. If the combined lights of history and of travels let us see more of the character and ways of mankind, they also prove more 
clearly and unequivocally, that man has never risen by his own unaided exertion to a pure religion, or the conception of a pure morality. With the completed Scriptures in our hands in a printed form, and with the light thrown upon them by the observation of travellers in eastern countries and the researches of scholars, we can more readily compare one part with another and rise to a connected view of the whole. We now see more fully than our fathers could do the fulfilment of prophecy; in the Jews scattered among all nations; in the present condition of the Bible lands; in the fate of the Assyrian, the Babylonian, and Egyptian empires; in the progress of the kingdom of Christ; and in the mighty power once reacbed by the Romish Church, and the struggles it is making prior to its ultimate fall. We have a wider experience, than those who lived in former times, as to the inability of unaided reason to provide a pure religion satisfactory to the wants of mankind. The Fathers of the Church urged, with great power, that for many long ages human nature had had a fair field in which to shew what it could do without a revelation. But, to the experimental facts known to the early apologists of the faith, we have now an immense addition gathered from all descriptions of countries, from the savage life of Africa, America, and Australia, 
and from the hundreds of millions of the semicivilized inhabitants of China and Japan.

We can likewise point to experiments of a new kind, in the attempts which have been made to supersede Christianity by those who have had the advantage of the light shed by its revealed truths. We had, for example, the attempts of the French deists or atheists towards the close of last century, leading to the disorganization of all society, and kept from intolerable disorder only by the rise of a military despotism, and a determined reaction in favour of Romish Christianity. About the same time we had, in our own land, the rationalistic and good morality school, which has been felt to be utterly powerless to move the heart or gain the affections of the great mass of the people, who were left in the lower streets of our great cities, and in many of our rural districts too, without any attempt to elevate them. It has been shewn by this last experiment, that while a fair outward morality may abide for an age or so after religion has ceased to operate as a living power, it is only to disappear and to be turned into vice and degradation in the succeeding generation,-just as the train may go on for a time after the engine has been taken off, but will cease in the end to have any motion-except it be a downward and destructive one. We have also had, at a later date, 
among a portion of the educated classes all over Europe, the bolder attempts of the great pantheistic school of Germany, ending in utter speculative confusion, and in acknowledged failure in the land of its birth, and sweeping over other countries without influencing any beyond a few speculative or literary men, who cannot be said to have got peace for themselves, and who have nothing to offer to others. Many a modern system builder, after spending a lifetime in opposing Christianity, has been obliged to feel, if not to say, with Julian, "Thou hast conquered me, O Galilean."

And what has the Naturalist School, which is now springing up on the debris of the rationalistic and pantheistic systems, to offer to the poor in their wants, to the sorrowing in their bereavements, to the sick in their helplessness, to the outcast in their degradation, to bear them up, to cheer them and regenerate them. The believers in mere natural force have generally kept out of the way of such-except indeed at times to relieve their temporal wants-and when at any time they have been brought face to face with them, they have commonly been struck with dumbness, as feeling that they have no balm to offer to their wounded and bleeding spirits. Not that we are to look on the Gospel as fitted only for the poor and degraded. I 
believe that the very rich are often made to feel their poverty in the midst of their wealth; and the gay their need of an abiding object in the midst of their pleasures; and the refined their need of a deeper enjoyment in the midst of their elegances and comforts; that the learned feel their ignorance in the midst of their accumulations of facts and opinions; that the self-righteous man feels that he wants an embankment to beat back the waters when they would flow in at the low places of his soul; and the strongest and most confident are impressed with their helplessness when temptations come in among their passions - as the burning ships did into the heart of the Armada; and where are remedies to be found for all these felt evils, so varied in the case of different individuals, and so deep in the heart of each, save in the religion of the cross of Christ?

SECT. II.-CONNEXION BETWEEN THE MIRACLE AND THE DOCTRINE.

The relation between these two easily settles itself practically, in the sincere and unsophisti. cated mind. We cannot have a clear idea of it theoretically, without making a number of explanations and distinctions. 
In regard to certain of the doctrines, such as that of the Holy Trinity, and the Deity of Jesus Christ, we accept them on the authority of God speaking in his Word, and we have proof that God there speaks, from the miracles wrought in attestation, taken always in combination with the general doctrines of Scripture, as commending themselves to our moral reason, and as being thus seen to be worthy of God. Again, in regard to some of the miracles, it may be said to be rather the general authority of Scripture which leads us to look on them as beyond natural power. For, taken apart and by themselves, they are not supported by such an amount of testimony as would bear them up; or they might be regarded simply as mundane occurrences. We believe them because we believe the Bible, which, however, has a combination of unimpeachable witnesses to vouch for it.

Deducting such cases, it appears to me that the doctrines and the miracles concur and conspire in the issue to which we are led. They unite, as mixed elements commonly do, as the ground of our convictions in the common affairs of life. How often, for example, do we look to the character of the witness, and to the manner of his testimony, and the nature of the fact he depones to, before we give or withhold our assent to his declarations. The man of candour and 
ordinary shrewduess easily combines these into a consistent unity, while it might require a skilful analysis to spread out the parts of the argument in a logical manner, and reduce them to regular formulæ. It is in much the same way, that the truths revealed and the miracles attesting them are blended into a very satisfactory evidence by a truth-seeking mind, which may not meanwhile, and unless it has been logically trained, be able or inclined to untwist the threads, and allot to each its evidential value.

As I understand the inspired writers, we are invited to look both to the miracles and to the doctrines, and also to the circumstances in which the revelation was made, and the position in which man is placed, as evidence of the truth of the Christian religion. The miracles are wrought in behalf of revelations which commend themselves to our higher reason and meet our deeper wants. In particular, the miracles of our Lord are associated with a character of the highest purity, with motives of the most perfect transparency, and with ends of the most disinterested benevolence. What we read of the person of Jesus, and of the spirit he exhibited, and the truths he set forth, and the precepts he inculcated, makes us attend to his miracles, which again assure us that he is a teacher sent from God, and we believe what he taught. We look 
to the revelation which God is alleged to have made, and we find it in every way suited to our moral nature and state, as bridging over the awful gulf which separates the holy God from the sinful creature, and thus bringing peace to our dissatisfied minds and troubled consciences, and providing a means of enabling us to rise to communion with God and a heavenly purity. We wonder if all this can indeed be true, and we examine the series of alleged supernatural events wrought in attestation, and we find them sustained by evidence quite as unexceptionable as we have in behalf of any occurrence handed down from ancient times. Our conviction is gained, not so much by the force of either of these considerations. singly, as by the way in which they fit into one another. This process is not " reasoning in a circle." We do not assume without evidence that the doctrine is true and proves the miracle, and then take for granted that a miracle has been wrought and establishes the doctrine. The character of Jesus commends itself to our highest moral idea, and the salvation provided by him meets our deepest moral wants; while we have satisfactory evidence of the performance of works which, from their very nature, must be superhuman. Each side stands on an independent basis; but each helps also to support the other, as they meet in an arch 
which bears up those mysterious doctrines which relate to distinctions in the Divine nature and the constitution of the person of Jesus.

All that a miracle by itself proves, is the operation of a supernatural power. The purpose for which it is wrought must be gathered from the concomitant circumstances, which, in the case of most of the miracles recorded in Scripture, are quite sufficient to shew that the event has been wrought by God, and rot by any inferior or evil power. Being openly and publicly appealed to, by those who performed them, as operations of God, they pledge the Divine veracity to the mission of the worker.

The question is here started, can a miracle vouch for an immoral doctrine or for an untruth? It is quite conceivable, I think, that a preternatural work might be wrought in behalf of a sinful practice or a positive falsehood. But even so, it could not sanction either the one or other. The good God being governor, we cannot believe him to allow an event to take place, fitted in itself, or meant by him, to support the evil which he so evidently condemns. As to a miracle or anything else proving a falsehood, it could do so only by destroying the primary laws of our intellectual constitution. A preternatural event, wrought in behalf of vice or falsehood (if such there be), must be the work of an evil 
spirit, and not of the God of goodness and truth. A question may be started as to whether God could or would permit an evil power so to interfere in our world. Of one thing I am very certain, that God would never allow such an interposition, unless he had provided a counter light sufficient to keep all who are seeking the truth from being deceived. I am inclined to think that God has allowed preternatural events to be wrought in our world by the great Adversary; but then there was always a means of enabling those who witnessed them to refer them to their proper author, to him who had been a liar from the beginning; and it is always arranged that the Wicked Power is immediately and evidently overwhelmed by the Good Power, bringing good out of evil and making the very malice of devils to praise him. In the tremendous convulsions which shook Pharaoh's throne, till the children of Israel were let go, there were awful exertions made by an ungodly power, and some of these, if we follow the obvious interpretation of Scripture, look as if they surpassed the limits of nature. But it is to be observed, that Satan's power is thus extended, only that it may be overwhelmed by the immediate forthputting of the higher power of God. In the opening of the New Testament dispensation, the license of Satan seems to be enlarged, and he is allowed 
to interfere in our world in a way usually forbidden, in gracious consideration of our weakness: but all this is only to call forth a more signal display of the powers of Jesus, and to draw a confession from the mouths of demons. These lurid lights are allowed to rise from the regions below to amaze and bewilder, only when there are superior lights hung out in the firmament to guide the seekers of truth in the right path.

As the revelation of God is unfolded; a system of doctrine emerges, which can easily be apprehended, and which may be legitimately employed to attest alleged miracles, at least so far as to entitle us in certain cases to reject them as deeds wrought by God. "If there arise among you a prophet or a dreamer of dreams and giveth thee a sign or a wonder, and the sign or wonder come to pass whereof he spake unto thee, saying, let us go after other gods which thou hast not known, and let us serve them; thou shalt not hearken unto the words of that prophet or that dreamer of dreams, for the Lord your God proveth you, to know whether ye love the Lord your God with all your heart and with all your soul" (Deut. xiii. 1-3). Here it is declared that a wonder, natural or preternatural, might be permitted to be wrought for ungodly purposes; that when so allowed, it is in order to test the loyalty of those who have light; and that 
the wonder is not to be viewed as having the sanction of God. The same principle is laid down in the warning (Deut. xviii. 20) against prophets that "shall speak in the name of other gods." A like test is announced in the New Testament dispensation. "But though we or an angel from heaven preach any other gospel unto you than that which we have preached unto you, let him be accursed" (Gal. i. 8). It is on this principle that Protestants reject in so summary a manner the miracles of the Romish Church; they say, that being wrought in behalf of error they cannot be from the God of truth. Those who are disposed to look upon the occurrences as preternatural will tell you that they are wrought by the Powers of Evil ; while the majority of Protestants maintain that they bear no marks of being isupernatural-that they are the offspring of a heated imagination or of deceit, of one or both. In all this they can be justified throughout, on the supposition that the system in behalf of which they are wrought is condemned in Scripture. If in the latter ages of the Church miracles of God be renewed, and lying wonders also permitted from beneath ( 2 Thess. ii. 9), depend upon it men will always have means of distinguishing between them, and tracing both to their proper source in heaven or in hell. 
SECT. III.-ENDS ACCOMPLISHED BY THE SYSTEMATIC CHARACTER OF REVELATION.

I. The way in which we reach the conviction that there is a supernatural system, does not differ so much as some imagine, from the process by which we discover and authenticate the natural system.

At the basis of our belief in regard to natural uniformity there are (as we have seen, Bk. I. c. iii.) certain intuitions which do not prove indeed that there is regularity, but are ever prompting us to take notice of it. The discovery is actually the result of a long course of inquiry, giving us an accumulation of inductions, all tending to one conclusion. Each department of nature, as it comes under inspection, is found to be conformed to uniform laws. It was perceived at a very early date that the sun, moon, and stars have settled courses, and are regular in their very irregularities. This did not prove that the tides are under the sway of physical causes; but as they who dwelt near the sea coast watched their ebb and flow, they found that they too had fixed times, which are shewn by later science to be determined by the attractions of the sun and moon. All this is no evidence that law rules among these winds, which seem to rise and fall 
so capriciously, but in due time it comes to be ascertained that according to a law of equilibrium, they ever flow towards the place at which the atmosphere is more rarefied. All this time there is no proof that the sun may not shine by a supernatural exercise of Divine Power, but later science informs us that the sunbeam is correlated with the heat and mechanical power which play so active a part in our earth and atmosphere. The evidence cumulates, till at last we have in the particular laws a sufficient support to the general law, that there is uniformity throughout the Cosmos.

But let us carefully observe what is the precise truth which we have reached. We have gained the positive rule, that there is a set of natural agencies everywhere acting uniformly, but we have. not established-which is a very different thing-the negative rule, that there is nothing else. Every one will admit that what astronomy has demonstrated is, that gravitation universally operates, but not that there is no other force acting in the world or beyond it. In like manner, what science as a whole has ascertained is, that natural law operates everywhere, but not that there is nothing but natural law. We have good grounds of belief as to the prevalence of mundane law, but no "grounds of disbelief" as to the exercise of preternatural power, so as to entitle us to 
say that it is impossible, inconceivable, or incredible. So far from this, it is quite by an analogous process that we reach the conviction that there is a supernatural system, superinduced upon the natural and acting in the midst of it.

First, there are certain internal convictions and feelings which prompt us to look for a supernatural power. There are deep mental principles which, as they look to certain obvious facts in nature, constrain us to believe in a Being above nature. This does not prove that this Being acts in our world in a supernatural way; but it prepares us to believe that he may so act if it pleases him. And everywhere are there facts pressing themselves on our notice, from without and from within, which seem to say that it is possible or probable that God may interpose among natural agents, not to thwart his own ends, but to complete his evident plans. We are made to acknowledge on the one hand that God hates sin, and on the other hand that sin universally prevails. We are sure that God will by no means clear the guilty, and yet we cling to the hope that he is not altogether unappeasable. When we look up to him we are made to feel that he is at an infinite height above us, and yet we have a strong confidence that he is not altogether unknowable or unapproachable. But, however anxiously we may go in search of it, we can find 
in nature no reconciliation of these separated truths. Under these fears and hopes, there has ever been a disposition on the part of men to look for supernatural manifestations, and they have discovered them when they had no evidential warrant for so doing; in the awful stillness they have heard sounds which originated in the subjective intensity of their own longings; as they strained their eyes in the terrible darkness, they have mistaken imperfectly-seen earthly objects for heavenly visitants. The profoundly wise man who has, as for himself, studied the problems or realized the perplexities of the universe, will never be inclined to look contemptuously on the deep religious anxieties of mankind; nor will he allow himself to speak in tones of ridicule of the premature beliefs in a supernatural revelation, which some have been led to cherish from the very excess of their longings,he looks on these as he would on the hasty judgments of the child who, in expecting his father to return, mistakes the stranger for himas he looks on those fanciful analogies among natural objects, which Pythagoras and Plato found before the time. So far from despising these, the true philosopher will rather look on them as intimations of deep natural impulses and anticipations, which seem to guarantee an accomplishment in the end. Those who have 
felt-as I suppose we must all have felt in our hours of deepest weakness and greatest strength -these failings and aspirations of heart, will be inclined to long and to pray that the Supernatural Being would come out of his infinite distance, that he would break his silence and make known his will to us; and they will reckon themselves bound to give their candid consideration to an alleged revelation, which is to all appearance well accredited, and seems to meet the wants of our nature and position.

It should be freely admitted that these desires and cravings do not of themselves prove that there has been an actual revelation; in order to carry the conviction of the reason, they need to be supported by a corresponding body of attested facts. Here, as in so many other cases, we require objective realities as the complement of subjective anticipations-the latter, howerer, supplying the impulse which leads us to observe and collect the former. It is at this point that the systematic character of revelation comes in, to strengthen tenfold the force of the evidence.

In looking at the professed Revelation in order to determine whether it actually comes from God, we begin, we may suppose, with the examination of the parts. We look first at the character of God as presented in the Bible, and find it to be different from that given in any other 
religion:-unlike the gods of the neighbouring nations, he is one; and unlike the Deity created by philosophy, he hates sin and yet loves the sinner. We look at the view given of our own essential being, and we find it to be in exact conformity with our deepest convictions; for the soul is represented as possessed of high endowments; as immortal and infinitely precious; as polluted by sin; as about to appear at a judgment seat; and yet as capable of being restored to the favour and image of God, and to communion with him. We look at the historical events recorded, and we find that they constitute a series; that the characters are after a type; that the occurrences and ordinances raise up a set of ideas connected with sin and salvation; and that they all culminate in the appearance of a Saviour of the world. We look at the prophecies, and we find them uttered in appropriate circumstances, and the fulfilment of them realized in a succession of occurrences stretching over many ages and wide countries. We look at the miracles, and we find the narratives of them to be characterized by artlessness and guilelessness, and the deeds themselves to be such as only God could perform, while they are signs of his great supcrnatural work in conquering evil. We look at the general doctrine, and we find it true to the character of God, and the 
character of man, as revealed by nature, above which, however, it rises in an immeasurable degree. We look at the precept; we find it worthy of God, and suited to man as a sinner returning to God. We look to the functions of the Church, and we find it a peace-giving and purifying element in the world. Or we look first, and we look finally, and we ever look most fondly, to the person and the character of Jesus, and we see that he has come from Grod even as he has gone to Grod; that he came down from heaven to establish a reign of heaven on earth, and to carry up to heaven a people from the earth. Every one of these considerations carries its weight, which will be felt more or less by different minds. Each seems to shew that the religion which embraces them must be Divine. But their overwhelming force arises from their being each a system, and connected parts of one great and consistent system, which must be supernatural.

Much of the controversy in the Christian Evidences has turned round the subject of testimony. Deistical writers have shewn how testimony is often untrustworthy, especially when detailing matters which excite wonder. Dr. Chalmers, on the other hand, has argued that the testimony of witnesses of a certain character is such that the improbability of their telling a 
falsehood is, to say the least of it, as great as the improbability of an interference with the laws of nature. The defenders of Christianity have laboured to prove, and have succeeded in proving, that we have as full evidence of the genuineness of the books of the New Testament, as we have of that of any other work handed down to us from antiquity; and that there are witnesses in favour of certain central events, such as the crucifixion and resurrection of Jesus, quite as trustworthy as there are in behalf of any occurrence in ancient times. But it is a great misapprehension and mistake to suppose that the Christian Evidences lean entirely, or even mainly, on evidence derived from testimony; and it is not wise in certain apologists to make the whole hang on one thread, when we have a "triple cord which cannot be broken." In re. gard to many of the evidences, we are dependent on testimony only to the very smallest possible extent,- to no greater extent than the astronomer or the geologist is when he uses reports drawn out by observers in various parts of the world, he himself being all the while quite competent to test their credibility. We must have it certified that the Scriptures have come down to us from a very old date, and that they were written by persons in the land of Judea; but with a very few such facts given or granted, 
we are prepared to apprehend and appreciate the force of by far the greater part of the Christian Evidences, and particularly of all the Internal Evidences; and if we are led by these to add the Experimental Evidence, derived from the power of religion in and over the heart, we have gained a conviction which can never be shaken. For the question now is, not whether testimony may not be fallacious, but whether all the evidence, external and internal, can possibly be deceptive.

I allow freely that a wide experience has settled that there is a system of nature. But I claim that a large observation, coupled with deep thoughts and deep convictions, has determined that there is also a preternatural system. Principal Campbell, in his reply to Hume's objections to Miracles, supposes that a person had lived for some years near a ferry, and that he had seen the passage-boat cross the river a thousand times in safety; this experience, he argues, would not entitle him to disbelieve the statement of a credible witness who comes and tells him that he has just seen the same boat overwhelmed. This illustration will suit our present purpose, if we are allowed to modify it. Let us suppose that the person had seen the ferry-boat cross day after day with wonderful regularity, but had observed that on certain days it did not ply as usual, and 
that, on more careful inquiry, he found that the days on which it rested were Sundays; he would now have the general rule, but he would also have the rule of the exceptions, and he would see the propriety of both-the one being for secular good, and the other to promote sacred ends. The case is very analogous to what we have in our world; we observe a uniformity in nature to meet man's intelligence and convenience, and possibly to serve many other ends; but our attention is also called to a course of supernatural action, coincident with the natural, and joining on to it, to meet man's spiritual wants, and to harmonize heaven and earth, - the two being, after all, the essential parts of one comprehensive system, the outward and inner compartments of one grand temple.

II. This systematic character of revelation makes it impossible for us to explain it by natural agency.

It is now acknowledged, that the old naturalistic explanations are all failures. Every one now sees that we cannot account for the Christian religion by a studious deception. This hypothesis, with the aid of a considerable straining and perversion, might be held as explaining certain very small parts here and there; but it furnishes no plausible account of the whole, which, because of its comprehen- 
siveness, could not have proceeded from one mind, and because of its consistency and connexions reaching through long ages, could not have sprung from a concurrence of minds all bent upon deceit. It is just as clear that it could not have been fashioned by enthusiasm and superstition, which, in their extensive sway, shew that man is a religious being, but which, from their very nature, lead only to incongruous and inconsistent results. Nor will the-union of the two,- of deceit with genuine but deluded feeling,-render any reasons for a system which embraces holy doctrine and high morality, and connected events, which run through long successive ages, and are brought about unconsciously by persons utterly ignorant of the ends accomplished by them.

The more modern theories equally fail. The hypothesis of Paulus, that the Gospel narratives were natural occurrences misunderstood and misinterpreted, has now no supporters. Whatever superficial plausibility it might have, as applied to a very few isolated incidents, it was seen to be utterly incapable of accounting for the whole series in its integrity and connexions, and it had no explanation to give of the high morality and the holy doctrine which are imbedded in the heart of such an accumulation of supposed misapprehensions and perversions. This weak sup- 
position has given way to another-the last resource of infidelity,-and it, too, is now being seen to be as signal a failure as the others.

It is alleged that the whole supposed supernatural system has sprung from those principles of human nature which produce myths in all countries. As long as it wraps itself up in vague general statements, it is difficult to fight with this theory, which, when it is caught in one shape, quickly assumes another. But when it takes the form of affirming that the Scriptures are a myth, or a series of myths, it can be satisfactorily met and overthrown.

Of late years a vast amount of curious information has been collected, and a great deal of speculative and learned sense and nonsense has been written, about myths. Myths are, in fact, stories embodying and expressing a pre. vailing belief or feeling in a family, a district, or a nation. Sometimes they had a foundation in historical incidents, which, however, have been so buried in the accumulated additions, that it is impossible to find the fact in the fable. Sometimes they are mere fictions got up (like the modern romance) to please the phantasy and move the feelings-not unfrequently, I suspect, of children, and in all cases of a people credulous as children. At times they are afterinventions to explain or justify certain beliefs 
and prepossessions. In order to be myths, and not mere tales or legends, they must express a reigning sentiment in a community, and it is thus they pass so readily from indivilual to individual in the region in which the feeling prevails, and are handed down from one generation to anothier, and often go in a somewhat modified form with colonists into their new country. The myths may relate to anything that interests a people, to the honour of the family or nation, to the romance of love or of war, or to the character and worship of the gods.

The religious myth is expressive of the religious beliefs of the tribe or country. It arises out of the anterior sentiments of the people, and it reacts upon these sentiments, especially in the way of giving a form to what was before germinant but shapeless. It springs spontaneously from certain deep mental tendencies:-it has its root in the religious instincts of our nature; and the tale is fashioned to gratify the phantasy or imaging faculty; and to furnish a body in which the feeling may dwell, and become objective and visible. Existing first in a floating oral form, it may have a permanence given to it by being embodied in written poetry or prose; at times a selfish interest has been created in its favour by its becoming associated with a particular shrine or temple. Religious myths spring up in all 
countries, till the critical spirit rises, to suppress them, or mankind have something better supplied to them in the Word of God. As they are the product of human nature and of the circumstances of the people, so they fully reflect these. It has been shown that they follow some sort of laws, which have been traced with amazing erudition and excessive ingenuity by German critics. All these laborious researches have only shewn how wide the difference between the myths of the Gentiles, and the narratives of the Old Testament and the doctrines of the New Testament.

It holds true of all myths, that they are polytheistic. They originate always in a state of society in which it is the tendency of mankind to call in a multitude of gods, to meet their rude wants, and to account for what they see. This is the first and a fundamental distinction between them and the Scriptures; which are throughout a protest against polytheism. Again, the tales comprised in the myths, at least when they become numerous, are always incongruous and inconsistent. Springing up in divers places, and variously reported as they pass from mouth to mouth, no attempt is made to render them harmonious till the critical ages arrive, and then they cease to have power. All later historians have ceased to try to bring a connected train of 
events out of myths; Mr. Grote, for example, makes no attempt to draw history out of the hunting of the boar of Calydon, of the Argonautic expedition, and the siege of Troy. This is a second point of difference between myths and the writings of the Old and New Testament, in which we have a long series of connected narratives palpably consistent with one another, and with external history-despite the few seeming discrepancies which we may not be able to clear up. No one attempts to confirm Homer, or Hesiod, or the gigantic myths of Brahminism and Buddhism by historical incidents, such as we can bring to corroborate Scripture from the tombs of Egypt, from the sculptured slabs of Nineveh, and from the works of such writers as Josephus and Tacitus.

Myths, as they spring from human nature, so they faithfully represent it-in its strength, but also in its weakness. In giving expression to the religious fears and hopes of man, they likewise display the foibles, the aberrations, the sins of humanity. Proceeding from the human heart, they can never rise above the level of the fountain whence they issued. They are all marred, less or more, by caprices, by impurities, or by awful cruelties, supposed to be perpetrated by their very gods. This is the third and the most important point of difference between 
them and the views of God, and of Christ, and of morality, presented in the Scriptures, say in the Discourses of our Lord and the Epistles of Paul and John. It has been maintained, that these last are myths growing out of the religious consciousness of the times. In opposition to this allegation it has been shewn, that the Gospel narratives and the Epistles appeared far too soon after the time of the death of Jesus to allow of the growth of myths. It has been shewn, too, that there was nothing in Jewish feeling, nothing in Phariseeism, or Sadduceeism, or Essene mysticism, nothing in Eastern or Alexandrian theosophies, nothing in the religious feeling of all these countries, to generate those high and yet tender, those sublime and yet practical, views of God and his interest in mankind which are given in the New Testament. But the strongest ground which we can take up in reply to the mythic theory is, that no Gentile myths have ever given us any such high and holy pictures, as we have presented to us in the life of Christ, and in the doctrine and precepts of the New Testament. These arose, it is said, out of the religious consciousness of the times! But how do we get a religious consciousness that would yield such a product-an earthly soil or an earthly seed which would produce such a plant? It lias been 
shewn again and again, that there are far greater difficulties involved in supposing that the life of Jesus is an idea evoked out of human nature, than in at once allowing it to be a reality.*

The extensive inductions which have been gathered by later research as to myths, their nature and their laws, all go to prove that the Scripture narratives and doctrines differ from them in their whole letter and spirit.

But while all this is resolutely maintained, it is not needful to affirm that there is no resemblance whatever between any portion of Scripture and the spontaneous myths of the Gentile nations. It is conceivable that a likeness might arise from two circumstances, both of them quite consistent with the inspiration of the Word of God. One is, that the deeper religious myths are the expressions of the religious feelings of mankind, which ever hold in solution a considerable body of important truth. I believe that this arises in part from the traditions of primitive faith which have been preserved in most nations, but mainly from the fact that man has a deep religious nature which ever seeks an outlet. In particular, man has ever spontaneously held by two deep convictions, that there are supernatural

* It is scarcely necessary, in this connexion, to refer to two such well-known works as "Taylor's Restoration of Belief," and "Young's Christ of History." 
powers, and that he as a sinner has given offence to them. Out of these two strong impulses have arisen, in heathen countries, a body of rites and concomitant myths, which bear a rude resemblance to certain ordinances and narratives of Scripture, bearing on the relation of God and man. It may be admitted, that in some of the Eastern religions there is a dim appreciation of the duty of rising above the pollutions of the flesh; that in Buddhism, and many forms of mysticism, there is an ill-directed aspiration after a closer communion with God; and that even in those stern superstitions which demanded that on great emergencies parents should make their children pass through the fire, there was a sense of the need of an atonement; and from these profound causes myths may at times have some things in common with Scripture. Nor do I see evil likely to arise from making a farther admission. We have seen that the natural mind of the prophet was not destroyed in the utterances which came from him. As Moses and Ezekiel both used the Hebrew language as they found it, it is also conceivable that the former may have taken some of his symbols from Egypt, and the latter much of his imagery from the figures on the temples and palaces of Assyria. It is certain that the inspired ideas of the older prophets would, if left to their spontaneous flow, 
come out in forms analogous to the myths of the poets and sages of the Gentile nations; and I see no reason why God should have interfered with the sinless powers of the prophets in the way of mutilating them,-the more so as what came naturally from the heads of the writers would go home most effectively to the intelligence of the readers. But all this applies only to the earlier prophets. In the course of ages there came to be a set of writers educated up to higher conceptions, and a class of readers ready to understand them. In the New Testament the special resemblance to myths altogether ceases. There are still parables and symbols addressed to the phantasy, and narratives of such simplicity that babes drink them with eagerness, but these have no likeness to myths; and mingled with them we have brief sentences, which combine the lights from a thousand points into one bright focus which renders everything luminous.

III. The circumstance that there is a supernatural economy in the midst of the natural, entitles us to regard certain events as preternatural, which we might not have been able to prove to be so, had they stood alone and isolated from the system. The most rigid believer in natural law, were he to look at certain phenomena apart from his settled belief in the 
prevalence of uniformity, might be inclined to admit that they are under no law, but holding by his general conviction he at once declares them to be natural in spite of appearances. It may, in like manner, be admitted by the most determined adherent of supernaturalism, that there are incidents recorded in Scripture which, if viewed apart from their connexions, might be represented as flowing entirely from human or mundane agencies; but when we find them to be parts of the heavenly revelation, we declare, and are entitled to declare them to be supernatural, or at least providential. Just as our reasonable conviction of the existence of a natural system makes us claim for nature much which we might, on the first impression, have been inclined to place beyond it, so our equally reasonable conviction as to a supernatural economy authorizes us to refer to the immediate operations of God not a few things, which we might otherwise have ascribed to the agency of mundane causes.

IV. The systematic character of revelation enables us to get tests of the supernatural. It is in consequence of nature being a system, that we are able to determine, in most cases with considerable ease, what is natural and what is not natural. Nature has everywhere a certain method or style or aspect, which enables us to 
recognize what belongs to her domains, and to distinguish between what is natural and what is artificial or unnatural or preternatural. We can commonly distinguish at once between what is produced by physical agency and what is effected by human skill. 'The naturalist rejects at once the stories about the mermaid, the unicorn, and the sea serpent, because such creatures are not in conformity with the homologies of the animal kingdom. We pay no attention to the common ghost stories, because they carry us into a preternatural region. But Revelation comes to us also as a system, with its laws, its analogies, and its doctrines. It all revolves round one central point,-round the Incarnation of the Son of God for the purpose of bringing a lapsed world into a state of reconciliation with its own Governor: By the careful examination of it we may, in a general way, ascertain what is its method of procedure; what is in accordance with it, and what is not in accordance with it; what are the means it may employ, and what the means it cannot sanction.

It may now be asked, How should we deal, according to the principles reached in these discussions, with the common pretensions to preternaturalism? Some one tells us an ordinary ghost story, about a person whom he knows having in a dark night seen a white figure 
moving and glaring at him. How are we to treat the narrative? It is clear, on the instant, that the supposed facts do not connect themselves with that supernatural system for which we have such a body of evidence. The story, then, cannot derive any prepossession in its favour from Revelation. It must stand or fall on its own merits. Now, it has been ascertained, by a long induction not contradicted by any authenticated case, that ghosts are not among mundane agencies; that the dead do not rise again to take a part in the affairs of this world. In the cases of the kind which we have been at the trouble to inquire into, we have found the tale to grow very much in the reporting and as it passed from mouth to mouth; and when, at last, we got at the exact facts, we found that the supposed supernatural figure was simply an earthly object imperfectly seen, or that it was a mental image called up by fear, which so affected the brain that the person imagined that what he saw was an actual figure. Believing that the whole can be accounted for in this, or in a similar way, we fall back on the uniformity of nature as the general law, and think ourselves quite justified, while important duties derolve upon us in this busy world, to make no farther inquiries into the matter. In acting thus, we do not go the unreasonable length of 
affirming, that a narrative of a preternatural event-that even a ghost story-could not possibly be true, or could not possibly be proven. Still less do we act on any principle which would, in the least degree, interfere with the powerful evidence, derived from so many sources, which we have in favour of Christianity. We simply say, that we have no proof, and are not likely to get any proof, to counterbalance the improbability of such a preternatural occurrence, which is in its whole nature different from the miracles of Scripture.

These same principles may guide us in the view which we should take of mesmerism, and clairvoyance, and spirit-rapping. As to mesmerism, there is every reason to believe that there is a series of phenomena which may go by this name-till their nature has been more thoroughly explored. But mesmeric affections so counect themselves with certain pathological states of the body and psychological facts, that we at once declare them to be natural, and hope at last to discover the laws which they obey. As to clairvoyance, it is certainly opposed to the whole analogy of nature as disclosed by modern science. It is also and equally inconsistent with the whole analogy of the supernatural revelation of God in the Word, for nowhere in that revelation is there a miraculous event reported 
except as vouching for, or as a part of, the plan of redemption. Clairvoyance has thus the analogy both of the mundane and revealed system, against it. I do not say, that it could not possibly be substantiated by evidence, but the proof urged in its behalf is of far too uncertain, and at times suspicious, a character to bear up the superstructure. In regard to most of the pretended cases, I think we are entitled at once to reject them without farther inquiry, and, as to others, which may look more fair and plausible, it is enough to ask the supporters of them to submit to such scientific tests as those to which table-turning was subjected by Faraday. What is now said of clairvoyance applies also to spirit-rapping. But if ever such phenomena are established on good authority,-which they have not hitherto been, and, as I think, are not likely to be,-we would seek to construct them into a system, natural, or preternatural, or half way between; and then we might have rules by which to distinguish between real and pretended cases. Meanwhile, the established systems of God, both natural and supernatural, are against all such pretensions.

The principles here enunciated, and so far applied, shew at once how we are to answer Mr. Powell, when he would place the record of the miracles of Scripture alongside of the ordinary tales about ghosts, mermaids, and witches. 


\section{CHAPTER IV.}

ANALOGY BETWEEN THE NATURAL AND SUPERNATURAL SYSTEMS.

The word " analogy" is frequently used in our common literature as synonymous with " resemblance," and denotes a likeness of any kind. But it has a more narrow and technical signification, and denotes a resemblance of relations. Thus we speak by "analogy" of a particular principle acting as the foundation of an argument, meaning that the principle has a like relation to the conclusion, as the foundation has to the building erected on it. In natural history, the wing of a bird and the wing of a butterfly are not reckoned the same organs, but they are said to be analogous, because to the animals they discharge the same functions. In this Chapter the phrase is employed in the more rigid sense. I am to gather out of the preceding discussions the points of resemblance between the natural and supernatural systems, in their relation to God on the one hand, and to man on the other. I do not go so far as to maintain that this single 
circumstance does of itself prove the religious system to be supernatural and to have the sanction of God. But taken along with other facts and considerations, it has a considerable amount of force in shewing that the two came from the same Being. In a negative way, it has great power in answering objections derived from the alleged anomalous or lawless character of the supernatural. Taking the lowest ground, it should lead all who believe in the natural as a manifestation of God to give their candid consideration to the professedly supernatural system, which so corresponds to and so fits into the natural.

I. In both we discover a plan developed in connected acts. Nature is not a wayless waste; it is a rich territory, divided, allotted, and fenced with alleys to walk in, and a provision for the wants of those who dwell in it. There are different systems in nature-as there are different systems in the animal body; but as in the animal frame the various parts constitute one living being, so in the physical universe the different portions are made to constitute one Cosmos. But we have seen that there is a like ordination and subordination in Revelation. The parts, such as the history, the ordinances, the prophecy, the doctrine, constitute systems, which again combine in one grand system, with the 
Logos as the central attraction and the central light. The order of the universe shews that it had been purposed in the Divine Mind in eternity; it also makes it comprehensible by man, and invites him to derive instruction from it, and to accommodate his actions to it. Similar ends are accomplished by the methodical character of revelation; we are enabled thereby to rise to some comprehension of it, to fall in practically with its mode of procedure, and to discover in it a manifestation of the Divine perfections and the evolution of an eternal counsel.

II. In both there is a progressive plan. The progressive plan of nature is seen specially in the science of geology. It should be freely admitted that we cannot at this present time draw out a perfect reconciliation of Scripture and geology, as to the appearance of the living beings on the earth's surface. On the one hand, we are not quite sure how to read the record in the two opening chapters of Genesis; and on the other hand, geology, in opening new truths, is at the same time ever disclosing new mysteries. But on the very face of the two records-the record on parchment and that on stone-there is a general correspondence. Both tell us that there was a time when there were no plants, no animals on the earth. The latest science seems to accord with the Word of God, in declaring 
that the earth is older than the sun; that there were epochs in our earth's history when it was illuminated by a general light, ere that light had been concentrated into a central sun. Both an. nounce that there has been a progression, from the lower to the higher, in the appearance of plants and animals on the earth's surface. Both assure us that man came upon the scene at a comparatively late date. These are surely very wonderful correspondences, which should keep all men of science from scoffing at the narrative in the Word of God. For when science was entirely ignorant of all this, it was written there in a Book, the general meaning of which is clear and explicit.*

- I have often thought that, in order to settle the questions agitated, we would require to know what was the nature of the transaction which issued in man appearing upon the earth. Can we be wrong in guessing that the mystery which yet hangs over the thorough reconciliation of the two records, Mosaic and Geological, will bo cleared up when the nature of this transaction is made known to us,-it may be, in this world as science advances, it may be, only in the world to come? Who will venture to affirm that the God who has proceeded from the beginning in our Cosmos according to the method of type, that is, model or exemplar, by animal type in the geological ages, by human but still outward type in the Old Testament disponsation, and even now by more spiritual type in the New Testament Church, may not have proceeded by type likewise in that necessarily wonderful transaction which ushered man upon the scene? Von Baer has shewn that the development of the animal in the womb proceeds according to a prede. termined plan, advancing from the more general to the more special. Professor Owen and Dr. Carpenter have shewn pretty satisfactorily, that there is a parallel advance in the production of animals in the geological ages, - an advance from the more general to the more special. 
But the correspondence to which I refer under this head, is not that between geological science and the Book of Genesis, but between the progressive work on the earth's surface and the progressive character of the work of redemption. In geology, we have stratum superimposed upon stratum in due order, and a pre-ordained advance from the lower to the higher plant and animal, the earlier being prefigurations and prognostics of the later. And in the history of redemption we have layer added to layer, and lower life ever

If these views be correct,--and they are held by the highest authorities,--then the growth of the higher animals in the womb is of the same type as the successive creations revealed in geology. It has also been shewn by geologists that the existing order in organic forms is a type of the geologic order in time. Who will venture to sas, then, that the mysterious transaction at man's creation was not an epitome, a type, of what had gone before, just as the scarcely less mysterious transaotion of the infant's growth in the womb is a type of all Palæontology? The account in Genesis may thus be a description of six literal days, as representative of six epochs, just as our Lord's prediction of the destruction of Jerusalem has, through it, a reference to the final day. Every student of ecclesiastical history knows that the experience of the individual Christian is an epitome of the experience of the Church at large, as a heavenly life in the midst of opposing corruption. Should there be any truth in this view, the transaction recorded in the opening of Genesis may not be a mere vision, but a reality, -a reality supernatural, but in harmony with all natural operation, which is, after all, Divine operation, - a reality instructive as any vision, - a reality which retains the natural days, as after the type of the natural epochs, and keeps the seventh day as a true day, and yet a prefiguration of the Sabbath of rest which remaineth for the people of God. This view will thoroughly fall in with the account given of the garden of Eden, which we may regard as a reality on the earth, yet a prefiguration of the inheritance of the saints in heaven. 
rising to a higher, and a typical system consummated in Christ the Great Archetype.

III. Both have a very special relation to man. They have also, both the one and other, farther relations towards other worlds and towards God himself, some of which we may discover, but all of which can never be known to us. But both have a regard to man which we can discern, and which we are expected to observe. The natural system has a manifest relation to man; it provides a supply for his animal wants; it furnishes enjoyments to his emotional nature; it is admirably suited to his searching and contemplative intellect. We are told here and there in the Scriptures, that the grand supernatural event, the Incarnation of the Son of God, has a respect to other worlds; but it has a special reference to man, to his restoration and regeneration; being addressed to his higher and deeper, as the other is to his superficial and material wants; having in view to elevate his moral and spiritual character, as the other has to improve his intellectual and emotional constitution.

IV. Both are so far understood, but neither is fully understood. We do understand so much of nature, and we are ever understanding more, and are encouraged to seek after higher and ever higher knowledge. Still we can never comprehend the whole. Placed as we are in the centre 
of boundless space, and in the middle of eternal ages, we can discern only a few objects immediately around us, and the others fade in outline, as they are removed from us by distance, till at length they lie altogether beyond our vision. Nay, it would seem as if the wider the boundaries of knowledge are pushed, and the greater the space illuminated by the torch of science, the greater in proportion the bounding sphere into which no rays will penetrate,-just as when (to use an old comparison) we strike up a light in the midst of darkness, in very proportion as the light becomes stronger so does also that surface, black and dark, which is rendered visible. It is the same with the supernatural light vouchsafed. All who are blessed with the light of revelation can know something of the action, something even of the laws and of the theory of the mediatorial work of Christ. Every one can see what God intends by it; every one may know what he ought to do to secure the blessings. We all see enough of the Gospel to discover it to be the Power of God, and the Wisdom of God, and the Goodness of God. By a closer study of the Word, and by an experimental acquaintance with its truths, many obtain a deeper view of its mysteries-that is, of truths once hid, but now revealed. But, after all, there is much which remains, and must ever remain 
uncomprehended and incomprehensible. In regard both to natural and spiritual things, we live in a world "where day and night alternate,"-in the light, we go everywhere accompanied by our own shadow.

V. In both we can accommodate ourselves to modes of procedures on the part of God which we do not fully comprehend. Thus, in God's natural economy we all act upon laws, the precise nature of which is very much unknown to us. Mankind conformed to and profited by the regularity of the seasons, long before they knew any thing of those cosmical arrangements which give us the return of seedtime and harrest, of summer and winter. We act upon empirical knowledge as to the springing and growth of the plant, while we are entirely ignorant of the chemical and vital agencies by which the regular result is effected. We guide and control magnetism and electricity, and turn them to most important practical uses, and all the while the most advanced science cannot tell us what is the nature of these agents. It is much the same in the supernatural economies of God. As much is always revealed as enables us to exercise faith, and to conduct courses of practical action, but seldom enough to make us understand all the bearings and relations of the doctrine. It is thus that we must believe in much which we cannot fully 
comprehend; believe in the eternity of God, while we cannot grasp it as a positive conception; believe in the triune nature of Grod, while we cannot explain the mysteries of the relation of the one to the other, and of the three to the one. It is thus, too, that we use the appointed means for securing the spiritual blessings, and pray for the Spirit of God to give efficacy to them, while we are entirely ignorant of the way in which the Spirit works, and of the relation between his operations and the instrumentality which we have employed.

VI. In both we use means, and yet know that the end may depend on arrangements which are made by a Higher Power. It is thus that, in the affairs of this world, all prudent men are active and industrious in the hope of reaching, if not wealth, at least a competence of earthly necessaries and blessings; and it is usual that these means are made to secure the desired result; yet it will happen not unfrequently that these virtues may be sedulously practised-and the expected consequences fail, because of some cross incident occurring in the providence of God, because of the folly or treachery of some one who had been trusted apparently on good grounds, or by a calamity which the person had no reason to fear, produced by agencies over which he had no control. By this double provision of God's 
natural providence, mankind are at one and the same time allured to activity and made to see that their exertions may after all be unsuccessful; encouraged to persevere, and yet taught impressively that they are dependent on the plans of a Higher Wisdom. In like manner, the believer is commanded to labour and pray, to work out his salvation with fear and trembling; and he is encouraged to do so by a reasonable prospect of success; but he is taught at the same time that every spiritual grace is wrought in him by the power of God, and that it is God that worketh in us both to will and to do of his good pleasure. No doubt there is this difference between the two kingdoms - the kingdom of nature and the kingdom of grace-that in the former the means themselves tend to produce their ends, and do produce them except when they are thwarted by natural agencies; whereas in the latter the means secure the end only so far as there is a Divine Power working in them. But this difference of the mode only evinces the need of supernatural power to accomplish high spiritual ends, and impresses us the more with the correspondence of the two economies, which thus secure similar ends by a difference of means.

VII. In both, the moral is higher than the spiritual. Bishop Butler has shewn, that when we properly interpret our moral nature, it is 
found to declare not only that moral good is to be commended, but that it is higher than any other good, higher than the merely pleasurable, higher than the simply beautiful; and other moralists have shewn, from the intimations of our moral reason, that the law of God is eternal and immutable. But every one who has taken a profound view of the Gospel provision knows that all this is presupposed in it, and that it was because of the everlasting and essential holiness of God and of the unbending character of his law, that the Son of God behoved to suffer and to die, in order that God's everlasting purposes of grace might be carried out.

VIII. The one system fits into the other. This is the most characteristic and wonderful point of correspondence. The two have not only a likeness in mode and manner, in style and means, but the one is adapted to the other,- as in the natural kingdom the mineral is adapted to the plant and the plant to the mineral, and the sky above to the earth beneath. Where the one ends the other begins, where the lower fails the higher comes in and succeeds. The natural cries out for something which it feels that it wants, the supernatural answers the cry, and supplies what is needed. And yet the supernatural does not destroy the natural, but uses it, elevates it, and sanctifies it. The super- 
natural, though far above the natural, joins on to it, and embraces and canopies it, as the heavens do the earth.

Some may be inclined to look on the analogies we have traced merely as furnishing profitable matter for meditation, fitted to excite admiration and kindle adoration on the part of those already believers in revelation. Even so, they will have served a good end. But I am inclined to think that they have also considerable force as evidences of the truth of Christianity. The two do look as if they had the same all wise and good God for their author. We discover everywhere a certain style, and method, and end in God's operations, which enable us easily to recognize them as His works. The plant is not the same as the animal, the crystal on the earth is not the same as the star in heaven, but we see at once that he who made the one also made the other. It should be acknowledged by all that the natural structure is not the same as the spiritual; but there is a sameness in the style and plan which suffice to shew that they are both designs of the same Great Architect.

It should be observed that the argument is not drawn simply from a vague general resemblance. It is derived from the relation of each to God and to man, from the fitting of the one into the other, and from the common ends of 
beneficence and of righteousness served by them. We have a right to demand of the opponents of Christianity that they shew how this correspondence could have arisen. The supposition that it has been produced by studious design, on the part of the human framers of the supposed supernatural system, needs no confutation. Bat it is scarcely less preposterous to suppose, that it can have proceeded from the unconscious operation of human nature through long ages. The correspondence is far too free in its manner to allow of the former supposition; it is far too congruous and consistent in its method to allow of the latter; it is far too moral and spiritual to admit of either. The most reasonable conclusion is, that the two are compartments of one great building; not antagonistic, but adaptive; not conflicting, but corresponding; not contradictory, but complementary.

"Truth, so far, in my book; - the truth which draws Through all things upwards; that a twofold world Must go to a perfect cosmos; Natural things And Spiritual." 


\section{APPENDIX.}

Ant. 1.-OXFORD PHILOSOPHY.

Withis the last eventful age we have had two important religious movements originating in Oxford-the one coming to a head about thirty years ago, and the other making its appearance within the last few years. It has been shewn again and again that these two have a closer connexion than the superficial thinker might imagine. There is the old maxim of extremes meeting, of extremes producing each other; there is the more modern law of action being followed by an equal reaction. Plutarch shewed how it is that superstition produces atheism: thinking men, put into a state of merriment or of pain by the absurdities of an abject superstition, are tempted to cast away all faith. But, in addition to the action of these more general laws, the leaders of the medieval school had exposed those who looked up to them to more particular and fatal influences. They took special pains to shew that not only human reason and natural religion, but the Word of God itself, cannot be relied on. Their sincere aim was to induce their followers to hand themselves over unreservedly to the teaching of the Church. The disciples went so far with them. They gave up the ordinary arguments for the existence of a personal God, and faith in the Bible as an infallible guide; but many of them became restive when they were taught to fall back on Church principles, and, following out the premises given them, they have arrived at conclusions very different from those which their preceptors anticipated. 
But, instead of speculating on the causes which have produced what has already taken place, it is of more importance to inquire what is likely to be the issue, in the next few years, of the causes operating at this present moment.

So far as I have means of judging, it appears to me that the two philosophic lights in Oxford at the present time are Kant, as modified by Sir W. Hamilton and Dr. Mansel, and Mr. John S. Mill in his integrity. Let us inquire how the youth is equipped who has to form an independent opinion, on the great religious questions started, after having been disciplined in the forms of Kant, and having drunk into the spirit of Mill.

Kant has taught him that there are deep speculative principles in the mind, but that these have no objective value whatever, and guarantee nothing as to the real world, nay, land us in contradictions when we suppose them to have an application to things. He is told that cause and effect have links given them by the mind, but may have no connexion in the actual world or beyond it. He is instructed that we cannot prove the existence of God from his works, and is referred to some other way of reaching the Divine Being which the student does not very well understand; but so far as he comprehends it, he does not deem it very satisfactory, for if the speculative reason be delusive, why may not the moral reason also be deceptive?

I have frequently taken occasion to express my high opinion of the philosophy of the late Sir W. Hamilton. I believe that he has added immensely to our knowledge of every department of the human mind, and that his criticism of the philosophy of the Absolute has not been answered, and never will be answered. But I have always regretted that he adopted so many of the principles of Kant. He allows that the mind starts with phenomena in the sense of appearances, and not with things, and that the mind, in its knowledge of objects, adds elements of its own. "Suppose that the total object of consciousness in perception $=12$; 
and suppose that the external reality contributes 6 , the material sense 3 , and the mind 3 ; this may enable you to form some rude conjecture of the nature of the object of perception" (Metaph. vol. ii. p. 129). His philosophy, beginning in nescience, must end in nescience. He thus sums up the results reached by him in comparing his philosophy of the Conditioned with that of the Absolute: "In one respect both coincide, for both agree that the knowledge of nothing is the principle or result of all true philosophy; 'Scire Nihil-studium quo nos laetamur utrique.' But the one doctrine maintaining that the Nothing must yield everything is a philosophic omniscience; whereas, the other holding that Nothing can yield nothing, is a philosophic nescience. In other words, the doctrine of the unconditioned is a philosophy confessing relative ignorance, but professing absolute knowledge; while the doctrine of the conditioned is a philosophy professing relative knowledge, but confessing absolute ignorance" (Discuss. p. 609). Following out these principles, he declares that the argument for the Divine existence, got by human intelligence, is inconclusive; and, though he stands up for it, I cannot see how even the moral argument remains, if "good and bad" (Discuss. p. 604) are subject to the same all-sweeping system of relativity and nescience. Time and space are forms of the mind ; our conviction as to cause and effect is a mere impotency, implying no objective existence; and the highest effort of philosophy is to shew us that God is unknowable in his real nature. Nor is his position much amended by his handing us over, after he has landed us in nescience, to a faith of which he gives no account, and which is well described by Dr. Dorner as the despair of knowledge rather than anything else.*

\footnotetext{
* For years past, I have been calling on the school of Hamilton to give us some account of the nature and claims of that unexplained faith, on which they ever fall back, when their nescience leads them to conclusions which alarm them. An able and faithful disciple admits, "The absolute or infinite is cast beyond the sphere of thouglit and science; it is still, however, allowed by Hamilton to remain in some sense in consciousness,
} 
I have ever felt great pleasure in giving my feeble testimony to the pre-eminent merits of Dr. Mansel, as a scholar and a philosopher. I am prepared to maintain, that his objections to the a priori theologies of the absolute have not been answered, and that his services, in so thoroughly undermining the ambitious speculations which were coming in upon us, directly or indirectly, from the schools of Schleiermacher and Hegel, have entitled him to the perpetual gratitude of all sound thinkers and friends of Christian truth. But $I$ have ever regretted that he should have adopted so many of the principles of $\mathrm{Kant}$, and that he should have followed so implicitly the nescient philosophy of Sir W. Hamilton. Eminently successful in attack, I cannot see that he has any body of fundamental truths on which to rear a sound philosophy, or by which to lend positive aid to Christian theology. The works which have been called forth by these discussions, such as those of Chretien (Letter to Mr. Maurice); of Young (Reason and Faith); of Calderwood (Philosophy of the Infinite, Second Edition) ; of Robins ( $A$ Defence of the Faith); of Professor Goldwin Smith (Rational Religion, \&c.) of Timologus (Scoto-Oxonian Philosophy)-shew that there are minds of a high order which cannot be made to submit to the philosophic and religious nescience which it is attempted to impose on them. In particular, there has been a general disposition to take exceptions to the view which is given of the conceptions of morality furnished by the moral reason; these, Dr. Mansel thinks, are and must be relative to the structure of our minds, and may not at all represent the absolute or divine morality. But, in fact, these defective views of our

for it is grasped by faith, and faith is a conscious act. The question, accordingly, at once meets us-In what sense, and how far, can there be an object within consciousness, which is not properly within thought or knowledge? In other words, how far is our faith in the infinite intelligent and intelligible? This point demands farther and more detailed treatment than it has met with either at the hands of Sir W. Hamilton himself, or any one who has sought to carry out his principles."-Imp. Dict. Univ. Biog. Art., Hamilton, Sir W., by J. V. (Professor Veitch.) 
moral cognitions originate in a defective philosophy, which sets out with the dogma that we cannot know anything as it is.

I ventured, at a very early date, to intimate my apprehensions that the principles which lie at the foundation of the philosophy of Sir W. Hamilton might be turned to sceptical purposes (Method of Divine Government, Appendix to Fourth Edition, 1854, and subsequent Editions). Very soon after the publication of Mansel's Limits of Religious Thought, and when the religious press was unanimous in approving of it, I pointed out fundamental defects in the principles proceeded on, which I feared that those opposed to religion might not be slow to turn to purposes of their own (Article in North British Review, February, 1859, on Intuitional Theology and Limits of Religious Thought, and Intuitions of the Mind, 1860). I am sorry to say that these fears have been too speedily realised. Mr. Mill (Logic, I. iii. 5), for his own purposes, quotes with approbation the language of Hamilton- All that we know is, therefore, phenomenal,-phenomenal of the unknown." Professor Alexander Bain, of the same school, seizes on the doctrine of relativity, and shows that we are not entitled to look on mind or matter as independent existences (The Emotions and the Will 641-646). Mr. Powell has called in the same philosophy to his aid, and quotes with approbation the statement of Dr. Mansel, that "creation is to human thought inconceivable" (The Order of Nature, p. 256). Dr. Duncanson, of the Westminster Review School, has drawn the religious conclusion, which I fear many others will draw-" There is a still more advanced stage of opinion, but as it has as yet been entered by a very few, it is unnecessary to do more than notice it here. All knowledge is of phenomena; things by themselves cannot be known from the very nature of knowledge." "To represent the supernatural as spiritual, is to assume that it may be known. When we say that the supernatural is the spiritual, we offer an 
explanation of it, for we class it with personal agency. The supernatural agent may be represented as more mysterious than a human being, but he is conceivable only to the extent he is assimilated to humanity. But a thing that is explained must be part of the system which supplies the explanation; so that the supernatural, when explained, ceases to be supernatural. The spiritual may be the highest form by which we can symbolize the supernatural, but it is far from representing the unknowable, as the most concrete and sensible form. The supernatural, then, is not the spiritual, but simply the unthinkable, the unconditioned, or infinite" (The Providence of God, 87, 88.)* To complete the succession, Mr. Herbert Spencer avows that he is to rear his huge system of what most men would call atheism, on the principles given him by Hamilton and Mansel, and has actually begun to raise his structure with great intellectual vigor, but with sad defects in his original principles, and mighty gaps in his deductions. (See Circular announcing his Works, and First Principles.)

Turning to Mr. Mill, we find him represented by competent witnesses as the person who, at this present time, exercises the greatest influence over the young thought of Oxford. M. Taine opens an ar-

* It is curious to observe how nearly a writer in the North British Revievo comes to this nescience. An able and elaborate article in the number for May, 1861, thus closes:- "Truth, like the Deity, is hid in darkness. It is not that we are nnable to divine the mysteries of the soul and God; the simplest phenomenon of sense defies our wit. Of the future destinies of philosophy it is in vain to speak. Phenomena we can observetheir laws we are able to ascertain-existence is beyond our ken. The riddle of the sphynx has never yet been read. The reil of Isis has nerer yet been drawn. The hieroglyphics of the unirerse are yet undeciphered." If it is meant that we do not know existence apart from things existing, I admit the statement, which is worth nothing, for there can be no such thing as existence apart from things existing. But if it is meant that we do not know things, say ourselves or God, as existing, the statement may form the first stone in a system of unirersal scepticism. I have evidence that in Scotland the younger metaphysical talent at present runs along the " conditions" and " relations" of Hamilton-as along rails set for it ; just as, thirty years ago, it flew off with the "feelings" and "suggestions" of Brown. It remains to be seen what influence this " Know-Nothing" philosophy is to excrcise on the religious thought of Scotland. 
ticle on "Contemporary English Philosophy" in the Revue des Deux Mondes for March, 1861, by telling us that when he was at the meeting of the British Association for the Promotion of Science, at Oxford, in 1860, he met a young Englishman of genius whom he catechised as to the philosophy of his country. After listening to the scientific papers, and going through the museums, the Frenchman says to the Englishman, "You have no philosophers. You have savans, but not thinkers." The young Englishman, thrown upon his defence, names, as the original thinkers of England, Mr. Jowett, of the "Essays and Reviews," and Mr. Mill! The answer is quite characteristic of a young Oxonian who has caught the present spirit of his university. Testimonies to the same effect might be quoted from late Numbers of Macmillan's Magazine, and the Literary Gazette, as to the sway which Mr. Mill has over thought at Oxford. I suppose we may reckon the Saturday Review as a fair sample of Young Oxford (quite as much so as the equally elever and equally flippant and arrogant Edinburgh Review, at the beginning of the century, was of the then Young Edinburgh); and any one may see that certain writers in that Review are erudite in Mr. Mill, and erudite in no other philosophy.

Every one who has himself learned to think must speak with profound respect of Mr. Mill. His opinions on all questions of social science are always worthy of bcing carefully weighed. Many of the principles of his inductive logic are well founded. But underneath all his opinions on more practical matters there is a fundamentally defective philosophy, which is ever cropping out. As I have said elsewhere:"The only satisfactory admission of Mr. Mill is, ' whatever is known to us by consciousness is known beyond the possibility of question.' (Logic, Introd. p. 6.) What does this admission amount to? First, as to self, or mind, he says, 'But what this being 
is, although it is myself, I have no knowledge, other than the series of its states of consciousness.' As to body, he says the reasonable opinion is, that it is the 'hidden external cause to which we refer our sensations.' (I. iii. 8.) Sensation is our only primary mental operation in regard to an external world, and perception is discarded ' as an obscure word.' (Compare Dissertations, vol. i., p. 94.) 'There is not the slightest reason for believing that what we call the sensible qualities of the object are a type of anything inherent in itself, or bear any affinity to its own nature.' 'Why should matter resemble our sensations?' (Logic, I., iii. 7.) Speaking of the feelings which are excited by bodies, and the powers or properties whereby they are excited, he says that he includes these 'rather in compliance with common opinion, and because their existence is taken for granted in the common language, from which I cannot deviate, than because the recognition of such powers or properties appears to be warranted by a sound philosophy." Mr. Mill labours to shew that there is no necessary truth, and that it is quite conceivable that, at a reasonable distance beyond our world, the principle of cause and effect may not operate. It is also well known that he is by far the ablest and most plausible defender of utilitarianism in our day.

Now the question arises, What sort of new school is likely to rise out of Oxford under these influences? I put the question, and it is for those who watch over the principles of the rising generation in that university to answer it. What I fear is a combination of the empty forms of Kant, with the phenomenal philosophy of Comte and Mill; and the impression left will be, that it is useless to inquire into religion, since no certainty can be attained on such a subject. To all this I have no doubt a vigorous opposition will be offered, but I anticipate. it will be on extreme grounds, which can issue only in a rationalism or 
intuitionalism which overrides the Word of God; and religious thought will go, as it has done for the last age, by oscillations-ever swinging past the point of rest.

Bacon says, "As concerning Divine Philosophy, or Natural Theology, it is that knowledge or rudiment of knowledge concerning God, which may be obtained by the contemplation of his creatures; which knowledge may be truly termed divine in respect of the object, and natural in respect of the light. The bounds of this knowledge are, that it sufficeth to convince atheism, but not to inform religion" (Advanc. of Learning, Bk. II). It can easily be shewn that this is the position which has been taken by the great divines of the Anglican Church, and by British theologians generally.* They have maintained with wonderful unanimity that man's reason, intellectual and moral, can do something in religion, but that it cannot do everything; that it can conduct us to thoroughly ascertained and positive truth concerning God, though it cannot announce how we, as sinners, may approach him with acceptance. The few divines in our country, such as B shop Peter Browne of Cork, who held that man cannot rise to any proper knowledge of God by the light of nature, have never had much influence over thought, or been supposed to speak the general mind of the Churches of these lands. On the other hand, those who have given to natural reason a sufficiency in itself, or have constituted it into a "verifying" faculty to determine what we should take and what we should reject in Scripture, have been characterized as rationalists, and have never been held as representing the Christian Churches in these lands. I look on the position thus taken up by the great body of British theologians as the right, the

* This is scarcely the place (another opportunity may present itself) for offering any more elaborate defence of this position from the objections taken against it, and against me for holding it, by Dr. Dorner, of Gottingen, in his long, and able, and candid review of Hamilton, Mansel, Maurice, Fitzgerald, and myself, in an Article (occasioned by my "Letter to the German Churches") in the "Jahrbuicher fuir Deutsche Theologie" for 1861 . 
wise, and the safe one; and we peril the cause of religion if we depart from it to one side or other. I believe it to be the very position taken by the Apostle Paul in the opening of the Epistle to the Romans, and indeed by the inspired writers all throughout the Scriptures. The Bible comes to us as the Word of God,pre-supposing that we believe in God, on the natural evidence supplied by his works without and convictions within. Pre-supposing that God and his eternal power and godhead may be thus so far known-yes, known

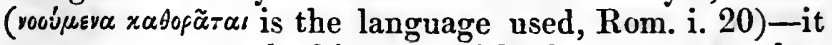
comes to us to make him more fully known, as to what he is in himself, and as to what he has done for man. The great philosophers of our country have held, with Bacon, " that by the contemplation of nature, to induce and enforce the acknowledgment of God, and to demonstrate his power, providence, and goodness, is an excellent argument" (Advanc. of Learning, Bk. II.); and I hope they will continue to do so in England and in Scotland, despite the authority of Kant and Hamilton. The great theologians of our country, and of Germany too, have drawn their most powerful arguments in behalf of the Bible as the Word of God from the revelations given to man by the "law of conscience which is a sparkle of his first estate," of the perfect and unchangeable morality of God; and I trust they will never allow themselves to be drawn from this by the temptation held out to them, of lowering the pretensions of rationalists by taking lower and negative grounds on the subject of man's moral reason. On the other hand, they must beware, lest the extreme position taken by the nescient school should allure them to go to the opposite extreme, and to ascribe to unaided human reason a sufficiency, which all history and all experience shew that it has never realized. The constant appeals which are being made in our day to the idea of the infinite and the moral reason, should induce all thinkers to set about an earnest inquiry, pursued in the inductive manner, as to the precise conceptions and beliefs 
which the human mind entertains in regard to infinity, and as to the intimations actually made by the conscience. As the result of such an investigation, it will be found that we have positive and very profound conceptions on such subjects, but that they are utterly, and obviously, and deplorably insufficient " to inform religion."

ART. II.-BUNSEN AND GERMAN THEOLOGY.

As the name of Bunsen has been employed for a purpose in one of the "Essays and Reviews," and as I have had occasion more than once to refer to that distinguished man, I feel as if it were due to his memory to give some particulars of the delightful intercourse which $\mathrm{I}$ had with him, several hours every day for five successive days, in the month of August, 1858.

It was on the afternoon of Tuesday, August 4, that I waited on him at his pleasant villa, at Charlottenburg, near Heidelberg, with a letter of introduction, with which I had been favoured, from a distinguished British nobleman, a special friend of Bunsen's. As I went up to his residence, a carriage passed out having in it a gentleman of a singularly grave and noble countenance, and $I$ was sure this must be Bunsen himself. Not finding him at home, I left my card and introductions, and the same evening I had a kind letter from him inviting me to visit him next day, and pressing me to give him as much of my time as possible. Next day I secured my first interview with him, and on each successive day, to the Sunday following, inclusive, I waited on him by appointment, at dinner, or for coffee, or for tea, and on each occasion had lengthened conversations with him. And what a talker! Interesting as many of his writings are, they are not nearly so much so as was his conversation. The man himself 
was an object of the highest interest to all who could ' appreciate him. With a head that rose like a dome, he had a heart from which there glowed a genial heat as from a domestic fire. He talked of education in Germany and in England, of religion, of theology, of philosophy, of the state of the Romish and Protestant Churches on the Continent, and interspersed the grand theoretical views which he delighted to expound with anecdotes of kings, statesmen, philosophers, and theologians of the highest name, with whom he had been intimate. But his noble enthusiasm ever kindled into the brightest flame when he spread out before me his own intended works, as illustrative of the Bible, of philosophy, and history, and fitted to help on the education of the race. I have met with many talented men, with many good men, with not a few men of genius; but I have had the privilege of holding confidential intercourse with only three whom I reckoned "great men." One, the greatest, I think-Dr. Chalmers-ever rises up before my memory as a mountain, standing fair, and clear, and large. The second, Hugh Miller, rises as a bold rocky promontory, covered all over with numberless plants of wild exquisite beauty. The third, Bunsen, stretches out before me wide, and lovely, and fertile-like the plains of Lombardy which I had just passed through before visiting him.

I have referred to the fondness with which he dwelt on his contemplated publications. He was now, in his retirement, to give to the world the views on all subjects, historical, philosophical, and theological, which had burst upon him in their freshness when he spent so many of his youthful years in Rome. I confess, however, that, deep y interested as I was in his speculations-as these came forth with such a warmth and radiance from his own lips-I had all the while an impression that he would require to live to an antediluvian age in order to commit all his theories to writing, - and also a very strong conviction that his 
views belonged to the past age rather than the present, and that some of them would not, in fact, promote the cause of religion which he had so much at heart. It ever came out, that he drew no distinction between the natural and preternatural. He was a firm believer in mesmerism and clairvoyance (in favour of them he mentioned some circuunstances which seemed to me to have no evidential value), and was apt to connect them with the inspiration of the writers of the Bible.*

He talked in terms of intense affection of Alexander von Humboldt, with whom I had had some intercourse a short time before. My interview with that illustrious man was held by appointment (through Herr Sydow who had introduced me to him), in his own house in Berlin, on June 15th of the same year, only a few months before his decease. The conversation began by his referring to my published views as to the correspondence between the ramification of the plant and the venation of its leaves, as shewing that there is a unity of plan and structure throughout the plant,- to the general doctrine he gave his decided adherence, and said that he had himself noticed the correspondence. He passed on to discourse of the injurious imputations which had been cast on his religious principles by certain Jesuits, and in doing so, spoke in terms of strong indignation of the way in which the great German Leibnitz, had sought to prejudice the Electress of Brandenburg against the English Newton, because of the supposed irreligious tendencies of his works. He branched off into the latest discoveries in science; shewed me curious natural objects which he had picked up in various parts of the world; he talked of the plurality of worlds, which he believed in as

* Since writing the above my eye has alighted on a passage in one of Schleiermacher's Letters, written in 1817 (Life, translated by F. Rowan, p. 260), in whieh, speaking of animal magnetism, he says :- "My opinion, in regard to the nature of these mental phenomena and to their truth, is this: any distinction between the natural and supernatural, between the compreheusible and the incomprehensible, I do not, upon the whole, recognize. 
being most consonant with his conception of God; and . he encouraged me to speak of religion and of the reconciling work of the Saviour. "You are going to risit Bunsen," he said; "you must by all means do so ;" and he proceeded to speak of him in the language of the greatest admiration and affection, adding, "I do not understand some of his writings, but I have formed the very highest opinion of his Bibelwerk." It is not for one who had so imperfect an acquaintance with Humboldt as l'had to attempt to reconeile what he said to me with harsh expressions about Bunsen scattered throughout his letters to Varnhagen. Were his feelings towards Bunsen softened in his later days? Or was he rejoicing in the Bibelwerk because he saw that it would further very different ends from those contemplated by Bunsen? On my reporting to Bunsen how kindly Humboldt had spoken of him, he said, "I am bringing out a certain portion of my Bibelwerk before other parts which should come earlier, in order that it may fall under the eye of Humboldt ere he is removed from us." The way he said this shewed the great love he had for Humboldt; and he intimated pretty plainly that he hoped the part of the Bibelwerk to which he referred might help to draw Humboldt towards deeper religious convictions.

Whether any such end was accomplished, I have no means of knowing. I have doubts as to whether the means were fitted to attain the object fondly desired. For Bunsen was already in a very ambiguous position in his own country. Respected and beloved by allexcept the enemies of civil and religious liberty-his speculations, philosophical or theological, carried, I found, very little weight in Germany. The great divines of the orthodox school, while they loved him for his piety, just regretted the more that in his opinions as to the authenticity and inspiration of the Old Testament he was adhering to views which had been very prevalent in the earlier part of the century, but had been for years abandoned by all who had given their 
attention to the subject. The rationalists, who, in the days of their strength, had hated Bunsen for his warm evangelical piety, were rejoicing, now that the tide was against them, that they had in him an unconscious auxiliary in their work of undermining the inspiration of the Bible,- but they set no value whatever on his own speeulations and opinions. His venerated name is being extensively used by the rationalists of this country; it is right that they should know that he ever spoke of rationalism in terms of strongest disapprobation and aversion, and he wished it to be known everywhere that he identified himself with the living evangelical piety of Britain. While Bunsen was able to retain his piety, in spite of the vagueness and wanderings of his speculative opinions, it is difficult to see how any young man trained in the creed left to Bunsen could ever rise to a belief in the Saviour.

What I have now said indicates pretty clearly the state of theological belief of late years in Germany. The rationalists of the two last ages, though their immediate power was restricted to their students in the universities, had yet, through them, as they scattered through the country, spread a most baleful influence, resulting in a general disregard of religion among all classes, beginning with the educated and going down to the lowest. But since 1848-when the country became alarmed at the extremes to whieh infidelity led-there has been a reaction in favour of orthodox doctrine and evangelieal sentiments. This has been specially felt by students intending for the pastoral office, who have very much abandoned the old rationalistic and Hegelian professors, and are erowding the elass-rooms of those who defend the inspiration of Scripture and the old doctrines of salvation by the eross of Christ. The great German theologians of the age now passing away, and of the present age have, with unmatehed erudition and profound speculative ability, defended the Bible from the assaults made upon it; and as it was from Germany we got the bane, so it is from Germany, or rather from 
English writers who can use the stores of German learning, that we must look for the antidote.

But to return to Bunsen. I am able to say-what I believe I can say of no other with whom I had so much intercourse-that we never conversed during these five days, for ten minutes at a time, without his returning, however far he might be off, to his Bible and his Saviour, as the objects that were evidently the dearest to him. Some of my British readers will be astonished when I have to add, that one evening he told me that he "was not sure about allowing that God is a Being, and that he certainly could not admit that God is a Person." The question will be asked, How was it possible for one entertaining such theoretical views to love his God and Saviour, as Bunsen seemed to love them, supremely? Having a considerable acquaintance with the Hegelian philosophy, and having only a short time before listened to the lectures of some of the most devoted disciples of that school, I think I can understand this inconsistency, though I would never think of defending it. Bunsen had been trained in the first quarter of this century, when Schelling and Hegel (of whom he always spoke with profound admiration) ruled in the universities, and he had so lost himself in ideal distinctions and nomenclature, that his words were not to be interpreted as if the same expressions had been used by another man. He was for ever talking, in Kantian phraseology, of the forms of space and time, and of the manifestations of God in space and time. I laboured to shew that there were other intuitive convictions in the mind as well as those of space and time, and, in particular, that we all had an immediate consciousness of ourselves as persons, and that this conscious personality, duly followed out, raised our minds to the contemplation of God as a Being and a Person. One evening, in his house, I thought I had shut him up to a point, but the conversation was interrupted by the breaking up of the large company. We met next day, by appointment, to resume the dis- 
cussion, but amid the flow of his grand conceptions I never got him back to the point at which we had broken off.

The last day I passed with him was a Sabbatha Sabbath indeed-for I never in all my life spent a more profitable day. In the forenoon, I sat with him in his seat in the University Church at Heidelberg, where we had the privilege of listening to a powerful Gospel sermon from Dr. Schenkel. I spent the afternoon in his house, where he read to us in German, or in English translations, out of the fine old devotional works of his country, interspersing remarks of his own, evidently springing from the depths of his heart, and breathing towards heaven - to which, I firmly believe, he has now been carried. 


\section{$E R R A T A$.}

Page 16, line 14, for was, read is.

"122, lines 23,24 , delete or mental.

"129, line 12, delete the in in fits in.

"189, line 3, for derivations, read derivatives.

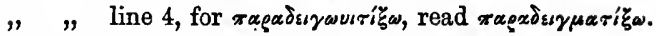

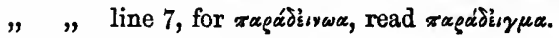

"258, line 4, for as, read in.

" 292, line 1 from foot, for Tahrbücher, read Jahrbücher.

"314, line 13, for attest, read test.

"322, line 17, for them, read it. 
Seventh Edition, 10s. 6d.

\section{THE METHOD OF THE DIVINE GOVERNMENT, PHYSICAL AND MORAL,}

By Rev. James M'Cosh, LL.D.

Book I.-General View of the Divine Government. BooK II.-The Physical World; General Laws; Providence. Bоок III.-Man's Moral Nature. Book IV.-Reconciliation of Man and God.

"The work is of the compact, thought-elevating complexion which men do not willingly let die; and we promise such of our readers as may possess themselves of it, much entertainment and instruction of a high oriter, and a fund of solid thought which they will not soon exhaust." Hugh Miller.

"The work is distinguished from other similar productions by its being based on a thorough study of natural science and an accurate knowledge of its present condition, and by its entering, in a profounder and more unfettered manner than its predecessors, into the discussion of the appropriate psychological, ethical, and theological questions. The author keeps aloof at once from the $a$ priori idealism and dreaminess of German speculation since the days of Schelling, and from the onesidedness and hasty generalizations, of empiricism and positivism, which have been, till recently, so prevalent in England."-Zeitschrift für Philosophie-(by Dr. Ulrici, one of the Editors.)

Second Edition, 7s. 6d.

\section{TYPICAL FORMS AND SPECIAL ENDS IN CREATION,}

By Rev. Jayes M'Cosh, LL.D., and George Dickie, M.D.

BooK I.-Principles of General Order and Spccial Adaptation. ВооK

II.-Typical Forms and Special Ends in the Plant and Animal.

BooK III.-Interpretation of the Facts.

The researches embodied in this volume were referred to in commendation by the Duke of Argyll, and an epitome of the work itself, with laudatory remarks, was given by Dr. Daubeny of Oxford, in their opening addresses as Presidents of the British Association for the Promotion of Science.

"It is clearly and simply written, in a style well suited for the general reader. As a mere epitome of facts it is useful; as a generalisation of mental and physical science it is interesting; and in reference to the moral object which has suggested the plan, we think the authors have most ably and truthfully fulfilled their task."-Critic.

"It is a noble and eminently successful attempt to advance natural theology to a higher level than it has yet attained."-Morning Post. 
Lately Published, 128.

\title{
THE INTUITIONS OF THE MIND
}

\author{
I N D C TIVLY IN E T T GATED.
}

By Rev. Jasres M'Cosh, LL.D.

PART I.-General View of the Intuitive Convictions of the Mind. Part II.-Particular Examination; Primitive Cognitions; Primitive Beliefs ; Primitive Judgments; Moral Convictions. PART III.Intuitive Convictions and the Various Sciences inclnding Theology.

" The work surveys, more or less completely, all the ground indicated by its title. The principles which it discusses are the most vital in modern metaphysics. The appearance of the volume is pre-eminently seasonable; its plan symmetrical and comprehensive; and its temper admirably, we may say characteristically, candid and catholic. No philosophic student can afford to be ignorant of its contents. No philosopher before Dr. $M^{\prime}$ 'Cosh has clearly brought out the stages by which an original and individual intuition passes-first, into an articulate but still individual judgment, and then into a universal maxim or principle. Nor has any one before him so clearly or completely classified and enumerated our intuitive convictions, or exhibited in detail their relations to the various sciences which repose on them as their foundations." - The London Review.

“ Dr. M'Cosh's works have the merit of speaking to living questions, and meeting an existing desideratum. He has the merit of meeting the exact issue, of facing, instead of shirking, the difficult problems which are either intrinsic to philosophy, or which emerge in the attempt to conciliate it with religion. There is in his works a quick discernment of truth and error, good and evil; of the weak side of splendid and imposing philosophic systems; and a ready perception and a bappy setting forth of the harmony between the light of Nature and Revelation; and all this with reference to living issues, which impart great value to his writings, especially his latest work. Like the magnet cast into a heap of sand and iron filings, his judgment picks up the true metal and rejects the worthless dirt. It is this sound, sensible, judicial quality of mind that renders him a sober and safe thinker, and communicates to his works a healthy tone and salutary influence. In this view their wide popularity is both deserved and explained."-Princeton Review. 


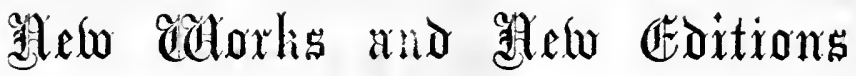

\author{
PUBLISHED BY \\ MACMILLAN AND CO. \\ CAMBRIDGE,
}

AND 23, HENRIETTA STREET, COVENT GARDEN, LONDON, W.C.

COMPLETION OF THE FOURTH VOLUME.

M A C M I L L A N'S

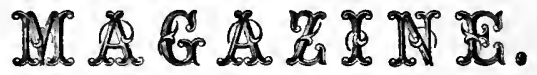

EDITED BY DAVID MASSON.

PRICE ONE SIILLING MONTHLY.

Volumes I. to IV. are now published, price 7 s. $6 d$. each, bandsomely bound in cloth.

RAVENSHOE ; OR, THE ADVENTURES OF A YOUNG ENGLISH GENTLEMAN; is now in course of publication in this Magazine.

Life and Correspondence of M. De Tocqueville.

Translated from the French by the Translator of Napoleon's Correspondence with King Joseph. With numerous additions. In Two Vols.

Crown 8ro. $21 s$.

The Golden Treasury : A Collection of the best Songs and Lyrical Poems in the English Language. Edited by F. T. Palgrave.

Beautifully printed, and bound in extra cloth. Fcap. 8vo. 4s. $6 d$. "No book in the English language vill make a more delightful companion than this."-SPEctator.

$\frac{12.11 .61 .}{6,000 \text { crown. }}$ 


\section{B OOKS FOR THE. YO U N G.}

\section{Price Five Shillings each.}

TOM BROWN'S SCHOOL DAYS. By AN OLd BoY. With

a new Proface. Twenty-seventh Thousand. Fcap. 8vo. 58 .

"Tho:e manly, honest thoughts, expressed in plain words, will, we trust, long find an echo iu thou sands of Englis! lieart s."-Quarterly Review.

OUR YEAR. A Child's Book in Prose and Rhyme. By the Author of "John Halifax." With numerous Illustrations by Clarexce Dobelt. Roval 16 mo. cloth, gilt leaves, 58 .

"Just the book we could wish to see in the hands of every child."-English Churchman.

PROFESSOR KINGSLEY'S HEROES, OR GREEK FAIRY TALES FOR MY CHILDREN. New Edition, with Illustrations.

Royal 16 mo. cloth, gilt leares, 5 s.

"A welcome and delightful volume, for the stories are prose poems both as to matter an i manner."-Eclectic Review.

RUTH AND HER FRIENDS. A Story for 'Girls. With

Frontispiece. Third Edition. Royal $16 \mathrm{mo}$. cloth, gilt leaves, 58 .

"A book which girls will read with avidity, and cannot fail to profit by."-Literary Churchman.

EGYPTIAN HISTORY FOR THE YOUNG. By the Author of "Mria and Charley." Feap. 8ro. 5s.

DAYS OF OLD : Stories from Old English History. By the Author of "Ruth and Her Friends." With Frontispiece. Rojal $16 \mathrm{mo}$. clolh, gilt leaves, $5 s$.

"A delightful little book, full of interest and instruction . . . f fine fecling, dramatic weight, and descriptive power in the stories."-Literary Gazette.

AGNES HOPETOUN'S SCHOOLS AND HOLIDAYS. By Mrs. Oliphaxt (A uthor of "Margaret Maitland"). With Frontispiece. Royal $16 \mathrm{mo}$. cloth, gilt leaves, 5.

"Described with" exquisite reality.. . teaching the young pure and good lessons."-John Bull.

LITTLE ESTELLA, AND OTHER FAIRY TALES. By

May Beverley. With Frontispiece. Royal 16mo. cloth, gilt

leaves, $5 s$.

"Very pretty, pure in conception, and simply, gracefully related . . genuine story tell n,."-Daily Neves.

DAVID, KING OF ISRAEL. A History for the Young. By Josiah Wright, Ilead Master of Sutton Coldfield Grammar School.

With Illustrations. Koyal $16 \mathrm{mo}$. cloth, gilt leaves, $5 s$.

"An excellent book . . . well conceived, and well worked out."-Literary Churchman.

MI F FRT JOURNAL: A Book for Children. $\overline{\mathrm{By}}$

Grokgiana M. Cratk, Author of "Last and Won." With Frontispiece. Royal $16 \mathrm{mo}$. cloth, gilt leaves, $4 s .6 d$.

"True to Nature aud to a fine kind of nature ... the style is simple and gracefal. . . "wo:k of Art, clever and liealthy toned."-Globe. 


\section{P O P U LA R N O V E L S.}

TOM BROWN AT OXFORD. By the Author of "Tom Brows's School DAYs." Three Vols. crown 8vo. 1l. 11s. $6 d$.

THE BROKEN TROTH: A TALE OF TUSCAN LIFE. Translated from the Italian by Phimip Ireton. Two Vols. fcap. 8 ro. 128.

"A charming story. The pictures are life-like in every touch."-Athenaum.

THE MOOR COTTAGE : A TALE OF HOME LIFE. By MAY BeverLex, Author of "Little Estella, and other Fairy Tales for the Young." Crown 8vo. cloth, price 10s. 6d.

"This charming tale is told with such excellent art, that it reads like an episode from real life."-Atlas.

\section{A Six Shiluing EDition of}

\section{PROFESSOR KINGSLEY'S WESTWARD HO! Crown}

8 vo. eloth.

"Almost the best Historical Novel, to our mind, of the day."-Fraser's Magazine.

A Six Shiluing Epition of

\section{PROFESSOR KINGSLEY'S TWO YEARS AGO. Crown}

8 vo. cloth.

"Genial. large-hearted, humorous, with a quick eye, and a keen relish alike for what is beautiful in nature, and for what is genuine, strong, and earnest in man." - The ruardian.

\section{MR. HENRY KINGSLEY'S RECOLLECTIONS OF GEOFFRY IIAMLYN. Crown 8vo. cloth.}

"Mr. Ilenry Kingsley is no ordinary writer. He has hoth the eye and the heart of a poet; and like a true poet he knows how to reach the hearts of others."-Freeman.

ARTIST AND CRAFTSMAN.

Crown 8vo. cloth, price 10s. $6 d$.

"Its power is unquestionable, its felicity of expression great, its plot fresh, and its characters very natural ... Wherever read, it will be enthusiastically admired and cherished."-Morning Herald.

A LADY IN HER OWN RIGHT. By Westland Marston. Crown 8 vo. cloth, price 10s. $6 d$.

" Since 'The Mill on the Floss' was noticed, we have read no work of fiction which we can so heartily recommend to our readers as 'A Lady in her own right :' the plot, incidents, and characters are all good: the style is simple and graceful: it abounds in thoughts judiciously introduced and well expressed, and throughout a kind, liberal, and gentle spirit."-Church of England Monthly Review.

YES AND NO; on, GLIMPSES OF THE GREAT CONFLICT. Three Vols. crown 8 vo. cloth, price-1l. 11 s. $6 d$.

"Original in conception .... Of the merits of the book as a piece of writing, it is almost impossible to speak too highly - so unaffertedly sincere, so clear and inpressive, so graceful and so strong is it."-Nonconformist.

BRITISH NOVELISTS AND THEIR STYLES; being a Critical Sketch of the History of British Prose Fiction. By DAVID Masson, M.A. Crown 8vo. cloth, 78. 6 d. 


\section{CAVOUR: A MEMOIR.}

WITH A PORTRAIT FROM AN ORIGINAL PHOTOGRAPH. By EDward Dicer, Author of "Rome in 1860."

Second Edition. Crown 8vo. choth, price 6s. 6l.

"Gires a fu'l view of Carour's infuence on the Italian Revolution, with details of his life, from authentic sources."-EXaMINrR.

THE ITALIAN WAR OF 1848-9,

And the Last Italian Poet. By the late Henry Lushington, Chief Secretary to the Government of Malta. With a Biographical Preface by G. Stovis Vexables.

Crown 8vo. clotl, 6s.6d.

\section{THE PRISON CHAPLAIN.}

A Memolr of Rev. John Clay, late Chaplain of -Preston Gaol.

With Selections from his Writings and Correspondence, and a sketch of the progress of Prison Discipline in England. Edited by his Son. 8vo. clotls. With Portrait. 15s.

\section{SCOURING OF THE WHITE HORSE.}

By the Author of "T'om Brown's Schoor DaYs."

ivith numerous Illustrations by Richaro Doyce. Eighth Thousand. Imp. $16 \mathrm{mo}$. printed on toned paper, gilt leaves. $8 s .6 d$.

" Like Tom Brown's School Days, the While Horse gives the reader a feeling of grat it ude and personal esteem lowards the author."-SATURDAY REVIEw.

EDITED BY W. G. CLARK, M.A.

Public Orator in the University of Cambridge.

George Brimley's Essays. With Portrait.

Second Edition. Fcap. 8ro. clotl. 5s.

"To evcry cultivated reader they will disclose the wonderful clearness of perception, the delicacy of feeling, the pure taste, and the remarkably firm and decisive judgment which are the characteristics of all Mr. Brimley's scritings on subjects that really penetrated and fully possessed his nature."NONCONFORMIST.

Cambridge Scrap-Book. Containing in a Pictorial Form a Report on the Manners, Customs, Humours, and Pastimes of the University of Cambridge. Containing 1early 300 Illustrations. Second Edition.

Fancy Boards, half-bound, $7 s, 6 d$. 
Volunteer's Scrap-Book. A Series of Humorous Sketches - Illustrative of the Volunter, Movement: By the Author of the "CaMbridge Scrap-Book." Fancy boards, half-bound, 7s.6d.

\section{NEW VOLUME BY DR. TEMPLE.}

Sermons preached in Rugby School Chapel in 1859, 1859, 1860. By the Rev. Frederick Temple, D.D. Chaplain in Ordinary to Her Majesty, Head-Master of Rugby Schooi, Chaplain to the Right Hon. the Earl of Denbight.

8 ro. price $10 s .6 d$.

\section{BY ALEXANDER SMITH, Author of a "Life Drama, and other Poems."}

Edwin of Deira.

Second Edition. Feap. 8vo. $5 s$.

"A perfeclly original poen, and full of rare beauties."-Morning Chronicus.

City Poems.

Feap. 8vo. cloth, $5 s_{\text {a }}$

A Life Drama and other Poems. Feap. 8ro. cloth, $2 s .6 d$.

\section{BY JOHN MALCOLM LUDLOW,} Burrister-at-Law.

British India, its Races, and its History, down to the Mutinies of 1857. 2 vols. feap. $8 \mathrm{ro}$, cloth, $9 s$.

"The best historical Indian manual existing, one that onght to be in the hands of every man who writes, speaks, or rotes on the Indian question."-EXAMINER.

"The best elementary work on the History of India."-HoMrward MaTL.

\section{WORKS BEARING ON THEOLOGICAL DIFFICULTIES.}

FOR STUDENTS AND GENERAL READERS.

BY THE REV. T. R. BIRKS, Author of "The Life of the Rev. E. Bickersteth."

Difficulties of Belief, in connexion with Creation and the Fall.

Crown 8vo. cloth, 4s. $6 d$.

\section{BY THE REV. F. D. MAURICE.}

Incumbent of St. Peter's, Marylebone.

Theological Essays. Second Edition. Crown Sro. clotl, 10s.6d. 
WORKS BEARING ON THEOLOGICAL DIFFICULTIES.

FOR STUDENTS AND GENERAL READERS-continued.

\section{BY THE REV. HENRY CALDERWOOD. of Greyfriars' Church, Glasgour.}

Philosophy of the Infinite :

A Treatise on Man's Knowledge of the Infinite Being, in Answer to Sir Wm. Hamilton and Mrr. Mansel.

Second Edition, greatly enlarged. $8 \mathrm{ro}$. cloth, 148 .

BY THE REV. H. C. GROVES, M.A.

Perpetual Curale of Mfullarilly, Diocese of Armagh.

A Commentary on the First Book of Moses, called Genesis. For the Use of Students and Readers of the English Version of the Bible. Crown 8ro. cloth, 9 s.

BY THE REV. B. F. WESTCOTT,

Lale Fellow of Trinily College, Cambridge.

Characteristics of the Gospel Miracles. Sermons preached before the University of Cambridge. With Notes.

Crown 8vo. cloth, 4s. $6 d$.

BY THE REV. J. LLEWELYN DAVIES, Reelor if Christ Church, St. Marylebone.

The Work of Christ; or, the World reconciled to God. With a Preface on the Atonement Controversy. Fcap.8vo. cloth, $6 s$.

\section{BY THE REV. J. M. CAMPBELL, Author of "Christ the Bread of Life."}

The Nature of the Atonement, and its Relation to Remission of Sins and Eternal Life. 8vo.cloth, 10s.6d.

BY THE REV. JAMES M'COSH, LL.D. Professor of Logic and Melophysics in Queen's College, Belfast.

The Method of Divine Government, Physical and Moral. Seventh Edition. Demy 8vo. cloth, price 10s. $6 d$.

The Supernatural in Relation to the Natural, with Spccial Reference to Existing Controversies.

In the Press, in crown 8 ro. 


\section{THE PLATONIC DIALOGUES,}

For English Readers. By W. Wheweut, D.D. F.R.S. Master of Trinity College, Cambridge.

Volume I. Second Edition, containing the Avri-sopiIst DraLOGUES. $7 s, 6 d$.

Volume II. containing the Socratic Dialogues. $6 s .6 d$.

Volume III. containing the Republic and the Trmeus. 7s. 6d.

"In the present instance ve have most appropriately one of the deepest thinkcrs

of the present day making the Platonic Dialogues as intelligible in an Engtish garb, to the English reader, as they are in the original to himself and the comparatively few scholars. . . . The Dinlogues are rendered additionally intelligible, and, indeed, interesting to the English reader, by copious explanatory passages thrown in parenthetically here and there."-GENTLEMAN'S MAGAZINE.

\section{THE REPUBLIC OF PLATO.}

A New 'Translation into English. With an Analysis and Notes. By J. L.. Daries, M.A., and D. J. Vaugiran, M.A., Fellows of Trinity College, Cambridge. Second Edition.

8vo. cloth, 10s. C.

"So eloqueut and correct a version will, we trust, induce many to become students of the Republic... The whole book is scholarlike and able."-GUARDIAN.

MEMOIR OF GEORGT WILSON, M.D. F.R.S.E.

Regius Professor of Technology in the University of Fdinburgh. By his Sister, Jessie Aitnin Wilson. With Portrait, 8vo. cloth, 14.

The Five Gateways of Knowledge. A Popular Work on the Five Senses. By George Wilson, M.D.

In fap. 8vo. cloth, with gilt leaves, $2 s .6 d$. People's Edition, in ornamental stiff covers, $1 s$.

The Progress of the Telegraph. By Gronge Wilsov, Mr.J). Fcap. 8vo. 1s.

"Most interesting and ins/ructive... at once scientific and popular, religion's and technical; a worthy companion to the "Gateways of Knowledge." Literary Churchmas.

BY DR. GE0. WILSON, AND A. GEIKIE, F.G.S.

Life of Edward Forbes, the Natnalist. 8vo. cloth, 14s.

"Few readers vill lay it down without haring realized the personality of the mau, and taken a warm interest in his fortuncs."-JCHN BUIL.

\section{BY THE REV. R. TUDOR,} Curate of Helston, Cornwall.

The Decalogue viewed as the Christian's Law :

With Special Reference to the Questions and Wants of thic Times. 


\section{MEMOIR OF THE REV. GEORGE WAGNER,} Lale of St. Slephen's, Brighton.

By J. N. Simpkinson, M.A., Rector of Brington, Northampton. Second Edition. Crown 8vo. cloth, 9s. "A deeply interesting picture of the life of one of a class of men who are indeed the salt of this land."-MorNing HERALD.

BY FRANCIS MORSE, M.A. Incumbent of Sl. John's, Ladywood, Birmingham.

Working for God. And other Practical Sermons.

Second Edition. Fcap. 8vo. 5s.

"For soundness of doctrine, lucidity of style, and above all for their practical teaching, these sermons will commend themselves."-Jorn BuLL.

"There is much earnest, practical teaching in this volume."- ExglisI Churchuav.

\section{BY THE REV. D. J. VAUGHAN, M.A,}

Vicar of St. Martin's, Leicester, late Fellow of Trinity College, Cambridge.

1. Sermons Preached in St. John's Church, Leicrster, during the years 1855 and $1856 . \quad$ Crown 8vo. cloth, 5s. 6d.

2. 'Three Sermons on the Atonement. With a Preface.

Fcap. Sro. 1s. 6d.

3. Sermons on the Resurrection. With a Preface.

Fcap. 8vo. cloth, $3 s$.

4. Sermons on Sacrifice and Propitiation.

Fcap. Svo. cloth, 3s.

\section{BY THE REV. J. F. THRUPP, M.A.}

Late Fellow of Trinily College, Cambridge.

Introduction to the Study ard Use of the Psalms.

Two Vols. Sro. 21 s.

"The plan, considering that the author appeals to the great body of English readers, is admirable. The result is a volume as interestingly reudible as it is critically valuable."-FrE EMAN. 


\section{BY REV. H. MACMILLAN, F.R.S.E.}

Foot.notes from the Page of Nature; or, First Forms of Vegetation. With numerous Illustrations and a Coloured Frontispiece. A popular work on Mosses, Lichens, Fresh-water Algæ, and Fungi.

Fan. 8vo. cloth, $5 s$.

"A rery pleasantly writlen summary of the structural peculiarities, wses, associations, and other interesting topics connected with the humblest forms of plant life."-Westmisster Review.

\section{BY JOHN PHILLIPS, M.A. L.L.D. F.R.S. \\ Professor of Geology in the University of Oxford.}

Life on the Earth : its Origin and Succession.

Crown 8vo. cloth, 6s. $6 d$.

Lectures to Ladies on Practical Subjects.

Third Edition. Crown 8vo.7s.6d.

\section{BY FREEMAN OLIVER HAYNES,}

of Lincoln's Inn, Barrister-at-Law, and late Fellow of Caius College, Cambridge.

Outlines of Equity. Being a Series of Elementary Lectures: delivered at the request of the Incorporated Law Society.

8 vo. eloth, 1.08 .

"Of real service to the Students, and to them we cordially recommend it."SOLICITORS' JOURNAL.

"All Law Students will peruse these Lectures with profit, whether reading for the Bar or for the Desk."-Law Times.

"Well adapted to the uants of all Students who desire to derive an elementary knowledge of the principles of and the practice in Courts of Fquity." $\mathrm{L}_{\Delta} \mathrm{x}$ MAgAzine.

\section{BY C. A. SWAINSON, M.A.}

Principal of the Theological College, and Prebendary of Chichester.

1. 'The Authority of the New Testament; the Conviction of Righteousness, and other Lectures delivered before the University of Cambridge.

8 ro. cloth, $12 s$.

2. The Crceds of the Church. In their Relations to the Word of God and the Conscience of the Christian. 8vo. cloth, 9s.

3. A Handbook to Butler's Analogy. With a few Notes. 
W I L I A M A R CHER B U TLER, M. A.,

Late Professor of Moral Philosophy in the Oniversity of Dublin.

FIVE TOLUMES 8vo. UNIFORMLT PRINTED AND BOUND. Price 2l. 18 s.

"A man of gloving genius and diversified accomplishments, whose remains fill these five brilliant volumes."-EDINBURG REVIEW.

SOLD SEPARATELY AS FOLLOWS.

1. Sermons, Doctrinal and Practical. First Serres. Edited by the Very Rev. Thos. Woodwarn, M.A., Dean of Down. With a Memoir and Portrait. Fifth Edition. 8ro. cloth, 128.

"Present a richer combination of the qualities for Sermons of the first class than any we have met with in any living writer."-BRITISH QUARTERLY ReviEw.

2. Sermons, Doctrinal and Practical. Second Series. Edited by J. A. Jeremie, D.D., Regius Professor of Divinity in the University of Cambridge. Third Edition. 8vo. cloth, 10s.6d.

"They are marked by the same originality and vigour of expression, the same richness of imagery and illustration, the same large views and catholic spirit, and the same depth and feroour of devotional feeling, which so remarkably distinguished the preceding Series, and which rendered it a most raluable accession to our theological literature."-From Dr. Jaremie's PrF.FACE.

3. Letters on Romanism, in Reply to Dr. NewMas's Essay on Development. Edited by the Very Rev. ThomasWoodward, M.A., Dean of Down. Second Editios. Revised by the Ven. ARchDEACON HARDWICK. $\quad$ svo. cloth, 10s. $6 d$.

"Deserve to be considered the most remarkable proofs of the Author's indomitable energy and power of concentration."-EDINBURGH REvIEW.

4. Lectures on the History of Ancient Philosophy. Edited from the Author's MSS.; with Notes, by Williay HEFworri Thompson, M.A., Regius Professor of Greek in the University of Cambridge.

2 vols. 8vo., \&l $5 . s$.

"Of the dialectic and physicsof Plato they are the only exposition at once full, recurate, and popular, with which I a m acquainted: being far moreaccurate than the French, and incomparably more popular than the German treat ises on thes: departments of the Platonic philosophy."-From Pror. Thом pson's Prr.racs. 


\section{THE WORKS OF \\ JULIÚS CHARLES HARE, M.A.,}

Sometime Archdeacon of Lewes, Reclor of Herslmonceux, Chaplain in Ordinary to the Queen, and formerly Fellow and Tulor of Trinily College, Cambridge.

NINE VOLS. 8RO. UNIFORMLY PRINTED AND BOUND.

1. Charges to the Clergy of the Archdeaconry if Lewes. During 1840 to 1854 , with Notes on the Principal Events affecting the Church during that perind. And an Intreduction, explanatory of his position in the Church, with irference to the Parties which divide it.

3 vols. 8ro. cloth, \&l 1]s. fid.

2. Miscellancous Pamphlets on some of the Leading Qnestions agitated in the Church during the years 1845 to 1851 .

8vo. cloth, $12 \mathrm{r}$.

3. Vindication of Luther against his recent English Assailants. Second Edition. 8vo. cloth, 7 s.

4. The Mission of the Comforter. With Notes. Second Edition. 8ro. cloth, ]2s.

5. 'The Victory of Faith. Second Edition. 8vo. cloth, 5s.

6. Parish Sermons. Second Series. 8vo.cloth, I:s.

7. Sermons preacht on Particular Occasions. 8vo. Izk.

The two following books are included among the collected Charges, but are publis: a separately for purchasers of the rest.

Charges to the Clergy of the Archdeaconry of Lewes. Delivered in the years 1843, 1845, 1946. Nevrr before published. With an Introduction, explanatory of lis position in the Clurch, with reference to the Parties that divide it.

8vo. cloth, 6s. $6 d$.

The Contest with Rome. A Charge, delivered in 1851. With Notes, especially in answer to Dr. Newrisan on the Position of Catloolics in England. Second Edition. 8vo. cloth, 10s. $6 d$. 


\section{WORKS BY}

CHARLES KINGSLEY, M.A.

Chaptain in Ordinary to the Queen, Rector of Eversley, and Regius Professor of Modern History in the Universidy of Cambridge.

1. The Limits of Exact Science as Applied to History: An Inaugural Lecture, delivered before the University of Cambridge.

Crown 8vo. $2 s$.

2. T'wo Years Ago. Third Edition. Crown 8vo. cloth, $6 s$.

"Genial, large hearted, humorous, with a quick eye and a keen relish atike for what is beuuliful in nalure and for what is genuine, strong, and earnest in man."-GuardiaN.

3. "Westward Ho!" or the Voyages and Adventures of Sir Amyas Leigh, Knight, of Burrough, in the County of Devon, in the reign of Her most Glorious Majesty Queen Elizabeth. New Edition. Crown 8vo. cloth, 6s.

"Almost the best historical novel to our mind of the day."-FRASER's MAGAZINE.

4. The Heroes: Greek Fairy Tales for my Children. New aud Cheaper Edition, with Eight Illustrations. Royal 16mo. beautifully printed on toned paper, gilt edges, 5 s.

" We dos:bt not they will be read by many a youth with an enchained interest

- almost as strong as the links which bound Andromeda to her rock."--BRITISH QUARTERLY.

5. Glancus; or, the Wonders of the Shore. A Com. panion for the Sea-side. Containing Coloured Illustrations of the Objects mentioned in the Work. Fourth Edition. Beautifully printed and bound in cloth, gilt leares. $7 s .6 d$.

"Its pages sparkle with life, they open up a thousand sources of unanticipated pleasure, and combine amusement with instruction in a rery happy and unzonted degree."-Eclectic REview.

6. Phaethon ; or, Loose Thoughts for Loose Thinkers. Third Edition.

Crown 8 ro. boards, $2 s$.

7. Alexandria and Her Schools. Four Lectures delivered at the Philosophical Institution, Edinburgh. With a Preface.

Crown 8vo. cloth, 5 s. 


\section{WORKS BY}

\section{CHARLES JOHN VAUGHAN, D.D.}

Chaplain in Ordinary to the Queen, Vicar of Doncaster, and Chancellor of York Calhedral.

1. Notes for Lectures on Confirmation. With Suitable Prayers. Third Edition. Fcap. 8vo. limp cloth, red leaves, 1s.6d.

2. St. Paul's Epistle to the Romans. The Greek Text with English Notes.

Second Edition. Crown 8vo. cloth, 5s.

3. Memorials of Harrow Sundays. A Selection of Sermons preached in the School Chapel. With a View of the Interior of the Chapel. Third Edition.

Crown 8vo. cloth, red leaves, $10 s .6 d$.

4. Epiphany, Lent, and Easter. A Selection of Dxpository Sermons. Second Edition.

Crown Svo. cloth, red leaves. 10s. $6 d$.

5. Revision of the Liturgy. Five Discourses. With an Introduction. I. Absolution. II. Regeneration. III. The Atlianasian Creed. IV. Burial Service. V. Holy Orders.

Second Edition. Cr. 8vo. cloth, red leaves (1860), 117 pp. $4 s .6 d$.

6. Rays of Sunlight for Dark Days. A Book of Selcct Readings for the Suffering. With a Preface by C. J. Vaughan, D.D. Royal $16 \mathrm{mo}$ Elegantly printed with red lines, and handsomcly bound, red edges, 4s. $6 d$. Morocco, old style, gilt leares, $10 s .6 d$.

7. Four Sermons preached before the University of Canbridge.

Crown 8vo. 1s. 6d.

8. Doncaster Sermons. Fcap. 8ro. [Shortly. 


\section{BY CORNWALL SIMEON.}

Stray Notes on Fishing and Natural History. Wirh Illustrations.

$7 s .6 d$.

"If this remarkably agreeable work does not rival in popularity the celebrated

' White's Selborne,' it will not be because it does not deserve it." -THE FreLd.

BY THE RIGHT REV. G. E. LYNCH COTTON, D.D.

Lord Bishop of Calculta and Metropotitan of India.

Sermons and Addresses delivered in Marlborough College, during Six Years.

Crown 8vo. cloll, price 10s. 6 d.

"We can heartily recommend this volume as a most suitable present for a yonth, or for family reading; wherever there are young persons, the leaching of these discourses will be admirable."-LIterary Churenman.

Sermons : Chiefly connccled witl Public Events in 1854.

"A volume of which we can speak with high admiration."

Fcap. 8vo. cloth, 3s.

Cinristian Remembrancer.

Charge delivered to the Clergy of Calcutta at his Primary Visitation in September, 1859. 8vo. 2s.6d. THE ORE-SEEKER.

A Tale of the Hartz Mountains. By A. S. MI. Illustrated by L. C. H. Printed on toned paper, with elaborate full-page Illustrations and Initial Letters, and bound in elegant cloth with gilt, leaves, $15 s$.

This work is most elaborately illustrafed, and is published as a Christmas present. 'The Orserver of Nov.18, 1860, says of it:-

"One of the most beautiful of the illustrated volumes published in the present season, and one pre-eminently fitted for a Christmas present. . . Love aith truth beautify the storn, and render it delightful to all persons. . . . The ill'strations are many of the finest specimens ext ant."

BY THE REV. C. P. CHRETIEN, Fellow of Oriel College, Oxford; and Rector of Chotderton, Wilts.

The Letter and the Spirit. Six Sermons on the Inspiration of Holy Scripture, Preached before the University of Oxford. Crown 8vo. $5 s$.

BY THE REV. H. MONTAGU BUTLER, Head Master of the Sehool, and late Fellow of Trinity College, Cambridge. Sermons Preached in Harrow Sehool Chapel. 


\section{BY THE RIGHT REV. W. COLENSO,}

\section{Lord Bishop of Natal.}

The Epistle to the Romans, newly translated from a Nissionury point of view.

Crown 8 ro. clotli, $7 s .6 d$.

\section{BY THE VENBLE. ARCHDEACON HARDWICK.}

1. Christ and other Masters: A Historical Inquiry into some of the chicf Parallelisms and Contrasts between Ciristianitg and the Religious Systems of the Ancient World;

The Religions of China, America, and Oceanica. In one volume. The Religions of Egrypt and Medo-Persia. In one volume.

8vo. cloth, 7s. 6d. each.

"Never was so dificull. and complicated a subject as the history of Paysn religion handled so ably, and at the same time rendered so hucill and attractive." -Colonial. Cuvren Curontcle.

2. History of the Christian Chureh during the Midlie Ages. With Maps. Crown 8vo. cloth, 10s. 6tl.

3. History of the Christian Church during the Reformation.

Crown 8ro. cloth, 10s. 6l.

4. Sermons Preached to Town Congregations.

Crown 8vo. cloth, 6s. 6\%.

BY THE VERY REV. R. C. TRENCH, D.D.,

Dean of Westminster.

1. Synonyms of the New 'Testament.

Fourth Edition. Fcap. 8vo. cloth, 5 s.

2. Hulsean Lectures for $1845-46$.

Contents. 1.-The Fitness of Holy Scripturc for unfolding the Spiritual Life of Man. 2.-Christ the Dcsire of all Nations; or the Unconscious Prophecies of Heathendom.

Fourth Edition. Fcap. 8vo, cloth, $5 s$.

3. Sermons Preached before the University of Cambridge.

Fcap. 8vo. cloth, 2s. $6 d$. 


\author{
BY் DAVID MASSON, M.A., \\ Professor of English Lileralure in Unirersily Collcge, London.
}

1. Life of John Milton, narrated in connexion with the Political, Ecclesiastical, and Literary History of his Time. Vor. I. Svo. With Portraits. 18s.

"Mfr. Masson's Life of Millon has many sterling nerits . . . his industry is immense; his zeal unflagying; his spe:ial knowledge of Mlitton's life and times extraordinary. . . . with a zeal and indistry which we caunot sufficiently com. mend, he has not only availed himself of the biographical stores collected by his predecessors, but imparted to them an aspect of nocelly by his skilful rearrangement."-EDINBurgi Review.

2. British Novelists and their Styles:- Being a Critical Sketch of the History of British Prose Fiction. Crown 8vo. cloth, 7s. $6 d$.

"A work eminently calculaled to win popularity, both by the soundness of its doctrine and the skill of its art."-TIIE Press.

3. Essays, Biographical and Critical: chiefly on English Poets.

8vo. cloth, $12 s .6 d$.

"Distinguished by a remarkable power of anatysis, a clear statement of the actual facts on which speculation is based, and au appropriate beauty of lanynage.

These Essays should be popular with serious men."-THE A THENxUy.

\title{
BY DR. REINHOLD PAULI.
}

Pictures of Old England. Translated, with the Author's Revision, by E. C. OtTÉ.

Crown Sro. cloth, 8s. $6 d$.

"Presents the facts of History with the pleasing accessories of a Romancc." Clerical Jourval.

\section{THE ILIAD OF HOMER.}

TRANSLATED INTO ENGLISH VERSE.

By I. C. Wright, M.A., Translator of "Dante," late Fcllow of Magdalen College, Oxford. Books I.-XII. Crown 8 ro. cloth, 10s. $6 d$.; or in 2 separate Parts, 5s. each.

"We kuowo of no edition of the 'sovran poet' from which an English reader can derive on the whole so complete an impression of the immortal Epas." DAILY NEWS. 
TIIE WORKS OF THE REV.

FREDERICK DENISON MAURICE, M.A.,

Incumbent of St. Peter's, St. Marytedone.

On the Lord's Prayer. Ticap. 8vo. Fourth Edition. 2s.6d. Lectures on the Apocalypse, or Book of the Revelation of St. John the Divine. Crown 8ro. cloth, 10s. 6d. What is Revelation? With Letters on Mr. Mansel's Bampton

Lectures.

$10 s .6 d$ Sequel to the Inquiry, "What is Revelation?"

With Letters on Mr. Mansel's Strictures.

Exposition of the Holy Scriptures:

(1.) The Patriarchs and Lawgivers.

$6 s$.

(2.) The Prophets and Kings.

$6 s$.

(3.) The Gospel of St. John.

$10 s .6 d$.

(4.) The Epistles of St. John.

$10 s .6 d$.

$7 s .6 d$.

Exposition of the Ordinary Services of the Prayer

Book:

5s. $6 d$.

Ecclesiastical History.

10s. 6d.

The Doctrine of Sacrifice.

$7 s .6 d$.

Theological Essays. Second Edition.

10s. $6 d$.

The Religions of the World. Third Edition. $5 s$.

Learning and Working.

$5 s$.

The Indian Crisis. Five Sermons.

$2 s .6 d$.

The Sabbath, and other Sermons.

$2 s .6 d$.

Law on the Fable of the Bees.

1s. $6 d$.

The Worship of the Church. A Witness for the Redemption of the World. $1 s$.

The Name Protestant, and the English Bishopric at Jerusalem. Second Edition. $3 s$.

The Duty of a Protestant in the Oxford Election. 1847. $1 s$. 'The Case of Queen's College, London.

1s. Gid.

Death and Life. In Memoriam C.B.M.

$1 s$.

Administrative Reform.

$3 d$. 


\title{
MANUALS FOR THEOLOGICAL STUDENTS,
}

\author{
UNIFORMLY PRINTED AND BOUND.
}

This Series of Theological Manuals has been published with the aim of supplying books concise, comprehensive, and accurate, convenient for the Student and yet interesting to the general reader.

I.

Introduction to the Study of the Gospels. - By Broore Foss Westcott, M.A. formerly Fellow of Trinity College, Cambridge. Crown 8vo. cloth, 10s. 6d.

"The worth of Mr. Weslcott's volume for the spiritual interpretation of the Gospels is greater than we can readity express even by the most grateful and approving words. It presenls with an unparalleled completeness-the charatteristic of the book everywhere being this completeness-wholeness of riew, comprehensireness of representation, the fruits of sacred learning." - NoNCONFORMIST.

II.

\section{A General View of the History of the Canon of the} New 'Testament during the FIRST FOUR CENTURIES. By Brooke Foss Westcott, M.A.

Crown 8vo. cloth, 12s. 6 d.

"The Author is one of those who are teaching us that it is possible to rifle the storehouses of German theology, without benring away the taint of their atmosphere: and to recognise the value of their accumulated treasures, and exen track the ragaries of their theoretic ingenuity, without abandoning in the pursuit the clear sight and sound feeling of English common sense. . . . It is by far the best. and most complete book of the kind; and we should be glad to sce it well placed on the lists of our examining chaplains."-GuAdTaN.

"Learned, dispassionate, discriminnting, worthy of his subject, and the present state of Christian Literature in relation to it."-BRITISH QUARTRRLY.

"To the student in Theology it will prove an admirable Text-Book: and to all others who hare any curiosity on the subject it will be satisfactory as one of the most useful and instructice pieces of hislory which the records of the Church supply."-LONDON RUARTERTY." 


\section{THEOLOGICAL MANUALS-continued.}

III.

\section{History of the Christian Church, during the Middle} Ages and the Reformation (A.D. 590-1600). By the Venerable Charles Hardwick, Archdeacon of Ely.

2 vols. crown 8 vo. $10 s .6 d$. each.

Vol. I. History of the Church to the Excommunication of Luther. With Four IIaps.

Vol. II. History of the Reformation.

Each Volume may be had separately.

"Full in references and authority, systenatic and formal in dicison, with enculy of life in the style to counteract the drynessinseparable from ils brevity, ant exhibiting the results rather than the principles of investigation. Mr. HARIw ICK is to be congratulated on the sutcessful achievement of a difficult task." -Ciristian Remembratcer.

"He has bestowed patient and extensive reading on the collection of his materials; he has selected them with julgment; and he presents them in an equable ant compact style."-SPECTATOR.

"To a good method and good materials Mr. IIARDwlck adds that great virtue, a perfectly transparent style. We did not expect to find great literary qualitics in such a mannal, but we have fount them; we shoutd be satisfied in this respect wilh conciseness and intelligibitity, but while this book has both, it is also elegant, highly finished, and highly interesting."-Noxcox Formst.

IV.

History of the Book of Common Prayer, together with a Rationale of the several Offices. By Francıs Procter, M.A., Vicar of Witton, Norfolk, formerly Fellow of St. Catharine's College, Cambridge. Fifth Edition, revised and enlarged.

Crown 8vo. cloth, 10s. $6 d$.

"IIr. Procter's ' Ilistory of the Book of Common Prayer' is by far the best commentary extant. . . . . Not only do the present illustrations embrace the whote ranje of original sonrces indicated by IIR. PALMER, but MR. PROCTEI: compares the present Book of Common Prayer with the Scotch and American forms; and he frequently sets ont in full the Sarum Offices. As a manual of extensive information, historical and ritual, imbued with sound Church principles, we are entirrly satisfied with Mr. Procter's important rolume."

Ciristiax Rimenuravcer.

"It is inleed a complete and fairly-uritlen history of the Lituryy; and from the dispassionate way in which disputed points are touched on, will prore to mary troubled consciences what ought to be known to them, viz.:- - that they may, without fear of compromising the principles of ecangelical truth, gire their assent and consent to the contents of the Bools of Common Prayer. IIR. PROCTER has done a great service to the Church by this admirable digest."

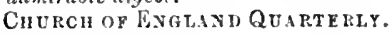




\section{MACMILLAN AND CO.'S \\ Class 侽oolis for Colleges and Sithools.}

\section{ARITHMETIC AND ALGEBRA.}

Arithmetic. For the use of Schools. By Barnard Surth, M.A. New Edition (186I). 348 pp. Answers to all the Questions. Crown 8vo. 4s. 6d.

Key to the above. Second Edition, thoroughly Revised (1860). 382 pp. Crown 8vo. Ss. $6 d$.

Arithmetic and Algrebra in their Principles and Applications. With numerous Examples, systematically arranged. By BarNard SMITH, M.A. Seventl Edition (1860), 69ii pp. Crown 8vo. 10s.6d.

Exercises in Arithmetic. By Barnard Surth, M.A. Part I. 48 pp. (1860). Crown Svo. 1s. Part II. 56 pp. (1860). Crown 8 ro. 1s. Answers, 6d. The Two Parts bound together 2s.; or with Answers, 2s. $6 d$.

Arithmetic in Theory and Practice. For Advanced Pupils. By J. Brook Smith, MI.A. Part First. 164 pp. (1S60). Crown 8vo. 3s.6d.

A Short Manual of Arithmetic. By C. W. Underwood, M.A. 96 pp. (1860). Fep. Svo. 2s. $6 d$.

Algebra. For the use of Colleges and Schools. By I. Todnunter, MI.A. Second Edition. Crown 8vo. 516 pp. (1S60). 7s.6d.

- Theory of Equations. With a Collection of Examples. 279 pp. (1861). Crown 8vo. cloth, 7s. 6d.

\section{TRIGONOMETRY.}

Introduction to Plane Trigonometry. For the use of Schools. By J. C. SNowaAli. M.A. Second Edition (1847). 8vo. $5 s$.

Plane Trigonometry. For Schools and Colleges. By I. TodHuxter, M.A. Second Edition, 279 pp. (I860). Crown $8 v 0.5 s$.

Spherical Trigonometry. For Colleges and Schools. By I. Todhoster, M.A. 112 pp. (1859). Crown svo. 4s. $6 d$.

Plane Trigonometry. With a numerous Collection of Examples. By R. D. Beasley, M.A. 106 pp. (1858). Crown 8ro. 3s. 6d.

Plane and Spherical Trigonometry. With the Construction and Use of Tables of I ogarithms. By J. C. Ssow Batc, M.A. Ninth Edition, 240 pp.

(1857). Crown 8vo 7s. 6d.

\section{MECHANICS AND HYDROSTATICS.}

Elementary Treatise on Mechanics. With a Collection of Examples. By S. PArkinson, B.D. Second Edition, 345 pp. (1860). Cr. 8vo. 9s. 6d. Elen:entary Course of Mechanies and Hydrostatics. By J. C. Snowbali, M.A. Fourth Edition. 110 pp. (1851). Crownsvo. 5 s. 


\section{MECHANICS AND HYDROSTATICS-continued.}

Elementary Hydrostatics. With numerous Examples and Solutions. By J. B. PuEAR, ML.A. Second Edition. 156 pp. (1857). Crown 8 vo. 5s. $6 d$.

Analytical Statics. With numerous Examples. By I. TodHUnter, M.A. Second Edition. 330 pp. (1858). Crown 8vo. 10s. 6d.

Dynamics of a Particle. With numerous Examples. By P. G. TAIt, M.A. and W. J. STeELe, M.A. 304 pp. (I856). Crown 8vo. 10s. $6 d$.

A Treatise on Dynamics. By W. P. Wilson, M.A. 176 pp. (1850). 8ro. 9s. 6d.

Dynamics of a System of Rigid Bodies. With numerous Examples. By E. J. Routr, M.A. 336 pp.(1860). Crown 8 vo. 10s. $6 d$.

\section{ASTRONOMY AND OPTICS.}

Plane Astronomy. Including Explanations of Celestial Phenomena and Instruments. By A. R. GRANT, M.A. 128 pp. (1860). 8vo. $6 \delta$.

Elementary Treatise on the Lunar Theory. By H. Godfrar, M.A. Second Edition. 119 pp. (1859). Crown 8ro. 5s.6d.

A Treatise on Optics. By S. Parkinson, B.D. 304 pp. (1859). Crown 8 vo. 10s. $6 d$.

\section{GEOMETRY AND CONIC SECTIONS.}

Geometrical Treatise on Conic Sections. With a Collection of Examples. By W. H. Drew, M. A. 121 pp. (1857). 4s. 6d.

Plane Co-ordinate Geometry as applied to the Straight Line and the Conic Sections. By I. Topruxter, M. A. Second Edition. 316 pp. (1858). Crown 8 vo. 10s. 6d.

Elementary Trentise on Conic Sections and Algebraic Geometry. By G. H. Puckle, M.A. Second Edition. 264 pp. (1856). Crown 8vo. 7s. 6d.

Examples of Analytical Geometry of Three Dimensions. With the Results. Collected by I. Todyuxtèr, M.A. 76 pp. (1858). Crown 8 ro. $4 s$.

Elementary Treatise on Trilinear Co-ordinates. By N. M. Ferrers, M.A. 154 pp. (1861). Crown 8vo. Cs. $6 d$.

A Treatise on Solid Geometry. By P. Frost, M.A. and J. Wolstenholme, M.A. 8vo. $18 s$.

\section{DIFFERENTIAL AND INTEGRAL CALCULUS.}

The Differential Calculus. With numerous Examples. By I. Tophoxter, M.A. ThirdEdition. 404 pp. (1860). Crown 8 vo. 10s. $6 d$.

The Integral Calculus, and its Applications. With numerous Examples. By I. Todhunter, M.A. 268 pp. (1857). Crown 8vo. 10s.6d.

A Treatise on Differential Equations. By George Boole, D.C.L. 486 pp. (1859). Crown 8vo. 14s.

A Treatise on the Calculus of Finite Differences. By Georae Boole, D.C.L. 248 pp. (1840). Crown 8 vo. 10s. 6 d.

A History of the Progress of the Calculus of Variations during the Nineienth.Century. By I. TopuUster, M.A. 530 pp. (1861). 8vo, cloth. 12 s. 


\section{APPLIED SCIENCE.}

On the Algebraical and Numerical Theory of Errors of Observations, and the Combination of Observations. By the Astronomer Royal, G. B. A 1 RY, M.A. $103 \mathrm{pp}$. (1861). 6s. $6 d$.

The Construction of Wrought Iron Bridges, embracing the Practical Application of the Principles of Mechanics to Wrought Iron Girder Work. By J. H. LATHAM, M.A. C.E With numerous plates. 282 pp. (1858). $15 s$.

Mathematical Tracts, On the Lunar and Planetany Theories, тнв Figure op the Earth, Precession and Nutation, the Calculus of Variations, and the Undulatory Theory of Optics. By the Astronomer Royal, G. B. ArRY, M.A. J'ourth Edition. $400 \mathrm{pp}$. (1858). 15s.

A Collection of Mathematical Problems and Examples. With Answers. By H. A. Miorgan, M.A. 190 pp. (1858). Crown 8 ro. 6s. 6d.

Senate-House Mathematical Problems. With Solutions-

1848-51. By FERRERS and JACKSON. 8vo. 15s. $6 d$.

1845-51. (Riders.) By JAMESON. 8vo. 7s. $6 d$.

1854. By WALTON and MACK ENZIE. $8 \mathrm{ros}^{\circ} 10 \dot{s}^{\circ} 6 d$.

185\%. By CAMPION and WALTON. 8vo. 8s. $6 d$.

1860. By ROUTH and WATSON. Crown 8 ro. 7s. $6 d$.

\section{LATIN.}

Ilelp to Latin Grammar ; or, the Form and Use of Words in Latin. With Progressive Exercises. By Josian Wright. M.A. 175 pp. (1855). Crown 8vo. 4s. 6d.

The Seven Kings of Rome. A First Latin Reading Book. By Josian Wrignt, M.A. Second Edition. 138 pp. (1857). Feap. 8vo. 3s.

Vocabulary and Exercises on "The Seren Kings." By JosraH WRlght, M.A. 94 pp. (1957). Fcap. 8vo. 2s. 6d.

A First Latin Construing Book. By E. Thring, M.A. 104 pp. (1855). Fcap. 8vo. 2s. 6d.

Rules for the Quantity of Syllables in Latin. 10 pp. (1858). Crown 8 vo. $1 s$.

Theory of Conditional Sentenees in Latin and Greek. By R. Honton Smith, M.A. 30 pp. (1\&59). sro. 28. $6 d^{\prime}$.

Sallust.-Catilina and Jugurtha. With English Notes. For Schools. By Charles Merivale. B.D. Second Edition, 172 pp. (1858). Fcap. 8v0. 4s, 6d.

Catilina and Jugurtlia may be had scparately, price 2s. 6d. each.

Jurcnal. For Schools. With English Notes and an Index. By J. E. Mayor, M.A. 464 pp. (1853). Crown $8 v 0.10 s .6 d$.

Cicero's Second Philippic. With English Notes. By JouN E. B. MAYOR. $168 \mathrm{pp}$. (1861). 5.

IX. GREEK.

Hellenica; a First Greek Reading Book. Being a History of Greece, taken from Diodorus and Thucydides. By Josrais Wright, M.A. Second Edition. 150 pp. (I85i). Fcap̧. 8vo. 3s,6d. 
GREEK-continued.

Demosthenes on the Cromn. With Euglish Notes. By B. DraкE, M.A. Second Edition, to which is prefixed Eschines against Ctesiphon. With English Notes. (1860). Fcap. 8vo. 5s.

Demosthenes on the Crown. Translated by J. P. Norris, M.A. (1950). Crown 8vo. 3s.

Thucydides. Book VI. With English Notes and an Index. By P. Frost, Jun. M.A. 110 pp. (1854). 8vo. 7s. 6d.

Aischylus. The Eumenides. With English Notes and Translation. By B. Drake, M.A. 144 pp. (1853). "8vo. 7s. $6 d$.

St. Paul's Epistle to the Romans: With Notes. By Charles JoHN VAUGHAN, D. D. Second Edition (1861). Crown 8 ro. $5 s$.

\section{ENGLISH GRAMMAR.}

The Child's English Grammar. By E. Thrine, M.A. Demy 18mo. New Edition. (1857). 1s.

Elements of Grammar taught in English. By E. Thring, M.A. Third Edition. 136 pp. (1860). Demy $18 \mathrm{mo}$. $2 s$.

Materials for a Grammar of the Modern English Language. By G. 11. Parminter, M. A. 220 pp. (1856). Fcap. 8vo. 3s. $6 d$.

\section{RELIGIOUS.}

History of the Christian Church during the Middle Ages. By Archoescon Hardwick. 482 pp. (1353). With Maps. Crown 8vo. cloth. 10s. 6d.

History of the Christian Church during the Reformation. By ArCHDEACON IIARDWICK. 459 pp. (1850). Crown 8vo. cloth. 108. 6d:

History of the Book of Common Prayer. By Francis Procrer, M.A. 464 pp. (1860). Fifth Edition. Crown 8vo. cloth. 10s.6d.

History of the Canon of the New Testament during the First Four Centuries. By brook Foss Westcotr, M.A. 594 pp. (1855). Crown 8ro. cloth. 12s. $6 d$.

Introduction to the Study of the Gospels. By Brooke Foss Westcotr, M.A. (1860). Crown 8vo. cloth. 10s.6d.

'The Church Catechism Illustrated and Explained. By Arthur RAMsAY, M.A. 204 pp. (1854). 18mo. cloth. 3s. 6d.

Notes for Lectures on Confirmation: With Suitable Prayers. By C. J. Vavginan, D. D. Third Edition. 70 pp. (1859). Feap. 8vo. 18. $6 d$.

Hand-Book to Butler's Analogy. By C. A. Swainson, M.A. 55 pp. (1556). Crown 8vo. 1s.6d.

History of the Christian Church during the First Three Centuries, and the Reformation in England. By WiLliam Sisrson, M.A. 307 pp. (185i). Fcap. 8vo. cioth. 5s.

Analysis of Paley's Evidences of Christianity. By Charties H. Crosse, M.A. 115 pp.(1955). Ismo. 3t. $6 d$. 


\section{FORTHCOMING BOOKS.}

\section{CRIMINAL LAW.}

By J. Fitzjames Stephex, Barrister-at-Law. In One Vol. 8vo.

\section{DONCASTER SFRMONS.}

By Dr. Vaughax. Fcap. 8vo. -

PRIVATE LAW AMONG THE ROMANS. FROML

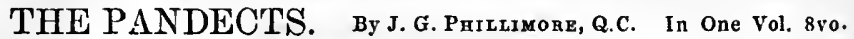
cloth.

\section{SERMONS PREACHED IN HARROW SCHOOL}

CHAPEL. By the Rev. H. Montagu Bureer, Head Master of the School, and late Fellow of Trinity College, Cambridge. Crown 8vo, choth.

\section{LIFE OF WILLIAM BLAKE: THE ARTIST.}

By AlexaNder Gischrist. With numerous Illustrations from his Works.

\section{AN ELEMENTARY TREATISE on QUATERNIONSS.}

With numerous Examples, By P. G. TAIT, M.A. Professor of Natural Philosophy in the University of Edinburgh.

\section{FIRST BOOK OF ALGEBRA FOR SCHOOLS.}

By the Rev. J. C. Elis, M.A. and P. M. Crark, M.A. of Sidney Sussex College, Cambridge.

[Preparing.

\section{EUCLID FOR SCHOOLS.}

By I. TODHUNTER.

In the press. 



